*ak RMIS View/Frint Document Cover Sheet tow

This document was retrieved from the Documentation and Records Manaqement (DRM) ISEARCH System. It is intended for Information only and may not be the most recent or updated version. Contact a Document Service Center (see Hanford Info for locations) if you need additional retrieval information.

Accession \#: D296005604

Document \#: SD-WM-ER-527

Title/Desc:

A RISK MGMT APPROACH TO DST WASTE VOL VS STORAGE CAPACITY

Pages: 149 
2. To: (Receiving Organization)

Distribution

TWRS

8. Originator Remarks:

Document transmitted for release.

3. Fram: coriginating organization) TWRS Technical Integration

6. Cog. Engr.:

R. A. Fordham
5. Proj./Prog./Dept./Div.:

4. Related EDT No.:

7. Purchase Order No.:

9. Equip./Component No.:

10. System/Btdg./Facility:

12. Major Assm. Dwg. No.:

13. Permit/Permit Application Mo.:

14. Required Response Date:

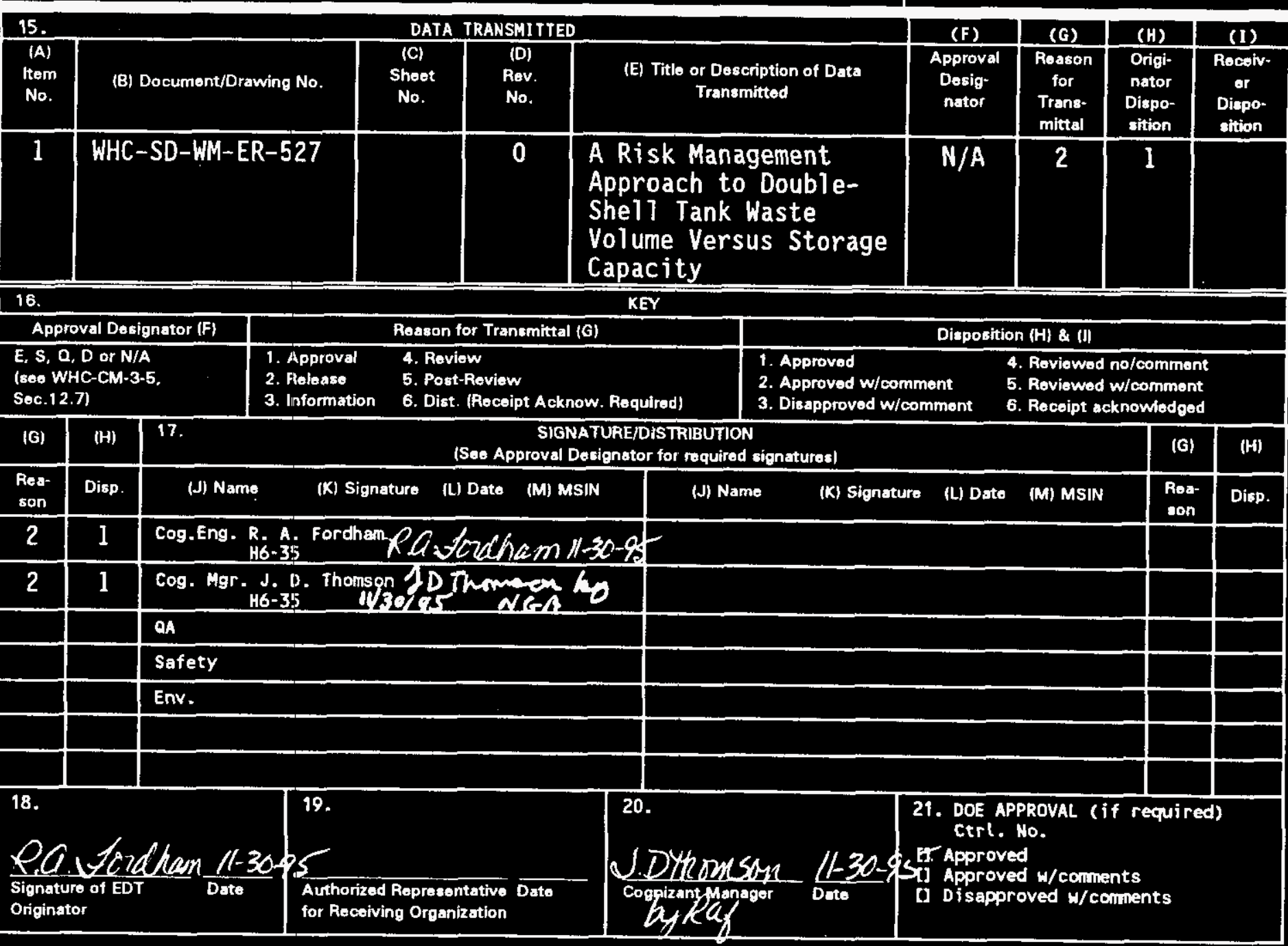

BD-7400-172-2(04/94) GEF097 


\title{
A Risk Management Approach to Double-Shell Tank Waste Volume Versus Storage Capacity
}

\author{
T. J. Thurkow, ARES Corporation \\ R. L. Fritz, ARES Corporation \\ L. D. Muhlestein, ARES Corporation \\ M. R. Allen, ARES Corporation \\ R. J. Stuart, ARES Corporation \\ G. A. Coles, Westinghouse Hanford Corporation, Richland, WA 99352 \\ U.S. Department of Energy Contract DE-ACO6-87RL10930
}

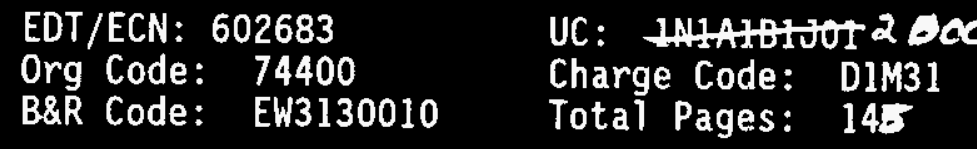

Key Words: Risk management, double-shell tank, waste volume, storage capacity

Abstract: A risk-based assessment of the overall waste volume versus double-shell tank storage capacity was conducted to develop fallback positions for projections where the waste volume was at a high risk of exceeding capacity. This study was initiated to provide that assessment. A working simulation model was the primary deliverable of this study. The model validates the approach and demonstrates that simulation analysis can provide a method of tracking uncertainties in available data, assessing probabilities, and serves as a tool to be used by management to determine the consequences of various off-normal occurrences.

TRADEMARK DISCLAIMER. Reference herein to any specific comercial product, process, or service by trade name, trademark, manufacturer, or otherwise, does not necessarily constitute or iliply its endorsement, recommendation, or favoring by the United States Goverrment or any agency thereof or
its contractors or subcontractors.

Printed in the United States of America. To obtain copies of this document, contact: WHC/BCS Document Control Services, P.O. Box 1970, Mailstop H6-08, Richland MA 99357, Phone (509) 372-2420;
Fax (509) 376-4989.
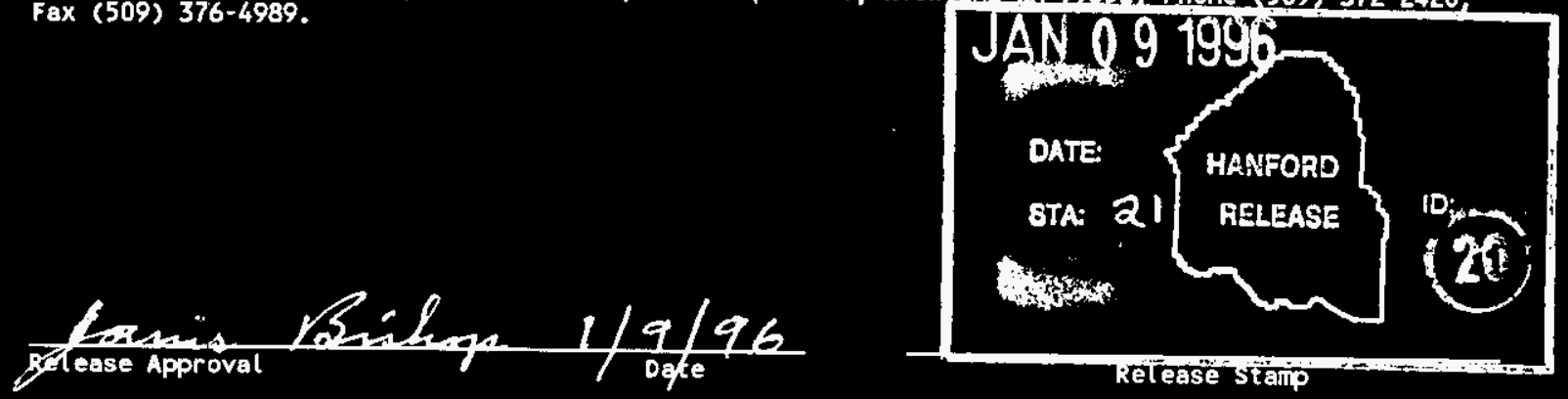

Approved for Public Release 


\title{
A RISK MANAGEMENT APPROACH TO DOUBLE-SHELL TANK WASTE VOLUME VERSUS STORAGE CAPACITY
}

\author{
Revision 0 \\ November 28, 1995
}

Prepared for

Westinghouse Hanford Company

Purchase Order MSJ-SBW-336070

Task A95-115

Prepared by

\section{T. J. Thurkow}

R. L. Fritz

L. D. Muhlestein

M. $\dot{R}$. Allen

R. J. Stuart

ARES Corporation

G. A. Coles

Westinghouse Hanford Company 


\section{A RISK MANAGEMINT APPROACH TO DOUBLE-SHELL TANK WASTE VOLUME VERSUS STORAGE CAPACITY}

Revision 0

November 28, 1995

Prepared for

Westinghouse Hanford Company

Purchase Order MSJ-SBW-336070

Task A95-115

Approved by: Rilhare $) \frac{\text { Xftuat }}{\text { R. J. Stuart }}$ 


\section{EXECUTIVE SUMMARY}

At the Hanford Site, radioactive waste is stored in underground storage tanks. An annual update of the waste volume projections (waste volume from existing storage, retrieval, processing, and new waste generation and available storage capacity) has been prepared which projects waste volume versus capacity through the year 2015 . This projection treats single-shell tanks as waste generators and double-shell tanks (DSTs) as available waste storage capacity. The current model used by Westinghouse Hanford Company (WHC) is a deterministic projection of the waste volume versus the DST capacity and is used for the planning of waste management activities.

Recently, WHC evaluated the Path Forward for the Hanford 200 West area tanks using riskbased techniques and determined that during the next ten years the uncertainties with waste volume/capacity could result in the need for additional DST storage capacity, or alternative actions. Therefore, WHC decided to conduct a risk-based assessment of the overall waste volume versus DST storage capacity and to develop fallback positions (i.e., management actions) for projections where the waste volume was at a high risk of exceeding capacity. This study was initiated to provide that assessment. A working simulation model was the primary deliverable of this study. The model validates the approach and demonstrates that simulation analysis can provide a method of tracking uncertainties in available data, assessing probabilities, and serves as a tool to be used by management to determine the consequences of various off-normal occurrences (i.e., upset conditions and/or programmatic changes).

Both a simple analytical model and a detailed simulation model were constructed to replicate the current Operations Waste Volume Projections through the year 2015. Separation of the DST waste volume into three waste streams (aging, complexed, and non-complexed) was found to be necessary in order to effectively model the current separation requirements. This "Base Case" model included time dependent ranges of volumes anticipated from each principal waste generator modeled as risk-based volume distributions. Multiple simulations were run using random selections of waste generation volumes for each time step. Statistical analyses were performed on the results and the "mean" and " $90 \%$ confidence" Base Case results were plotted versus current capacity for each of the three waste streams. The Base Case results indicated that two additional tanks will need to be designated as complexed waste tanks in order to have sufficient capacity for complexed waste for the years 1996 through 2005 . The resulting reduction in available non-complexed waste tanks for the Base Case does not result in a shortfall of non-complexed capacity. No other significant waste management actions were identified as necessary by this study.

The point was also considered during the course of this study that the DSTs may be nearing the period in their life that an increased risk of failure (leakage) may exist. Additional study is 
necessary to determine how age-related failure should be considered in the determination of available capacity during the latter portion of the 20-year projection period.

Three deterministic Off-Normal Condition sinulations have been evaluated for each of the three waste streams. These Off-Normal simulations reflect the authors' best judgment of both programmatic and upset risks influencing the Base Case simulation input. Six of the nine OffNormal Conditions required fall back positions. However, in all cases the fallback positions were sufficient to ensure that the capacity exceeded the volume for the affected waste streams.

Although more work is required to refine elements of the model and its input, this study has resulted in the "proof of concept" that a risk-based approach for DST waste volume versus capacity projections is viable using simulation analysis techniques. 


\section{TABLE OF CONTENTS}

\section{EXECUTIVE SUMMARY}

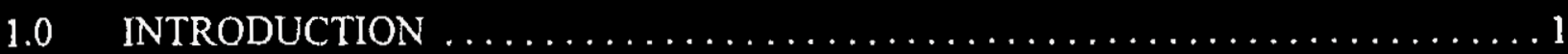

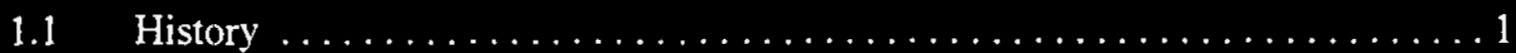

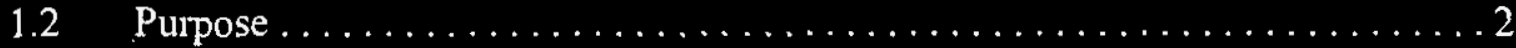

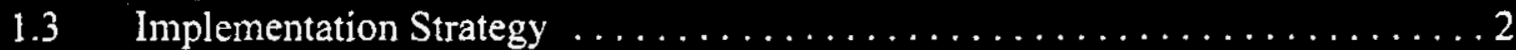

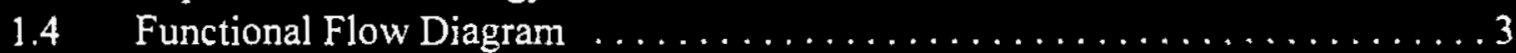

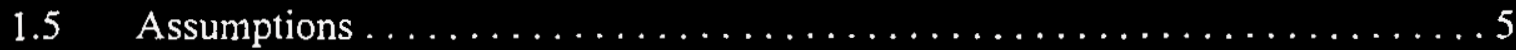

2.0 INFORMATION GATHERING PROCESS $\ldots \ldots \ldots \ldots \ldots \ldots \ldots \ldots \ldots \ldots$

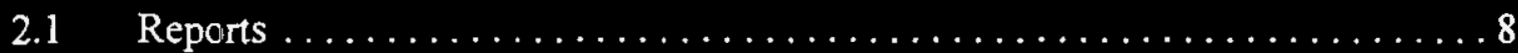

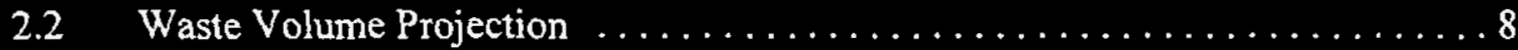

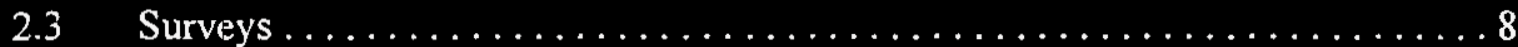

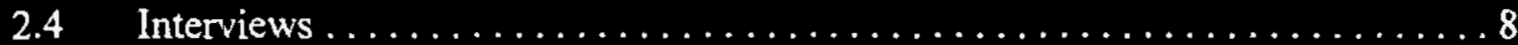

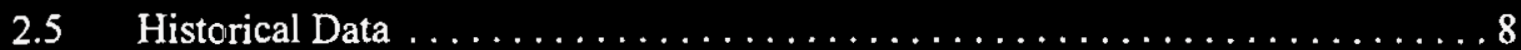

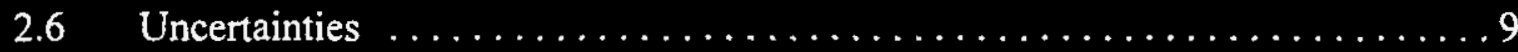

3.0 RISK ASSESSMENT MODEL DEVELOPMENT $\ldots \ldots \ldots \ldots \ldots \ldots \ldots \ldots \ldots$

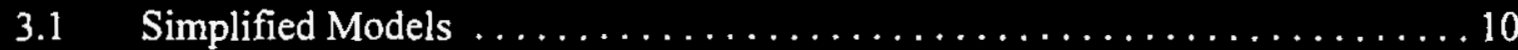

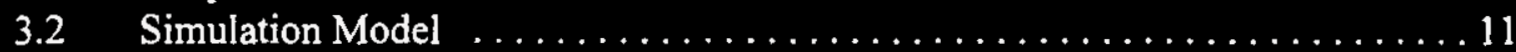

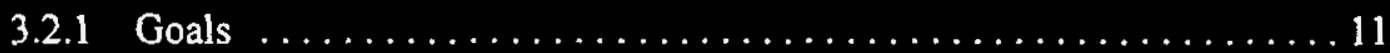

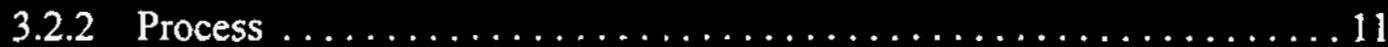

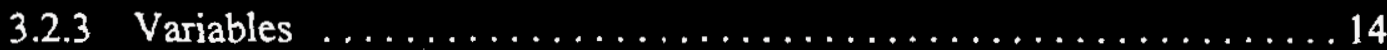

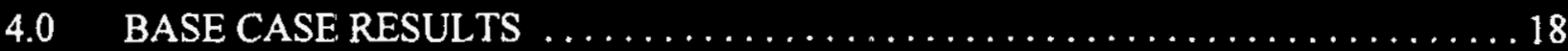

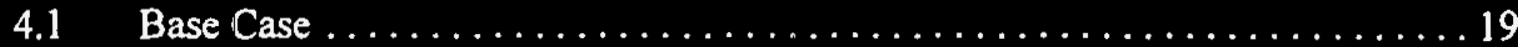

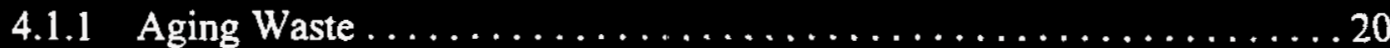

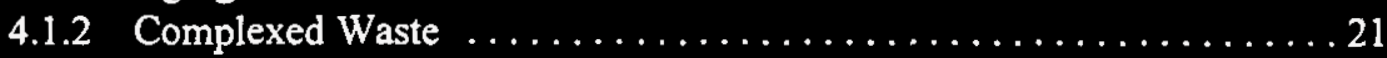

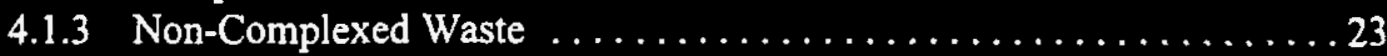

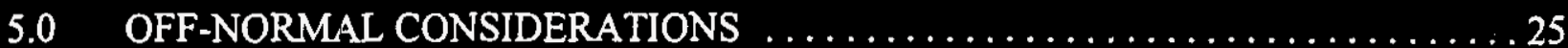

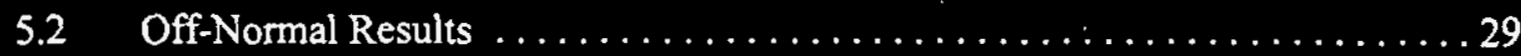

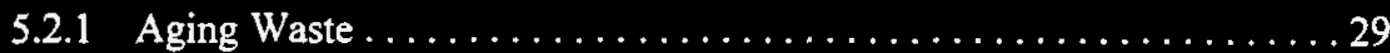

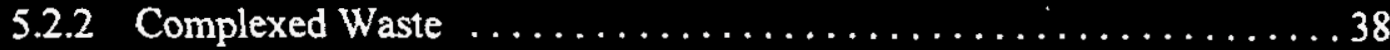

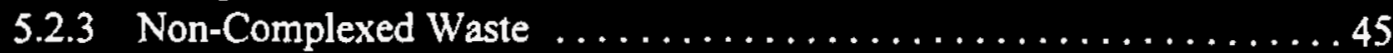

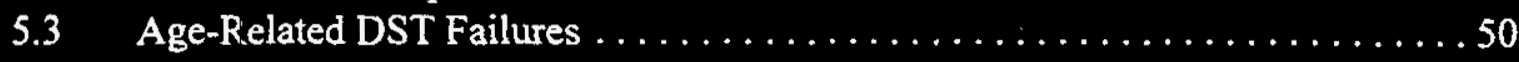




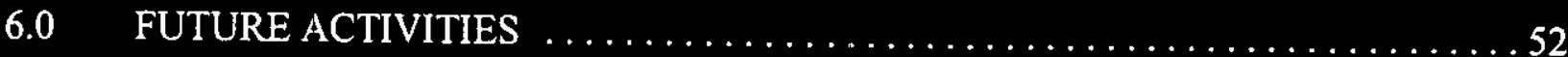

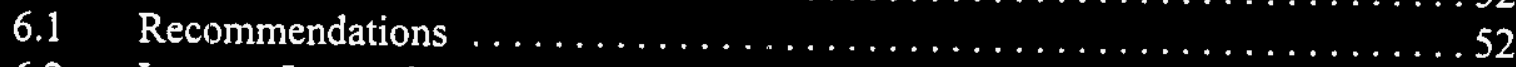

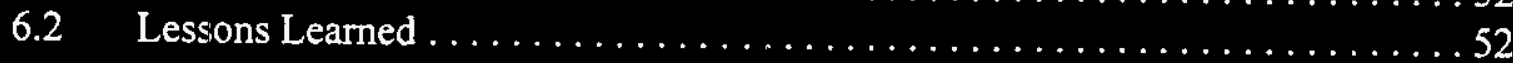

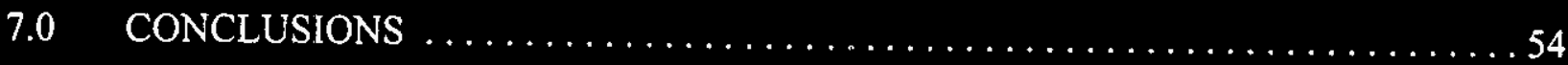

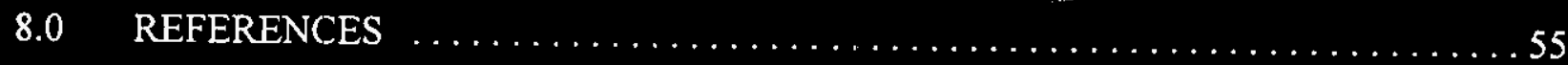

\section{APPENDICES}

Appendix A - Interview Process and Responses

Appendix B - Simple Model Analysis

Appendix C - General Description - Simulation Modeling

Appendix D - Simulation Model Basis and Program Listings

Appendix E - 200 Area Tank Farm Hardware Failure Assessment

\section{FIGURES}

Figure 1.4-1. Functional Flow Diagram of the Double-Shell Tank System . . . . . . . . 4

Figure $3.2-1$. Simulation Model Elements $\ldots \ldots \ldots \ldots \ldots \ldots \ldots \ldots \ldots \ldots \ldots \ldots \ldots \ldots \ldots 12$

Figure 4.0-1. Chart Interpretation Key $\ldots \ldots \ldots \ldots \ldots \ldots \ldots \ldots \ldots \ldots \ldots \ldots \ldots \ldots$

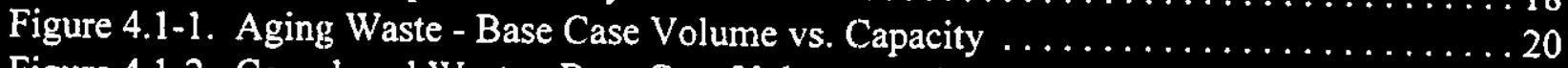

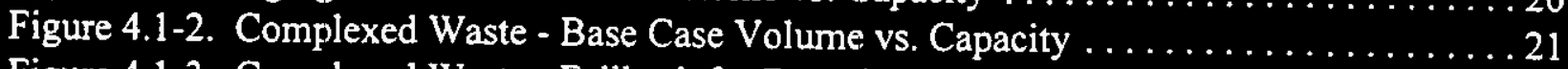

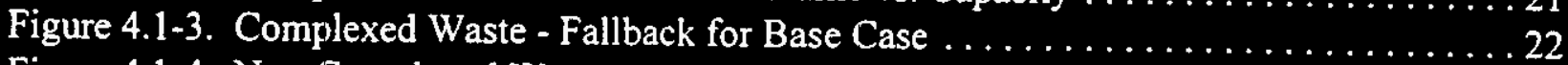

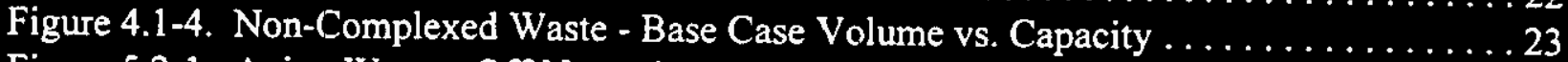

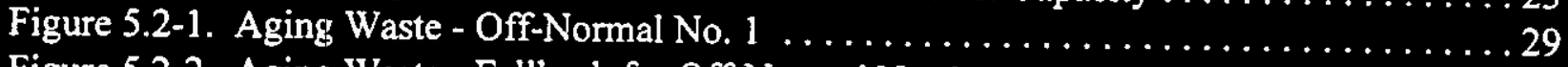

Figure 5.2-2. Aging Waste - Fallback for Off-Normal No. $1 \ldots \ldots \ldots \ldots \ldots \ldots \ldots \ldots$

Figure 5.2-3. Non-Complexed Waste - Consequences of Aging Waste Off-Normal No. 1 . . . 31

Figure 5.2-4. Aging Waste - Off-Normal No. $2 \ldots \ldots \ldots \ldots \ldots \ldots \ldots \ldots \ldots \ldots \ldots \ldots \ldots \ldots$

Figure 5.2-5. Aging Waste - Fallback for Off-Normal No. $2 \ldots \ldots \ldots \ldots \ldots \ldots \ldots \ldots \ldots$

Figure 5.2-6. Non-Complexed Waste - Consequences of Fallback for Aging Off-Normal No. 2

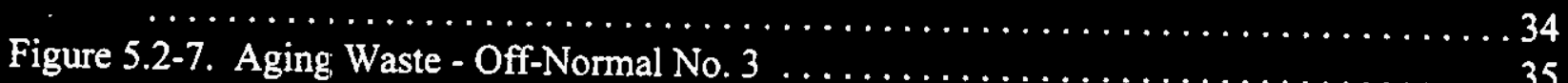

Figure 5.2-8. Aging Waste - Fallback for Off-Normal No. $3 \ldots \ldots \ldots \ldots \ldots \ldots \ldots \ldots \ldots \ldots \ldots \ldots$

Figure 5.2-9. Non-Complexed Waste - Consequences of Fallback for Aging Off-Normal No. 3

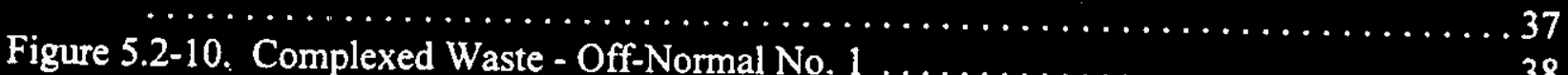


Figure 5.2-11. Complexed Waste - Fallback for Off-Normal $\# 1 \ldots \ldots \ldots \ldots . \ldots . \ldots 39$

Figure 5.2-12. Non-Complexed Waste - Consequences of Complexed Off-Normal \#1 . . . . 40

Figure 5.2-13. Complexed Waste - Off-Normal No. $2 \ldots \ldots \ldots \ldots \ldots \ldots \ldots \ldots . \ldots 4$

Figure 5.2-14. Non-Complexed Waste - Consequences of Complexed Off-Normal No. 2 . . 42

Figure 5.2-15. Complexed Waste - Off-Normal No. $3 \ldots \ldots \ldots \ldots \ldots \ldots \ldots \ldots \ldots 4$

Figure 5.2-16. Complexed Waste - Fallback for Off-Normal No. $3 \ldots \ldots \ldots \ldots \ldots \ldots . \ldots 44$

Figure 5.2-17. Non-Complexed Waste - Off-Normal No. $1 \ldots \ldots \ldots \ldots \ldots \ldots \ldots \ldots 4 . \ldots \ldots$

Figure 5.2-18. Non-Complexed Waste - Off-Normal No. $2 \ldots \ldots \ldots \ldots \ldots \ldots \ldots \ldots \ldots$

Figure 5.2-19. Non-Complexed Waste - Fallback for Off-Normal No. $2 \ldots \ldots \ldots \ldots \ldots .47$

Figure 5.2-20. Non-Complexed Waste - Off-Normal No. $3 \ldots \ldots \ldots \ldots \ldots \ldots \ldots . \ldots 48$

Figure 5.2-21. Non-Complexed Waste - Fallback for Off-Normal No. 3 . . . . . . . . . . . . 49

Figure $5.3-1$. Bathtub Curve .................................. 50

Figure 5.3-2. Age Effect on DST Capacity $\ldots \ldots \ldots \ldots \ldots \ldots \ldots \ldots \ldots \ldots \ldots \ldots \ldots \ldots \ldots \ldots \ldots \ldots \ldots$

\section{LIST OF TABLES}

Table 3.2-1. Input Data ...................................... 15

Table 5.1-1. Simulation Model Cases - Base and Off-Normal Conditions . . . . . . . . . . . 27

Table 5.1-2. Fallback Positions (Management Actions) .................... 28 


\begin{tabular}{lr}
\hline RISK MANAGEMENT APPROACH TO DOUBLE-SHELL TANK WASTE & WHC-SD-WM-ER-527, Revision 0 \\
VOLUME VERSUS STORAGE CAPACITY - Report No. 951115-001 & November 28, 1995 \\
\hline \hline
\end{tabular}

\section{TRADEMARKS}

GPSS Minuteman Software, Stow, MA

SIMAN Systems Modeling Corporation, Sewickley, PA

EXCEL Microsoft Corporation, Redmond, WA

@Risk Palisade Corporation, Newfield, NY

SIMSCRIPT II CACI Products Company, La Joya, CA

SLAMSYSTEM Pritsker Corporation, Indianapolis, IN 


\section{$1.0 \quad$ INTRODUCTION}

\section{$1.1 \quad$ History}

The Westinghouse Hanford Company (WHC) Tank Waste Remediation System (TWRS) has traditionally projected double shell tank (DST) waste storage capacity and waste volume (generation, reduction, and disposal) using deterministic techniques in the Operational Waste Volume Projection, or OWVP (WHC 1994). These waste volume versus capacity projections have traditionally determined a path forward through the next ten years of operation and, thus far, they have not been risk based.

A recent study, Operational Risk in the 200 West Area (WHC 1995g), evaluated the Path Forward for the 200 West area of the Hanford Site using risk based techniques. The results indicated that, during the next ten years, waste volume uncertainty is projected to be in the range of 3,000,000 gallons and that a large likelihood exists that adverse conditions, such as leaks, facility upsets, and/or cross-site transfer line failure may result in the need for more free tank space than is currently projected to be available. The cancellation of the Multi-Function Waste Tank Farm (MWTF) project increases the importance of managing TWRS waste due to the reduced margin of available capacity.

Based on the results of the 200 West Area study, TWRS Engineering determined that the entire DST system capacities and waste volumes (both 200 East and 200 West) should be modeled using risk based techniques in order to assess risks associated with DST storage. To implement their plan WHC conducted a two day workshop to develop the requirements for this effort. The participants decided that the scope of the risk assessment would focus on a ten-year window (plus an additional ten years to account for lead time for required actions) during which management decisions could be made that affect either the waste volume or DST capacity. An acceptance criteria was developed and it was decided to develop fallback positions (management actions) for each high-risk scenario.

The resulting risk assessment was completed by ARES Corporation, with a significant contribution from WHC personnel in the areas of data input, data collection, review, and analysis. This report sets forth a description of the risk assessment process and its results. A risk-based methodology has been developed to evaluate the TWRS DST waste volume versus DST waste storage capacity. In addition, an initial risk assessment has been completed for the TWRS DST system with fallback positions identified for both operational risks as well as offnormal (upset condition) risks. 


\subsection{Purpose}

The following objectives were established for this assessment:

- Development of a risk-based waste volume versus storage capacity risk assessment process, and

- Demonstration of the waste volume versus storage capacity risk assessment process including the use of fallback positions.

The following subtasks have been included:

- Development of a PC-based model to support management, utilizing probability distributions,

- Identification of risk-dominant contributors to both the waste volume projections and the waste tank storage capacity (for both base case and off-normal conditions),

- Development of fallback positions (management actions) to be implemented to alleviate the impact of the risk-dominant contributors to the waste volume, and

- Identification of any lessons learned.

\subsection{Implementation Strategy}

The DST waste volume versus storage capacity risk assessment was performed using some specific System Engineering principles and techniques, including baseline management and risk assessment, [see WHC TWRS Systems Engineering Manual, TSEP-04, Risk Management (Interim), dated August 1995 (WHC 1995h)]. The assessment was initially integrated with Hanford Site-wide System Engineering through the use of the Operational Waste Volume Projection (OWVP), Revision 20, dated June 1994 (WHC 1994). Revision 21 of the OWVP, dated September 1995 (WHC 1995b), formed the basis for the final analysis and extended the baseline information to the year 2015 .

The following acceptance criteria was established for the DST waste volume versus storage capacity risk assessment:

- The risk-based waste volume projections through the year 2015 shall be less than or equal to the storage capacity (including handling capabilities and fallback positions) for each of the segregated waste types analyzed with at least a 90 percent confidence.

The following activities represent the principle steps utilized in the development of the risk assessment process and the model development, data collection, and analysis necessary to 
demonstrate its "proof of concept":

- Development of a Functional Flow Diagram to represent the DST systems, generators, transfer lines, capacity, and disposal,

- Development and use of a simplified risk assessment model to provide insight into the construction of the more sophisticated simulation model ,

- Use of survey questionnaires and interviews to collect risk-based waste volume profiles for each waste generator,

- Development and use of a "simulation model" to track individual waste streams (aging, complex, and non-complex) including transfer and queuing (delays due to lack of flow capacity),

- Comparison of the base case data, applied with waste generator uncertainty profiles and selected equipment/facility failure, to the acceptance criteria,

- Identification of selected upset conditions (off-normal situations including programmatic risks) that could significantly affect generator waste streams, transfer capabilities, and/or waste capacities,

- Comparison of each selected upset condition to the acceptance criteria,

- Development of fallback positions for each base case and upset condition models that exceeds the acceptance criteria, and

- Application of fallback positions to their respective models to demonstrate each fallback position's adequacy to alleviate the risk of the respective waste volume stream exceeding the applicable capacity.

\subsection{Functional Flow Diagram}

A functional flow diagram was developed to form the basis of the simulation modeling effort. The functional flow diagram is shown in Figure 1.4-1. The first level of the functional flow diagram is very general in nature and was used to establish the level of details to be considered in the simulation model. A second, and in some instances, a third level of the functional flow diagram were developed but are not shown within this report.

The main part of the waste storage system is the twenty-eight double-shell waste tanks (three in the 200 West Area and 25 in the 200 East Area). Also included in the system are the 200 West Area Transfer lines, the Cross-Site Transfer Line, the 200 East Area Transfer lines, the two double-shell tanks used as staging and receiving tanks for the evaporator, and waste disposal activities. The evaporator waste volume reduction is included, as is the waste volume reduction involved with waste pretreatment efforts. Any low-level waste vitrification is included in pretreatment losses. High-level waste returned to the waste storage system from pretreatment is identified as a cesium stream from pretreatment. Waste losses due to the vitrification of high- 


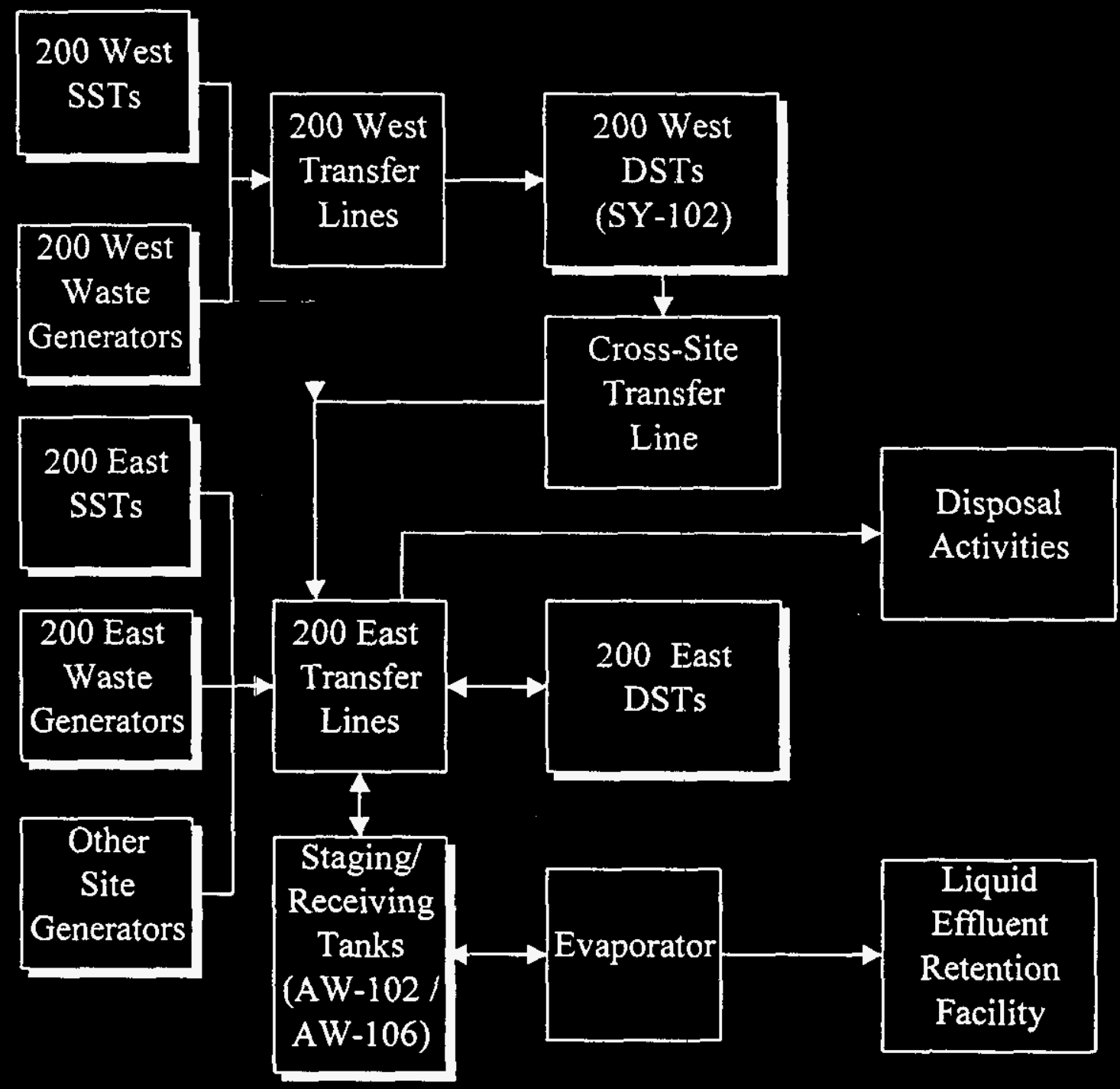

Figure 1.4-1. Functional Flow Diagram of the Double-Shell Tank System. 
level waste is also included as a waste volume reduction. The dotted line in Figure 1.4-1 from the 200 West Waste Generators to the 200 East Transfer Lines is intended to identify that some wastes from some of the waste generators can be shipped via truck and/or rail car. This waste would then avoid the 200 West Transfer Lines, staging in double-shell Tank SY-102, and transfer via the cross-site transfer line.

\subsection{Assumptions}

\subsubsection{General Assumptions}

Some general assumptions made for this task include:

The Base Case waste volumes and timing presented in the OWVP, Rev.21 (WHC 1995b) were the basis for the Base Case simulation models. Terminology applied to waste generators and volume reducers in the OWVP, Rev. 21 has been used in this report to maintain consistency.

- $\quad$ Terminology (per OWVP, Rev. 21)

- $\quad$ "Pretreatment" waste volume reductions include the effects of Low Level Vitrification.

- "Vitrification" waste volume reductions pertain to High Level Vitrification.

- "Waste Loss" refers to the waste volume reductions associated with the evaporator, pretreatment and low level vitrification, or high level vitrification.

- Other Important Terms

- "Off-normal conditions" are treated deterministically (as given conditions). Risk assessments are performed assuming the upset condition exists (probability $=1$ ). For example: Given Upset Condition A exists, the risk associated with the waste volume exceeding capacity at a $90 \%$ confidence level, is represented on the associated charts.

- "Fallback positions" are the actions taken by management to mitigate the effects of off-normal conditions.

- All DSTs remain functional during the time frame analyzed. 


\subsubsection{Model Assumptions}

As mentioned, above, the model was divided into the three primary waste streams in order to evaluate the effects on volume versus capacity for each waste stream.

Assumptions were made to assign the waste generation inputs and the evaporation and disposal volumes to the appropriate segregated waste stream. Details of these assumptions are included in Appendix D, Section D.2.

\section{Aging Waste}

There are four tanks designated as aging waste tanks. Currently, two of these tanks contain waste of the other two types (complexed and non-complexed waste). According to the OWVP, Rev 21, this is a temporary situation. Since waste can be transferred out of these two aging waste tanks in a relatively short amount of time to make room for aging waste, when needed, they are assumed to be available aging waste tanks.

The initial aging waste inventory was taken from Waste Tank Summary Report, Hanlon (WHC 1995d) and amounted to two, nearly full waste tanks. Initial waste capacity was taken to be the equivalent of 4 tanks, each with $980 \mathrm{kgal}$ usable capacity. Input waste streams to the model included tank $\mathrm{C}-106$ retrieval and the return of cesium from pretreatment. Waste removal was provided by vitrification and decanting non-aging waste during the consolidation process in preparation for tank washing. No evaporation of aging waste will occur.

\section{Complexed Waste}

The initial waste volume currently contained in the five tanks now designated for complexed waste was taken from Hanlon, (WHC 1995d) for the East and West tank farm portions. Initial capacity was taken to be five tanks, although a conservative assumption was made that 4 of the tanks were $1140 \mathrm{kgal}$ usable capacity, while one was $980 \mathrm{kgal}$ (due to the temporary use of an aging waste tank, as discussed above). Input streams during the 21-year projection period were the complexed waste portion from East and West saltwell pumping, SST retrieval, and SY-101 and SY-103 retrieval. Removal of waste was provided by a small fraction of pretreatment capacity and evaporation after the year 2000 . 


\section{Non-Complexed Waste}

Since there were only three waste streams identified in this analysis, non-complexed waste included all waste not considered complexed or aging waste. The initial waste inventory was the total DST waste shown in Hanlon (1995d) minus the complexed and aging waste portions. The usable capacity was the equivalent of 19 tanks, each at 1140 $\mathrm{kgal}$. Input streams included the non-complexed waste portion from SST saltwell pumping and retrieval, the many dilute non-complexed streams identified in the OWVP, Rev.21, the water addition from the transfer of SST sludge to vitrification, and the decanted waste from the aging waste tanks. 


\subsection{INFORMATION GATHERING PROCESS}

\section{$2.1 \quad$ Reports}

In order to effectively assess the risks associated with the waste volume projections and waste storage capacity, a data collection process was initiated. This process included: 1) developing survey forms, 2) producing telephone records; 3) conducting personnel interviews, 4) reviewing official planning documents, and 5) reviewing historical records. This process focussed on the major waste generators, waste receivers, and intermediate handling facilities, such as the evaporator. Each of the information gathering processes is discussed in more detail below.

\subsection{Waste Volume Projection}

The official document that provided the greatest amount of information for this effort was the Operational Waste Volume Projection. At the inception of this task, information provided in an interim waste volume projection (WHC 1995a) was used. In mid-September 1995, OWVP Revision 21 (WHC 1995b) was issued. The final analysis generated by this report utilized the information provided in Revision 21.

\subsection{Surveys}

A survey form was developed as part of this effort and was distributed to the representatives of facilities involved in waste generation, handling, or disposal. The survey form provided general topics for discussion and set the stage for the personnel interviews held with each involved organization. The survey form, as well as the results of the interviews, are provided in Appendix A.

\subsection{Interviews}

After completion of the surveys, interviews were held with facility representatives. The interviews were held to: 1) review the survey data, 2) understand the basis for the provided data; 3) discuss and document uncertainties, and 4) provide a better understanding of the interaction between the facility and the overall waste storage and handling system. After completion of the interviews, summaries were prepared and routed to participants for confirmation of translated information.

\subsection{Historical Data}

Historical data was, in some cases, well documented in the completed survey forms. Other 
sources of historical data were found in .MVTF Single-Shell Tank Liquid Contents (WHC 1995e) and Evaporator WVR Potential (WHC 1995f). WHC 1995e summarized single-shell tank stabilization efforts (in terms of type and quantities of waste). WHC $1995 \mathrm{f}$ identified projected evaporator performance characteristics based on historical data. These references provided input to the model development to allow for better projections of generated waste volume, upset conditions, potential failures, and failure rates.

\subsection{Uncertainties}

Various degrees of uncertainties exist with each input and output variable. However, by utilizing the best available information, introducing statistical distributions for input variables, and completing numerous simulation analyses, the most likely waste volumes can be developed. The mean and $90 \%$ confidence waste volume projections were determined for each case analyzed.

Major uncertainties associated with the waste generation and capacity information were documented in a qualitative manner on the survey forms. Uncertainties were accounted for in the simulation models through evaluation of potential "off-normal conditions," (see Section 5.1 of this document). 


\subsection{RISK ASSESSMENT MODEL DEVELOPMENT}

\subsection{Simplified Models}

One of the steps in a simulation study is to build a simple model that captures the essence of the problem to be considered without being overly complicated. The results of the simple model can then be used to guide development of, and provide validation for, a more exacting simulation model. Appendix $B$ provides the details and results of a simplified model that was developed to better understand the efforts required in the waste volume projection, and provide guidance in the development of the logic and process of the GPSS simulation model.

The simple model initially used point values of projected new waste from Table 10 of the OWVP, Rev. 21 (WHC 1995b). The projected waste loss due to the evaporator waste volume reduction, pretreatment losses, and vitrification losses were also used. The total end-of-year inventory was determined from the starting waste inventory, plus new waste additions, minus projected total waste losses.

The total available double-shell waste tank capacity is 28 double-shell tanks ( $31,280 \mathrm{kgal}$ total). The equivalent space of two waste tanks was maintained as spare capacity. The available waste tank capacity was taken to be the total capacity minus the spare capacity (i.e., $29,000 \mathrm{kgal}$ ). Uncertainty was assumed to be associated with each new waste addition and waste volume loss. The uncertainty was represented by a triangular distribution that varied from the provided point value by $\pm 20 \%$ and increased by $1 \%$ per year. These uncertainty assumptions were used in the simplified model to evaluate the effect of increasing uncertainty with time. Uncertainty assumptions pertaining to the simulation model are presented in Section 3.2.3.

Four cases were considered and analyzed. The detailed results are presented in Appendix B. Some of the most significant results will be reviewed here as a starting point to understand the more detailed simulation results. First, uncertainty in waste generation and waste loss information increases with time such that there is an increasing likelihood that specific action will be required in out-years to avoid having the waste volume approach the available waste storage capacity. Decisions whose actions would require eight to ten years to implement will need to be made based on increasingly more uncertain information.

A discussion of possible age-related failures of DSTs is included with the details of the simplified model in Appendix B.

Although treated in a different manner, the concept of applying uncertainty to the waste generation and waste loss information has been used in the simple model as well as the more 
detailed simulation model.

\subsection{Simulation Model}

\subsubsection{Goals}

The primary goals of creating a simulation model of the TWRS waste volume versus storage capacity were to:

- Capture the level of understanding currently available regarding the projected waste flows into and out of the double-shell tanks over the next 20 years,

- Include the appropriate levels of uncertainty gleaned from the interviews (discussed in Section 2 and Appendix A), and

- Provide a versatile method for determining the effect of specific deviations from the current waste process and schedule assumptions on storage requirements over the next 20-year period.

During the initial phases of the project, it became apparent that it would be difficult or impossible to adequately determine waste capacity requirements, by treating the DST waste as a single waste stream. Therefore, the scope of this task was expanded to create three separate, related models for waste types that were considered to have the greatest effect on understanding and managing future storage requirements. The waste types were: 1) High-heat, or aging waste, 2) Complexed waste, and 3) all remaining waste, included as Non-complexed waste.

\subsubsection{Process}

Simulation modeling was the principal tool used to evaluate DST waste volume and capacity. General simulation modeling is described in Appendix C. A simulation model was created to approximate the actual flow patterns existing in the 200 Area tank farms (see Figure 3.2-1). In summary, the figure shows West and East area elements, including SST and facility waste sources. The AR-204 unloading station has been shown to indicate that their are multiple pathways for waste to enter the DST system: some hardpiped and some using rail or truck transportation. Transfer piping segments are also included in the model coding even though this feature has not been activated due to a lack of detailed data (see following paragraphs) and the relatively coarse time step chosen for this analysis (quarter-year increments). The removal pathways include the 242-A Evaporator, through the Liquid Effluent Retention Facility (LERF), to the Liquid Effluent 


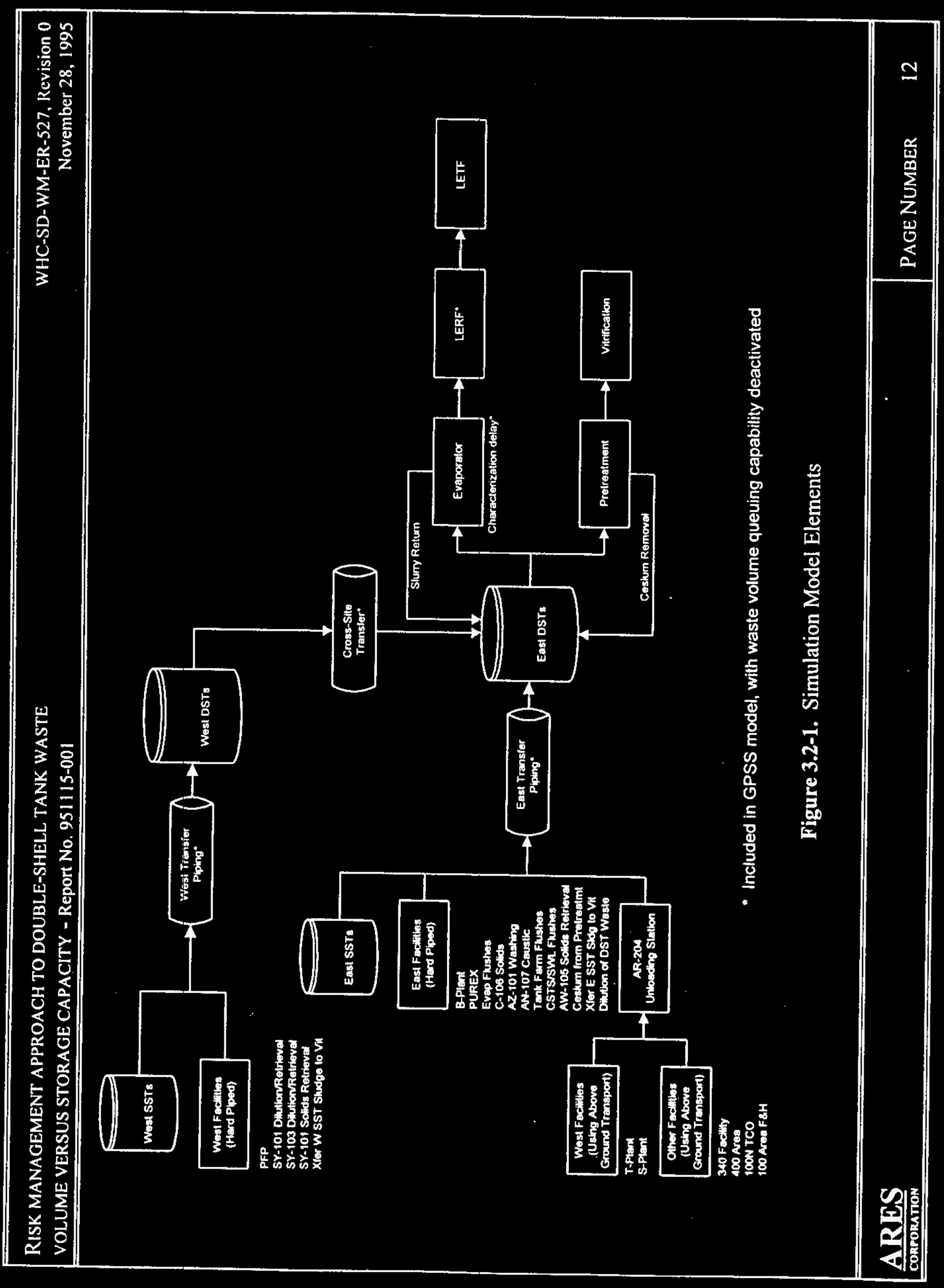


Treatment Facility (LETF), and the pretreatment/vitrification pathway. The slurry return from the evaporator is also included in the model.

Specific simulation model features are described below. The simulation model was created in the GPSS modeling language. Appendix D provides the details of the basis for this study and the program listings for the GPSS simulation code. The principal assumptions for the GPSS model are summarized as follows:

- Inflow (25 waste generation streams) and outflow (evaporation, pretreatment, and vitrification streams) are shown in the program listing (Appendix D) based on the OWVP, Rev. 21 (WHC 1995b) data.

- Transactions are generated within the model to simulate discrete volumes of waste moving through TWRS functional systems, such as the 200 West Area transfer lines, the 200 East and West Area DSTs, cross-site transfer lines, AR-204 Unloading Facility, and the Evaporator and disposal systems.

- A quarter-year time step was used to allow mid-year changes, such as Evaporator campaigns of less than year-long duration to be modeled accurately.

- Probability distributions were used for waste generator and disposal stream point values. The probability distributions were based on the results of waste generator interviews (Appendix A) and/or on engineering judgment. They were used to determine the effects of variability in input data on the waste inventory and waste capacity projections.

The features utilized in the GPSS model were:

- In the complexed and non-complexed waste models, which utilize the 242-A Evaporator, the evaporator feed lines were assumed to fail for one year (i.e., a one year mean-time-to-repair), triggered randomly approximately $10 \%$ of the time. Since the actual failure rate of the feed piping is yet to be determined, this feature was included in the model to approximate the effect of equipment failures associated with the evaporator. This feature was included as the result of the master logic diagram analysis (see Appendix E).

Features included in the model programming, but not activated for this analysis were:

- Sufficient data was not available to utilize mid-year generation and disposal adjustments to waste inflow or outflow. The OWVP, Rev. 21 (WHC 1995b), data was adjusted yearly. 
- Piping system flow rates for 200 West Area transfers cross-site transfers, and the AR-204 unloading station have been included in the model, but have not been activated due to lack of data. The AR-204 unloading station was identified in the master logic diagram analysis (Appendix E) to have no design redundancy and was added to the model so that this feature can be activated, along with the other deactivated features when adequate detail is available.

\subsubsection{Variables}

The primary source of input for the simulation model was the waste volume summary, Table 10, found in the OWVP, Rev. 21 (WHC 1995b). This data is tabulated, herein, as Table 3.2-1.

One of the main objectives of this simulation analysis was to provide a methodology to demonstrate the effects that suspected uncertainty in the input data has on the results. This was accomplished by developing frequency distributions for the data shown to be significant contributors to the results.

The significant contributors (waste generators) were determined using the method shown in Appendix D, Section D.1. A ranking was performed to identify the top ten contributors to the volume of new waste over the 12-year period covered by the interim waste volume projection (WHC 1995a) which was the latest OWVP available at that time in the analysis process.

For the top ten waste contributors, information gathered during the interviews with waste generator personnel (see Section 2.4 and Appendix A) was used to define a frequency distribution to indicate the minimum, maximum, and likely value (mode) for the yearly waste generation from each source. These values were used to create a triangular distribution which could be used by the simulation software. A triangular distribution was chosen over a normal distribution, or other shape distribution, due to its simplicity and the lack of waste generator data that would justify using a more elaborate model at this time. Sensitivity analyses were performed, substituting normal and uniform distributions for the triangular distribution. Due to the symmetric nature of most of the dominant data sets, the results were essentially identical. Therefore, triangular distributions were used throughout the analysis process. 


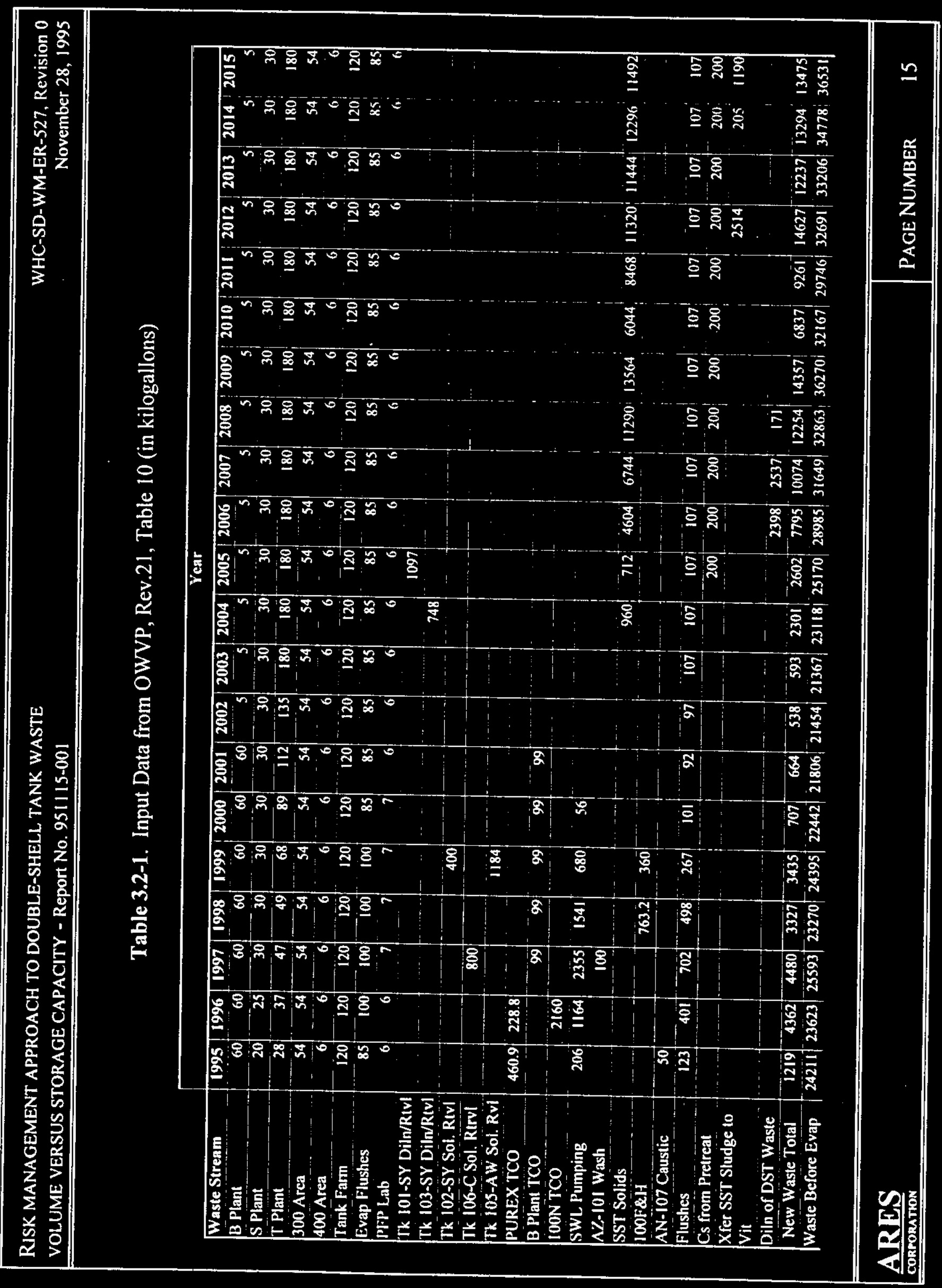




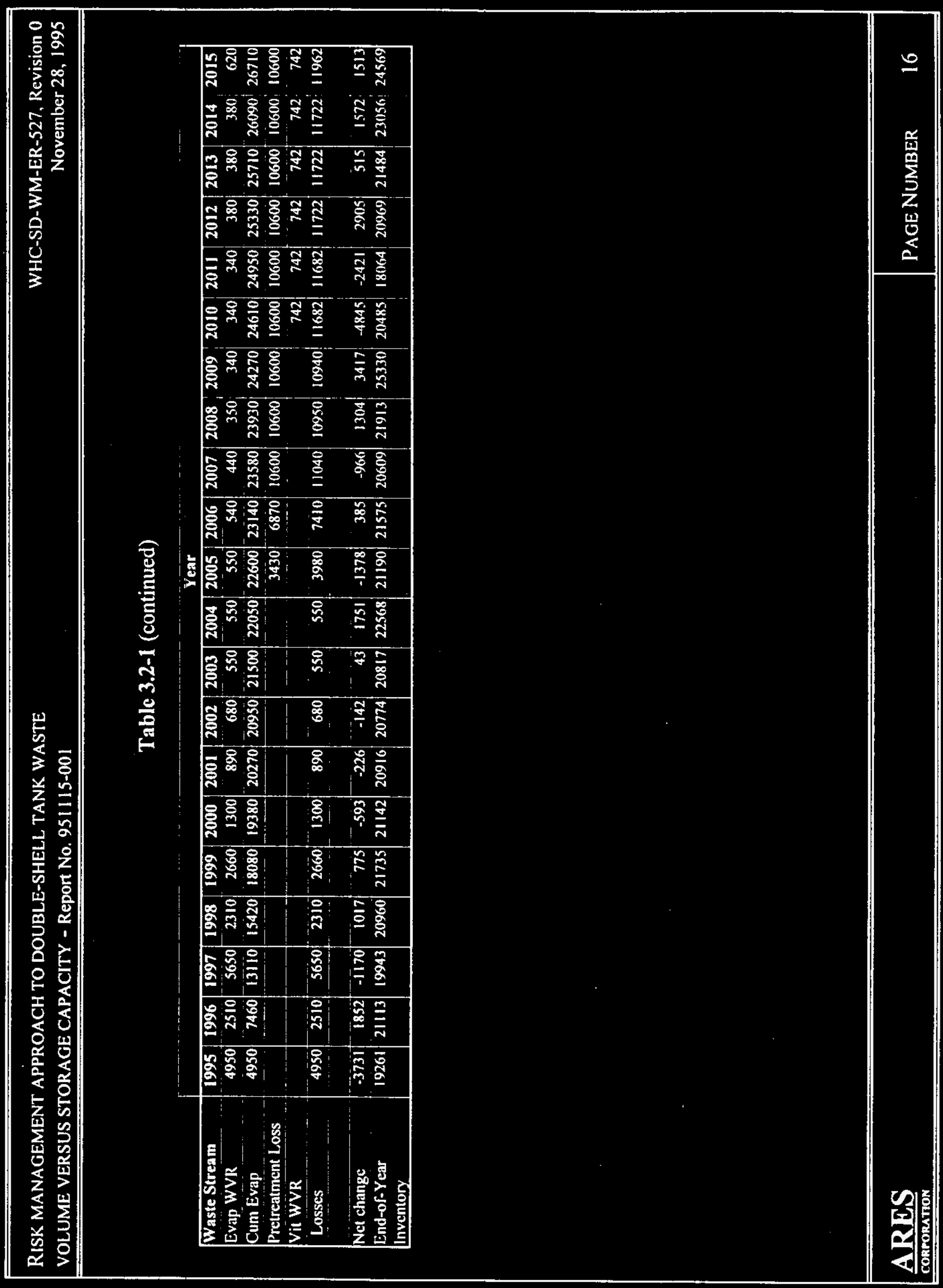


The basic operation of the GPSS program is based on the Monte Carlo process which uses random number generators to choose a point value for the volume of waste generation (or for that being removed from the system, i.e., disposal) from the provided frequency distribution. When many runs are made and the results are tabulated, a resultant frequency distribution is generated. The $90 \%$ confidence level is determined from this frequency distribution*.

* A $90 \%$ confidence level represents a waste volume projection with a probability of 0.9 that the actual waste volume will not exceed the projected waste volume. Or, conversely, a probability of 0.1 that the actual waste volume will exceed the projected waste volume. 


\subsection{BASE CASE RESULTS}

The base case simulation models for each of the three waste types analyzed (aging, complexed, and non-complexed) use OWVP, Rev. 21 "Base Case" waste input data and corresponding programmatic assumptions.

Charts have been created to depict the relationship between waste volume and capacity for the various cases throughout the rest of this report. Figure 4.0-1 provides a key to interpretation of the information presented on these charts.

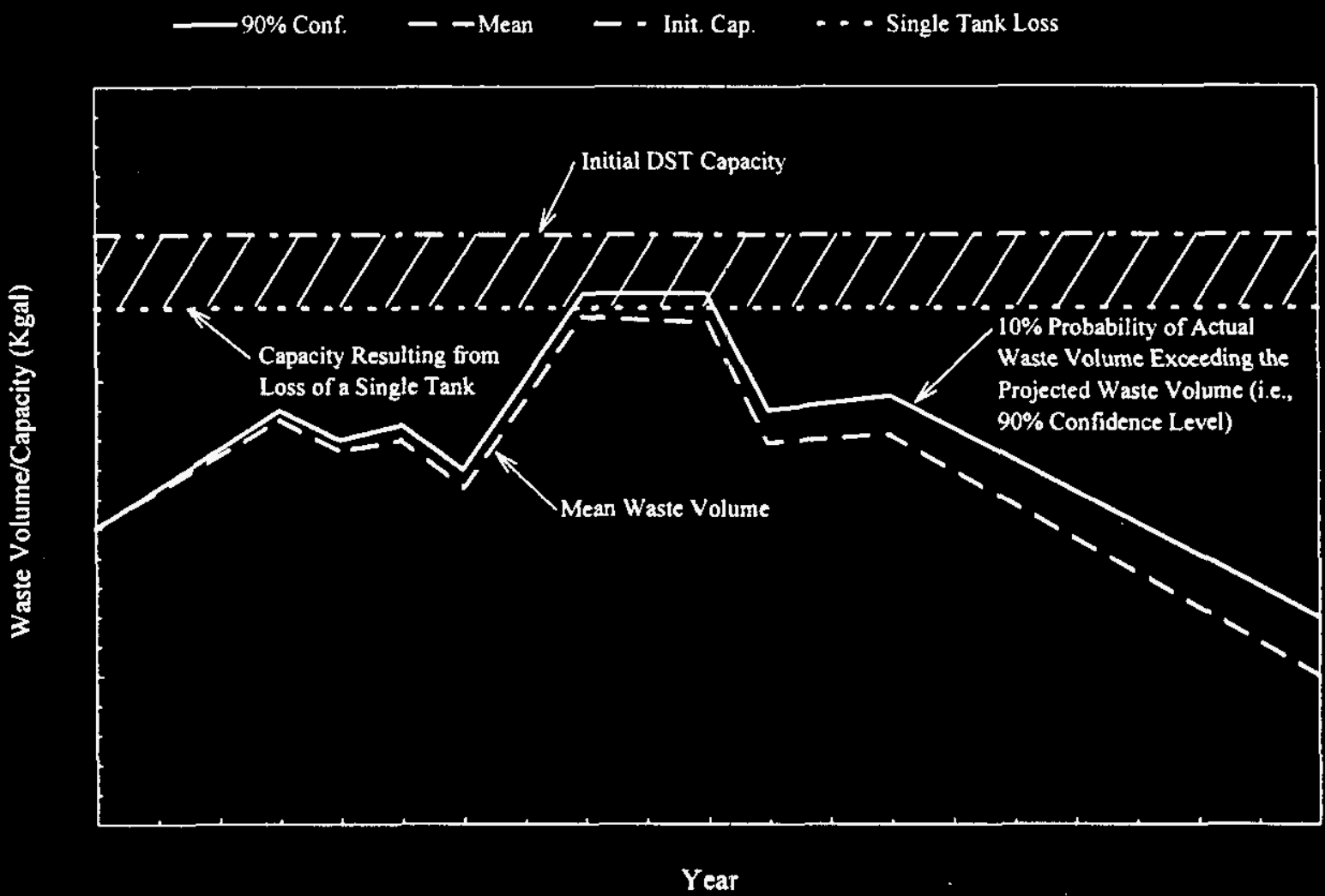

Figure 4.0-1. Chart Interpretation Key

Each of the following charts in Sections 4 and 5 show the waste volume or capacity in kilogallons on the $\mathrm{Y}$-axis, years on the $\mathrm{X}$-axis, the mean waste volume as the lowest, dashed line, the $90 \%$ confidence level as the solid line (directly above the mean), the initial waste tank capacity as the upper dotted/dashed line, and, if applicable, the effective volume loss if one DST 
failed during the period.

\subsection{Base Case}

The base case results assume completion of activities per the Planning Baseline Tri-Party Agreement (TPA) Milestones, and assume no component failures (except as noted). For the period evaluated, the three primary types of waste (aging. complexed, and non-complexed) are discussed in detail, below. 


\subsubsection{Aging Waste}

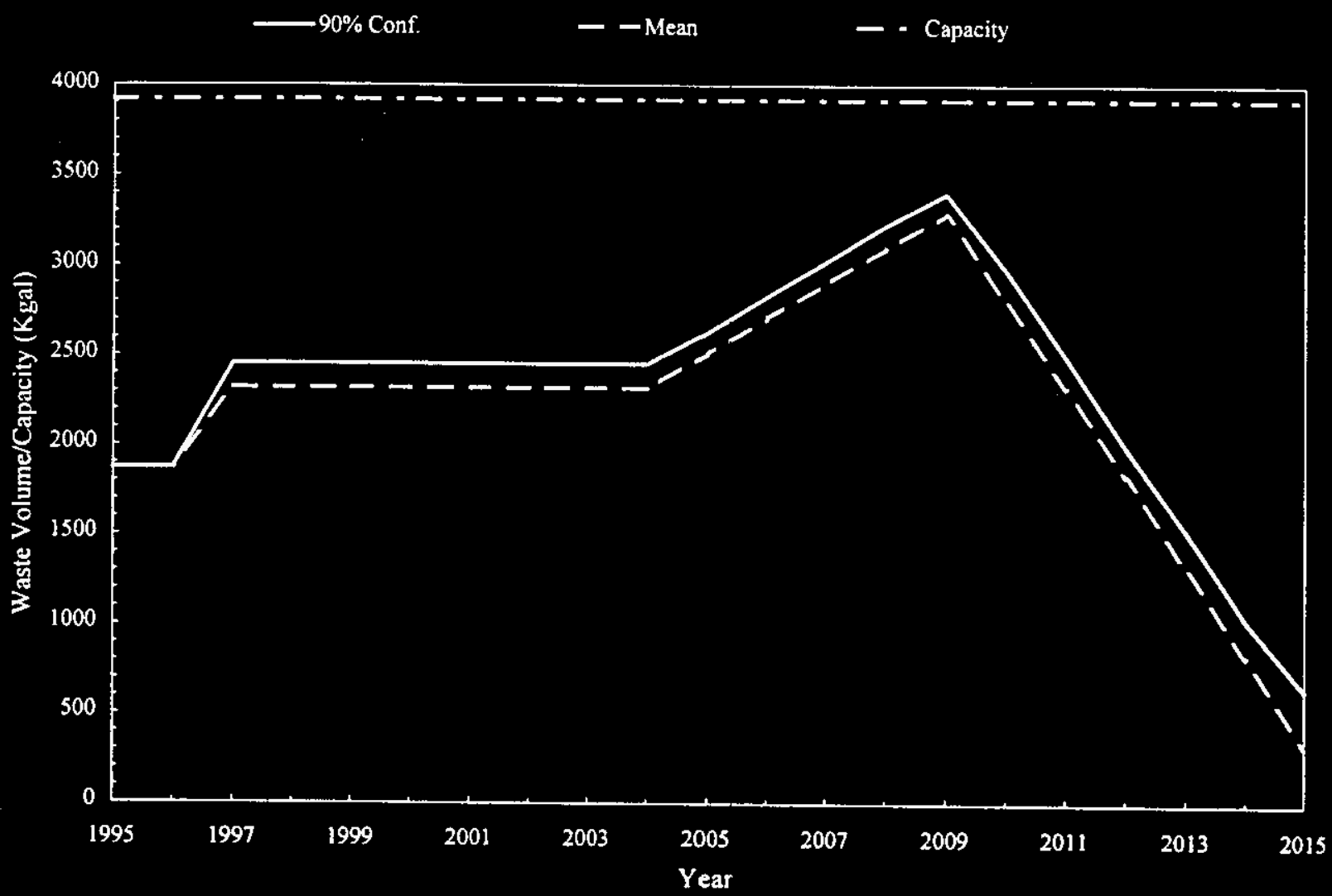

Figure 4.1-1. Aging Waste - Base Case Volume vs. Capacity

The shape of the base case inventory curve (Figure 4.1-1) is the product of the following elements. The beginning inventory is derived from the Waste Tank Summary Report (WHC 1995b) and is $1872 \mathrm{kgal}$. The retrieval of Tank C-106 adds $800 \mathrm{kgal}$ in 1997 and is affected by the uncertainty distribution described in Section 3.2.3. By decanting the non-aging supernatant from Tank AZ-102 in 1997 as part of the in-tank washing activities, $647 \mathrm{kgal}$ is removed from the aging waste inventory (per Hanlon, WHC 1995b, Table B-2 as the DN portion of NCAW). No additional high-heat waste comes in until 2005 , when the cesium stream from pretreatment is generated. Volume reduction occurs starting in 2010 with the commencement of high-level vitrification.

The evaluation of the Aging Waste base case model shows that, with a confidence level of $90 \%$, the waste inventory is projected to utilize a portion of aging waste spare tank 
capacity during the years 2006 through 2010 . One tank equivalent of spare capacity is required by DOE Order $5820.2 \mathrm{~A}$. However, due to the relatively short duration of the partial use of the spare tank, a fallback is not considered to be necessary.

\subsubsection{Complexed Waste}

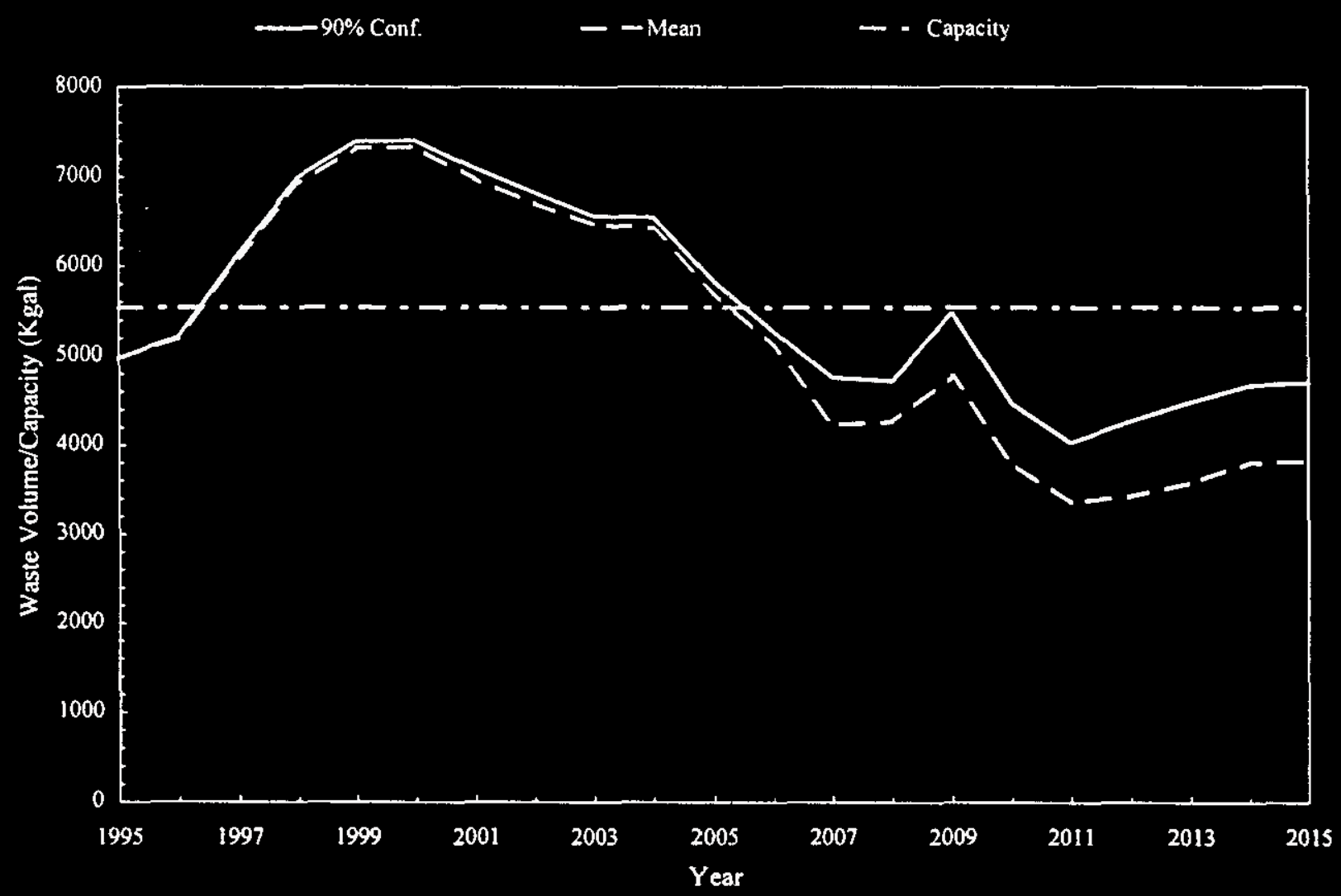

Figure 4.1-2. Complexed Waste - Base Case Volume vs. Capacity

The shape of the base case inventory curve for complexed waste (Figure 4.1-2) is the product of the following elements. The beginning inventory is derived from the Waste Tank Summary Report (Hanlon, WHC 1995b) and is $4926 \mathrm{kgal}$. The complexed waste portion of the salt well pumping enters the system through the year 2000 (per Table 3 of the OWVP, Rev. 21) and is affected by the uncertainty distribution associated with salt well pumping, described in Section 3.2.3. SST retrieval will also add to the volume during the years 2004 through 2015 and account for the minor peak in 2009. The retrieval of SY-101 and SY-103 is considered as no net increase in waste since these 
tanks are currently included in the complexed waste inventory and their waste will remain in this inventory, even if it is transferred to other tanks. Volume reduction occurs for a small fraction of the complexed waste through evaporation and pretreatment streams.

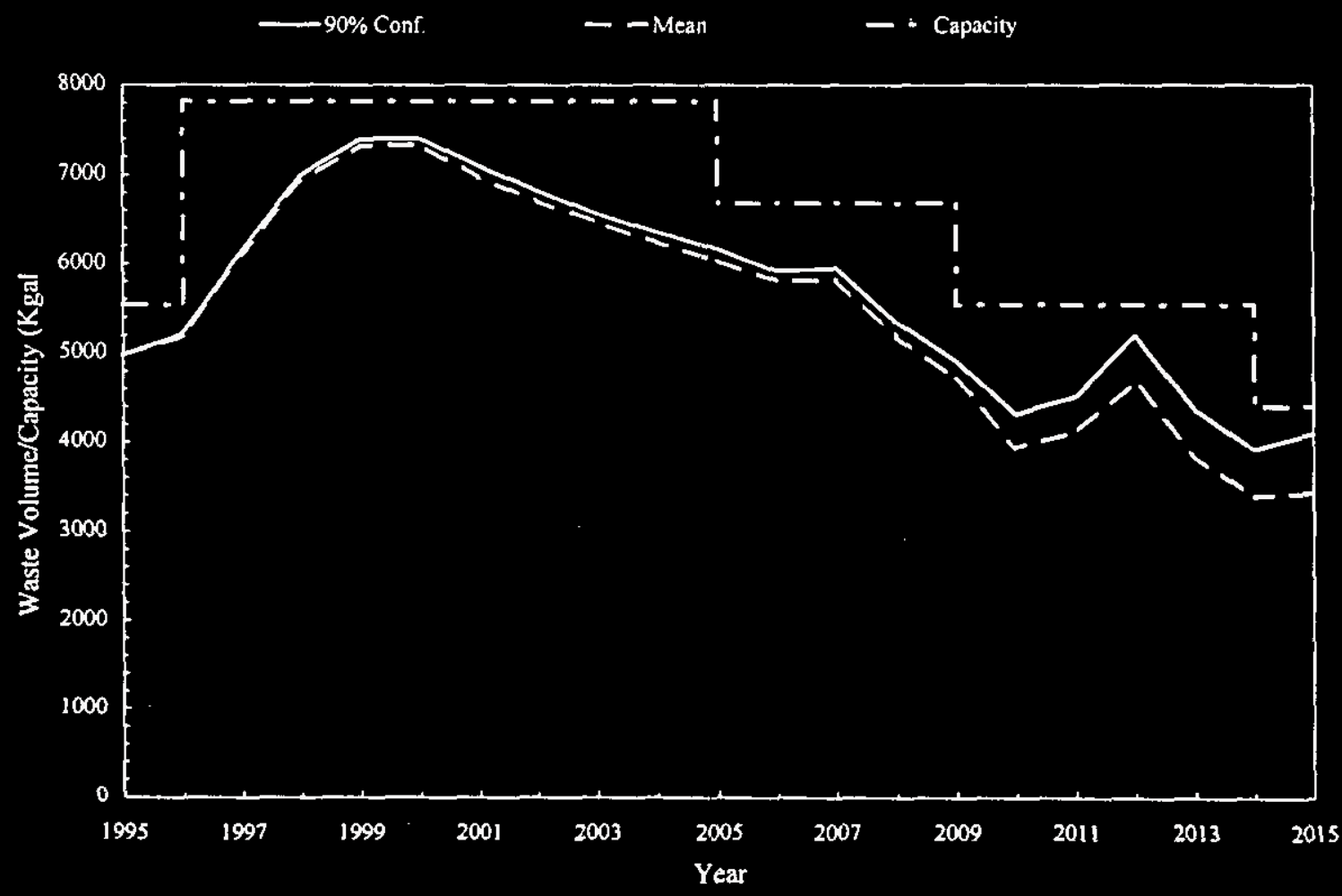

Figure 4.1-3. Complexed Waste - Fallback for Base Case

The evaluation of the complexed waste base case model shows that even the mean of the inventory is projected to exceed capacity by 1996 unless 2 additional non-complexed waste tanks are allocated to receive complexed waste (the $90 \%$ confidence value approximates the mean during this time frame, see Figure 4.1-3). The effect of the removal of two non-complexed waste tanks for allocation to complexed waste will not cause non-complexed capacity to exceed limits under projected conditions. According to the model, due to the gradual decrease in complexed waste inventory through pretreatment and vitrification after the peak in the year 2000 , individual complexed waste tanks can be emptied and released in 2005, 2009, and 2014 to be used for non-complexed waste. The removal of 2 tanks from non-complexed use and the readdition of the released tanks are reflected in the capacity for all non-complexed capacity curves other 
than the base case.

\subsubsection{Non-Complexed Waste}

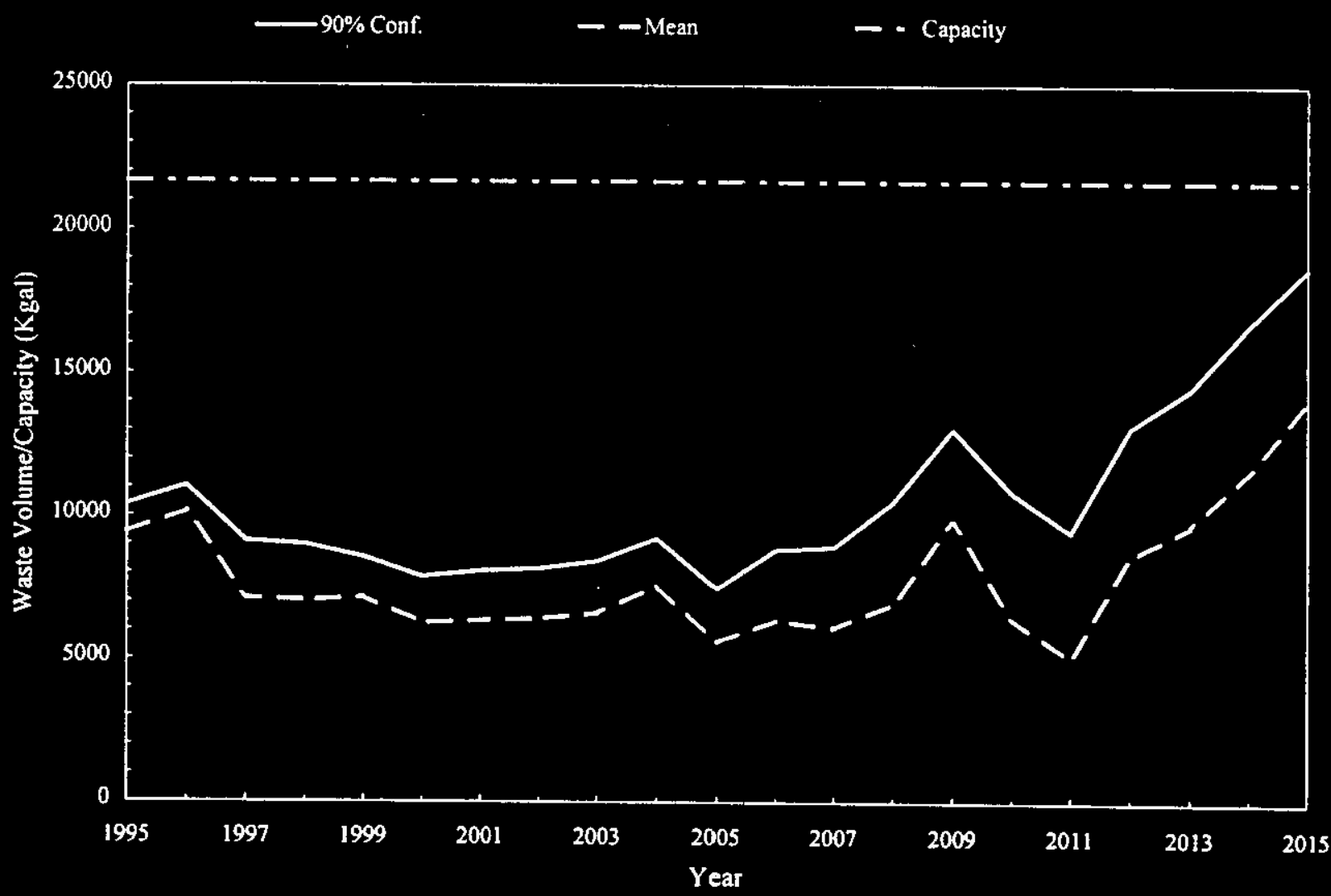

Figure 4.1-4. Non-Complexed Waste - Base Case Volume vs. Capacity

The shape of the base case inventory curve (Figure 4.1-4) is affected by the following elements. The beginning inventory is derived from the Waste Tank Summary Report (Hanlon, WHC 1995b) and is $12,424 \mathrm{kgal}$. The non-complexed waste portion of the salt well pumping enters the system through the year 2000 (per Table 3 of the OWVP, Rev. 21) and is affected by the uncertainty distribution described in Section 3.2.3, as are the many dilute non-complexed waste streams discussed in Section 3. SST retrieval and DST retrieval add to the volume between the years 2004 through 2015. Large volumes in the last few years of the projection window are generated by the SST retrieval and the transfer of SST sludge to vitrification. The various peaks and valleys seen toward the end of the period are from widely varying volumes in the SST sludge sent to vitrification. 
Volume reduction occurs through the major portion of the period analyzed through evaporation and pretreatment and vitrification. Additional reasons for the significant ramp up in volume toward the end of the period is due to the selective focus on volume reduction using the evaporator and pretreatment and vitrification facilities to reduce complexed and aging waste inventories. Shortly after 2015 , it can be expected that some tanks currently allocated to complexed and aging waste will be released, and become available to hold non-complexed waste. Also, the volume reduction efforts involving these other two streams (complexed and aging waste) can then be almost entirely devoted to the reduction of non-complexed waste.

The initial 19-tank capacity is reduced by the equivalent of 2 tanks which would be reallocated to complexed waste in 1996 . However, starting in 2005 , tanks which are no longer needed for complexed waste can be returned to the non-complexed waste capacity. A total of three tanks can be reallocated for non-complexed waste by 2015, according to the assumptions used in the simulation model.

The evaluation of the non-complexed waste base case model shows that the $90 \%$ confidence level volume projection does not exceed capacity. 


\subsection{OFF-NORMAL CONSIDERATIONS}

The original scope of this task was to provide a risk-based approach to the determination of whether projected waste volumes exceeded available capacity. The incoming waste streams and the waste removal streams had enough data available to form a basis for a risk-based treatment of that portion of the model. However, there was insufficient data available to provide the basis for the same treatment for off-normal events. Off-normal conditions are, therefore, treated deterministically in order to facilitate completion of the task and to provide an indication that the overall approach is feasible. (See Section 6.0 - Future Activities for the recommendation to develop risk relationships for off-normal events.)

\subsection{Off-Normal Condition Development}

As part of the overall development of this Risk Assessment, a series of off-normal conditions (upsets) were postulated for each of the main waste types. These off-normal conditions were developed based on data received during facility interviews (see Section 2.4 and Appendix A), historical information available in documents, authors' knowledge of Hanford activities, and engineering judgment of uncertainties associated with programmatic issues. These off-normal simulations reflect the authors' best judgment of risks associated with both programmatic and off-normal risks altering the Base Case simulation input information.

For each of the three main waste streams (aging waste, complexed waste, and non-complexed waste), three major off-normal conditions were chosen to represent a variety of causes considered to dominate the list of candidate events (Table 5.1-1). Each waste stream was analyzed for three off-normal conditions which represented 1) a major hardware loss (tank) due to accidentally inflicted damage or a loss caused by programmatic circumstances, 2) a major programmatic disruption (delay of key activities), and 3) a major change in the volume of waste requiring storage. These off-normal conditions represent large impacts to storage capacity and waste volume and, therefore, encompass many smaller off-normal conditions. Each of the off-normal conditions was then modeled and analyzed for impacts to the base case waste volume projections.

For those off-normal conditions that result in an unacceptable impact to the waste volume versus storage capacity projections, a fallback position was developed (Table 5.1-2). These fallback positions are described in sufficient detail to allow for a new analysis to be performed evaluating the off-normal condition-including-fallback to determine if the adverse consequences are prevented.

In some cases the off-normal conditions did not require a fallback position to be developed, since 
the available capacity was not exceeded. In several cases, the off-normal condition produced a very small likelihood of exceeding capacity near the end of the time frame analyzed in this report. In these cases, judgment was used to decide if the potential problem required any nearterm action, or if further analysis could wait for better data. In those cases where no near-term action was required, the results were simply noted, and no fallback position was developed.

The eventual use of the proposed fallback positions is dependent on many uncertainties. However, this study demonstrates that appropriate fallback positions can be developed to manage the risk associated with the described off-normal conditions. The fallback positions shown here are appropriate and reasonable, but are not purported to be the only fallback positions that could be deemed appropriate to mitigate the effects of the postulated off-normal conditions included in this analysis.

The specific off-normal conditions chosen for analysis, their associated fallbacks, and their effects on volume projections are shown within the following sections. 
Table 5.1-1. Simulation Model Cases - Base and Off-Normal Conditions

\begin{tabular}{|c|c|c|c|c|}
\hline \multirow[t]{2}{*}{ Waste Type } & \multirow[t]{2}{*}{ Base Case } & \multicolumn{3}{|c|}{ Off-Normal Conditions (from Base Casc) } \\
\hline & & Case \#1 & Case \#2 & Case \#3 \\
\hline Aging Waste & $\begin{array}{c}- \\
\text { Figure 4.1-1 }\end{array}$ & $\begin{array}{c}\text { Accidental loss of one } \\
\text { DST. } \\
\text { Figure } 5.2-1\end{array}$ & $\begin{array}{l}\text { Pretreatment increases } \\
\text { high-heat output by } 2 \\
\text { times. } \\
\text { Figure } 5.2-4\end{array}$ & $\begin{array}{c}\text { Safety concerns } \\
\text { require dilution of } 1 \\
\text { tank by } 2 \text { times in } \\
1998 . \\
\text { Figure } 5.2-7\end{array}$ \\
\hline Complexed Waste & $\begin{array}{c}\text { Includes effects of } \\
\text { evaporator line failure. } \\
\text { Figure } 4.1-2 \\
\end{array}$ & $\begin{array}{l}\text { Accidental loss of one } \\
\text { DST. } \\
\text { Figure } 5.2-10 \\
\end{array}$ & $\begin{array}{l}\text { Misrouting of } \\
\text { complexed waste into } \\
\text { a non-complexed tank } \\
\text { in } 1998 . \\
\text { Figure } 5.2-13\end{array}$ & $\begin{array}{l}\text { Pretreatment delay of } \\
\qquad 3 \text { years. } \\
\text { Figure } 5.2-15\end{array}$ \\
\hline $\begin{array}{c}\text { Non-complexed } \\
\text { Waste }\end{array}$ & $\begin{array}{c}\text { Includes effects of } \\
\text { evaporator line failure. } \\
\text { Figure } 4.1-4\end{array}$ & $\begin{array}{l}\text { Accidental loss of one } \\
\text { DST. } \\
\text { Figure } 5.2-17\end{array}$ & $\begin{array}{c}\text { Retrieval requires } \\
\text { additional dilution, } \\
\text { doubling SST retrieval } \\
\text { stream. } \\
\text { Figure } 5.2-18\end{array}$ & $\begin{array}{l}\text { Terminal cleanout } \\
\text { volumes from B- } \\
\text { Plant, PUREX, and } \\
100 \mathrm{~N} \text { are increased } \\
\text { by a factor of } 10 . \\
\text { Figure } 5.2-20\end{array}$ \\
\hline
\end{tabular}




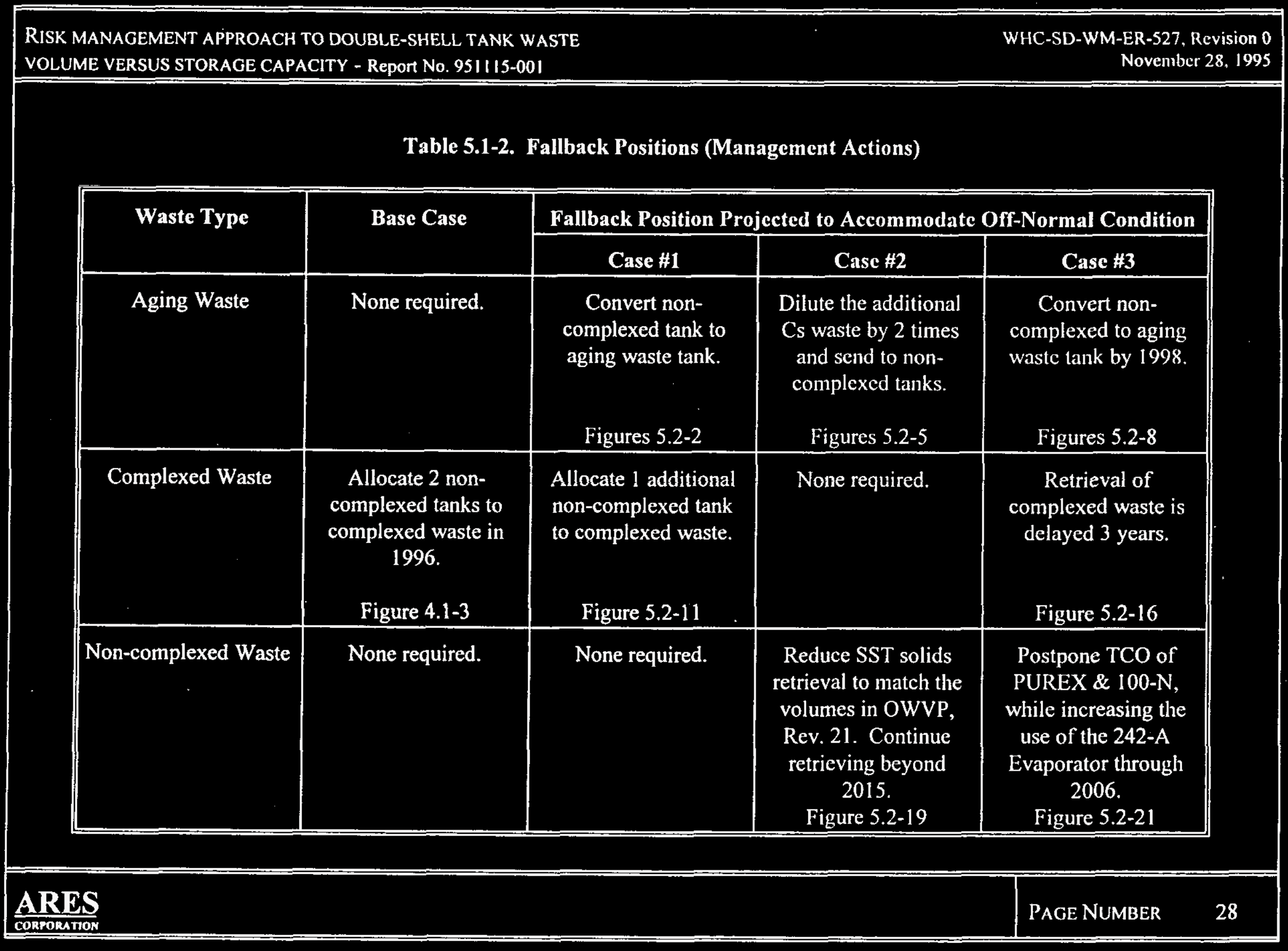




\subsection{Off-Normal Results}

\subsubsection{Aging Waste}

\subsubsection{Aging Waste Case \#1}

Off-Normal \#1 (Figure 5.2-1)

The first postulated off-normal condition is the loss of one DST. The result, shown by the lower border of the cross-hatched area on the chart, is that there would be less than one full tank of spare capacity for most of the projection period and, with spare capacity lost, inventory could exceed capacity for a period from 2006 to 2010.

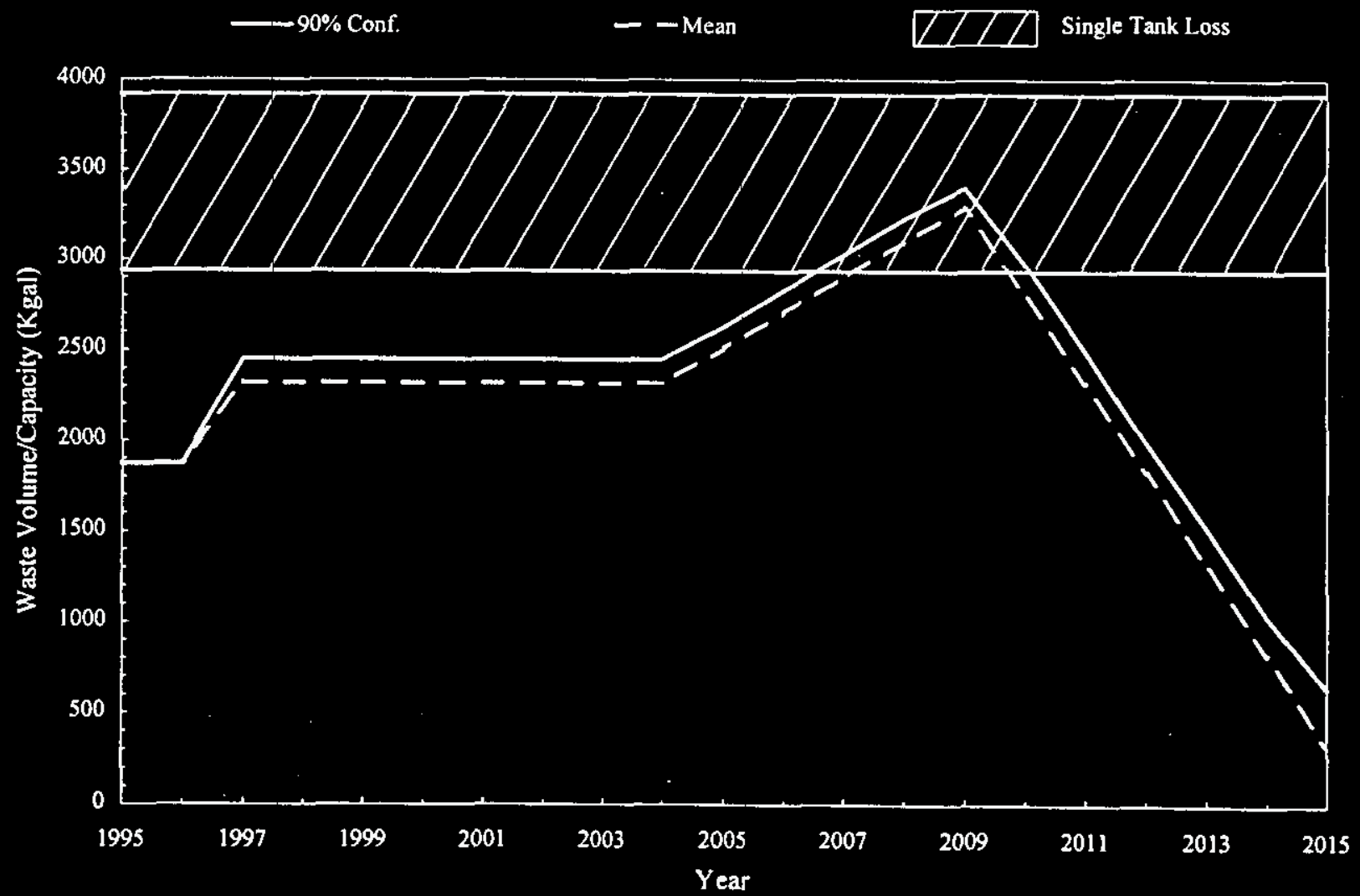

Figure 5.2-1. Aging Waste - Off-Normal No. 1 
Fallback for Aging Off-Normal \#1 (Figure 5.2-2)

Conversion of one non-complexed waste tank to aging waste storage (see upper border of crosshatched area on chart) will provide adequate capacity, including spare space, until 2006. At that time, the cesium stream from pretreatment adds enough high-heat waste to begin reducing spare capacity to less than one tank. Conversion of a non-complexed waste tank to aging waste storage can be accomplished by installing mixer pumps and cooling coils, that would require considerable design and procurement expense. Although a significant lead time (up to 3 years) may be required to design and procure the equipment needed for this conversion, if some preparation is made as a contingency, the conversion could be accomplished within a year of the loss of a tank.

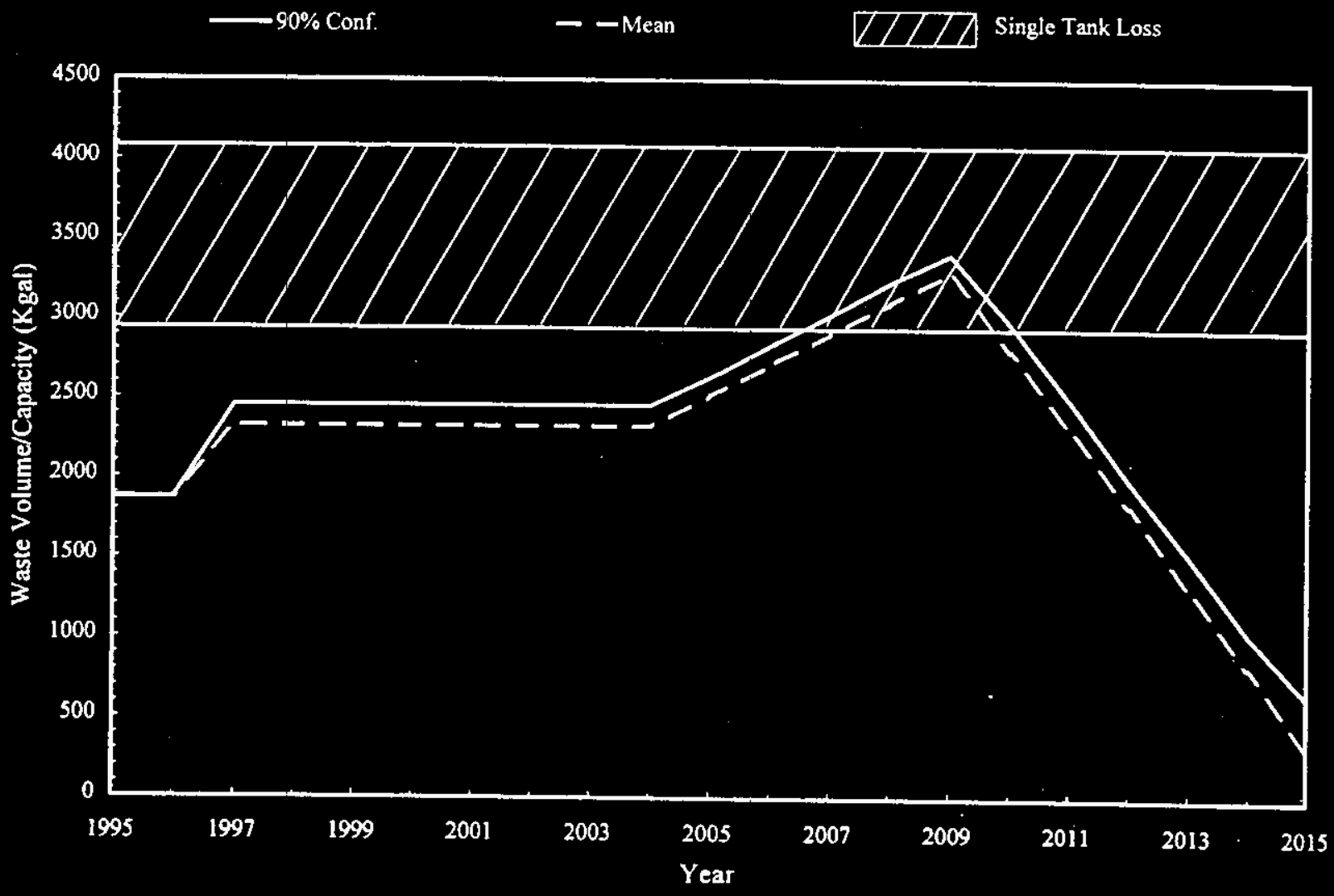

Figure 5.2-2. Aging Waste - Fallback for Off-Normal No. 1 
Consequences on Non-Complexed Waste Capacity from Fallback for Aging Waste Off-Normal \#1 (Figure 5.2-3)

The non-complexed waste tank converted to aging waste is shown to be removed from noncomplexed service (lower border of cross-hatched area on chart). This transfer does not cause the non-complexed waste capacity to be exceeded. (See Section 4.1.2 for an explanation of the increases in non-complexed capacity in years 2005,2009 , and 2014.)

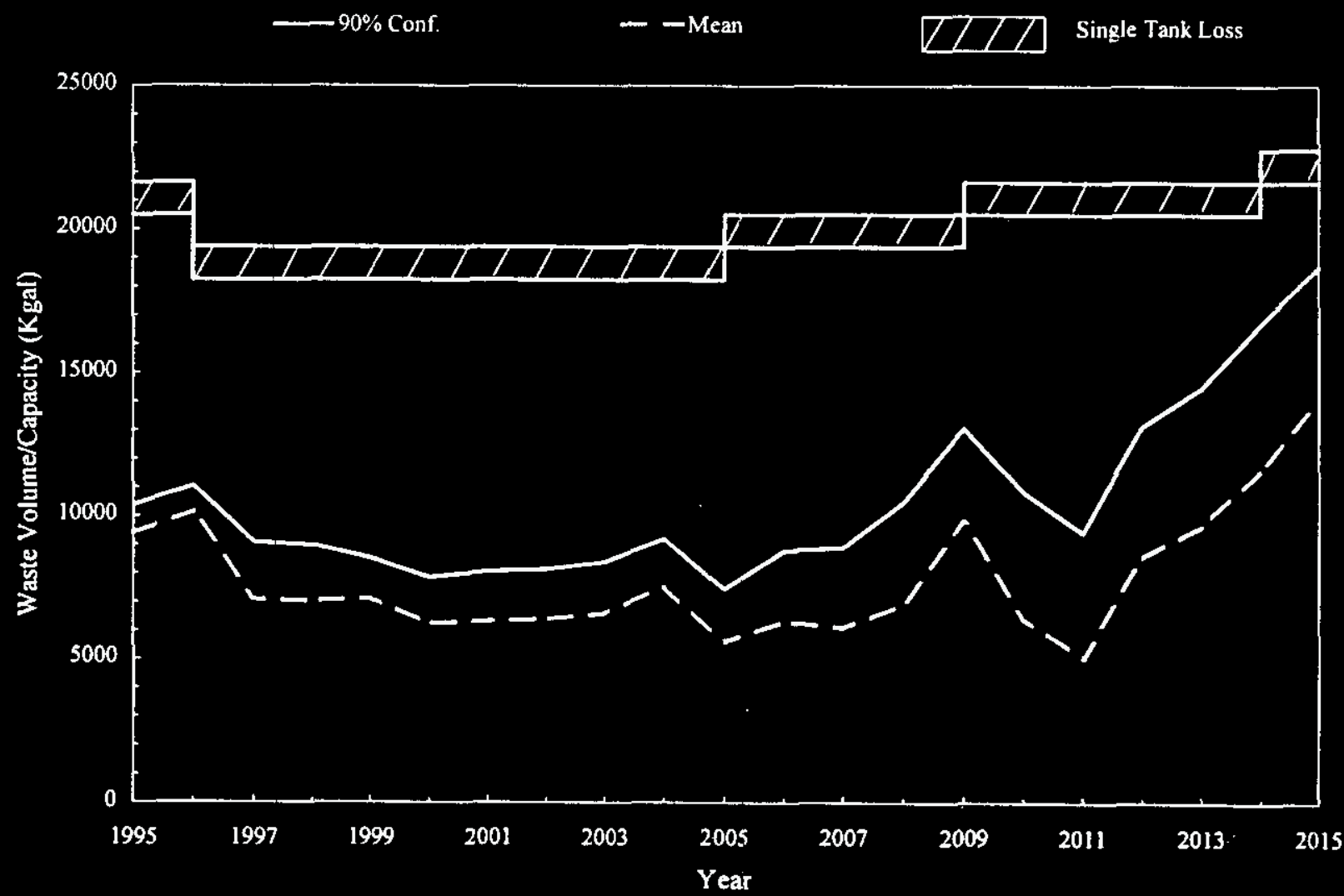

Figure 5.2-3. Non-Complexed Waste - Consequences of Aging Waste Off-Normal No. 1 


\subsubsection{Aging Waste Case \#2}

Off-Normal \#2 (Figure 5.2-4)

The next postulated off-normal condition in the Aging Waste subset is the volume of the cesium return stream from pretreatment is double the current projection (per OWVP, Rev. 21). This change in inventory projection results in the inventory exceeding capacity by the year 2006 and staying above the 4-tank capacity throughout the remainder of the projection window (through 2015).

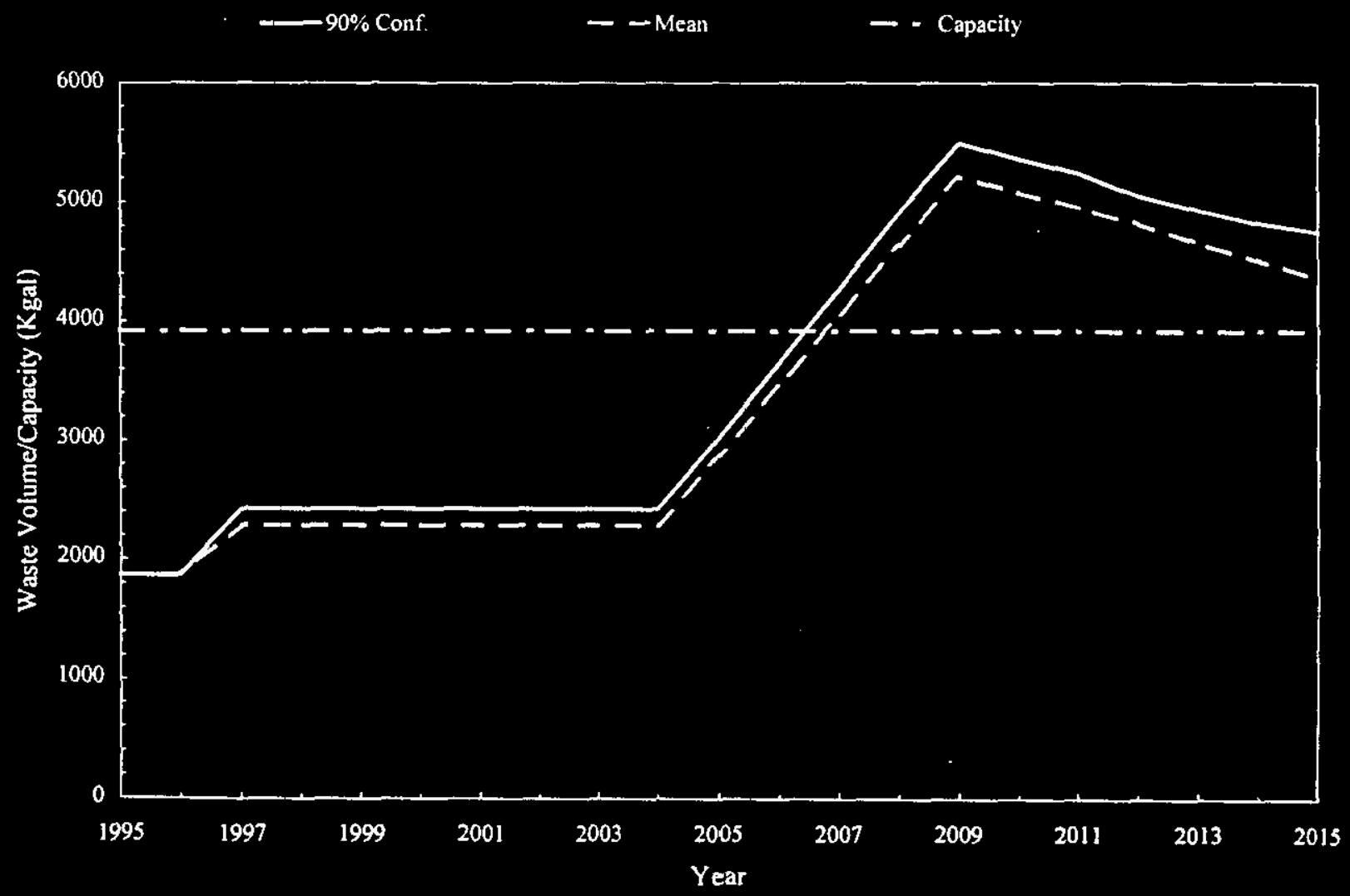

Figure 5.2-4. Aging Waste - Off-Normal No. 2 


\section{Fallback for Aging Off-Normal \#2 (Figure 5.2-5)}

The proposed fallback for off-normal condition $\# 2$ assumes the cesium stream will be diluted and stored in a non-aging waste tank. This fallback does not add waste to the aging waste inventory and, therefore, does not affect the aging waste base case model (i.e., this is identical to the base case curve, Figure 4.1-1).

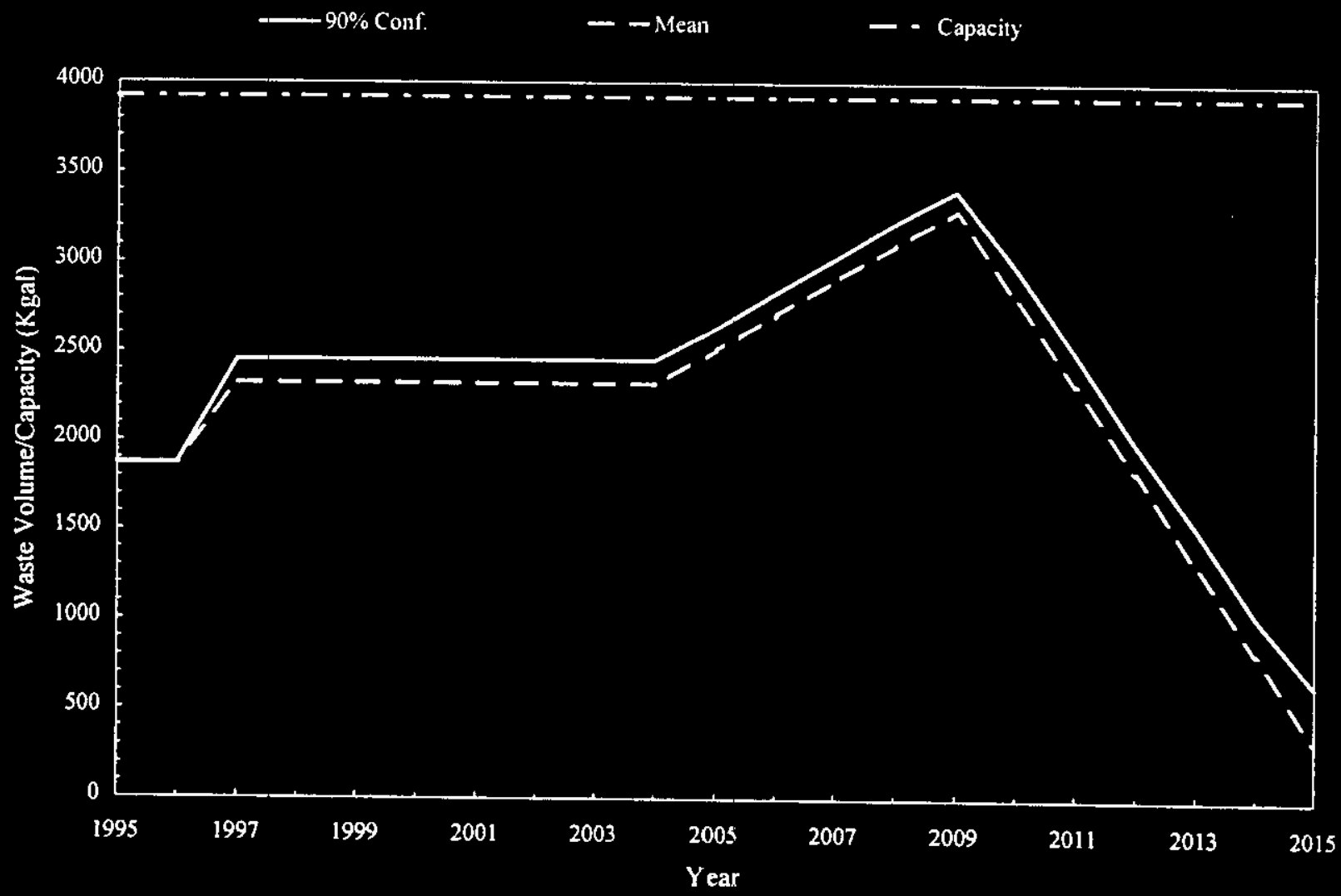

Figure 5.2-5. Aging Waste - Fallback for Off-Normal No. 2 
Consequences on Non-Complexed Waste Capacity from Fallback for Aging Waste Off-Normal \#2 (Figure 5.2-6)

The additional cesium waste generated is diluted by doubling its volume (to reduce its concentration below aging waste limits) and added to the non-complexed inventory, i.e., double that shown in OWVP, Rev. 21. Although this adds significant inventory, the resulting noncomplexed inventory (mean) remains below capacity limits. The $90 \%$ confidence level remains within limits through all except the final year of the simulation period. No further fallback was considered for this off-normal condition.

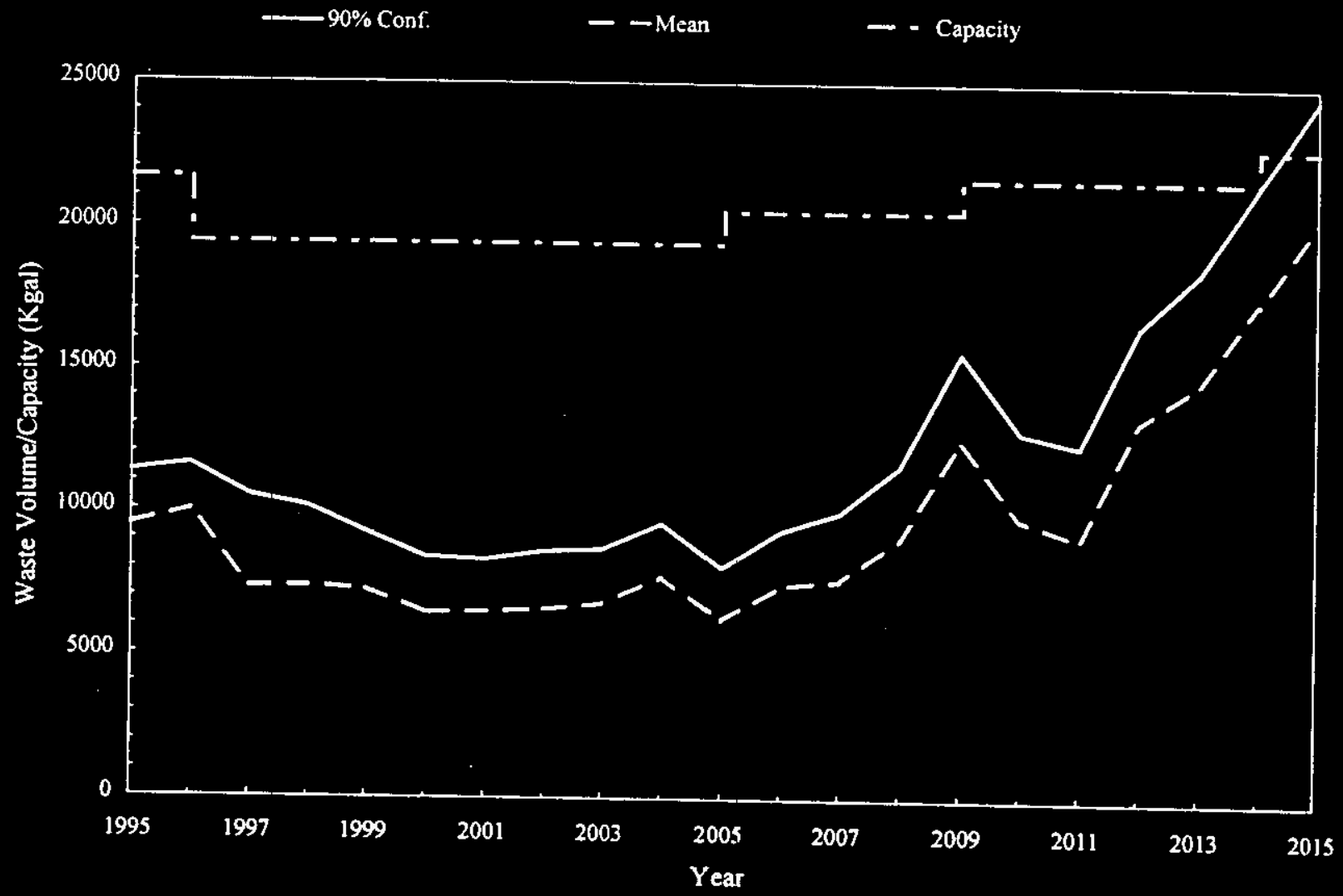

Figure 5.2-6. Non-Complexed Waste - Consequences of Fallback for Aging Off-Normal No. 2 


\subsubsection{Aging Waste Case \#3}

Off-Normal \#3 (Figure 5.2-7)

The last off-normal condition postulated for the Aging Waste tanks assumes that the volume in one aging waste DST in 1998 is doubled through dilution to relieve an unacceptable safety issue, such as criticality concerns or tank overheating (tank bump). This results in partial use of spare aging waste tank space beginning in the year 1998, and exceeding capacity for a short period from 2007 through 2010.

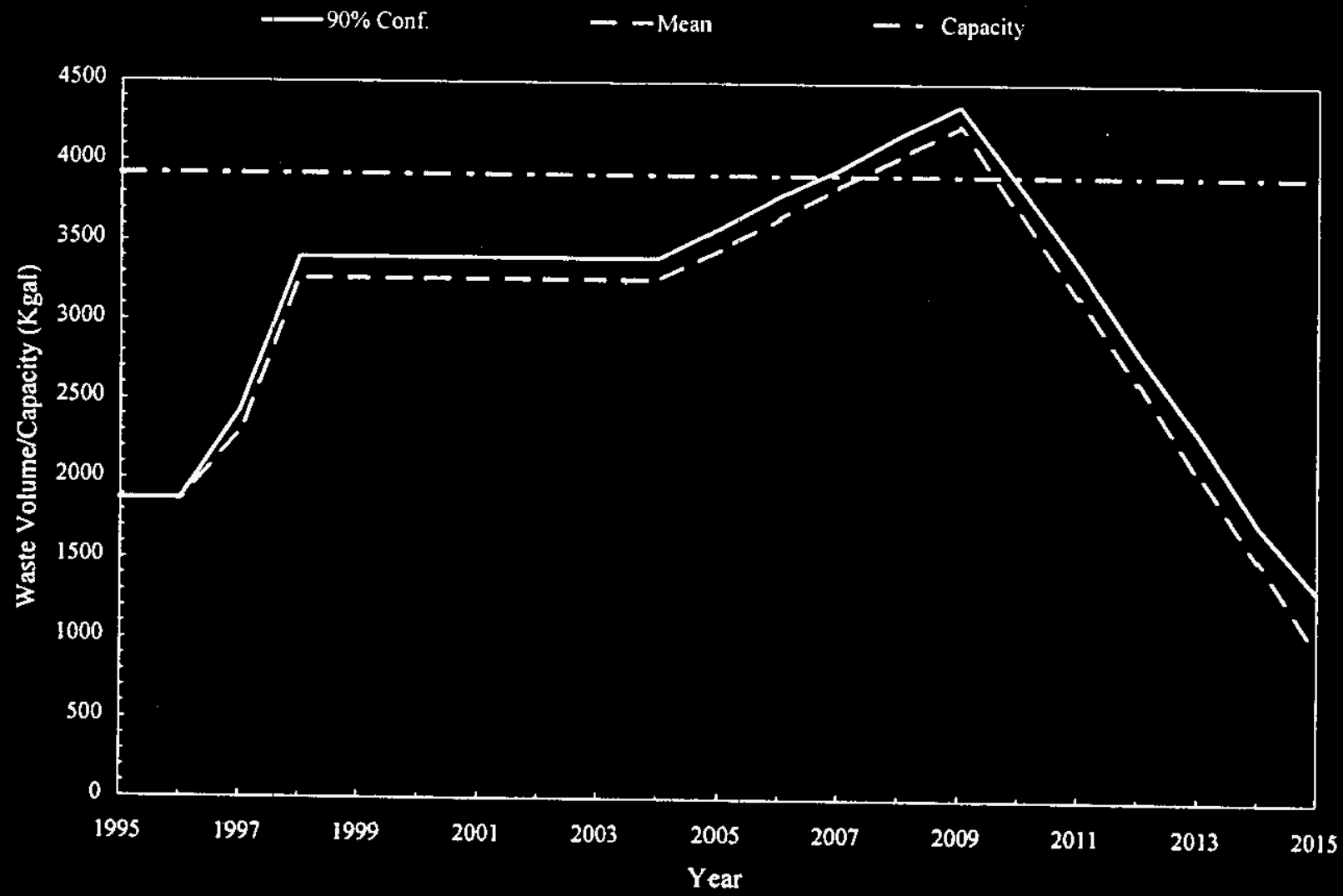

Figure 5.2-7. Aging Waste - Off-Normal No. 3 
Fallback for Aging Off-Normal \#3 (Figure 5.2-8)

To regain spare capacity for the years 1998 through 2004 and to provide for peak inventory (again using some spare space) from the years 2004 through 2011, a non-complexed waste tank is converted to accept aging waste by installing mixer pumps and cooling coils, similar to the fallback for Aging Off-Normal Condition \#1. The resulting inventory (mean) is below capacity limits, although spare capacity is not the equivalent of one tank's volume.

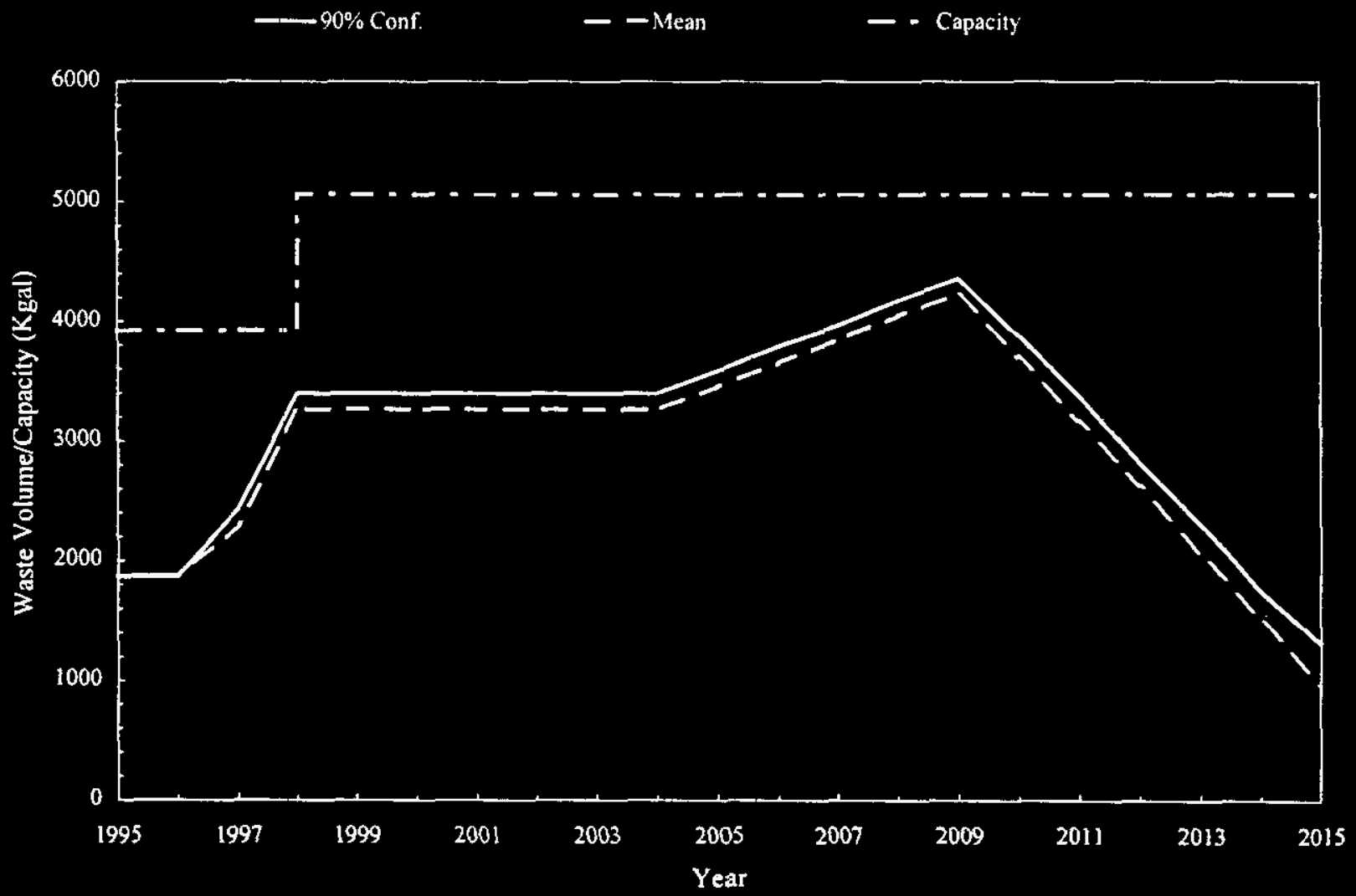

Figure 5.2-8. Aging Waste - Fallback for Off-Normal No. 3 
Consequences on Non-Complexed Waste Capacitv from Fallback for Aging Waste Off-Normal $\# 3$ (Figure 5.2-9)

The resulting loss of non-complexed storage capacity from the conversion of 1 tank in 1998 is shown on the associated non-complexed waste chart. The resulting non-complexed inventory ( $90 \%$ confidence value) is well below capacity limits. Thus, the reassignment of a noncomplexed tank does not result in the shortage of non-complexed capacity.

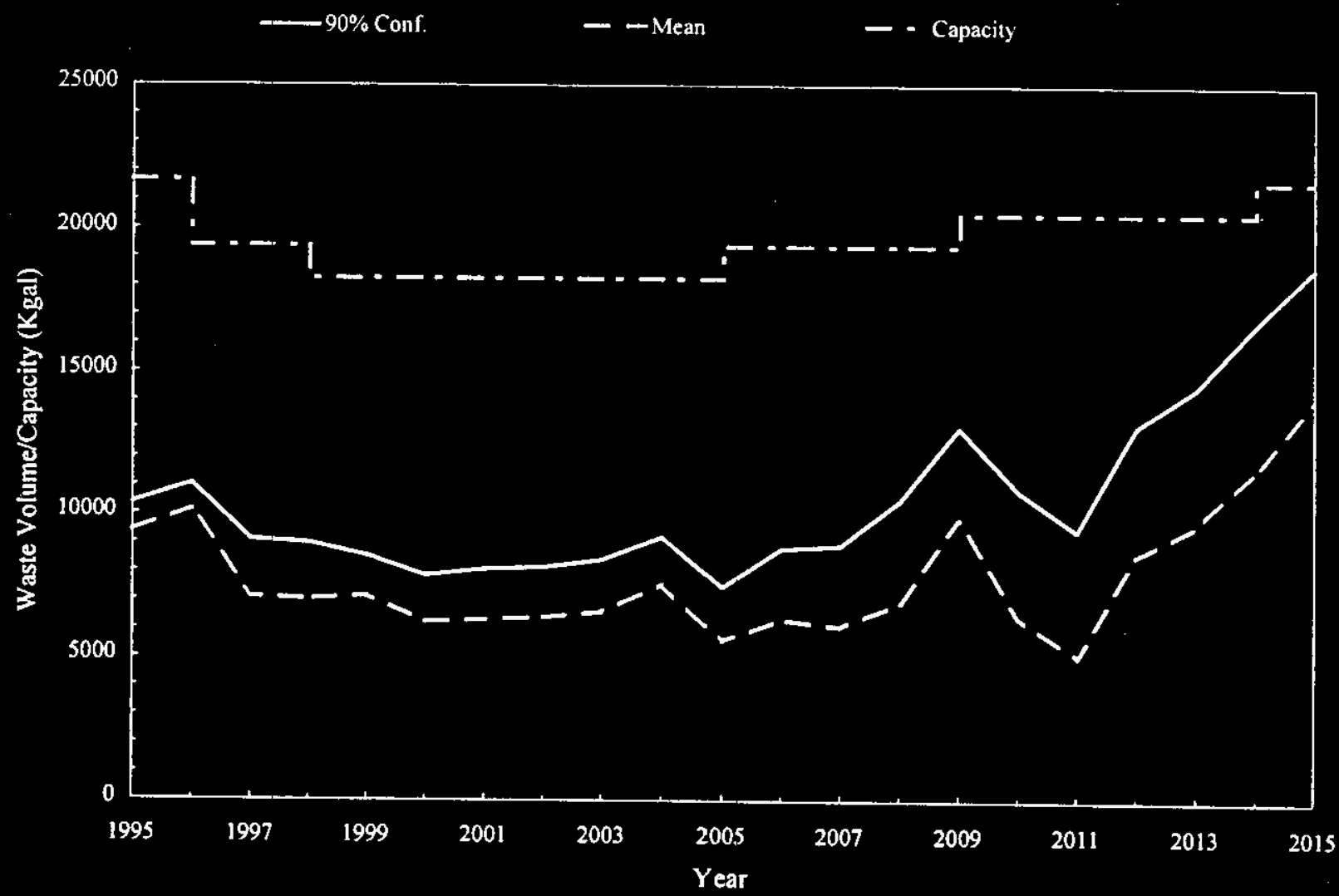

Figure 5.2-9. Non-Complexed Waste - Consequences of Fallback for Aging Off-Normal No. 3 


\subsubsection{Complexed Waste}

\subsubsection{Complexed Waste Case \#1}

\section{Off-Normal \#1 (Figure 5.2-10)}

The first postulated off-normal condition for complexed waste is the loss of one DST. Since only the required number of non-complexed waste tanks were reallocated to store complexed waste in 1996 (base case fallback), any loss of a DST before the year 2005 would result in insufficient waste storage capacity as shown by the lower border of the cross-hatched area on the chart. A fallback position which requires no physical alteration will accommodate this offnormal condition, and is described on the following page.

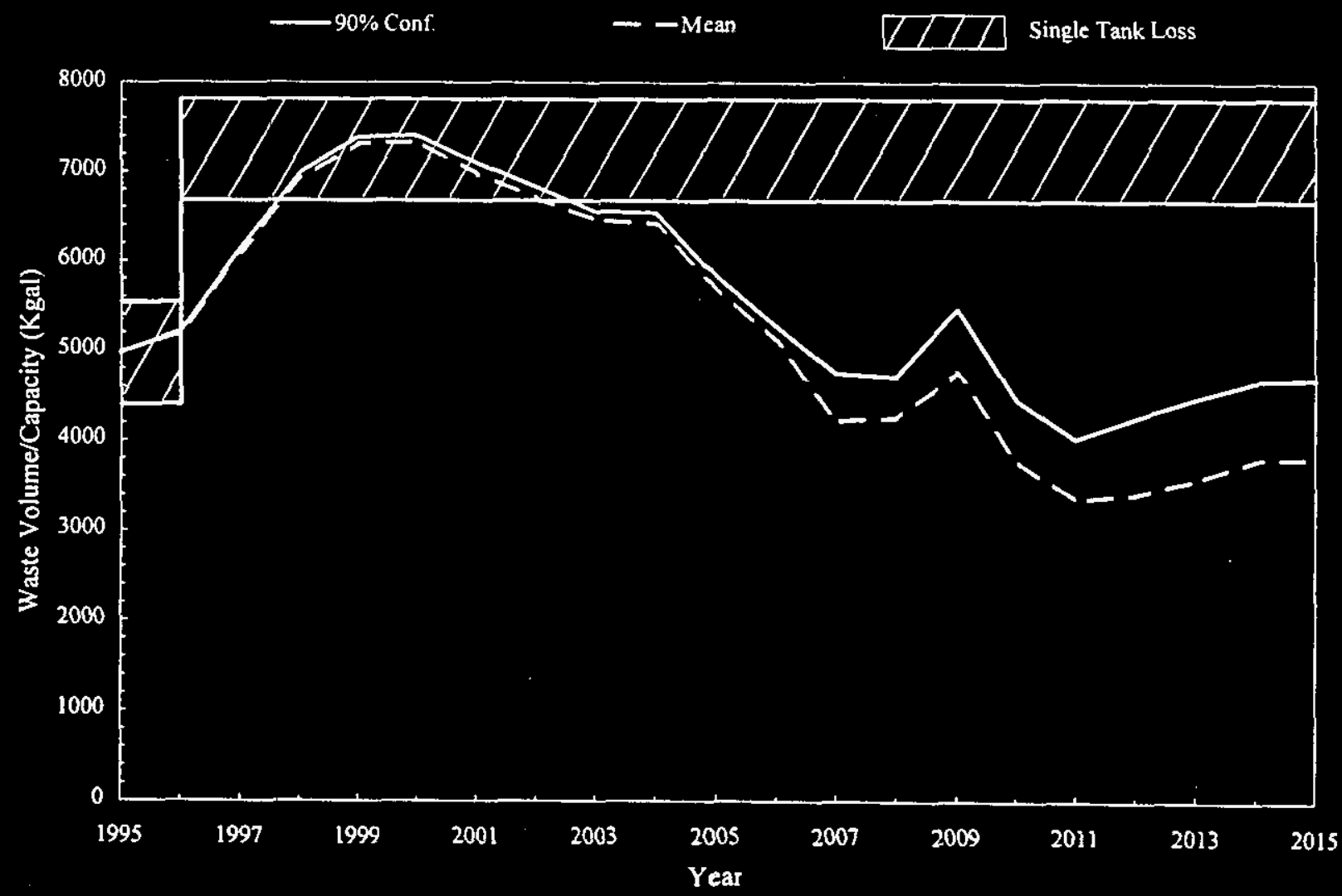

Figure 5.2-10. Complexed Waste - Off-Normal No. 1 


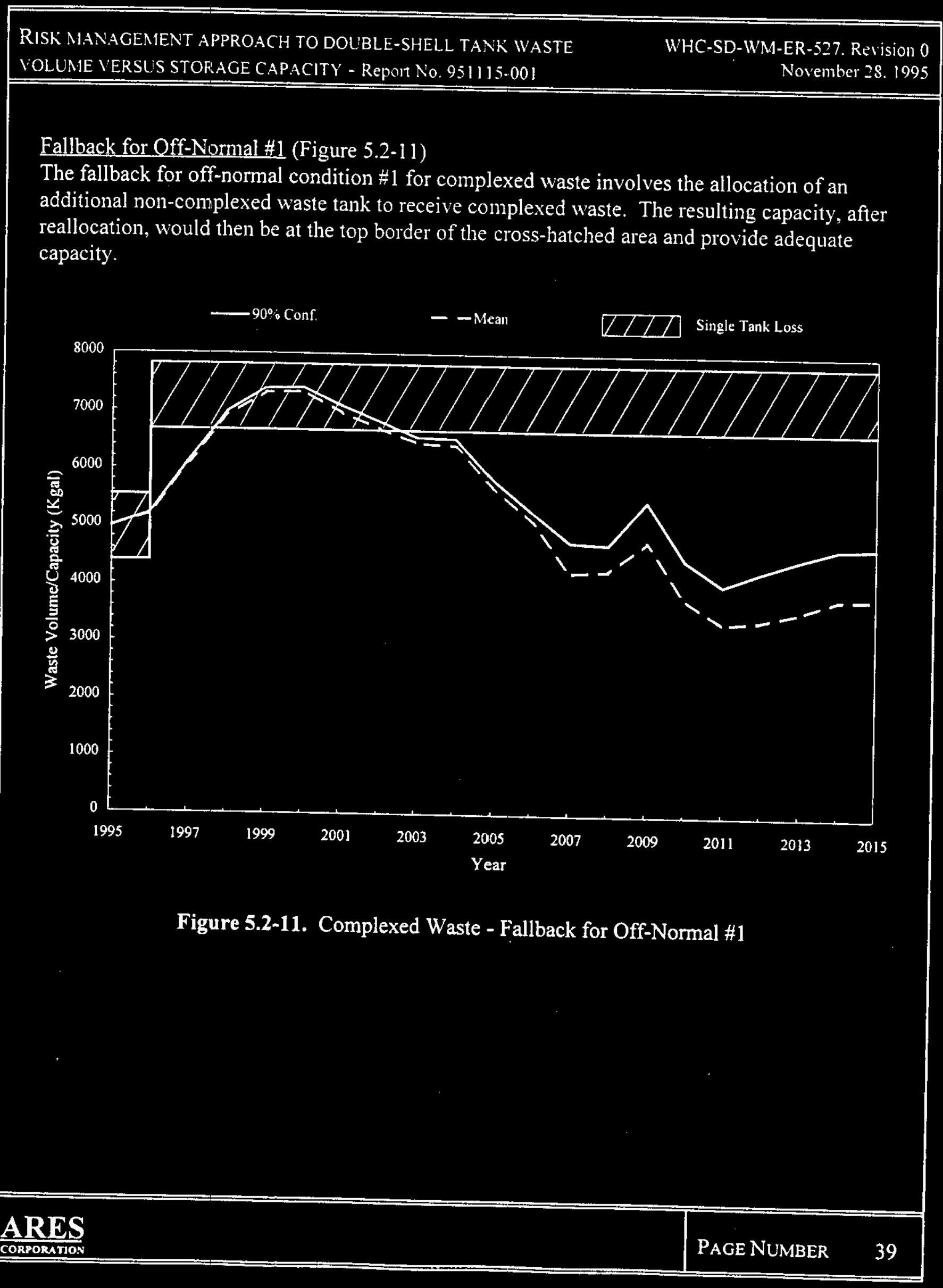


Consequences on Non-Complexed Waste Capacity from Fallback for Off-Normal \#1 (Figure 5.2-12)

The resulting loss of non-complexed storage capacity from the allocation of 1 tank is shown by the lower border of the cross-hatched area on the chart. The resulting non-complexed inventory ( $90 \%$ confidence curve) is well below capacity limits.

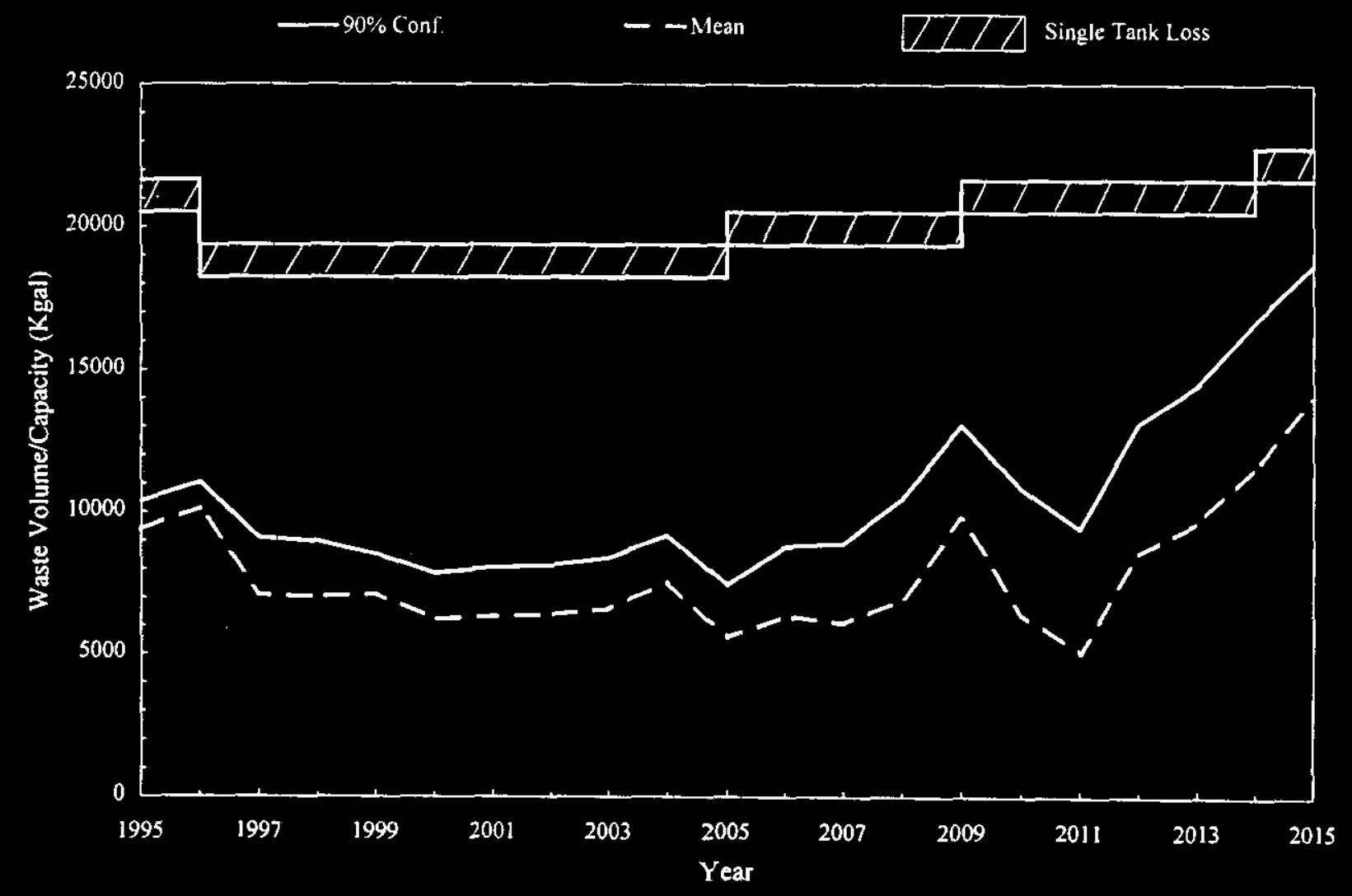

Figure 5.2-12. Non-Complexed Waste - Consequences of Complexed Off-Normal \#1 


\subsubsection{Complexed Waste Case $\# 2$}

Off-Normal \#2 (Figure 5.2-13)

The second postulated off-nomal condition for complexed waste is caused by misrouting a complexed waste transfer to a non-complexed DST containing $200 \mathrm{kgal}$. This previously noncomplexed waste is contaminated and becomes complexed waste. By default, the noncomplexed tank involved is now designated a complexed waste tank. Therefore, an additional DST is included in complexed capacity.

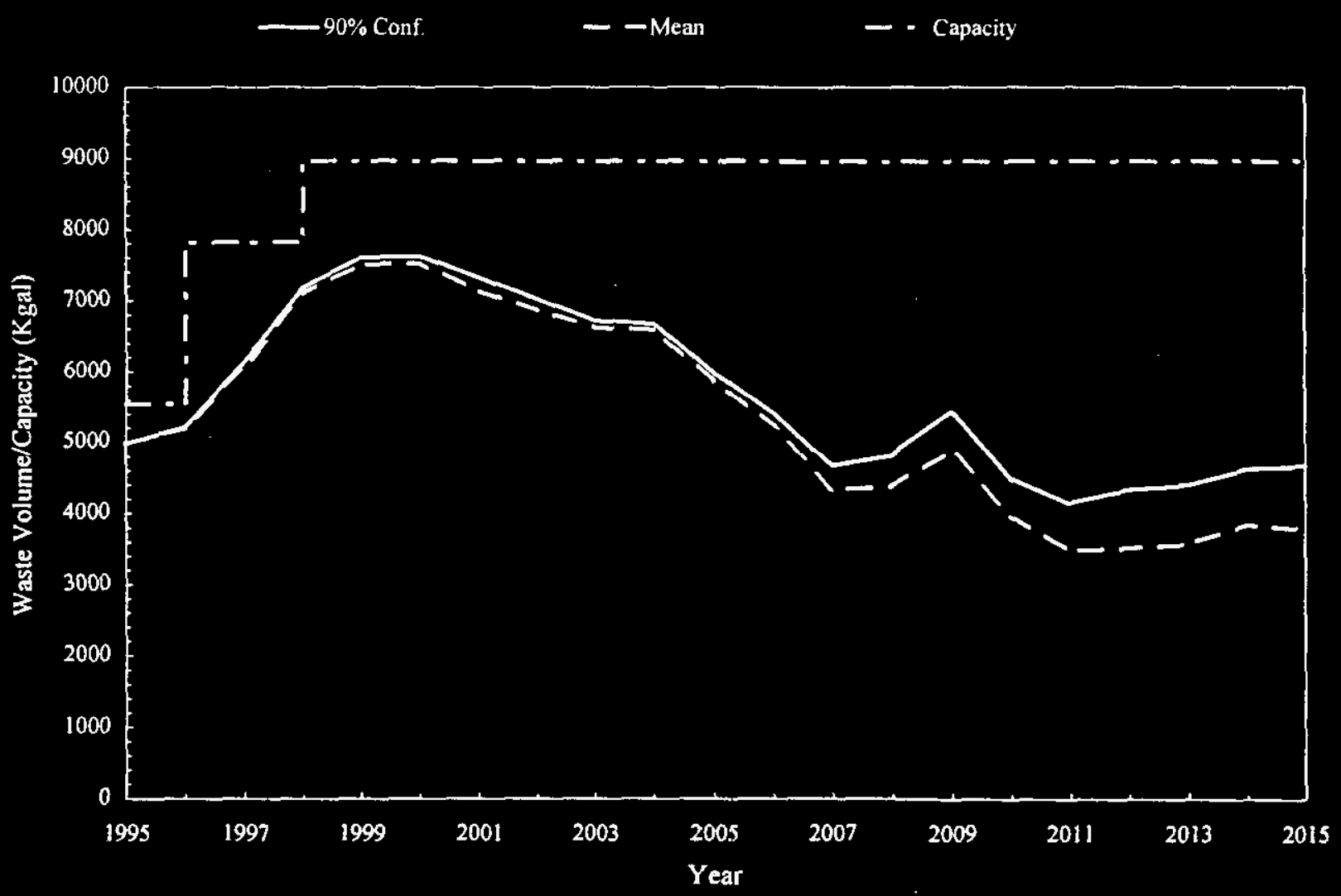

Figure 5.2-13. Complexed Waste - Off-Normal No. 2 
Consequences on Non-Complexed Waste Capacity from Fallback for Complexed Waste OffNormal \#2 (Figure 5.2-14)

The resulting loss of non-complexed storage capacity from the allocation of 1 tank in 1998 is shown on the chart as well as $200 \mathrm{kgal}$ of non-complexed waste being removed from inventory (it is now complexed). The resulting non-complexed inventory ( $90 \%$ confidence curve) is well below capacity limits.

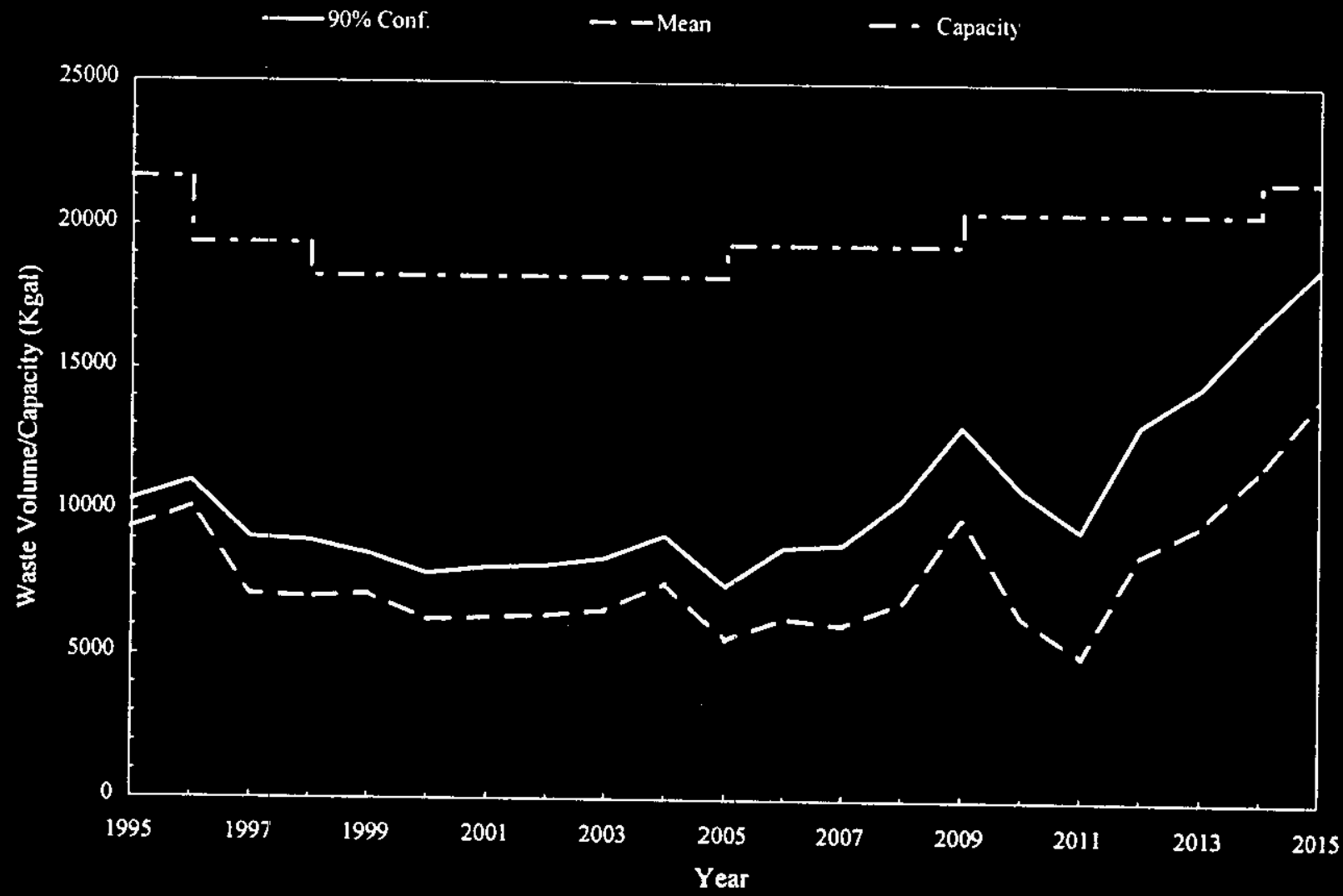

Figure 5.2-14. Non-Complexed Waste - Consequences of Complexed Off-Normal No. 2 


\subsubsection{Complexed Waste Case \#3}

Off-Normal \#3 (Figure 5.2-15)

This off-normal condition is caused by a pretreatment delay of 3 years with no increase in pretreatment throughput in subsequent years to make up for the delay. The result is that the inconing waste from SST retrieval is not balanced by a removal stream of comparable volume. Therefore, volume exceeds capacity after the year 2007.

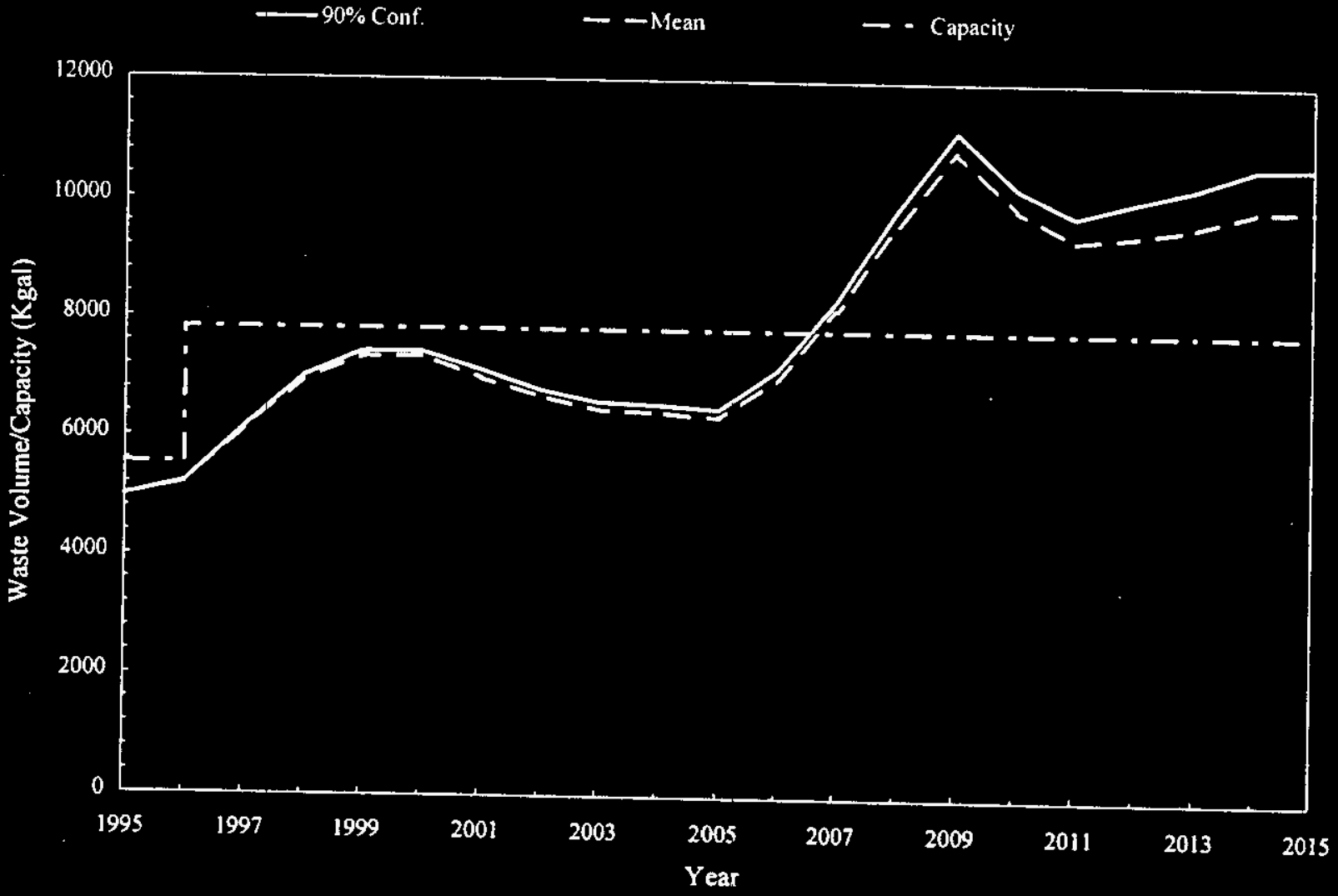

Figure 5.2-15. Complexed Waste - Off-Normal No. 3 
Fallback for Off-Normal \#3 (Figure 5.2-16)

By delaying retrieval of the complexed portion of SST waste by 3 years to compensate for the delay of pretreatment, the $90 \%$ confidence inventory curve remains below the capacity linits throughout the 21-year projection period.

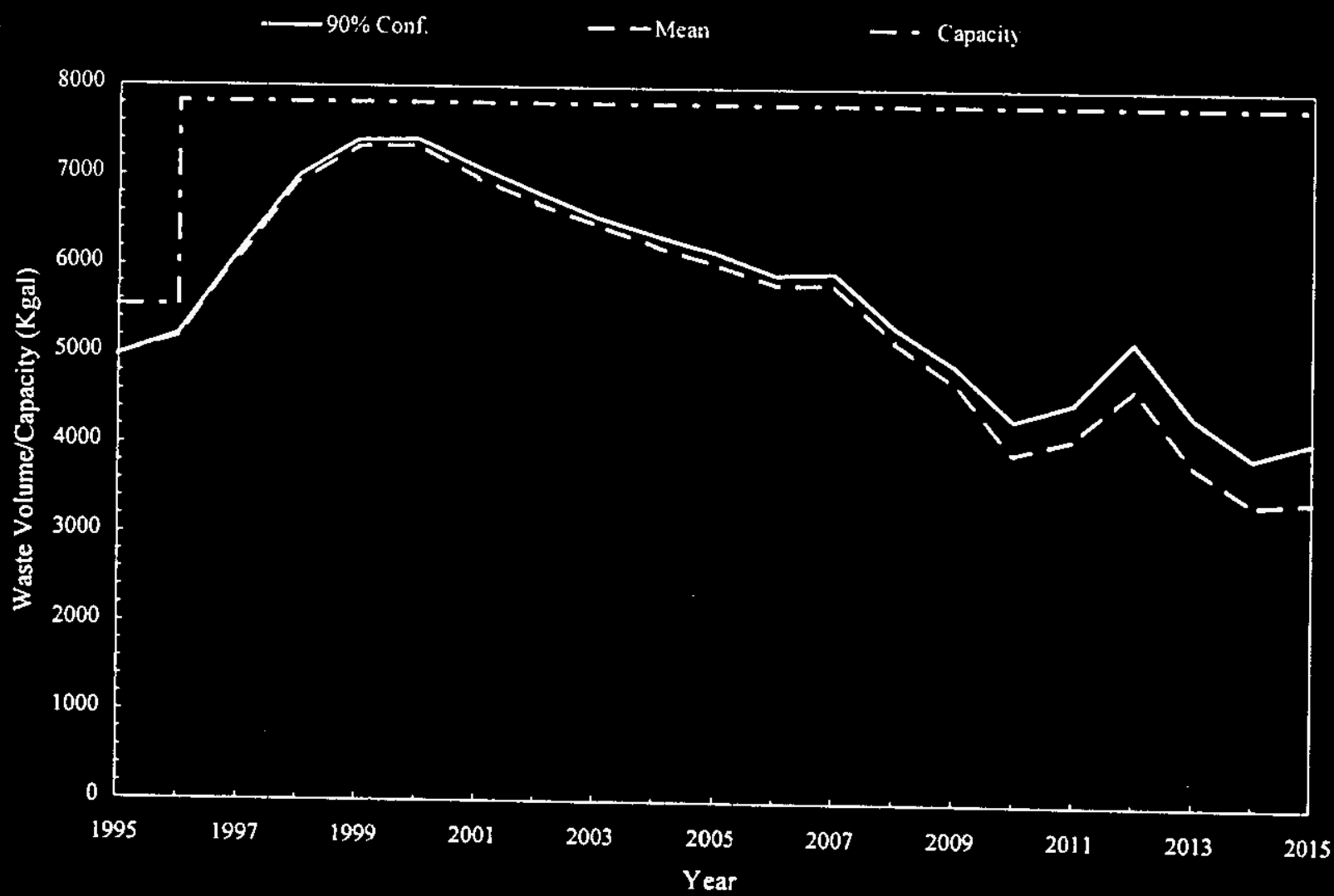

Figure 5.2-16. Complexed Waste - Fallback for Off-Normal No. 3 


\subsubsection{Non-Complexed Waste}

\subsubsection{Non-Complexed Waste Case \#1}

\section{Off-Normal \#1 (Figure 5.2-17)}

The first postulated off-normal condition for non-complexed waste is the loss of one DST. The resulting waste storage capacity is represented by the lower border of the cross-hatched area on the chart. Since there is spare capacity, the result is that inventory doesn't exceed capacity due to this off-normal condition. No fallback is required.

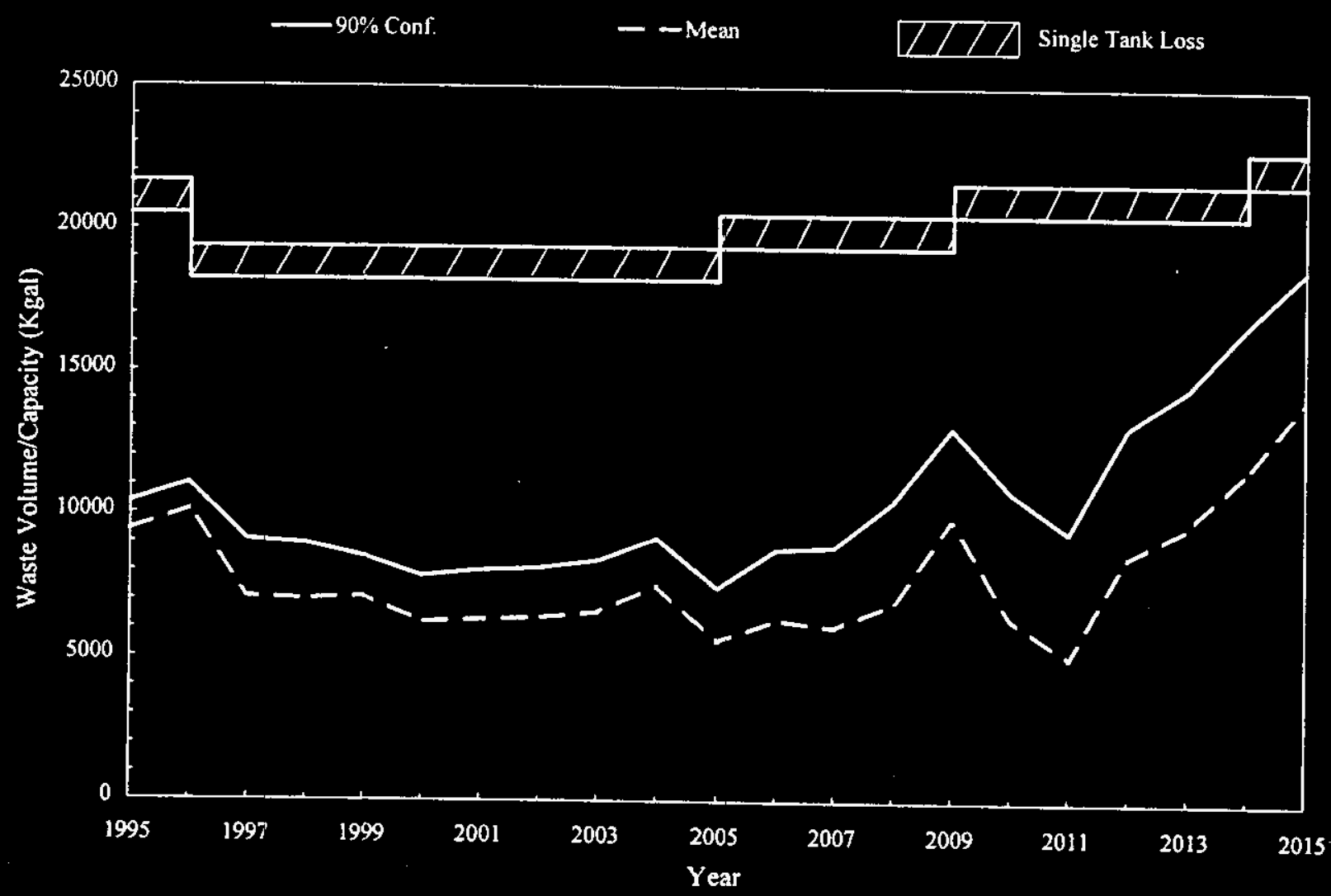

Figure 5.2-17. Non-Complexed Waste - Off-Normal No. 1 


\subsubsection{Non-Complexed Waste Case \#2}

Off-Normal \#2 (Figure 5.2-18)

This postulated off-normal condition involves a doubling of the waste volume from SST retrieval to the tank farms. This is possible if saltcake is more difficult to mobilize than currently expected and a much larger water addition is required (i.e., lower solids percent in the retrieval stream). The incoming waste volume grossly exceeds capacity by the year 2007 and continues rising throughout the simulation time frame.

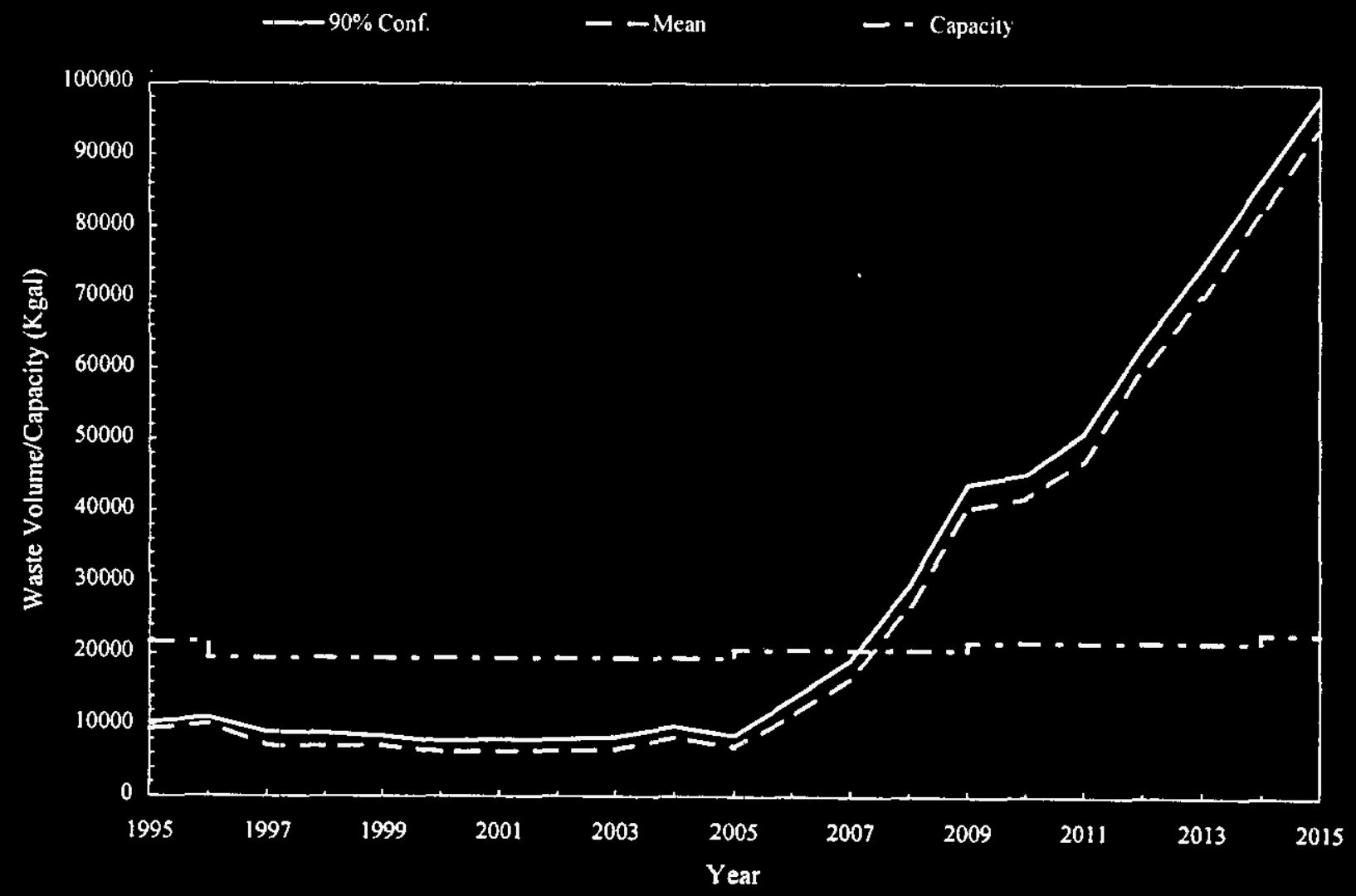

Figure 5.2-18. Non-Complexed Waste - Off-Normal No. 2 
Fallback for Off-Normal \#2 (Figure 5.2-19)

The fallback involves reducing the rate of SST solids retrieval by a factor of 2. This essentially nullifies the effect of the increase in volume on the inventory curve. However, it significantly increases the retrieval schedule, pushing much of the retrieval activities to beyond the year 2015. The resulting inventory ( $90 \%$ confidence curve) is well below capacity limits.

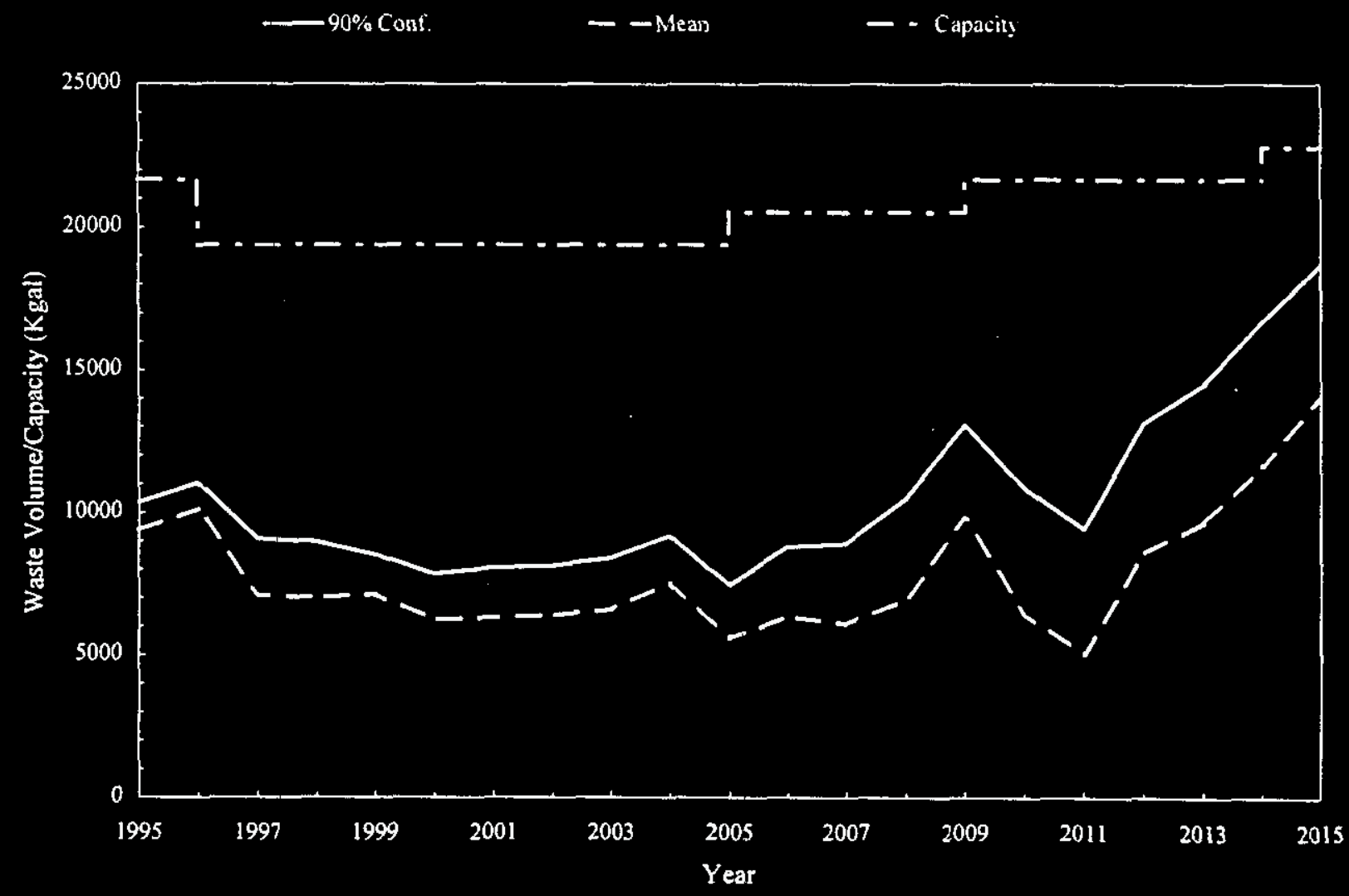

Figure 5.2-19. Non-Complexed Waste - Fallback for Off-Normal No. 2 


\subsubsection{Non-Complexed Waste Case \#3}

Off-Normal \#3 (Figure 5.2-20)

The third postulated off-normal condition occurs when waste volumes from terminal cleanout (TCO) of B-Plant, 100-N, and PUREX are increased by a factor of 10 . This could occur if either the cleanliness requirements for cleanout are increased or if the effectiveness of contaminant removal for the current projected water volume is much lower than anticipated. Since the TCO activity is currently planned for the early years, the projected waste volume curve quickly exceeds the capacity and remains above the capacity curve for the rest of the period.

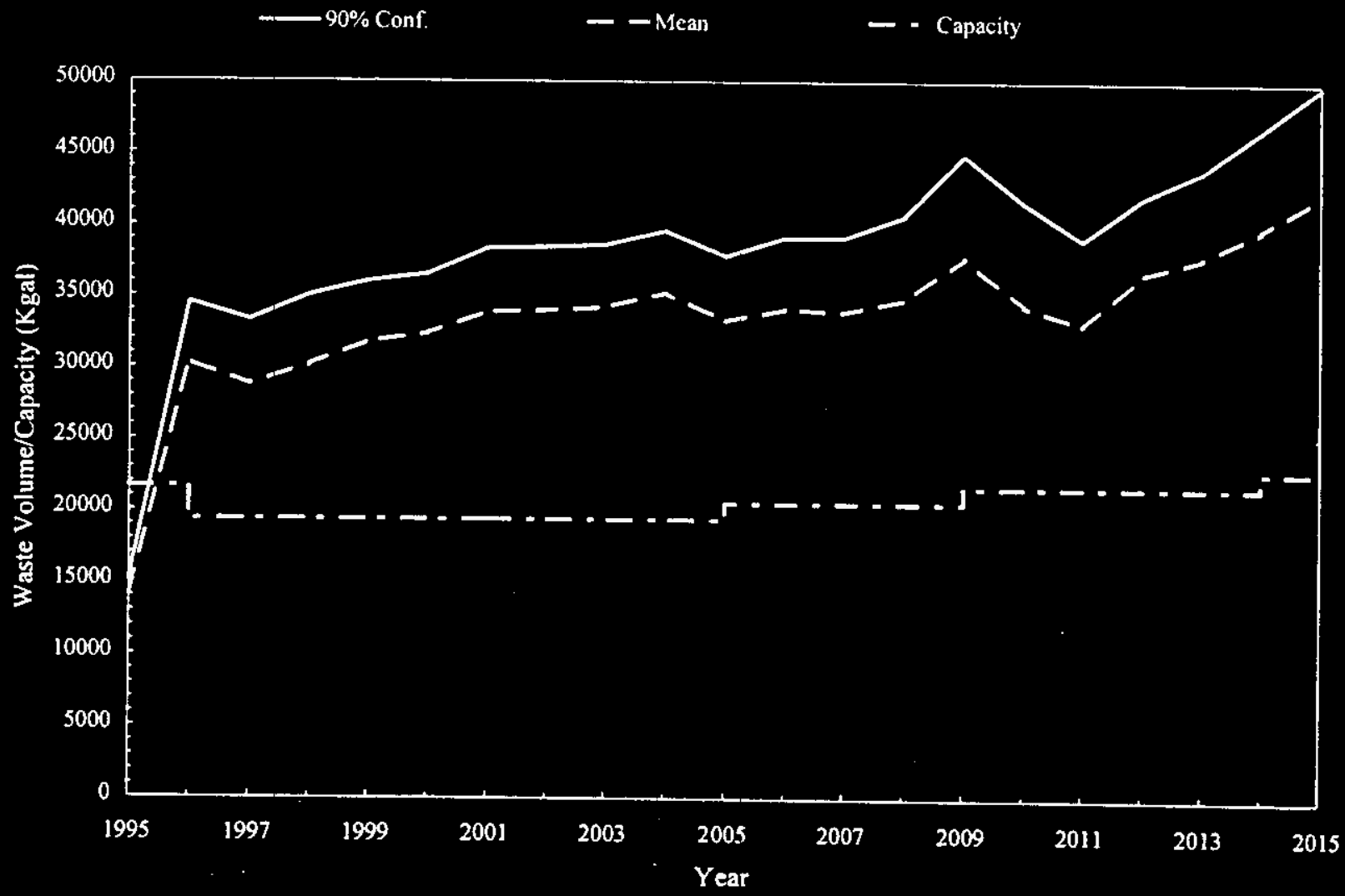

Figure 5.2-20. Non-Complexed Waste - Off-Normal No. 3 
Fallback for Off-Normal \#3 (Figure 5.2-21)

This fallback allows the TCO of B-Plant to continue on schedule (at its higher volume), while the TCO of PUREX is delayed until the year 2000 and TCO of 100-N is delayed until 2002 and spread over 5 years. In addition, the rate of evaporation of this dilute non-complexed waste (242-A throughput) is increased to 5.5 million gallons per year from 1998 through 2001, ramping down over the next few years eventually going down to the level of the OWVP, Rev. 21 yearly projections by 2007 . The resulting inventory ( $90 \%$ confidence level) is below capacity limits.

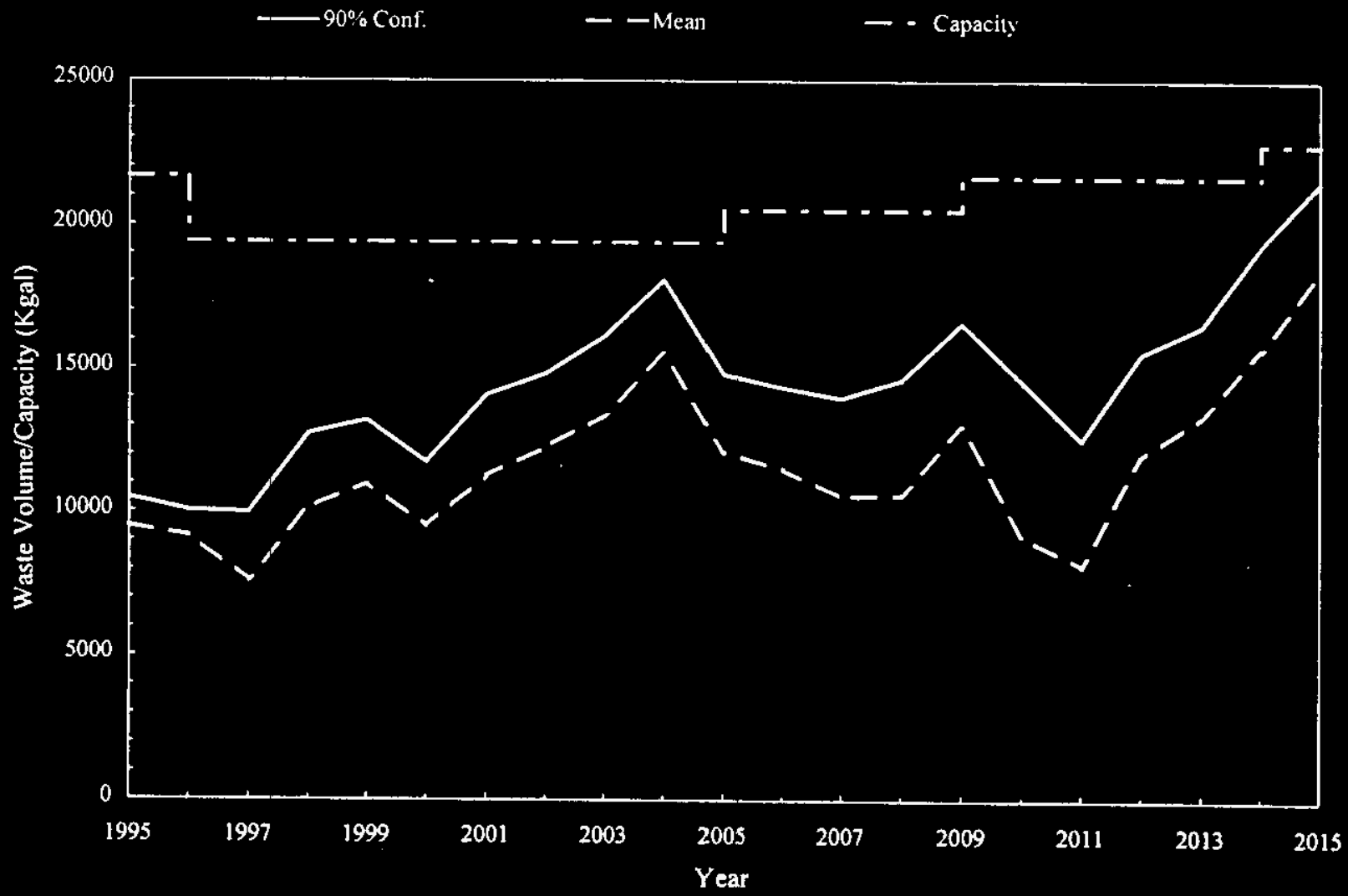

Figure 5.2-21. Non-Complexed Waste - Fallback for Off-Normal No. 3 


\subsection{Age-Related DST Failures}

Generally: failure rates for most components are recognized to fall into three time-dependent categories. typically termed startup deficiencies. constant failure rate or useful life, and wearout. The graphical representation of this relationship is often referred to as the "bathtub curve" (Figure 5.3-1).

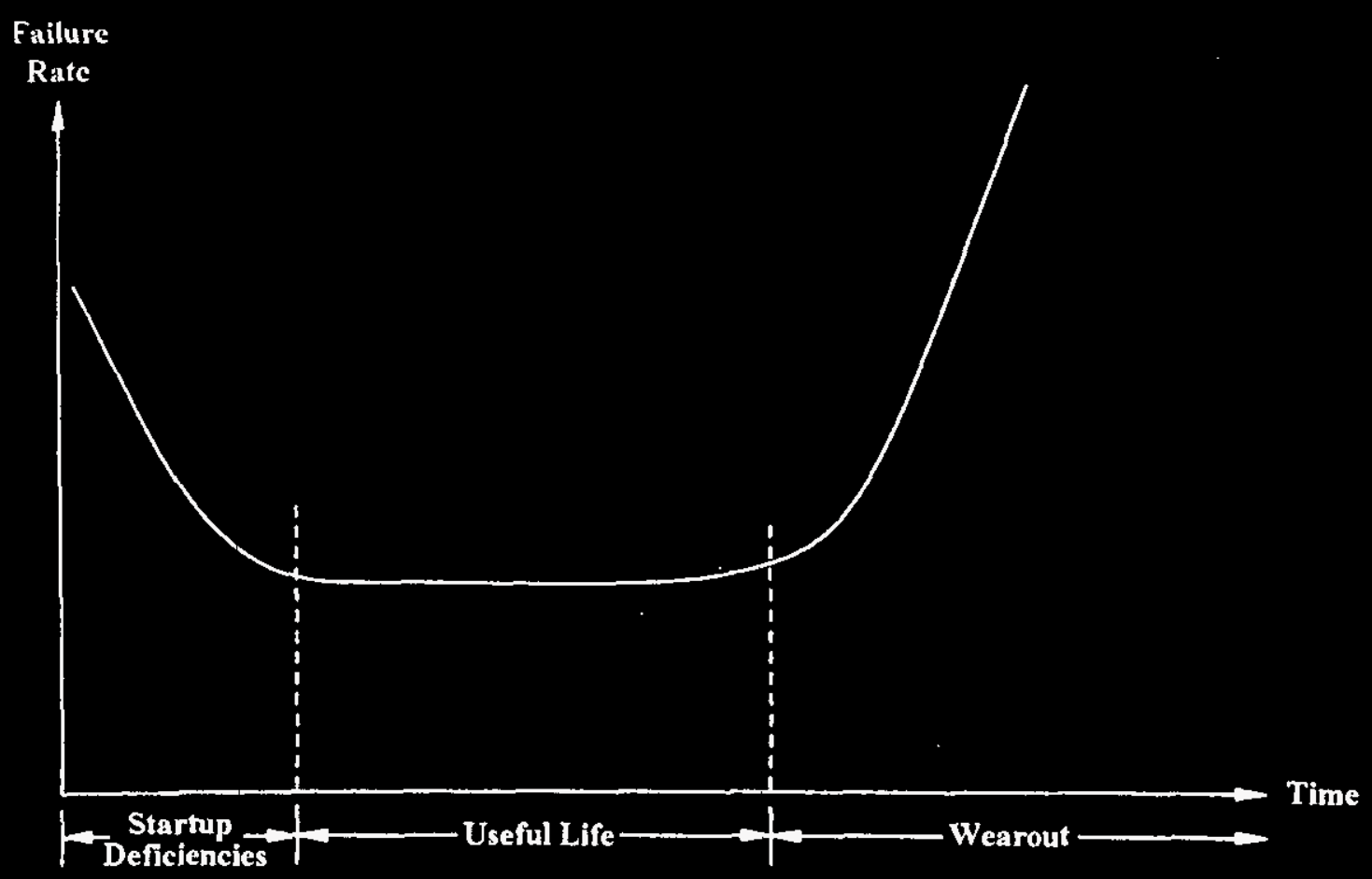

Figure 5.3-1. Bathtub Curve

The early period is that of startup deficiencies which refers to failures related to inherent faults, such as manufacturing or installation defects. This period is usually a relatively short time frame and occurs when the component is first placed into service (of no relevance to the DST situation). The period of constant failure rate which follows is usually relatively long and the failure rate drops below that in either the first or third periods and remains relatively constant. The last period shows the effects of operating a component beyond its effective life and is called wearout.

This last category is of concern regarding the double-shell tanks in the 200 Area. Many of these 
DSTs are approaching their design lives (25 to 30 years) and all will have passed their currently defined useful life within the 21-year projection window of this study. For such a small population of components (28 DSTs) and with no directly applicable data base of similar components from which to gain predictive insight, it is difficult to know when the DSTs will enter the wearout phase. An additional factor that effects the shape of the wearout curve can be linked to out-of-specification operation of equipment. There are documented cases where DSTs have been operated outside specification limits. This may increase the risk of failure to some extent, which could only be determined with additional study. However, with the knowledge that some of the tanks have periodically been operated at or beyond design specifications, and that they are approaching their original design life, there is adequate cause to speculate that the time will be reached prior to 2015 when the failure rate of some, if not all, of the DSTs could become a factor in waste management.

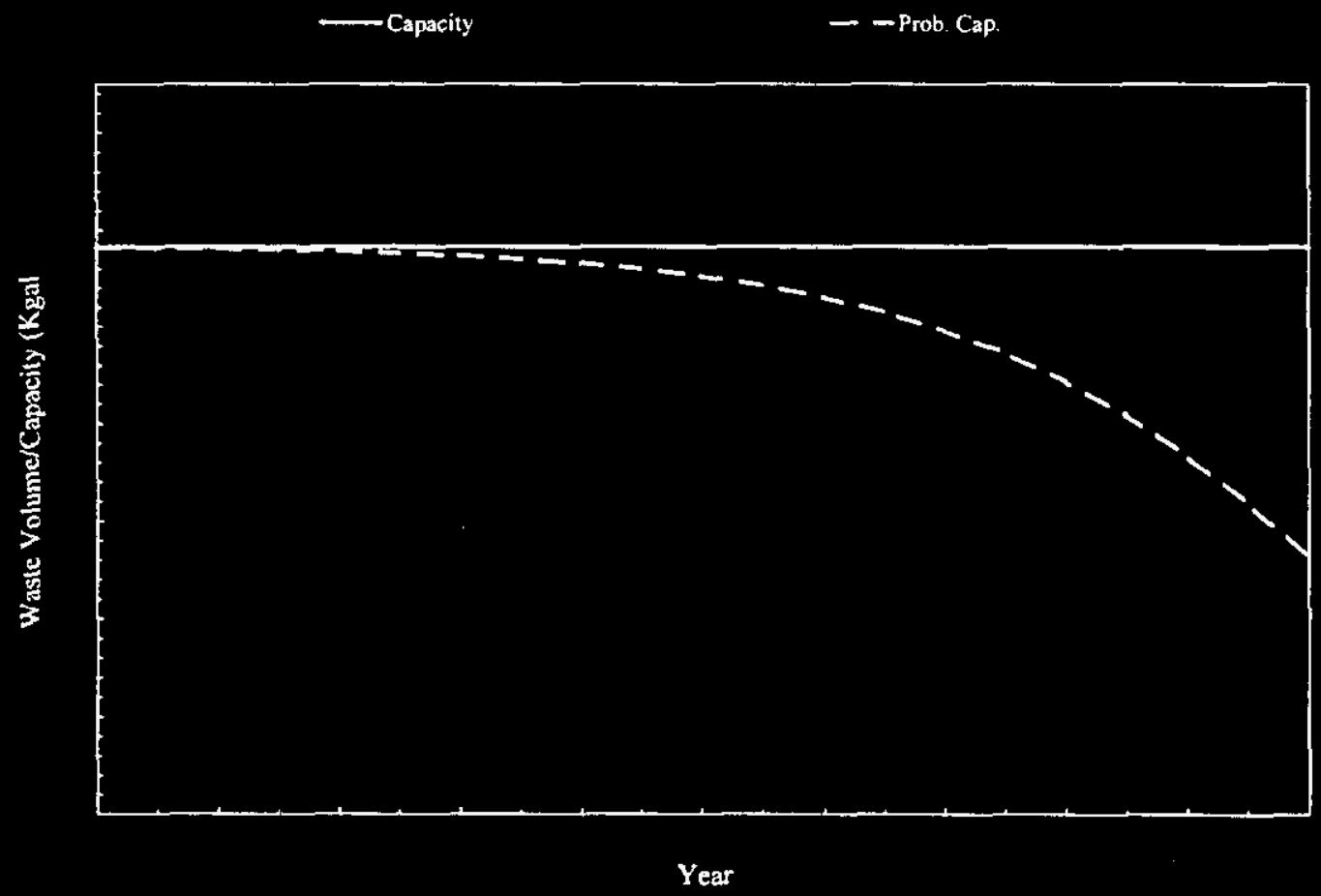

Figure 5.3-2. Age Effect on DST Capacity

The age-related failure effect for DSTs is also discussed in Appendix B. Using this approach as an example, wearout could have a significantly negative effect on the storage capacity for all waste types over the next 20 years and beyond. The depiction of this effect is shown in Figure 5.3-2 as a diminishing DST capacity (probabilistic capacity) with increasing time. 


\subsection{FUTURE ACTIVITIES}

\subsection{Recommendations}

The following activities should be evaluated for future development and use of risk-based waste volume versus capacity projections for TWRS.

- Establish a "privatization" case utilizing the latest available data, and rerun the Base Case to specifically include the assumptions, effects, and risks of privatization.

- Rerun the Base Case with all the segregation and head space requirements modeled (not just the most significant), in addition to watch list concerns.

- Develop risk relationships for off-normal events (i.e., ranking of relative importance and frequency distributions).

- Develop a defensible, end-of-life DST failure rate curve using available Hanford metallurgical study results, and historical and statistical data from other DOE sites and other industries.

- Develop a single GPSS or SIMAN model which models all three waste streams and their capacities simultaneously, in addition to modeling each individual waste tank.

- Consider replacing the existing waste volume projection computer program with a validated EXCEL computer program with user interface and coupled with a risk assessment computer tool, such as "@ Risk".

- Collect future OWVP data with uncertainties and risks quantified and with offnormal risks (both programmatic and upset conditions) and fallback positions identified and quantified.

\subsection{Lessons Learned}

In addition to the recommendations listed above, there have been several lessons learned from this study that may affect similar work in the future. 
- Risk-based data is currently not being collected. In the future, to take better advantage of risk-based projections, waste generators should be trained to collect and package their data for ready incorporation into probability distributions.

- The general concept of programmatic risks is not well understood within TWRS and the authors of this report needed to provide most of the programmatic risk input.

- The use of "workshops" to guide this effort and evaluate the conclusions is an effective means to gain TWRS understanding and buy-in. 


\subsection{CONCLUSIONS}

The risk assessment methodology described within this report has been shown to be a useful tool to manage the risk of exceeding waste capacity for TWRS. In addition to standard waste volume projection sources. the computer models utilized information gathered during interview sessions with waste generators, to determine frequency distributions to allow the tracking of uncertainties in the data. After multiple simulations, a curve could be plotted of waste volume versus time at a $90 \%$ confidence that this volume would not be exceeded. The $90 \%$ confidence curve was used to indicate when an anticipated action should be taken to prevent limits from being exceeded.

The division of the model into three waste streams (aging waste, complexed waste, and non-complexed waste) proved to be an effective method to see the effects on volumeversus-capacity that were difficult or impossible to observe using a model which combined these waste streams.

Based on clearly delineated assumptions, the computer models were exercised by postulating off-normal conditions covering a range of accidents and programmatic problems. Fallback positions were derived to counter the effects of the off-normal conditions which, in every case, after fallbacks, resulted in waste volumes falling within the limits of available capacity. The examined cases provided an indication of the sensitivity of the DST farms to variations in input and output waste streams. The offnormals and fallbacks described in this report serve as plausible examples of the types of perturbations that can be analyzed through the use of simulation modeling techniques.

By including an example of a probability of failure of the DSTs due to age-related effects, the point was made that there is an increasing likelihood that not all of the DSTs will be available in the "out years" of the waste volume projection. The effects of off-normal conditions on waste volumes were not combined with aging effects in this study. However, the effect of reduced capacity due to age-related failure is expected to worsen the problems simulated by the off-normals, due to the lack of availability of the tanks removed from service.

With the simulation modeling concept developed to the point allowed within the scope of this analysis, the future value of this technique is highly encouraging. Continued enhancement and integration of this model concept should provide a versatile risk management method for TWRS DST waste volume versus capacity projection. 


\subsection{REFERENCES}

WHC 1994. Operational Waste V'olume Projection. WHC-SD-WM-ER-029, Revision 20, Westinghouse Hanford Company, Richland, Washington.

WHC 1995a. Multi-Function Waste Tank Facility Phaseout Basis, Path Forvard Operational Waste Volume Projections, WHC-SD-W236A-ER-021, Revision 2, Westinghouse Hanford Company, Richland. Washington.

WHC 1995b. Operational Waste Volume Projection, WHC-SD-WM-ER-029, Revision 21, Westinghouse Hanford Company, Richland, Washington.

WHC 1995c. Hanford Waste Tank Summary Report for the Month Ending March, 1995, WHC-EP-0182-84, Hanlon, B.M., Westinghouse Hanford Company, Richland, Washington.

WHC 1995d. Hanford Waste Tank Summary Report for the Month Ending June, 1995, WHC-EP-0182-87, Hanlon, B.M., Westinghouse Hanford Company, Richland, Washington.

WHC 1995e. Multi-Function Waste Tank Facility Path Forward Engineering Analysis, Technical Task 3.3, Single-Shell Tank Liquid Contents, WHC-SD-W236A-ES012, Revision 0, Brown, R.G. and Mattichak, R.W., Westinghouse Hanford Company, Richland, Washington.

WHC 1995f. Waste Volume Reduction Factors for Potential 242-A Evaporator Feed, WHC-SD-WM-TI-690, Revision 0, Sederburg, J.P., Westinghouse Hanford Company, Richland, Washington.

WHC 1995g. Multi-Function Waste Tank Facility Path Forward Engineering Analysis, Technical Task 3.6, Estimate of Operational Risk in the 200 West Area, WHCSD-W236A-ES-014, Revision 0, Coles, G.A., Westinghouse Hanford Company, Richland, Washington.

WHC 1995h. WHC Tank Waste Remediation System, Systems Engineering Manual, Risk Management (Interim), WHC-IP, TSEP-04, Rev. 0, Westinghouse Hanford Company, Richland, Washington. 
Welker, E. L., and Lipow, M. 1974. Estimating The Exponential Failure Rate From Data With No Failure Events, Proceedings 1974 Annual Reliability and Maintainability Symposium. Los Angeles, California, January 29-31, 1974. 
Appendix A - Interview Process and Responses

A-1 


\section{APPENDIX A \\ INTERVIEW PROCESS AND RESPONSES}

\section{A.1 INTERVIEW PROCESS}

In order to assess the uncertainty and risks associated with the waste volume storage capacity projections, a two-part data collection process was initiated. For the first part, a survey form was developed and distributed to representatives of facilities involved in waste generation, handling, or disposal. A copy of the general interview form is provided at the end of this Appendix. The survey form provided general topics for discussion and set the stage for personnel intervieus that were held with each involved organization.

The second part of the data collection process included telephone records and personnel interviews. The telephone records and/or personnel interviews provided an opportunity to examine the survey data, understand the basis for the data, discuss and document uncertainties in the data, and provide a better understanding of the interaction between the facility and the waste storage and handling system. A summation of the interview records were routed to participants for confirmation and the opportunity to correct any information.

\section{A.2 INTERVIEW RESPONSES}

The following are summary records of information obtained from the Tank Waste Volume versus Capacity Risk Assessment interviews. In general, the summaries were sent to each interviewee for verification; and where necessary additional information is included in the following information. 
Date of Interview: $\quad 8 / 9 / 95$

Interviewer: · Tim Thurkow (ARES)

Interviewec: $\quad$ Chris Winkler (WHC)

Subject Area: $\quad$ 242-A Evaporator Operation

The following is information relevant to the conduct of the Waste Volume Risk task.

\section{General background:}

- Normal throughput for Evaporator is $45 \mathrm{gpm}$ without ion exchange.

- The Evaporator has been operated only 2-3 months per year; if it were able to be operated for the entire year, it could easily process 4-5 million gallons (mgal) per year.

- A 3 mgal campaign drawn from tanks $1 \mathrm{AW}$ (complexed), 4AW, 4AP (non-complexed), and 6AN (complexed slurry from previous campaign) to be completed this year.

- Evaporation will produce a slurry with Sp. G. of approximately 1.4.

- Some (essentially all, as far as Chris is aware) dilute non-complexed waste turns into complexed slurry when evaporated (confirm with Brian Von Bargen or Mike Guthrie).

- The Evaporator facility is in good shape after renovation, i.e., the "nominal" $10-y$ ear life extension has been completed.

- Operations wants to do wear out/campaign analysis to compare current data to that to be taken after future campaigns to get an indication of how much wear can be attributed to each campaign (this will allow a prediction of expected life).

- Life extension beyond 10 years could be justified if NDT results provide the basis.

- In the past ('85-87 time frame), linked runs were used to increase efficiency, e.g., they were allowed to run one tank after another in a group of tanks where process knowledge was used to indicate compatibility.

- It is more efficient to run 3-month or longer campaigns.

- There is no significant waste generation from the Evaporator which would be sent to the tank farms.

\section{Current extemal constraints preventing full utilization of the Evaporator:}

- Characterization in the laboratory currently takes approximately 6 months; the waste is staged in the AP farm tanks.

- There are some ETF permit problems, i.e., some waste streams are not allowed to be sent there.

- Since ETF is not currently in operation, the lack of space in LERF is preventing the use of the Evaporator.

\section{Qperational details:}

- The characterization analysis (sample) is drawn from tanks in the AP farm, then the waste is transferred to tanks in the $\mathrm{AW}$ farm for feed staging (2AW).

- Slurry from evaporation goes to $6 \mathrm{AW}$ and has recently been sent to $6 \mathrm{AN}$.

- Samples are to be taken from AP in Sept ' 95. 
- The analysis includes characterization of feed stock, boil-down to indicate what the slurry characteristics will be like. may suggest blending. if appropriate to stay within limits. e.g.. ammonia limited to $100 \mathrm{lbs} /$ day out of the stack.

- For a possible efficiency increase, of 8 tanks in the AP farm, 6 are usable/available; of these, the contents of 3 could be undergoing characterization while 3 are feeding a run (to reduce waiting time for characterization).

- Multiple passes are used for evaporation; the waste stream is recirculated through 6AW then back thru $2 \mathrm{AW}$ through special pits to the evaporator until there is 100 " of slurry in $6 \mathrm{AW}$; the slurry is then transferred out of $6 \mathrm{AW}$.

Equipment failures which could significantlv affect Evaporator operation:

- Recirculation pump (PB1) is a critical piece of equipment; a spare is available and an outage for replacement should last 1 to 2 months.

- Since Evaporator is an active facility, a raw water pipe break would not go unnoticed for . long, therefore the risk of generating significant waste from a pipe break is small.

- A vent system upgrade is underway to reduce outage risk from vent equipment failure.

- Operator error may contaminate "clean" areas which would be subject to administrative hold for review before startup is allowed.

Programmatic changes which could affect Evaporator operation:

- There currently is no requirement to monitor all types of releases; if required in the future, it could cause a long outage to retrofit monitoring equipment.

Note: The high-level process flowchart created by L. Muhlestein was marked up by Chris showing that waste from the tank farms is staged in the AP farm where samples are taken, then sent to evaporator feed tank $2 \mathrm{AW}$. From $2 \mathrm{AW}$ it goes to the Evaporator, out of the Evaporator to slurry tank $6 \mathrm{AW}$. The slurry is recycled back to $2 \mathrm{AW}$ or is sent to the tank farms. Slurry can also be sent directly from the Evaporator to the tank farms. 
Date of Interview: $8 / 3 / 95$

Interviewer: $\quad$ Bob Fritz (ARES)

Interviewees: $\quad$ 222-S Lab Personnel. Jay Warwick (WHC)

Subject Area: $\quad 222-S$ Lab

The following information was gathered in support of the Waste Volume Risk task.

Results: The 222s Lab personnel brought a completed questionnaire with excellent information. They had detailed upset information. had determined frequency of past events, and projected future situations, confidence levels. and consequences. They also indicated that potential fall back positions had been established to accommodate many of the upset conditions. They agreed to try to electronically retrieve this information and make it available to us. There were no open items after the meeting, other than a commitment to try and retrieve the old fall back planning document.

Note - The planning document was delivered to me sometime the week after the interview, and I subsequently passed it on to Tim Thurkow. 
Date of Interview: $\quad 8 / 2 / 95$

Interviewer: $\quad$ Tim Thurkow (ARES)

Interviewee: $\quad$ Steve Lowe (WHC)

Subject Area: $\quad$ LETF/LERF/340 Facility

The following information was gathered in support of the Waste Volume Risk task. General background:

- The LETF operational waste volume projection (OWVP) covers both the Liquid-W Waste Effluent Treatment Facility (LETF). which is a waste user (processor) and the 340 Facility, which is a waste generator. Therefore. the OWVP provided to Jim Strode included the $100 \mathrm{cu}$. m. (approximately 25,000 gal.) yearly waste projection from the 340 Facility. This projection carries through the entire 20-year period.

- The 340 Facility collects waste from the PNL discharges to the 300 Area process sewer and retention process sewer and transfers it to the unloading facility via rail car.

- The LETF was scheduled to startup in June of this year, but has been slipped to the October/November time frame. If permitting doesn't go as currently planned, startup could even slip to March 1996.

- The Liquid Effluent Retention Facility (LERF) consists of 3 basins at $6.5 \mathrm{mgal}$ each, two are nearly full and one is a spare. Effluent from these basins will be processed in the LETF when it comes on line.

Operational details:

- The capacity of the LETF is much greater than what is needed to process the output from the 242-A Evaporator. It was sized before PUREX was shutdown.

- The LETF can process between 40 and $150 \mathrm{gpm}$, while the Evaporator's output is approximately 45 gpm.

- With capacity in excess of the Evaporator feed, the LETF could accept flows from well purge water, K-Basin or N-Basin, or leachate from the ERDF trench after heavy rains.

Equipment failures:

- Upset conditions could include the filters being plugged by the feed stream (not a long outage) or the UV oxidation/reverse osmosis unit failing (although this is proven technology, therefore low probability).

\section{Programmatic effects:}

- There is uncertainty in the future of the 340 Facility in that it could be shut down if PNL replaces it with an equivalent facility.

- Consideration should be given to operating the LETF for at least one campaign per year to preclude the requirement to complete a Readiness Assessment before startup.

Note: A phone interview had been conducted with Alan Olander on July 26, 1995 which also pertained to the 340 Facility. From that conversation it was indicated that the rail transfers are scheduled every 90 days and are less than 10,000 gal each due to radiological limitations. 
Date of Interview: $\quad 8 / 1 / 95$ (with follow-up call on $8 / 22 / 95$ )

Comments incorporated 8/28/95

Interviewer: Tim Thurkow (ARES)

Interviewee: David Pisarcik (WHC)

Subject Area: $\quad$ N-Basin Waste Generation

The following information was gathered in support of the Waste Volume Risk task.

General background:

$100-\mathrm{N}$ reactors have been shutdown since 1988. The $\mathrm{N}$-Basin fuel pools have a total volume of $1.4 \mathrm{mgal}$, which is non-complexed and at a pH of 8 to 9 . The pieces of fuel rods remaining in the pools which are greater than $1 / 8^{\prime \prime}$ will be transported to K-Basin. Fuel particles less than $1 / 8^{\prime \prime}$ may be entrained in sediment slurry sent by rail car to the tank farms (flush water for rail cars is not included in the volume estimate). Only micro filtered liquid is allowed to be transported by truck tanker. The TPA milestones include removal of slurry from the pools to the tank farms.

Upper wall surfaces exposed during pump-down are expected to be radiologically hot. As an incentive to reduce ALARA concerns, a fairly aggressive removal schedule should be established (to reduce worker exposure time).

\section{Projections:}

All previous waste volume estimates have been met. The baseline includes evaporation of water from cells through the stack.

- The likelihood of the "most-likely" projection of $1.4 \mathrm{mgal}$, to be removed in FY 1996, is estimated at 0.9 (an award fee hinges on meeting the TPA milestone).

- The likelihood of achieving the low projection of no waste to tanks farms is 0.1 , due to anticipated permitting problems. The lower volume estimate includes contracted water cleanup and assumes tritiated water release to the river is permitted.

- A worst-case projection includes 200,000 gal of Emergency Dump Basin (EDB) waste estimated to be sent to the tank farms by the end of FY 1995, in addition to the 1.4 mgals in FY 1996, with a likelihood of 0.2 .

\section{Fallbacks to reduce volumes to tank farms:}

- An additional fall back would include the installation of an on-site ion exchange/micro filtration unit to allow the sending of treated liquid directly to the LETF, bypassing the tank farms.

- On-site evaporation of liquids and calcining of solids with a volume of approximately 70 cu. ft. if centrifuged or $410 \mathrm{cu}$. ft. if wet settled. Near surface burial at $200 \mathrm{~W}$ is possible.

\section{Upsets:}

If contaminated water is sent to a clean area and wash down is required to return it to a clean condition, additional waste would be created (no specific high-probability scenario identified). 
Date of Interview: $8 / 10 / 95$, by phone

Comments incorporated 8/28/95

Interviewer: $\quad$ Tim Thurkow (ARES)

Interviewee: $\quad$ Scott Anderson ( $1 \mathrm{H} H \mathrm{HC}$ )

Subject Area: $\quad$ New Rail Cars for above-ground waste transfer

The following information was gathered in support of the Waste Volume Risk task.

General background:

- $\quad$ T-Plant has the responsibility to procure 2 new waste transfer rail cars

- Design features include a sloped botton to improve clean out and an additional flush sluicing head

- Projected use at this time is for T-Plant (considered the owner) and the 340 Facility

Schedule:

- Approval for fabrication to be issued the week after this conversation (approved 8/15/95)

- Completion of fabrication by mid-November 1995 (hydro and He leak tests in fabricator's facility)

- $\quad$ ATP completion and placed in service by the end of February 1996

Waste volume effect:

The flush water usage could range from approximately the same as current requirements (estimated to be about 1,500 gal) to significantly less, due to the new design features (possibly $1,000 \mathrm{gal})$. 
Date of Interview: $\quad 8 / 10 / 95$

Interviewers: Tim Thurkow. Lewis Muhlestein (ARES)

Interviewees: $\quad$ Rick Wittman. Darid Garbrick (WHC)

Subject Area: $\quad$ Systems Engineering's Use of Simulation Analysis

The following information was gathered in support of the Waste Volume Risk task.

The l-Think computer program was used by D. Garbrick to model the movement of waste. including some in the 1994-2003 time frame. I-Think is a continuous-flow modeling technique versus the discrete transaction technique used in the SIMAN code (which Rick uses) or the GPSS code (used by ARES). The SIMAN output. along with inventory assumptions. is fed to the ASPEN computer code to estimate vitrification glass volumes.

The modeling being done by Rick is in support of the solid waste disposal effort beginning in 2003. The model shows the pumped retrieval waste going to settling tanks. After an accumulation of 10 feet of settled solids. the solids are washed with caustic while being mixed. The leaching removes cesium and technicium which leaves the tank in the liquid stream and is removed through ion exchange to allow the remaining liquid to be handled as low-level waste.

Although the uranium and plutonium are being concentrated in the washed sludge, it should still not pose a criticality concern. This should be looked into further.

The input to the SIMAN model includes the SST salt cake retrieval sequence. The retrieval stream is limited to $5 \mathrm{M} \mathrm{Na}$ or $10 \%$ solids. The sodium limit is typically reached first. The lowlevel vitrification process is driven by the $\mathrm{Na}$ concentration, while the high-level process is driven by chromium and phosphate concentrations. Two stages of evaporation are used. Components removed by ion exchange and the filter solids are returned to the DSTs. Some sensitivity analysis is done to reduce the volumes of high-level glass.

\section{Model Details}

The TPA milestones were incorporated in the model to show when facilities were expected to go on line. One spare tank (AP-104) was included for leaking DST contingency. TRU tanks were not reused.

Note: Copies were provided of the report titled "Baseline Simulation Model for Hanford TWRS" WHC-SD-TI-687, Rev. 0, Draft was provided by R. Wittman and the report "Description of the Waste Pretreatment and Interfacing Systems Dynamic Simulation Model" WHC-SD-WM-DR-013, Rev.0, 6/20/95, D. Garbrick. 
Date of Interview: $\quad 8 / 7 / 95$

Interviewer: $\quad$ Garill A Coles ( $1 \mathrm{HC}$ )

Interviewee: Carol Alderman. Don Precechtel. and Kathleen Pearce

Subject Area: $\quad$ K Basin Waste Volume Projection

1. Although, $530 \mathrm{~K}$ gallons is the estimate supplied to the waste volume people (B. Barton, J. Strode), a more up-to-date estimate puts that value between $126 \mathrm{~K}$ and $350 \mathrm{~K}$ gallons. This range corresponds to the 10 and 90 percentile of a probability distribution. One of the major uncertainties is the amount of solids that can be contained in a shipment. The limitation would be shielding. This estimate includes flush volumes. Chemical addition volumes are assumed to be small.

2. K-Basin sludge waste transfer shipments to TWRS will be made via a High Integrity Container (HIC) on a low bed trailer. The HIC will be 1600 gallons. The flush water will be in a separate container (500) gallons also located on the low boy trailer or else a water tank truck. .

3. The major part of the shipments will be made in 1999. The first shipments are not feasible till early FY '98. Although this is not a TPA milestone DOE wants the basins cleaned up as soon as possible. Spent Nuclear Fuels Project has established an accelerated schedule to meet remove fuel by $12 / 99$ and sludge by $12 / 00$. Shareholders have requested that the TPA reflect this accelerated schedule. Negotiations are ongoing.

4. If tank farms cannot receive the waste then another option is disposal as solid waste. However, this would dramatically impact the $12 / 00$ cleanup date and present a significant increase in cost due to the increase in sludge handling activity and associated process requirements. Also, the sludge in $\mathrm{K}$ east will most likely be classified as TRU waste. If it is, it has been suggested (Solid Waste group) that the sludge will need to be dried and packaged in 55 gallon drums. This represents significant technical design problems related to safeguarding worker risk.

5. Another key uncertainty is the amount of sludge that will be generated when the canisters are manipulated. The fuel itself is decomposing continuously. The amount of newly generated sludge could be substantial but is thought to be bounded in the $350 \mathrm{~K}$ gal estimate. 


\section{Date of Interview:}

Interviewer:

Interviewee:

Garill A Coles ( I'HC)

Subject Area:

Kelly Carothers

TANK 107-AN CAUSTIC ADDITION

1. Caustic addition is planned for $107-\mathrm{AN}$ in 1995 as a corrosion control measure. Other caustic additions are not planned or projected. This is true for tank 107-AN. However. we will be considering adding chemicals to tank 102-AN for corrosion control purposes. If addition of caustic is required. such additions probably wouldn't occur until FY 1997. The volume of caustic is unknown but is expected to be less than that added to tank 107-AN.

2. A volume of 65.000 gallons of chemicals plus a $10-20 \%$ flush estimated. This is an update to the Waste Volume Projection which shows a total of $50 \mathrm{~K}$ gallons.

3. The $90 \%$ confidence level is $70,000 \mathrm{~K}$ chemical gallons plus a $20 \%$ flush. The $10 \%$ confidence level is $60,000 \mathrm{~K}$ gallons plus a $10-20 \%$ flush.

4. This is a one time activity.

5. If tank farms cannot receive this waste (not a waste; a chemical addition) then needed corrosion control could be postponed which could lead to leaks to environs (Although the potential for leaks to the environs is increased because of failure of the primary tank, the secondary tank will mitigate such an event until corrective action can be taken. The greater risk to waste volume projections of postponing the caustic addition is that tank 107-AN could fail thereby loosing 1.14 million gallons of storage space in the double-shell tank system. The 107-AN waste would have to be pumped out to other tanks thus using up available space allocated for other future uses. The impact would be greater than 1.14 million gallon because some dilution will be required to retrieve the solids). 
Date of Interview: $\quad$ 10/4/95

Interviewer: $\quad$ Garill A Coles (IHC). Tim Thurkow (ARES)

Interviewee: Jahan Lohrasbi. and Namrata Shrivastava

Subject Area: $\quad$ PUREX WASTE VOLUME PROJECTION

1. Your best estimate of terminal clean out (TCO) volumes are provided in a memo to the waste volume projection people (II: B. Barton). Comments 5 and 6 below provide notable new information to that estimate. The subject memo was provided to us in the meeting and was dated July 17. 1995.

2. PUREX is shutting down in 1997 to meet a TPA milestone. so most waste will be transferred by the middle of next year (1996).

3. Waste volume estimates include a 10\% flush value but does not include a 500 gallon flush of the lines after the transfer. There is an average of 4 transfers a month. So. total flush water volume could be about $24 \mathrm{~K}$ gallons in a year.

4. Waste volumes estimates include an average rain. Higher than average rains, like this year, increase volumes due to flooding.

5. An important decrease in the waste volume estimate would occur if caustic is used to flush canyon vessels and P tanks. Actually, there is a $99 \%$ probability that caustic will be used. This reduces the flush volume form $305 \mathrm{~K}$ gallons to about $150 \mathrm{~K}$ gallons.

6. About 11,000 gallons of LSA nitric acid may not be shipped to British Nuclear Fuels Ltd. (BNFL) as planned. There is about an $80 \%$ chance that it will be. If not, then, it would have to be neutralized with sodium hydroxide and would create about 29,000 gallons of
concentrated waste.

7. The E-F11 evaporator at PUREX has been shut down, so concentration will have to occur in the 242-A evaporator. The difference in the $225 \mathrm{~K}$ gallons estimated for the DOE special waste volume projection done February 1995 and the July 17 memo is the shutdown of the E-F11 evaporator.

8. There is some chance that facility upsets could cause flooding in the $100 \mathrm{~K}$ gallon range. A $40 \mathrm{~K}$ gallon leak from a frozen line occurred in the $292 \mathrm{~A}$ basement. The chance of such an occurrence should increase considerably as lines are taken out of service.

9. If the present transfer lines fails (maybe 2 miles of line) then other options such as above ground transfers would be examined.

10. A major programmatic consideration involves a building owned by PNL ( 324 Waste Building). Twenty-four canisters of solid waste might be transferred to the PUREX \#2 railroad tunnel. This would cause logistical problems such as too many users for the canyon crane, which could delay PUREX TCO by as much as a year. 
Date of Interview: $\quad 10 / 4 / 95$

Interviewer:

Garill A Coles (WHC). Tim Thurkow (ARES)

Interviewee:

Duane Kutsch, and Stcre Godfrey

Subject Area:

B PLANT WASTE VOLUME PROIECTION

1. Your handout provides the baseline. lower and upper waste volume projection cases.

This handout is more current than the waste volume projection (Iim Strode) currently has. The lower and upper cases should comespond to the 10 and 90 percentile of a probability distribution.

2. The difference in the lower. baseline and upper cases is primarily the amount of decontamination activity. The lower case includes no activity and the upper case includes decontamination that supports terminal clean out (TCO).

3. The information on the provided table does not include flush water because flushes are not needed because the waste is so dilute.

4. There is a unlikely chance of a facility upset in the $100 \mathrm{~K}$ gallon range. Flooding and leaks have occurred at other facilities in the 5 to $50 \mathrm{~K}$ gallon range. An occurrence in 1993 involving a water seal in the ventilation system resulted in a $10 \mathrm{~K}$ gallon leak.

5. There is some probability that a Waste Encapsulation System Facility (WESF) capsule could fail. This would be a serious event and would lead to contamination of a very large amount of water. Likelihoods and consequences should be found in the safety authorization basis. A "klunk" test is performed monthly to catch leaking capsules. No capsules have leaked yet at Hanford but have elsewhere.

6. Dry storage of WESF capsules in being examined.

7. Failure of transfer lines or failure of steam ejectors (where pumps are not yet installed) would delay or fail transfers.

8. The Accelerated Hazard Reduction program could accelerate TCO volumes.

9. One of the primary programmatic uncertainties is the extent of TCO. The degree to which equipment and structures are required to be cleaned up affect the TCO volumes. B Plant will be transitioned to EM60 (decommissioning program) eventually and that program will dictate what condition the facility must be in before they will accept it.

10. Transfers are done in batches of about $7 \mathrm{~K}$ gallons as that is near the.capacity of the holding tank. 
Date of Interview: $\quad 10 / 4 / 95$

Interviewer: $\quad$ Garill A Coles (IHC). Tim Thurkow (ARES)

Interviewee: $\quad$ Glen Triner. and Stephen Metzger

Subject Area: $\quad$ T - PLANT WASTE VOLUME PROJECTION

1. For the foreseeable life of $T$ Plant. transfers of liquid waste will be on the average of about 5 per year. A transfer will consist of one rail car with 7 to $10 \mathrm{~K}$ gallons (probably about $9 \mathrm{k}$ gallons since that is near the capacity of the storage tank from which the tankers are filled).

2. The total uncertainty range for waste volume transferred is between 0.13 and $12 \mathrm{~K}$ gallons per month. The upper limit $(12 \mathrm{~K} / \mathrm{Mo}$...) is the maximum capacity of the plant assuming maximum output of steam cleaner and that jobs could be scheduled end-to-end. The lower limit $(0.13$ is assuning so decontamination activities. These limits are more extreme than the 10 and 90 percentile; perhaps the 5 and 95 percentile.

3. There is about a 1 in one thousand chance of a severe facility upset such as a raw water line break which could lead to $100 \mathrm{~K}$ gallons of contaminated water. In the past, rain water flooding into the $27006 \mathrm{~T}$ (Decontamination Facility) accounted for much of the liquid waste accumulation. Such flooding and leaks have already occurred in other facilities at somewhat lower volumes ( 5 to $50 \mathrm{~K}$ gallons).

4. Although the decontamination activities are increasing, new technologies (i.e., iceblasting, vacuuming) are decreasing the amount of flush water needed, so volume should stay about the same.

5. For the last two years only two transfers per year have been made.

6. New tanker cars have been ordered for this year. The certification on the old one runs out this year, so failure to get new tank cars could cause transfers to cease.

7. If tank farms can not receive any further waste, then that would preclude certain decontamination activities which would have unknown impacts (depends on customer).

8. There is one odd tank that could contribute about $15 \mathrm{~K}$ gallons to projection in a one year period. 
Date of Interview: $\quad$ 10/4/95

Interviewer:

Interviewee:

Subject Area:
Garill A Coles (WHC). Tim Thurkow (ARES)

Graham MacLean

IN - TANK WASHING WASTE VOLUME PROJECTION

1. Your best estimate of In-Tank Processing of High Heat Wastes impact and schedule is provided in a memo from you to J. S. Garfield dated 5/19/95 and a CC:Mail from R. A. Gilbert 10 you dated 6/27/1995. You provided copies of both to us. This essentially involves consolidating $\mathrm{AZ}-101 . \mathrm{AZ}-102$ and $\mathrm{C}-106-\mathrm{C}$ into $\mathrm{AZ}-101$.

2. This process requires several activities that must occur. such as miser pump installation. for the process to work. Accordingly: this leads itself to scheduling uncertainties which appear to be the biggest source of uncertainty.

3. Apparently, the Waste Volume Projection people (Jim Strode) make certain assumptions with respect wash water volumes and flows, because you do not supply that information to them. Furthermore, your best guess of wash volumes is 3 to 4 million gallons for the whole process. So, although the final result is the "freeing up" of an additional double shelled million gallon tank, the process involves lots of wash water to carry out dissolvable or suspendable particulates.

4. In addition to the schedule there is some uncertainty as the performance of the mixer pumps that will be installed. However, it is believed that they will most likely perform fine.

5. If some failure occurs, like loss of the evaporator, that would probably result in loss of schedule and not some safety impact. 


\section{Date of Interview:}

Interviewer: $\quad$ Garill A Coles (IHHC)

Interviewce: Phillip Miller

Subject Area: $\quad 400$ AREA GENERATION WASTE VOLUME PROJECTION

1. Planning transfers of:

$10 \mathrm{~K}$ gallons in 1997

$10 \mathrm{~K}$ gallons in 1999

$5.10 \mathrm{~K}$ gallons in 2001. plus or minus $10 \%$.

2. Cannot really transfer more than $10 \mathrm{~K}$ gallons as the load out facility in the Maintenance and Storage Facility (MASF) is limited to that capacity and so extra volume would require actions not worth the cost in manpower/resources etc.

3. One scenario that could affect volume generation is failure of the sodium removal system ion exchanger. This would mean that the remaining 305 core components would yield a generation of 200,000 gallons. This would be transferred over a period of about 4 year (so about $50 \mathrm{~K}$ per year). Other scenarios are highly unlikely.

4. Estimates includes flush volumes.

5. Inability of the tank farm to receive these volumes affects 400 area plant transition schedule and is not a safety issue. 
Date of Interview: $\quad 7 / 27 / 95$

Interviewer: (Garill A Coles ( $\mathrm{W} H \mathrm{HC}$ )

Interviewee: Paul Griffin

Subject Area: $\quad$ 105-F AND 105-H BASIN CLEAN OUT

1. Total volume from $\mathrm{HI}$ and $\mathrm{F}$ basin is estimated at $225 \mathrm{k}$ gal plus or minus $10 \%$ (at 10 and 90 percentiles).

2. Construction of hasin roofs have eliminated rain water infiltration and recharging concerns. thus considerably reducing the uncertainty ahout the volume that could be pumped/vacumned out. A neutron survey has validated the roof effects.

3. Analysis of pumped water shows it to be fairly low activity (dilute concentrate).

4. Entire volume will come from $\mathrm{H}$ basin as it is rocky. The $\mathrm{F}$ basin is sandy (so cannot be pumped). So, I assume that if $\mathrm{F}$ could be pumped this could double the projection, however, this is unlikely.

5. The $225 \mathrm{k}$ gal estimate includes flush water.

6. This activity is a one time case and will be done by close of 1996. It is part of the decommissioning schedule.

7. There are really no other scenarios that could increase volume (other than rain water), as all active water lines have been de-activated. 
Date of Interview: $\quad 10 / 4 / 95$

Interviewer: $\quad$ Garill A Coles (WHC)

Interviewce: Daniel Baide

Subject Area: HIGH-LEVEL WASTE VITRIFICATION WASTE VOLUME

1. The information being used by the waste volume projection people (Jim Strode) is based on old estimates made in about 1989. These are not valid any more (e.g... Amongst other changes. plant capacities have increased.) Jim Strode is in the process of soliciting more up-10-date information.

2. The Facility Configuration Engineering study from John Garfield should provide information for a more accurate baseline. Gail Allen (Process Flow sheet Engineering group) would be a good contact for plant capacities, return flows, assumptions, etc..

3. The privatization initiative could have a major impact on HLWV facility design. Performance requirements are being developed now but are probably not accessible due to legal/contracting constraints. All know commercial type units (English, French, Japanese, etc...) are smaller capacity units than the current Hanford design. These smaller units might be able to come on-line quicker. 
Date of Interview: 10/4/95

Interviewer:

Interviewce:

Garill A Coles (WHC). Tim Thurkow (ARES)

Subject Area:

Greg Hanson. and Dan Reberger

EAST AREA TANK FARM WASTE VOLUME PROIECTION

1. The waste volume estimate sent from W. E. Meeuwsen to N. W. Kirch January 12, 1995 in a memo is your best estimate of waste volumes generated by the East Area Tank Farm. This estimate (out to the year 2028) is an extrapolation of an analysis of 1994 waste streams. You provided us with a copy of this memo. It shows that best estimates waste rolumes decrease somewhat as tank farm operations begin to close down.

2. The uncertainty of the waste volumes estimates (conversation with W.E. Meeuwsen) should be assumed to be 10\% through 1997 and gradually increased to $75 \%$ for the out-years (2005 to 2028). The further out in time the projection; the more the uncertainty'. Of the 595,633 gallons estimated for the year 1997, 500,000 gallons of that is for sluicing tank C-106 (this is accounted for separately in the waste volume projection by Strode/Koreski).

3. There are two basic waste types which must be considered separately: complexed and dilute (TRU might be a category that should be considered separately as well, but presently it is not). Tank 101-AY and perhaps 105-AP is identified as complexed.

4. In the East Area there are at least two lines for all critical paths except: (1) Between the 204-AR rail car unloading station and the A Farm valve pit and (2) Certain paths in the aging tank farm (AY and AP farms). They are replacing a leaking line there now that should be completed in about 2 months.

5. All lines, except saltwell pumping lines, are double encased; either pipe-in-pipe or pipe in a concrete encasement. At this point the state will allow concrete encasement as secondary containment.

6. As is the case for PUREX and B-Plant, if the transferred waste is less than $3 \%$ solids, then no flush is required.

7. Contact Dave Bowers about project W-058, (new cross-site transfer system (CSTS)). In particular it is important to know if 102-SY will still be a bottle neck.

8. Pump failure may be problem because there are presently no options for disposal of the contaminated pump. This may delay replacement as the pump cannot be removed without a disposal option. 
9. All pits have leak detection and some redundancy (also a manual probe could be used as a hackup). However. about 2000 gallons could leak before being detected. See Matt Tiffany about how much rain and snow can contribute to volume catch tanks. Flush pits contain 1.5 inch raw water lines at 90-150 psig, so huge leaks not possible.

10. Tank 103-AP is designated as the receiver tank should a double shelled tank (DST) fail. Procedures for such a contingency are presently being written.

11. It is not clear what the State would require if the concrete containment (like a valve pit) were to crack or degrade. It could delay' or prevent certain transfers.

12. Waste characterization is presently not verified except by documentation. Chuck Mulkey is leading a effect to require spot checking.

13. Transfer of waste from $K$-Basin via 204-AR is being discouraged. Tank Farms would like $\mathrm{K}$-Basin to truck waste directly to appropriate DST.

14. Plugging might most likely occur at flexible jumpers which are usually looped. The flexible jumpers are easily replaced.

15. C-Farm experienced plugging problems in their saltwell pumping lines in the last six months. A. heavier than average hot flush is thought to have solved that problem. 
Date of Interview: $\quad$ 10/4/95

Interviewer:

Garill A Coles (WHC). Tim Thurkow (ARES)

Interviewe:

JR Biggs

Subject Area:

WEST AREA TANK FARM WASTE VOLUME PROIECTION

1. One of the six cross-site transfer sy'stem (CSTS) lines was successfully pressure tested May 29. Recently, 435.400 gallons of liquid waste was transferred from the West to the East Area. A second line will probably be tested this fall and it's expected to pass. because as its never been used. Therefore. in should not be corroded or plugged. If necessary helium tests could be performed on the other four lines to see if sections of those lines could be used.

2. A new CSTS is scheduled to be ready in 1998 via project W-058. Like the old line there is about a 3 foot drop in elevation from the West to East area. However, there is about a 85 foot incline up to the vent station at the midway point (like the old line).

3. The plugging of lines is really only a concern when pumping sludge. It is presently planned that all supematant (i.e... Saltwell pumping) would be pumped prior to sludge pumping (i.e... TRU waste in 102-SY).

4. The TRU versus complexed waste issue is being examined. If a complexed waste SST leaks now, there are no contingency plans in place to handle the leaking waste given there could be compatibility problem with the only available DST receiver tank (102-SY). However, it is not known with certainty that mixing complexed waste into 102-SY would have a negative impact. Also, many SST leaks are believed to occur at the liquid air interface, so its possible that only a some portion of the leaking tank would not have to be pumped.

5. If the 102-SY pump fails, then a new pump might be installed in 6 weeks, given a replacement pump is available. Given no priority, pump replacement could take 3 months. Disposal of the pump (as waste) is really the biggest problem and could affect the replacement. There are really no contingency plans in place to handle failure of the 102-SY transfer pump.

6. A transfer line being constructed from the 222-S lab to the 242-S would eliminate the need to truck the waste to the off-loading station in the East Area.

7. The C-Farm (East Area) has experienced a lot of plugging in the last 6 months and did weekly hot flushes to keep the lines open. This problem seems to have been rectified.

8. The S-Farm has known leaking lines. It is postulated that the conduit containing the heat trace lines filled with water. The conduit is next to the waste line and may have been the source of degradation. 
9. The U-Farm passed its hydrostatic leak tests, but the T-Farm had a problem (leaker) in 1991 and 1993 (test).

10. Tank Farms rerifies the waste characterization by documentation, not by testing. Sometimes sampling, after the transfer is made, would be done in the receiving tank. Homogeneity could be an issue.

11. The 24t-BX DCRT (East Area) has about a 3 foot heal. showing that sedimentation is an issue in some of these tanks. 


\section{Waste Generation Data Collection Questionnaire}

This questionnaire is provided to elicit important information from the TWRS waste generators and receivers in order to significantly improve the waste volume projection models and to enable planning of appropriate mitigating activities well in advance of when they might be required.

As a starting point, please use the waste volume projection input that you recently supplied to the TWRS Waste Volume Projection team. To save time, your recent waste volume projection information can be attached. Additional infomation requested below is necessary, howerer, in order to treat the waste volume projection. potential upsets. and mitigation factors (fallbacks) statistically and uniformly. The Questionnaire is divided into three parts. as follows:

1. Waste Volume Projection Information.

2. Failures and Programmatic Risk Analysis Information, and

3. Fallbacks Analysis Information.

Please provide your responses on the following form. If more space is required for any question, please note the section, question number, and response on an additional sheet of paper and attach the paper to this questionnaire.

The time period to be covered by the projections will correspond to the ten-year data supplied to the TWRS Waste Volume Projection team, plus an additional yearly projection for each of the next ten years (for a total of twenty years). If the 10-to-20 year data is difficult to derive, please do not expend undue effort to develop it. We are most interested in your best yearly estimate and the identification of major perturbations in the waste flows during that period.

\subsection{Waste Volume Projection Information}

\section{$1.1 \quad$ Historical Records}

1.1.1 How many times in the past ten years has your facility -

a. Significantly exceeded your previous year's waste volume projection? __ times

$\therefore$ b. Met your previous year's waste volume projection? times

c. Been significantly under your previous year's waste volume projection? times 


\subsection{Most-likely Waste Volume Projection}

1.2.1 What is the most-likely yearly waste volume projection for 1996 through 2015 for your facility? This is probably the information provided to the TWRS Waste Volume Projection tean for the short term. We recognize the inherent inaccuracies associated with out year projections. Information attached. Summary Information provided below. backup information attached.

\begin{tabular}{|l|l|l|l|l|l|}
\hline & Projection & Units & Year & Projection & Units \\
\hline 1995 & & & 2006 & & \\
\hline 1996 & & & 2007 & & \\
\hline 1997 & & & 2008 & & \\
\hline 1998 & & & 2009 & & \\
\hline 1999 & & & 2010 & & \\
\hline 2000 & & & 2011 & & \\
\hline 2001 & & & 2012 & & \\
\hline 2002 & & & 2013 & & \\
\hline 2003 & & & 2014 & & \\
\hline 2004 & & & 2015 & & \\
\hline 2005 & & & & & \\
\hline
\end{tabular}

1.2.2 Provide a short description of the basis for this most-likely waste volume projection. Identify those elements of the basis that are expected to affect the projection the most? Rank the elements from 1, provides the least impact, to 10, provides the most impact.

\begin{tabular}{|l|l|}
\hline \multicolumn{1}{|c|}{$\begin{array}{l}1=\text { least impact } \\
10=\text { most impact }\end{array}$} \\
\hline \hline Basis of Most-Likely Waste Volume Projection & Rank (1 to 10) \\
\hline & \\
\hline & \\
\hline & \\
\hline
\end{tabular}

1.2.3 What is the likelihood of meeting these most-likely waste volume projections (e.g., 8 in 10,9 in 10, etc.)? Likelihood is in Why? 


\subsection{Minimum Waste Volume Projection}

1.3.1 What is the minimum waste volume projection (i.e., least amount of waste generated) for each year 1996 through 2015 for your facility?

Information attached.

Summary lnformation provided below, backup information attached.

\begin{tabular}{|l|l|l|l|l|l|}
\hline Year & Projection & Units & Year & Projection & Units \\
\hline \hline 1995 & & & 2006 & & \\
\hline 1996 & & & 2007 & & \\
\hline 1997 & & & 2008 & & \\
\hline 1998 & & & 2009 & & \\
\hline 1999 & & & 2010 & & \\
\hline 2000 & & & 2011 & & \\
\hline 2001 & & & 2012 & & \\
\hline 2002 & & & 2013 & & \\
\hline 2003 & & & 2014 & & \\
\hline 2004 & & & 2015 & & \\
\hline 2005 & & & & & \\
\hline
\end{tabular}

1.3.2 Provide a short description of the basis for this minimum waste volume projection. Identify those elements of the basis that are expected to affect the projection the most? Rank the elements from 1, provides the least impact, to 10 , provides the most impact.

$1=$ least impact

$10=$ most impact

\begin{tabular}{|l|l|}
\hline \hline Basis of Minimum Waste Volume Projection & Rank (1 to 10) \\
\hline \hline & \\
\hline & \\
\hline & \\
\hline & \\
\hline
\end{tabular}

1.3.3 What is the likelihood of meeting these minimum waste volume projections (e.g., 1 in 10 , 3 in 10 , etc.)? Likelihood is in Why? 


\subsection{Maximum Waste Volume Projection}

1.4.1 What is the maximum waste volume projection (i.e.largest amount of waste generated) for each year 1996 through 2015 ? Information attached. Summary Information provided below. backip information attached.

\begin{tabular}{|l|l|l|l|l|l|}
\hline Year & Projection & Units & Year & Projection & Units \\
\hline \hline 1995 & & & 2006 & & \\
\hline 1996 & & & 2007 & & \\
\hline 1997 & & & 2008 & & \\
\hline 1998 & & & 2009 & & \\
\hline 1999 & & & 2010 & & \\
\hline 2000 & & & 2011 & & \\
\hline 2001 & & & 2012 & & \\
\hline 2002 & & & 2013 & & \\
\hline 2003 & & & 2014 & & \\
\hline 2004 & & & 2015 & & \\
\hline 2005 & & & & & \\
\hline
\end{tabular}

1.4.2 Provide a short description of the basis for this maximum waste volume projection. Identify those elements of the basis that are expected to affect the projection the most? Rank the elements from 1, provides the least impact, to 10 , provides the most impact.

\begin{tabular}{|l|l|}
\hline Basis of Maximum Waste Volume Projection & \multicolumn{1}{c}{$\begin{array}{c}1=\text { least impact } \\
10=\text { most impact }\end{array}$} \\
\hline \hline & Rank (1 to 10) \\
\hline & \\
\hline & \\
\hline & \\
\hline & \\
\hline & \\
\hline
\end{tabular}




\subsection{Local Waste Generators' Upset Conditions}

1.5.1 Identify significant upset conditions that have occurred over the last ten years that effected the generation of facility waste. Also. identify other significant upset conditions that may be possible in the future.

(a) Rank the upset conditions that have occurred. or could occur, from 1, provides the least impact. to 10 , provides the most impact.

(b) Identify how many times the upset conditions have occurred. or for future possible upset conditions. the likelihood that the upset could occur.

(c) Could the upset conditions occur again? Why, why not? What is the basis for possible future upset conditions.

\begin{tabular}{|l|l|l|l|l|}
\hline Upset Conditions & $\begin{array}{l}\text { Rank } \\
\text { (1 to 10) }\end{array}$ & Consequences & $\begin{array}{l}\text { Times Occurted } \\
\text { and/or } \\
\text { likelihood }\end{array}$ & $\begin{array}{l}\text { Could They } \\
\text { Occur Again? } \\
\text { Why, Why Not }\end{array}$ \\
\hline \hline & & & & \\
\hline & & & & \\
\hline & & & & \\
\hline & & & & \\
\hline & & & & \\
\hline & & & & \\
\hline
\end{tabular}




\subsection{Operational Upset Conditions}

The following items were developed during the Risk Management W'orkshop meeting.

\begin{tabular}{|l|l|l|}
\hline \multicolumn{1}{|c|}{ Opcrational Upset Conditions } & $\begin{array}{c}10=\text { most severe } 10=\text { most likely } \\
1=\text { least severe likely }\end{array}$ \\
\hline \hline $\begin{array}{l}\text { SST tank leak (until 1998. when salt well pumping is } \\
\text { complete) }\end{array}$ & Severity & Likelihood \\
\hline Pipe breaks in contaminated areas & & \\
\hline DST tank leak & & \\
\hline Extended outage of evaporator (on the order of years) & & \\
\hline Loss of existing cross-site transfer line(s) & & \\
\hline Local (important) transfer line failure & & \\
\hline Required dilution of safety tanks & & \\
\hline New tanks added to watch list & & \\
\hline DCRT Leak & & \\
\hline Stabilized SSTs have additional liquid & & \\
\hline
\end{tabular}

\subsection{Failures and Programmatic Risk Analysis Information}

Failure or operational upset conditions are those that could cause widespread disruption of waste flows throughout the Hanford Site. Programmatic risk is caused by significant management decisions, such as new tanks added to the Watch List or changes in seismic requirements (additional head space needed).

Please score the following items that were developed during the Risk Management Workshop (held on June 28 and 29, 1995) on the following scales.

$\because \quad$ Severity from 1 to $10 ; 10$ being the most severe consequence, 1 being the least severe, Likelihood from 1 to $10 ; 10$ being the most likely, 1 being the least likely.

Feel free to add items you think should be on the list, and score them on the same scale. 


\subsection{Programmatic Risk Items}

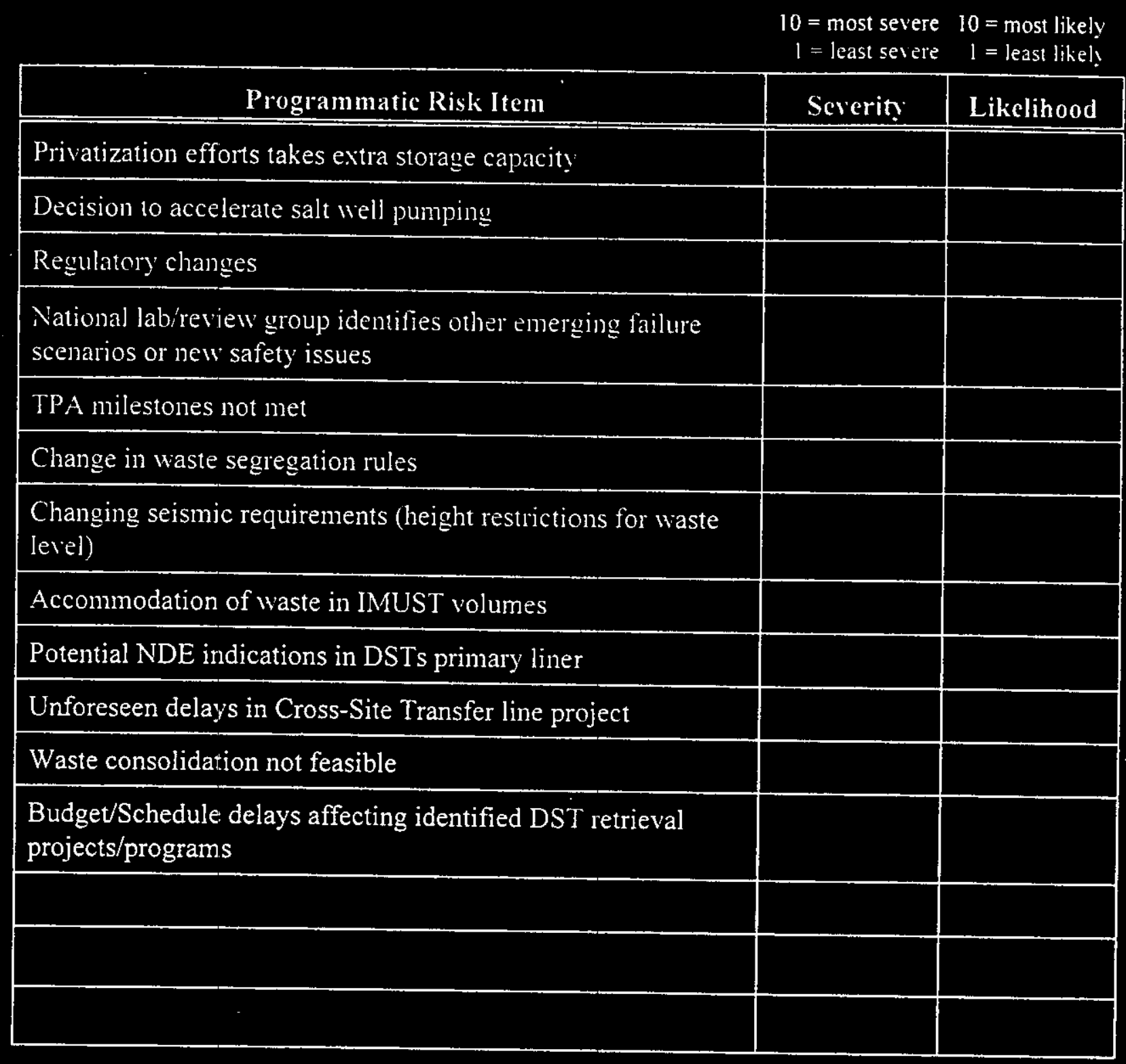

\subsection{Fallback Analysis Information}

Fallbacks are the alternative courses of action that are available to mitigate the consequences of adverse events. There are fallbacks to mitigate upset conditions and, typically, different fallbacks to mitigate significant programmatic changes. Of the identified fallbacks, they should be considered to fall into two arbitrary categories: (a) fallbacks that are easiest to implement and/or of lower complexity, and (b) fallbacks that are hardest to implement and/or of greater complexity. For example, there are fallbacks that are easily implemented and do not require any complicated regulatory justification (such as increasing flows to the evaporator), while other fallbacks could be more difficult to implement (such as building new DSTs). 
Please score the following potential fallback actions identified during development of this plan. The scoring is as follows:

(a) elfectiveness is a scalc from 1 to 10 for the fallback items effectiveness in mitigating a major risk item (10 being most effective. 1 being the least effective).

(b) relative cost is a scale from 1 to $10: 10$ heing the most expensive and 1 being the least.

(c) Use the last column to indicate which upset conditions (Section 1.5). programmatic risk items (Section 2.1), or operational upset conditions (Section 2.2) to which the fallback actions may apply.

Your responses should consider the benefit to the entire site and not just the benefit to an individual waste generating facility. Also, feel free to add items you think should be on the list. and score them on the same scales. Under the Difficulty column, please consider difficulty over the entire range of potential issues (i.e., regulatory. cost. schedule, others).

\section{$3.1 \quad$ Fallback Items}

\begin{tabular}{|l|l|l|l|l|}
\hline \multicolumn{1}{|c}{$10=$ hardest } & $10=$ most effective $10=$ most expensive \\
$1=$ Fallback Item & Difficulty & Effectiveness & $\begin{array}{l}\text { Relative } \\
\text { Cost }\end{array}$ & $\begin{array}{c}\text { Risk/Upset } \\
\text { Item }\end{array}$ \\
\hline \hline $\begin{array}{l}\text { Use of private contractor for liquid } \\
\text { cleanup }\end{array}$ & & & & \\
\hline Stop salt well pumping of SSTs & & & & \\
\hline Use above ground transfer alternative & & & & $\begin{array}{l}\text { Plugged } \\
\text { transfer } \\
\text { line }\end{array}$ \\
\hline $\begin{array}{l}\text { Use a non-leaking SST as short-term } \\
\text { storage }\end{array}$ & & & & \\
\hline Build new DSTs & & & & \\
\hline Activate grout program & & & & \\
\hline Use watch list tank space for storage & & & & \\
\hline $\begin{array}{l}\text { Use chemical adjustments to reduce } \\
\text { incoming waste volume }\end{array}$ & & & & \\
\hline Store waste in temporary tanks & & & & \\
\hline Accelerate disposal & & & & \\
\hline
\end{tabular}




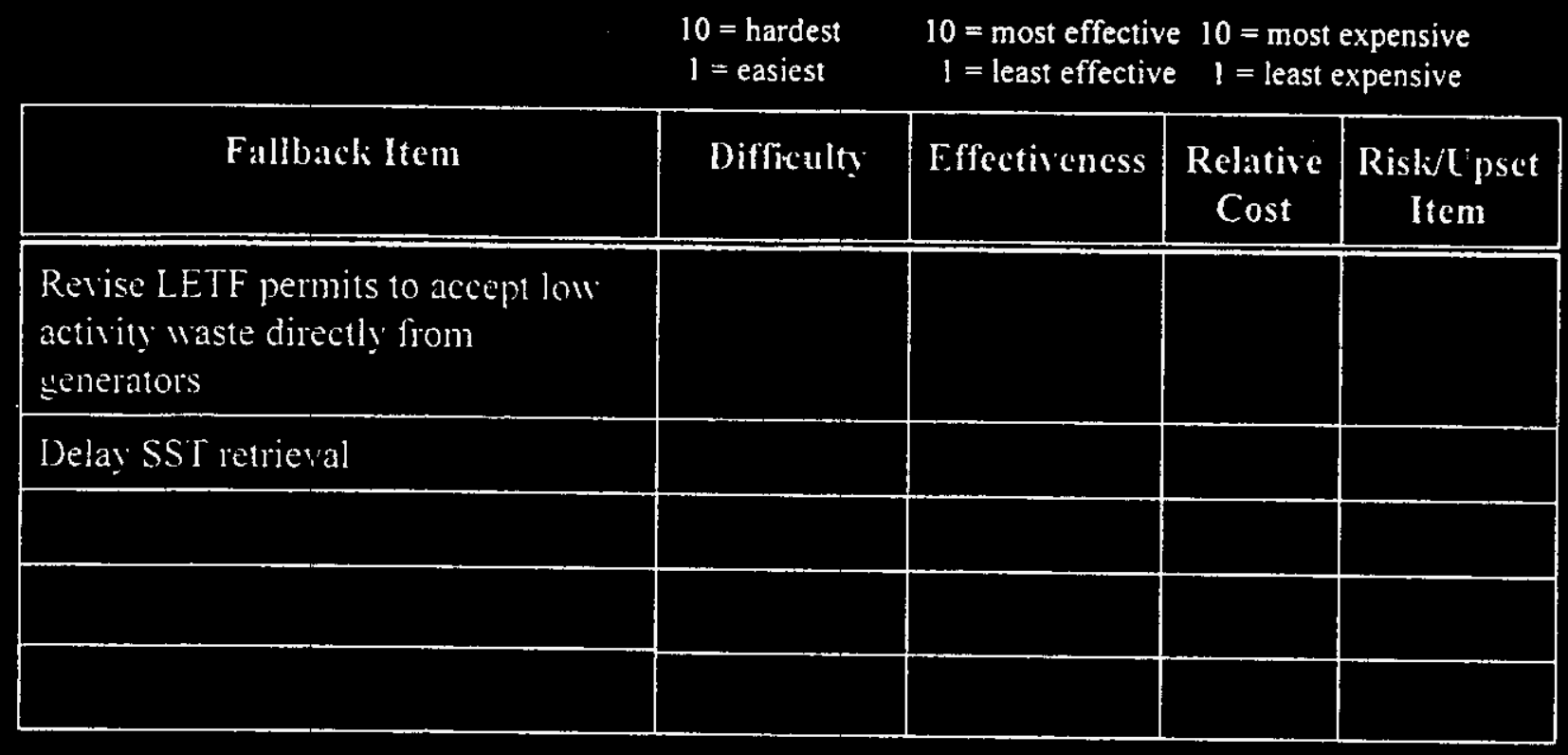


Appendix B - Simple Model Analysis

B-1 


\section{APPENDIX B}

\section{SIMPLE MODEL ANALYSIS}

\section{B.I Introduction}

As noted in Appendix C. one of the steps in a simulation study is to build a simple model that captures the essence of the problem to be considered without being overly complicated. The results of the simple model can then be used to yuide development of a more exacting simulation model. The objective of this Appendix is to describe the results of a simplified model developed for the high-level waste volume projection. The results of the simplified model were then used in the development of the logic and process of the GPSS simulation model and to provide independent verification of the simulation model results.

\section{B.2 Model Description}

The simple model uses as its starting point the most recent Westinghouse Hanford Company Operational Waste Volume Projection, Revision 21 (WHC 1995). The waste volume information presented in Revision 21 of the Operational Waste Volume Projection is detailed in Table 8 of the document and summarized in Table 10, Spreadsheet of Waste Additions and Reductions for Baseline Case. The information presented in Table 10 of the document is then the basis for the simple model.

The simple model uses the point values of projected new waste generated each year from 1995 to 2015. The projected waste losses due to the evaporator waste volume reduction, pretreatment losses, and vitrification losses are also used. The total end of year inventory for each year is then determined from the starting waste inventory plus new waste additions minus projected total waste losses. The Operational Waste Volume Projection identifies spare tank space that is required to be maintained by DOE Orders, available waste tank space contained in watch list tanks, available waste tank space contained in tanks with segregated waste, and available priority or operational tank space.

The total available double-shell waste tank capacity is 24 double-shell tanks of $1,140 \mathrm{kgal}$ capacity each and 4 double-shell tanks of $980 \mathrm{kgal}$ capacity each $(31,280 \mathrm{kgal}$ total $)$. The equivalent space of two waste tanks maintained as spare capacity is $2,280 \mathrm{kgal}$. In the simple model the remaining waste tank space (from watch list tanks, segregated waste: priority and "operational space) is considered part of the operational process. Therefore, the available waste tank capacity is taken to be the total capacity minus the spare capacity $(31,280-2,280=29,000$ kgal).

Each new waste addition was assumed to have associated uncertainty. The uncertainty was represented by a triangular distribution that varied from the provided point value by $\pm 20 \%$. In addition, the uncertainty was increased by $1 \%$ per year from 1995 to 2015 . The waste volume loses were also assumed to have uncertainty. The uncertainty was also represented by a 
triangular distribution that varied from the point value by $\pm 20 \%$, and increased by $1 \%$ per year.

A Monte Carlo uncertainty analysis was completed by randomly selecting a value for each new waste generated from within the specified triangular distributions. Each waste volume loss was also randomly selected from a value within the specified triangular distributions. The resulting yearly waste volume projection was calculated as a distribution, and a correlation was developed for the vears from 1995102015 . The mean waste volume projection is graphed as functions of time with the available waste volume capacity. Also plonted are the $10 \%$ and $90 \%$ confidence values for the waste volume. The $90 \%$ confidence value represents a waste volume projection with a probability of 0.9 that the actual 1 aste rolume will not exceed the projected waste volume. A $10 \%$ confidence value represents a waste volume projection with a probability of 0.3 that the actual waste volume will not exceed the projected waste rolume. Various other assumptions were developed. as described below. for each case that was analyzed.

\subsection{Model Results}

\section{Case 1}

The first case was an evaluation of the total waste volume versus available capacity as a function of time with increasing uncertainty as described above. The results are shown in Figure 3 . The $90 \%$ and $10 \%$ confidence values are shown as a solid line above and a dashed line below the mean waste volume, respectively. The total waste tank capacity of $31,280 \mathrm{kgal}$ is shown by the solid straight line, and the available waste tank capacity (total minus two spare tanks) is presented as the straight dashed line.

As expected, representing uncertainty in both the waste generation and waste losses with increasing uncertainty in time tends to result in a continuous increase in the spread between the $10 \%$ and $90 \%$ confidence level of the projected waste volume about the mean. The results of this analysis provide the following insights relative to the waste volume projection. First, this is a total model, rather than the segregated waste stream model used in the GPSS simulation analysis, and detailed, specific information is lost in the general results of total waste volume. Second, the uncertainty in available information increases with time such that there is an increasing likelihood that specific action will be required in the out-years to avoid having the waste volume approach the available waste capacity. However, by continually updating available information the uncertainty can be reduced and decisions in the out-years can be made with more current information. Third, decisions whose actions would require eight to ten years to implement may need to be made based on increasingly more uncertain information. 


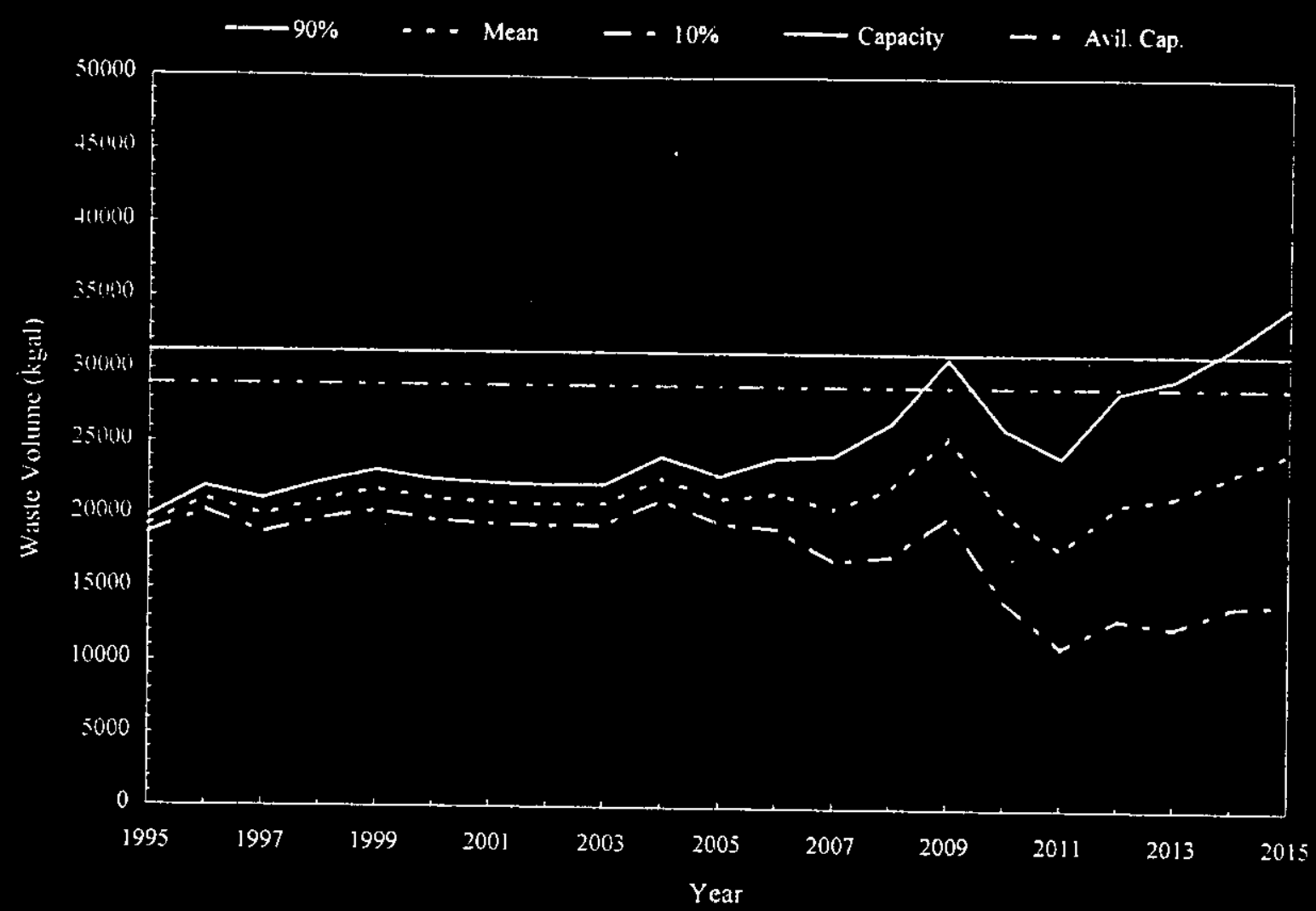

Figure B-1. Case 1, Projected Waste Volume versus Available Capacity with Postulated Uncertainty.

\section{Case 2}

The second case was similar to the first, but it was further assumed that pretreatment activities could be delayed by two years. A zero or one random number generator was used. If the selected number was zero, then pretreatment was delayed by two years from 2005 to 2007 . If the selected number was one, then pretreatment was started as projected (2005). This potential delay was in addition to the uncertainty used in Case 1. If delayed, no attempt was made to increase pretreatment activities once started, or to decrease or defer any waste generation activities. The results are presented in Figure B-2. With potential delay in pretreatment activities and no attempt to make up waste losses, the likelihood that specific action will be required in the outyears to avoid having the waste volume approach available waste capacity occurs at an earlier time. Also, there is a higher likelihood that such action would be required. 


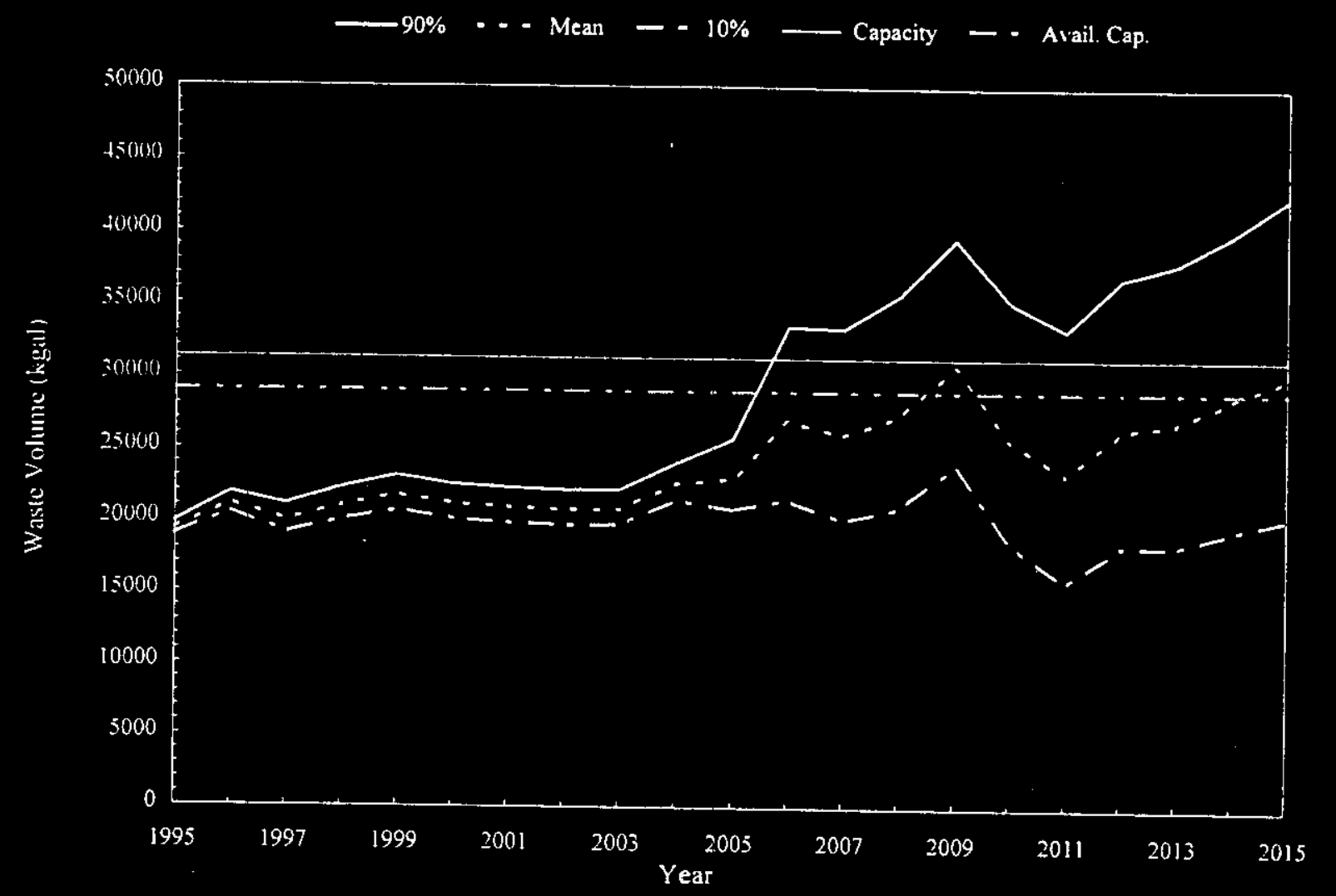

Figure B-2. Case 2, Projected Waste Volume versus Available Capacity with Uncertainty and a Delay in Pretreatment Activities.

\section{Case 3}

The third case considered waste generation, transfer, storage and treatment of complexed waste only. This example illustrates the particular information that is available is considering a specific waste type. There are four (4) large double-shell waste tanks $(1,140 \mathrm{kgal})$ and one smaller double-shell waste tank $(980 \mathrm{kgal})$ that are devoted to storing complexed waste $(5,540 \mathrm{kgal}$ total). The same uncertainty model was used for complexed waste as was used in Case 1 above. The results are presented in Figure B-3. Note that the results suggest that at least two other double-shell tanks need to be designated for storing complexed waste for the next 10 years. 


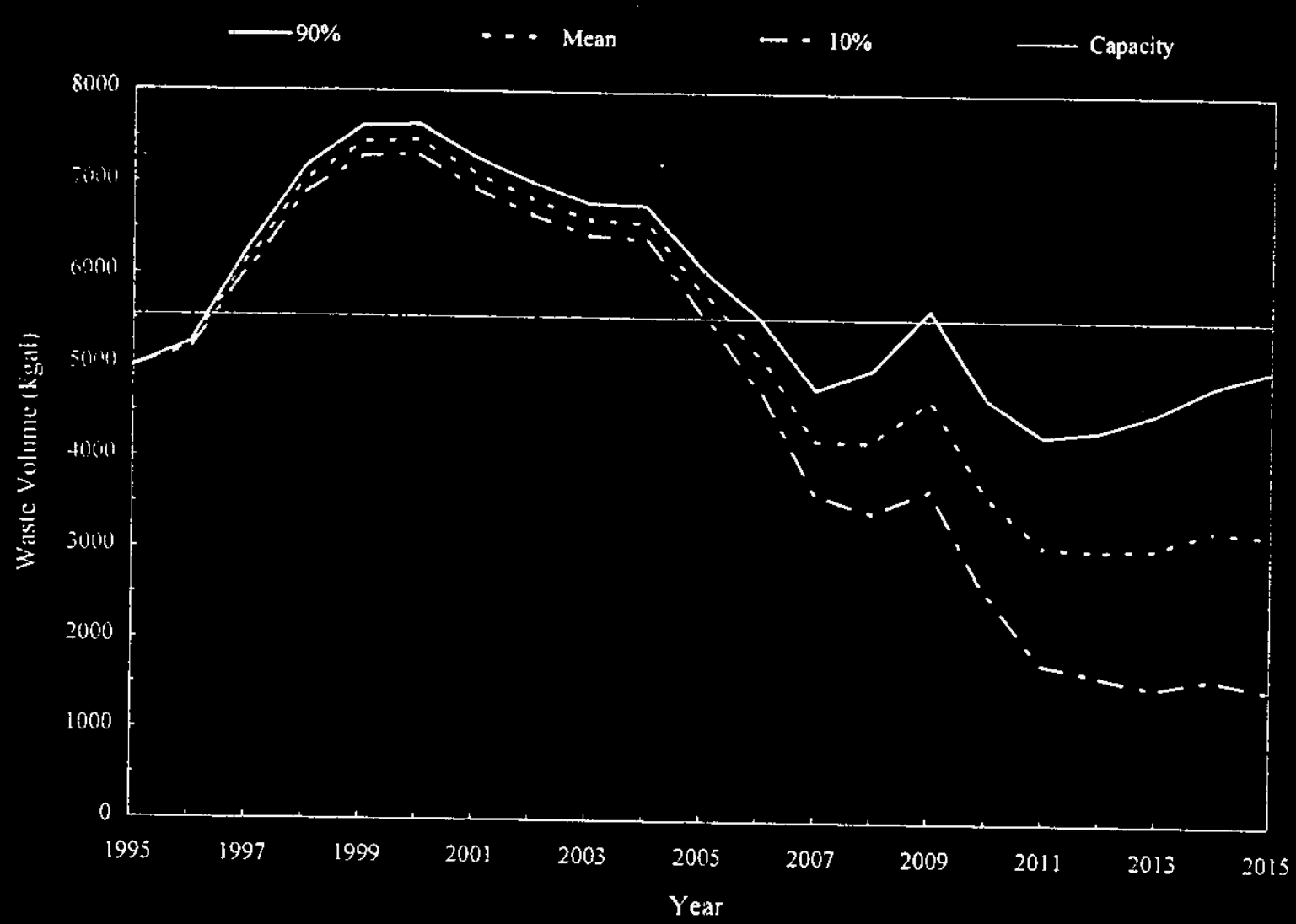

Figure B-3. Case 3, Projected Waste Volume versus Available Capacity with Uncertainty for Complexed Waste.

\section{B.3 Waste Tank Failure Rate and Failure Probability}

The first double-shell waste tank was placed in operation in 1970 and the last double-shell waste tank was placed in operation in 1986. Thus, the first double-shell waste tanks placed in operation will approach their 30 year design life near 2000; while the later tanks will approach their design life near 2015. Beyond the design life there is an increasing likelihood that a double-shell tank could fail. Failure could occur from natural operational activities due to corrosion of the steel liner leading to a leak. In terms of a risk assessment it is desirable to consider the likelihood of a failure of a double-shell waste tank and the effect such a failure would have on the waste volume projection versus capacity.

There have been no failures for twenty-five years of operation for double-shell tanks AY-101 and AY-102. Thus, the failure rate due to corrosion would be smaller than 1 in 50 tank years, or $2 x$ $10^{-2}$ per tank year. A process for estimating the exponential failure rate from data with no failure events (Welker 1974) provides an estimated failure rate of one over three-times the operating time. The total tank operating years for the entire 28 double-shell tanks is 407 tank years which would give an estimated failure rate of $8 \times 10^{-4}$ per tank year. Thus, a reasonable failure rate during the design life of the double-shell tanks would be approximately $1 \times 10^{-3}$ per tank year.

For a system or component, the failure rate is nearly constant during the design life and 
significantly increases beyond the design life. The shape of the failure rate curve, or "bathtub" curve, is usually decreasing during the early life time (startup deficiencies), constant during the design life. and significantly increasing beyond the design life. The failure rate for a probability distribution function is given by:

$$
r(t)=\frac{f(t)}{\mathrm{l}-F(t)}=\frac{f(t)}{R(t)}
$$

where $f(t)$ is the probability distribution function, $R(t)$ is the reliability function. and $F(t)$ is $t h e$ failure probability. Considering a Weibull probability density function. the failure rate is given by:

$$
r(t)=\frac{\beta}{\eta}\left(\frac{t-\underline{\gamma}}{\eta}\right)^{(\beta-1)} .
$$

The parameters $\beta$ and $\eta$ of a Weibull probability density function were varied until a nearly constant failure rate of approximately $1 \times 10^{3}$ per tank year was obtained for the time interval $(t-\gamma)$ up to 30 years. This failure rate is shown in Figure B-4.

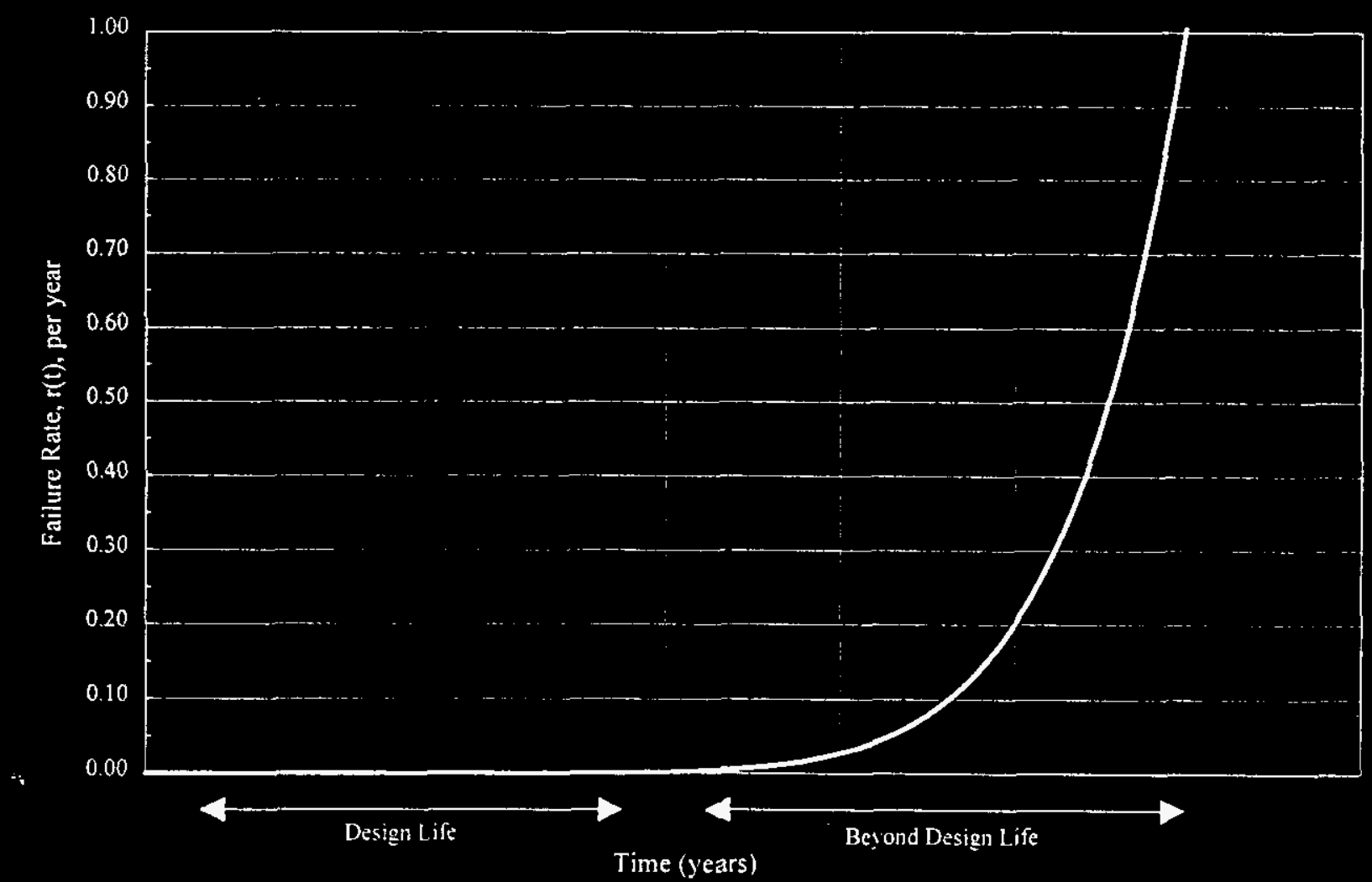

Figure B-4. An Approximate Failure Rate per Year per Tank.

It is emphasized that the failure rate in Figure B-4 is an approximation that suggests a nearly 
constant failure rate during the design life of a tank (about $1 \times 10^{-3}$ per year during the design life), with an increasing failure rate beyond the design life. However, the results in Figure B-4 appear to be reasonable in that it is more likely for a significant failure rate beyond the design life.

A failure probability for a single double-shell waste tank was developed by using the Heibull parameters from the failure rate of Figure B-t. The results are shown in Figure B-5. Again it is emphasized that the failure probability curve in Figure B-5 is approximate and is used in the analysis only to illustrate the point that beyond the design life of the double-shell tanks there is a bigher likelihood of a tank failure. or of a mumber of tanks failing.

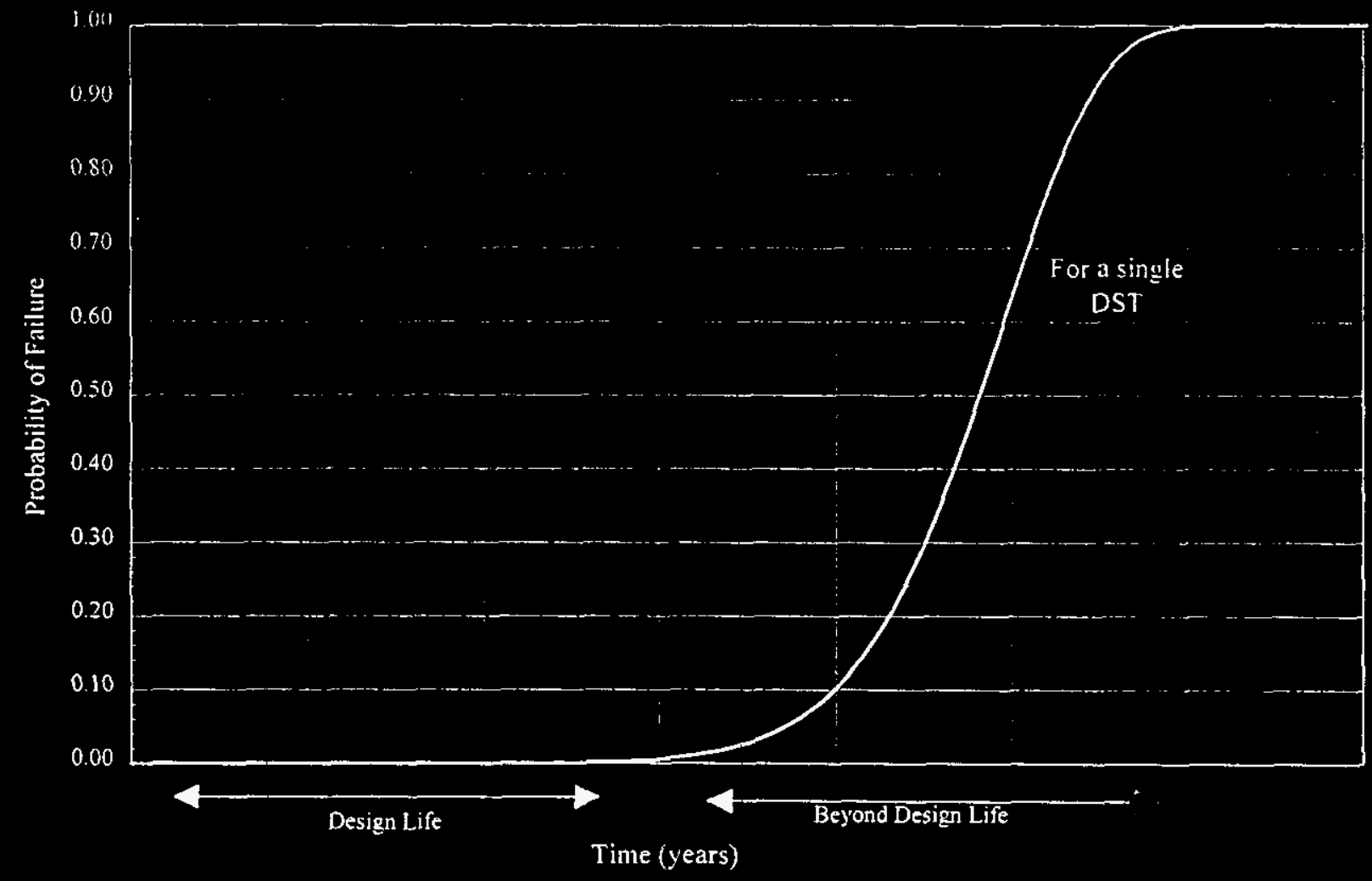

Figure B-5. Probability of Failure for a Single Double-Shell Tank.

\section{Case 4}

The failure probability for a single double-shell waste tank was used in the analysis of Case 4 . The same assumptions used in Case 1 relative to the uncertainty in input information were also used in this case. However, the available waste tank capacity was determined as the number of available waste tanks times the average capacity per waste tank times the probability that the waste tanks have not failed (i.e., one minus the probability of failure). See Equation B-3.

$$
\text { Capacity }=\{1-\operatorname{Pr}[\text { failure }]\} N Q_{\text {ave }} .
$$

The results were normalized to the average capacity per waste tank and are presented in Figure 
B-6. The major difference between the results for Case 1 (Figure B-1) and Case 4 (Figure B-6) is the consideration of the likelihood of double-shell waste tank failures which increases with time. The result of waste tank failures is a waste capacity that decreases with time as shown in Figure B-6 as the dashed line. In this analy sis there is a high probahility that seren (7) waste tanks have failed by 2015 which is illustrated by a decreasing waste capacity. The point is that by including the probability of double-shell waste tank failures. there is a larger likelihood that the waste volume will exceed the available waste tank capacity unless appropriate action is taken.

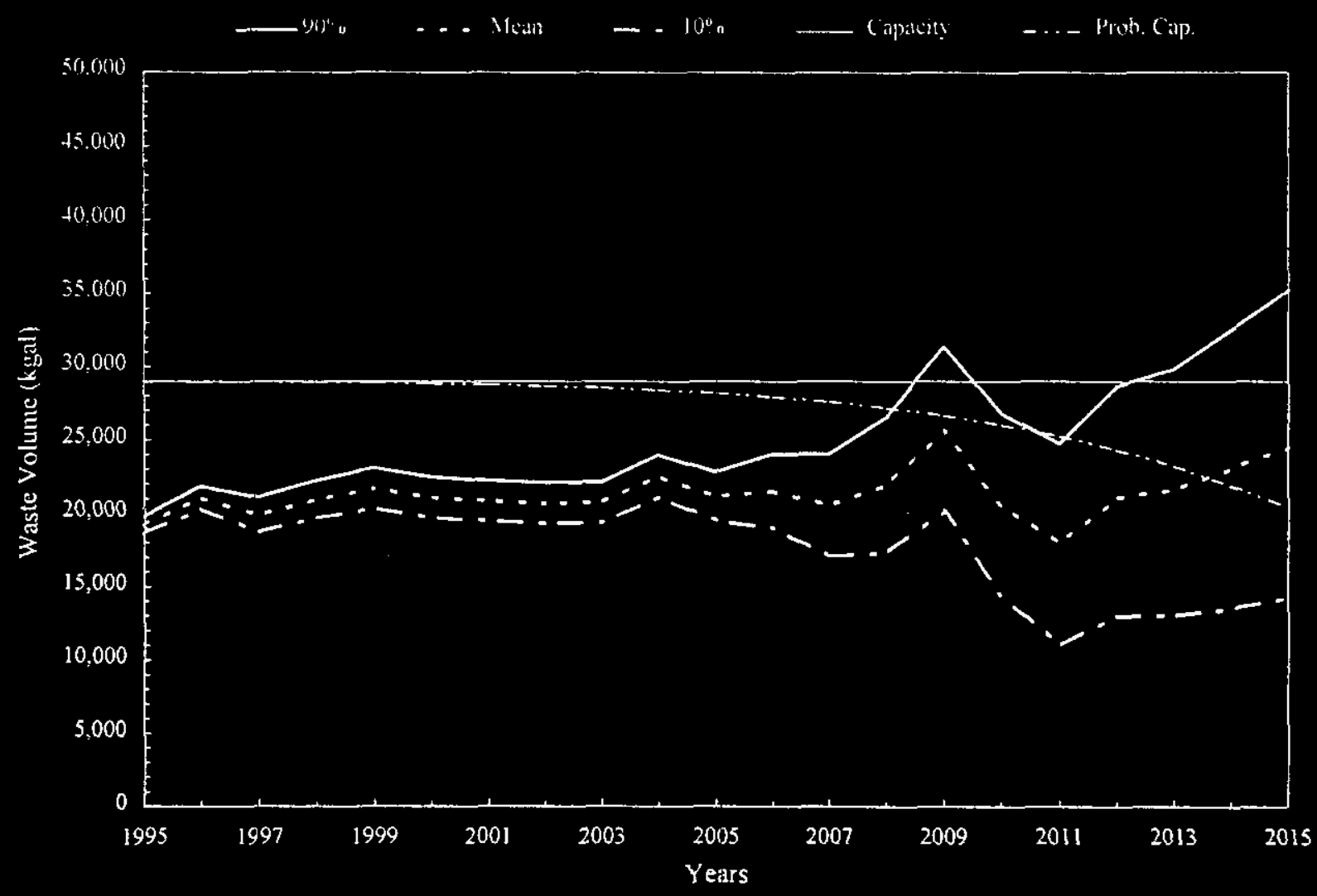

Figure B-6. Case 4, Projected Waste Volume versus Available Capacity with Postulated Uncertainty and Considering the Likelihood of Waste Tank Failure.

\section{Case 5}

The failure probability for a single double-shell waste tank was also used in the analysis of Case 5 for complexed waste. The same assumptions relative to the uncertainty in input information as used in Case 3 were also used in this case. Again, the available waste tank capacity was determined as the number of available waste tanks (5) times the average capacity per tank, times the probability that the waste tanks have not failed. The results are shown in Figure B-7. 


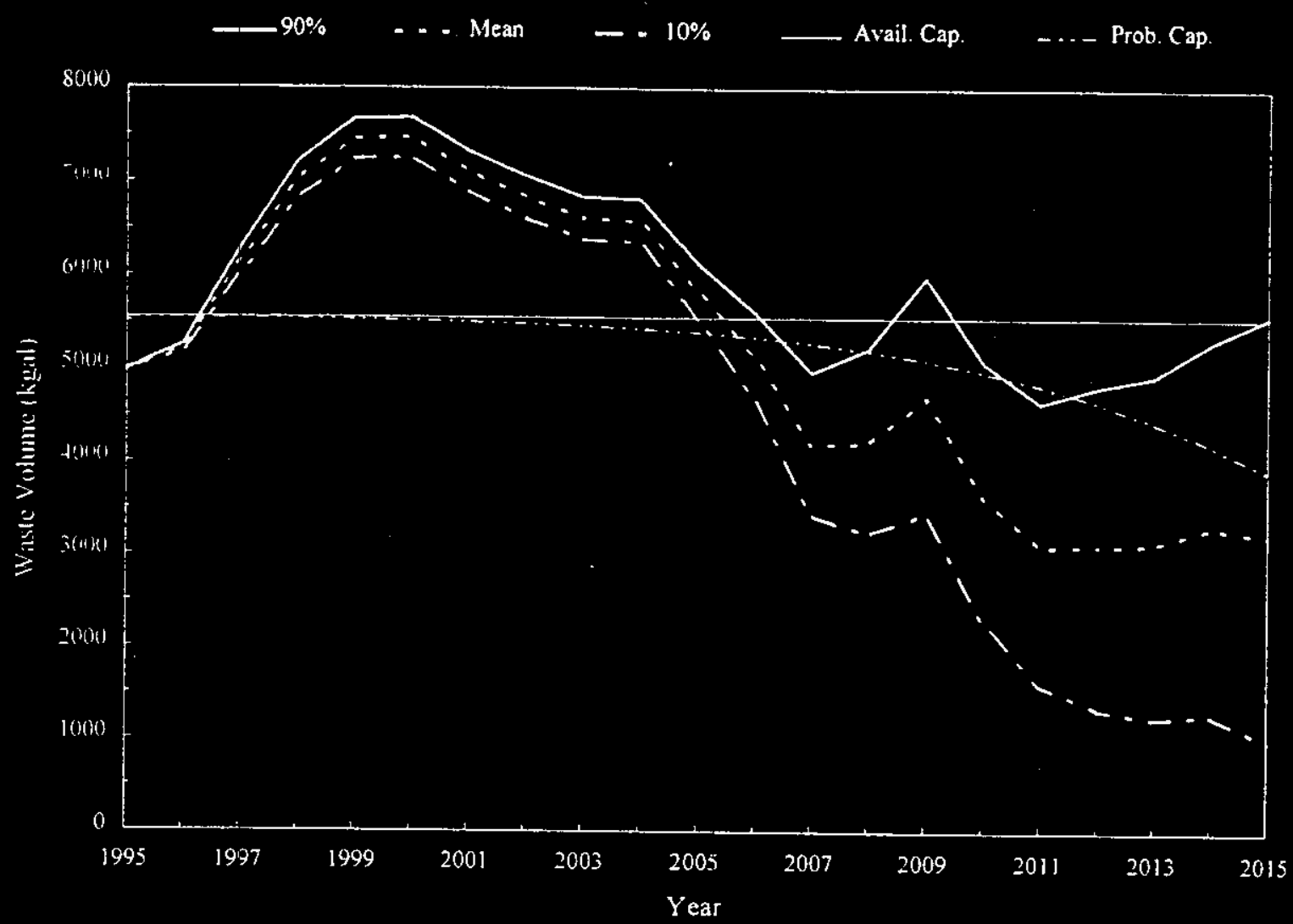

Figure B-7. Case 5, Projected Waste Volume versus Available Capacity with Uncertainty for Complexed Waste Considering the Likelihood of Waste Tank Failure.

The results of Case 3 suggested that two additional waste tanks would need to be designated for storing complexed waste for the next ten years. If the likelihood of a failure of a double-shell waste tank is considered, then it may be necessary to designate these two waste tanks for storing complexed waste until all disposal activities for complexed waste have been completed. 
Appendix C - General Description - Simulation Modeling

C-1 


\section{APPENDIX C}

\section{GENERAL DESCRIPTION - SIMULATION MODELI.YG}

\section{C.1 SIMLLATION MODELING}

Computer simulation is a technicue used to predict how a system will behave hy using a computer model to numerically evaluate and'or estimate desired characteristics of the system. The system assumptions. usually in the form of mathematical or logical relationships. constiture a model that is used to gain some understanding of how the corresponding system would behave under a variety of situations. A system can be defined broadly as a collection of entities lhat act and interact together toward the accomplishment of some logical end product. The state of a system is the collection of variables necessary to describe a system at a particular point in time.

Often the mathenatical relationships used in a model can not be listed in closed-form with exact solutions. Rather the mathematical relationships are exercised by means of a simulation technique where the inputs of the model are varied over a wide range to see how they affect the output variables. The simulation can be static or dynamic, where a static model represents the system at a particular time and a dynamic model represents the system as it evolves over time. The simulation can be deterministic or stochastic. For a deterministic simulation the variables do not contain any random components usually represented by probabilities (that is, the output is determined once the set of input quantities and relationships in the model have been specified). A simulation is stochastic if the input variables are represented by random components or probability distribution functions. For a stochastic simulation the output variables are also random and are treated as only estimates of the true characteristics of the model with associated uncertainties.

The simulation can be discrete or continuous. A discrete simulation evaluates a system as it evolves over time by a representation in which the state variables change instantaneously at separate or discrete points in time. A continuous simulation evaluates a system over time where the state variables change continuously with respect to time. Most simulation models are discrete, dynamic and stochastic. That is, the model evaluates a system where the state variables evolve with time (dynamic) but change instantaneously at discrete points in time (discrete), and the input and output variables are represented by probability distribution functions.

Using a simulation model and the present speed of personal computers, the system can be run or exercised through large time intervals in a matter of minutes. Several scenarios ("What if?") can be evaluated within minutes whereas evaluating the real system would require significant time at considerable cost.

Typical steps used in completing a simulation study are presented in Figure C.I and briefly discussed as follows.

1. Formulate Problem. Formulate the problem and plan the study to be completed including a clear statement of the objectives, issues to be addressed, alternatives to be considered, and criteria for evaluating alternatives. 
2. Define Model. The model is defined including a definition of the input and out variables, probability distribution functions for the random input variables, existing data, and available information. Construction of a mathematical and logical model of a real system with giren objectives is still as much an, art as it is a science. As a result. a simplified model is tirst developed and exercised: one that later can be developed to be more sophisticated.

$\therefore \quad$ Model Verification. In building a simple model that captures the essence of the problem to be considered without being overly expensive or complicuted. it is essential that individuals involved with operation of the actual system be continuously involved in the model development. Also. the values of the decision makers need to be incorporated into appropriate objectives and criteria.

4. Computer Simulation. The method to be used for computer simulation needs to be evaluated. General-purpose computer languages, such as FORTRAN, Pascal, or C, can be used to develop a specific model. A specially designed sinulation language program, such as GPSS, SIMAN, SIMSCRIPT, or SLAM, can also be used. Other general purpose. but less sophisticated programs can be used such as PC-based spreadsheets with simulation capabilities.

5. Pilot Runs. Pilot runs, or base case runs, are completed to assist in validation of the model results.

6. Model Validation. The pilot runs are used to test the model, evaluate sensitivities of the input variables, and evaluate the model for reasonableness of the output results. This step provides an opportunity for further model definition and/or changing the model if required.

7. Alternative Evaluation. The various alternatives being considered are evaluated.

8. Data and Sensitivity Analysis. Sensitivity studies are completed and data are analyzed. An investigation is conducted to find which data inputs and model elements have the greatest effect on the results.

9. Documentation. The results of the study are documented and prepared for presentation. 


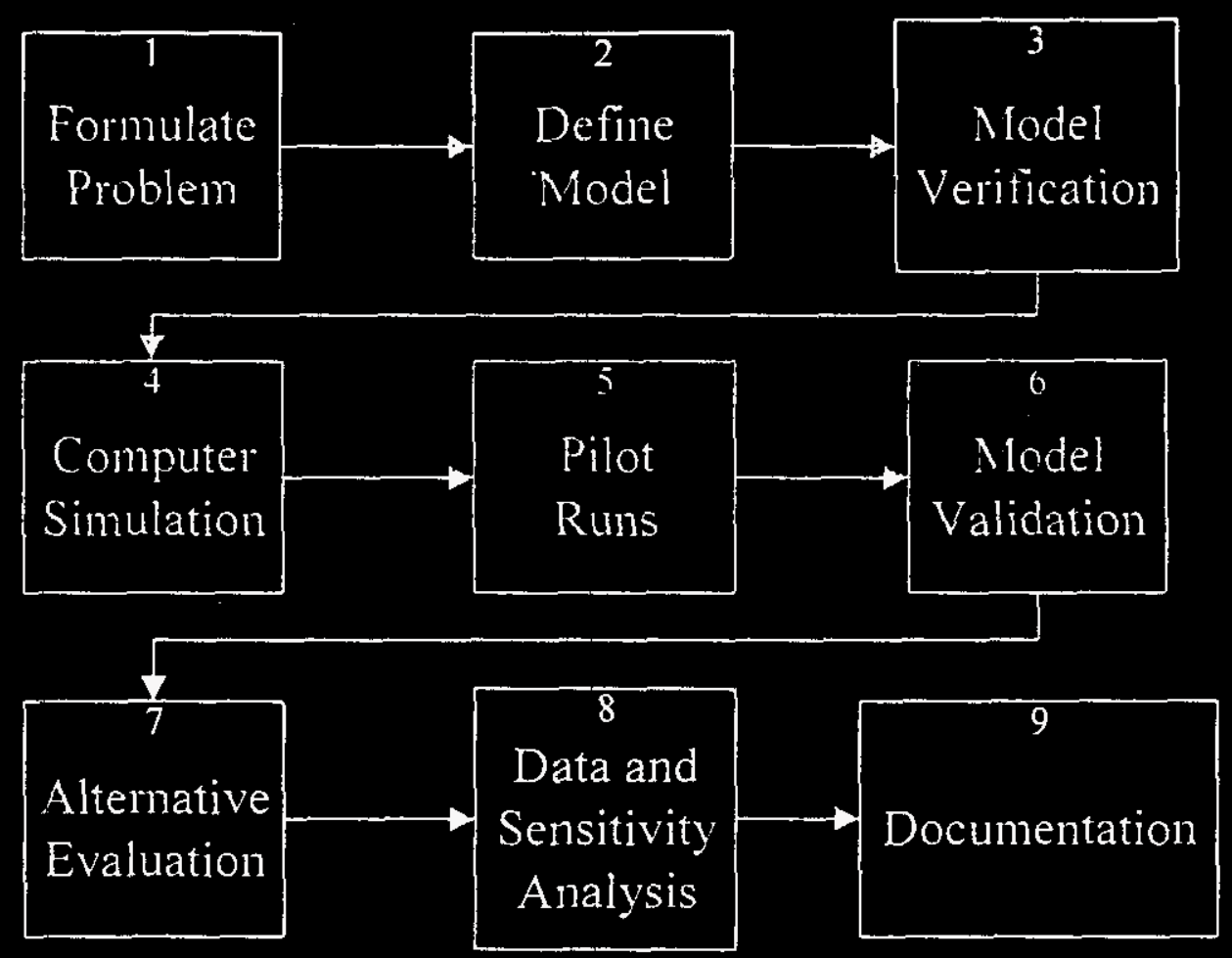

Figure C.1. Steps in a Simulation Study.

\section{C.2 SIMULATION LANGUAGE PROGRAMS}

As noted there are several general-purpose computer languages (FORTRAN, Pascal, or C) that can be used to develop a specific simulation model. These computer languages provide flexibility in model development, but are more difficult to use than specific simulation languages, specifically in introducing probability distribution functions and completing simulation modeling. Simulation language programs are available, such as GPSS, SIMAN, SIMSCRIPT, or SLAM, that are easier to use. Each of these more specific simulation language programs will be briefly reviewed. More general descriptions can be found in the references and in the book by Law and Kelton (Law 1991). The discussion will then focus on the simulation program(s) chosen for the analysis considered in this study.

\section{GPSS}

General Purpose Simulation System (GPSS) is a process-oriented simulation language that was first developed by Gordon (Gordon 1975). GPSS has now evolved through Version V. A more recent version of GPSS is GPSS/H developed by Henriksen (Banks et al. 1989). GPSS/H is a compiled language with enhancements relative to GPSS V, including a real-ralue clock, ability to read and write external files, tailored output reports, improved control statements, mathematical functions, and a limited number of routines for generating random values from 
probability distributions. The GPSS/H language consists of numerous standard statements such that a model is developed by combining a set of standard blocks into a block diagram and then compiling the program.

\section{(IPSS/PC (Current Version GPSS-lvorld)}

GPSSPC (Minuteman 1994) is a simulation !anguage designed specifically for use on the IBM $P C$ and compatibles. GPSS $P C$ has on-line input error checking. on-line help. and the ability to grajhically see transactions flowing through a block dingram. GPSS PC is not a compiler so changes made to a model are seen immediately without waiting for the program to be recompiled. Included are graphical display s for facilities, storages. and histograms that are
updated dynamically during the execution of a simulation.

\section{SIMAN}

SIMAN (SIMulation ANalysis) is a simulation language (Pegden, et al. 1990) in which one can build a process-oriented model, an event-oriented model, or a combination of the two. Most of the simulation model is developed using process orientation. Complicated decision logic can be coded in event routines and then called from the process model. SIMAN is simulation language available for microcomputers.

\section{SIMSCRIPT II. 5}

SIMSCRIPT II.5 is a process-oriented or event-oriented simulation language (Law 1984). SIMSCRIPT is a general programming language containing capabilities for building discreteevent, continuous, or combined simulation models. The language syntax is English-like and free-form making the documentation easier. SIMSCRIPT provides a general process approach, has sophisticated data structures, and powerful control statements. SIMSCRIPT II.5 is available for microcomputers, work stations and minicomputers/mainframes. An version for IBM PC and compatibles is embedded in a SIMLAB package, which is an interactive, multitasking programming environment for facilitating the use of SIMSCRIPT. SIMLAB contains an editor, compiler, a debugger, and on-line help.

\section{SLAM II}

SLAM II (Simulation Language for Alternative Modeling) is a simulation language (Pritsker 1986) that can be used to build a process-oriented model, an event-oriented model, or a combination of the two. Decision logic is coded in event routines and called from the process model. The model is developed from a graphical network diagram for the system constructed by combining standard symbols, called nodes and branches, into an interconnected network that represents the flow through the process. The network model of the system is then translated into an equivalent set of SLAM II program statements for execution on a computer. Program statements can also be coded directly in FORTRAN. SLAMSYSTEM is a microcomputer version of SLAM II that is integrated with Microsoft Windows and provides animation and graphics. 


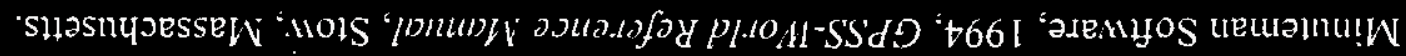

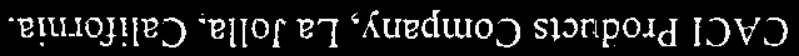

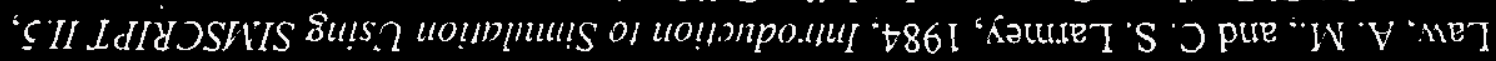

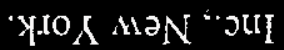

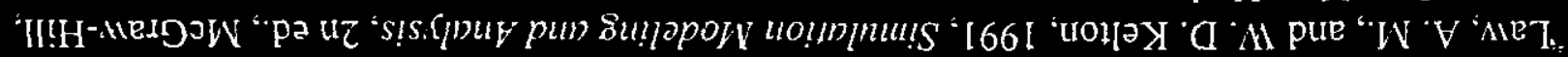

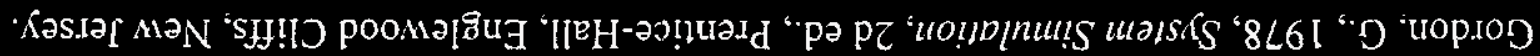

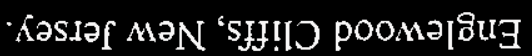

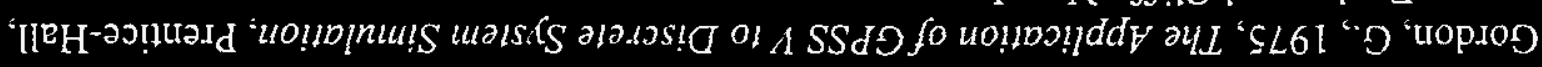

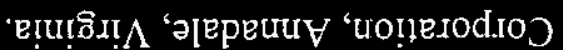

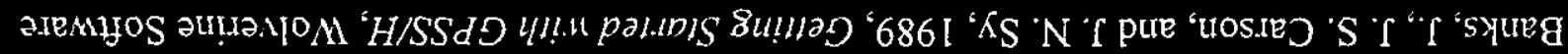
SGDNGYGHTH

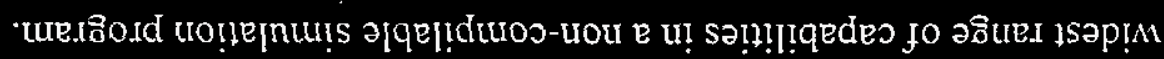

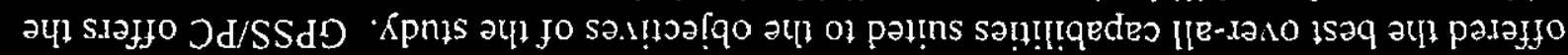

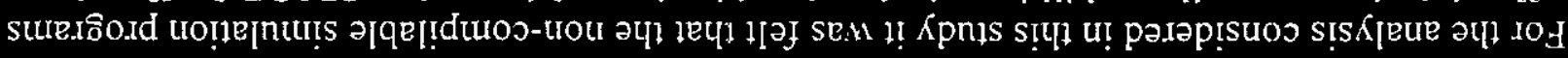

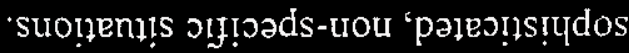

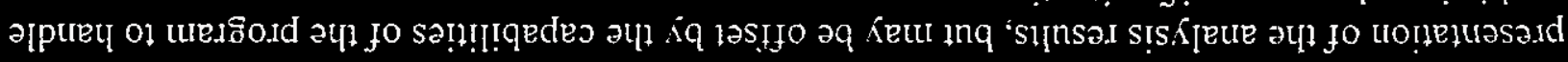

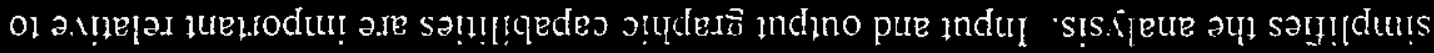

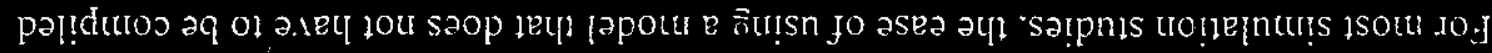

- wo!nenjesə

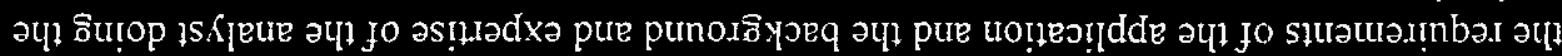

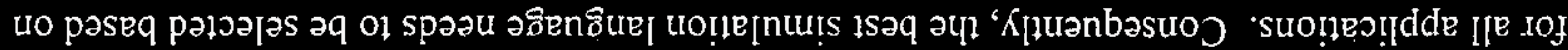

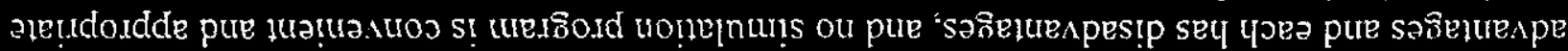

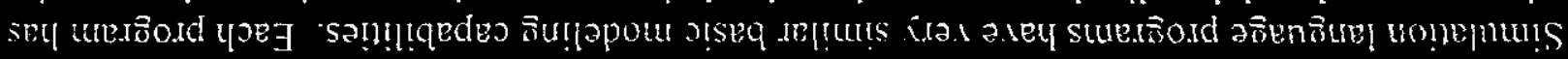

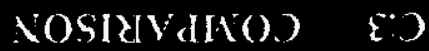

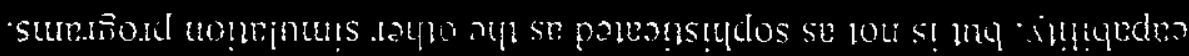

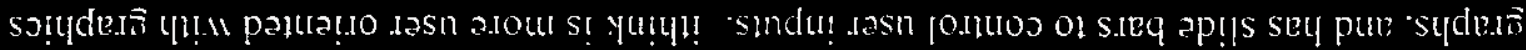

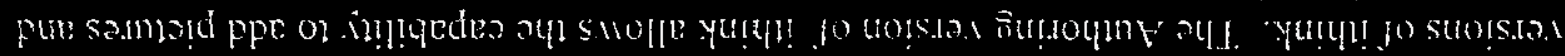

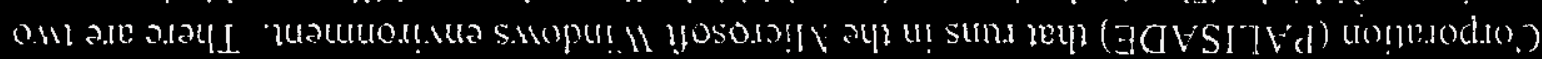

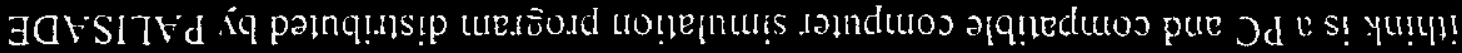


PALISADE Corporation, ithink, distributed by PALISADE Corporation, Newfield, New York for High Performance Systems, Hanover, New Hampshire.

Pegden.. C. D. R. P. Sadowski. and R. F. Shannon. 1990. Introhuction to Simulktion Lising S7l.t.l. Systems Modeling Corporation. Sewichle!. Pennsyliania.

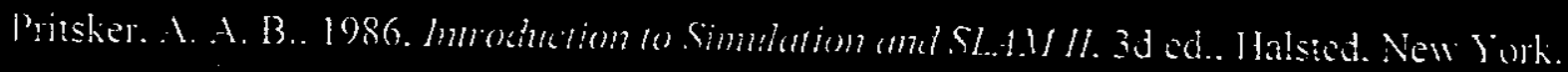


Appendix D - Simulation Model Basis and Program Listings

D-1 


\section{APPENDIX D}

\section{SIMULATION MODEL BASIS AND PROGRAM LISTINGS}

\section{1 Basis for Waste Generator Volume Distributions}

Ranking Waste Gencrator Contributions to Total Waste Volumes

The following ranking of " aste generators. by rolume. was performed using data from the OWVP. Rev. 20\%2. (HHC 1905a) befor ONVP. Rev. 21 (H HC 1995b) was arailable.

From the summary table Appendix 3. Attachment 5 of Rev. 201\%. the total new rolumes for each identified waste stream (for the period 1995-2006) were calculated and ranked by contribution to the 12-year total.

$\begin{array}{llll}\text { Salt well liquid (SWL) } & 25.04 \% & \text { AZ-101 Tank Washing } & 4.02 \% \\ \text { SST Solids (salt cake) } & 24.09 \% & \text { B-Plant + B-Plant TCO } & 3.77 \% \\ \text { Fac. Gen+S WL+X-site Flushes } & 10.58 \% & \text { Evaporator Flushes } & 3.37 \% \\ \text { 100N TCO } & 9.97 \% & \text { C-106 Solids Retrieval } & 3.21 \% \\ \text { Tank Farm (raw water use) } & 5.78 \% & \text { All others conbined } & 5.02 \% \\ \text { T-Plant } & 5.16 \% & & \end{array}$

The waste streams which were added in OWVP, Rev. 21 had no relevant distribution information provided in the interview process and, therefore, the "wide triangular distribution" was applied as a reasonable approximation of uncertainty (see description, below).

\section{Waste Volume Distributions Used in the Simulation Code}

The waste volume distributions for the ten largest waste generators from this list were developed from the interview data gathered from the generating organizations.

Distribution for SWL - Estimates of salt cake porosity means historically varied from $35 \%$ to $80 \%$ with the current estimate, based on the R. G. Brown report, WHC-SDW236A-ES-012, Rev. 0, of $61 \%$. Therefore, a triangular distribution was chosen with a minimum value of 35 , a maximum of 80 , and a mode of 61 . In order to apply this relative distribution to varying yearly volumes, the triangular distribution curve was normalized by dividing by the mode. The built-in triangular distribution function provided in the GPSS computer program was used.

Single-Shell Tanks Solids Retrieval - Solids volume should be fairly well known after SWL pumping is completed. Assuming the first tanks to be retrieved are the ones which have already been pumped, the distribution chosen can have a relatively small variance. A narrow, symmetrical triangular distribution was used with the minimum chosen to be 80, the maximum of 120 and a mode of 100 . This distribution was nomalized by dividing by 100 . 
CSTS/SWL Flushes - There was no basis included in the responses solicited for the "Rev. 21" OWVP. The flushes required for the Cross-site Transfer System (CSTS) and SWL are considered for this analysis to be hased on the anticipated number of transfers per year. Therefore. a triangular distribution with a wider variance than that used for the SST Solids. above. is chosen for this instance. This distribution has a miniminn of 50 . a maximum of 150 . a mean of 100 . and 100 in the denominator as a normalization factor.

100N TCO - According 10 interviews. $\mathrm{N}$-Basin has 1.4 million gallons of dilute noncomplexed waste in its pools. The Rer. 201/2 stmmmary table shows 2.5 mgal divided into two y ears. Ret. 21 response documentation shows a possibility of 0 gallons going to the tank farms if (contracted) local evaporation is approved. and a worst case of an additional $200 \mathrm{kgal}$ from the Emergency. Dump Basin having to be included with the 1.4 mgal going to the tank farms. The triangular distribution used to represent this situation has a minimum of 0 , a maximum of $2.5 \mathrm{mgal}+200 \mathrm{kgal}$, and a mode of $2.5 \mathrm{mgal}$ to approximate the number used in Rev. 201/2, for the base-case GPSS model. 2500 is used as a normalization factor.

Tank Farm Internal Transfer Piping Hushes - Notes on the Rev. 21 response documentation indicate that the data provided was not adequate to provide the basis for a concise prediction of raw water used for internal farm flushes. The volume chosen to be used in the OWVP was $10 \mathrm{kgal}$ per month. A triangular distribution with a relatively large variance is chosen for this case. The minimum is chosen to be 50 , the maximum is chosen to be 150 , the mean is 100 , and 100 is used in the denominator as a normalization factor.

T-Plant - Decontamination of Hanford site equipment performed at T-Plant is expected to increase in activity level into the future. The interviews indicated that if T-Plant decontamination activities approached the maximum capacity of the facility, the waste generated would be lower (approx. $50 \mathrm{kgal} / \mathrm{yr}$ ) than the OWVP, Rev. 21 value (showing a maximum of $180 \mathrm{kgal} / \mathrm{yr}$ ). The triangular distribution chosen has a minimum of 50 , a maximum of $200 \mathrm{kgal}$ (only slightly higher than the Rev. 21 value shown), and a mode of $180 \mathrm{kgal}$ to place more emphasis on the officially reported number from Rev. 21. 180 is used as a normalization factor.

AZ-101 Sludge Washing - Washing AZ-101 sludge is shown at $1 \mathrm{mgal}$ in Rev. 201/2, while interviews indicated 3 to $4 \mathrm{mgal}$ to be the more likely volume generated by multiple washes. The triangular distribution minimum is taken to be $800 \mathrm{kgal}$, slightly lower than the value used in Rev. 201/2, the maximum is $4000 \mathrm{kgal}$ (per the maximum indicated in interviews), and the mode is the $1000 \mathrm{kgal}$ used in Rev. 201/2. 1000 is the normalization factor.

Note: In Rev. 21, the in-tank washing volume projection has been reduced to $100 \mathrm{kgal}$. Although the volume is a factor of 10 lower, since the distribution has been normalized. it should still be appropriate to indicate the wide variation in the projected values. 
B-Plant (plant waste generation + TCO) - Only one input stream is used in the GPSS model, where the two are shown separately in the Rev. 21 summary. Baseline, low, and upper projections were provided by B-Plant personnel. It was indicated in the interview that the low could be considered the loth percentile and the upper could be considered the 90 th percentile : alues. The triangalar distribution minimum is $25 \mathrm{hgal}$. whicla th the lower projection for a high volume year. the maximum is the upper projection. and the mode $(60 \mathrm{kgal})$ is the likely projection. 60 is the nomalization factor.

Evaporator Flushes - As indicated in the Rev. 21 responses. there was "taining-run" and miscellaneous water sent to the tank farms every year. Since this has significant uncertainty associated with the estimate. a distribution with a large variance is used. The triangular distribution with a minimum of 50 . a maximum of 150 , a mean of 100 . and normalization factor of 100 is used for this and other waste generators and disposal streams with a large projected variation. In the model, it is termed the "wide triangular
distribution."

C-106 Solids Retrieval - The volume of solids in C-106 is not known precisely, although it should be after sluicing is begun (when most pumpable liquid is removed. an early step in the sluicing process). Since working fluid is recirculated (after initial charging) the liquid addition should be a known quantity. The charging fluid (treated raw water) volume was not included in the Rev. 21 summary, because the decision to add it was made afterward. A triangular distribution showing the possibility of liquid addition is used with a minimum of 700 , slightly less than the value in the Rev. 21 summary, a maximum of 1600 , or double the Rev. 21 value to show the water addition, a mode of 800 , from the Rev. 21 summary, and a normalization factor of 800 .

Other Waste Generators - Using the waste generator ranking based on Rev. $201 / 2$, the generators other than top 10 contributors listed, account for only $5 \%$ of the total and are included in the model without an associated distribution being applied. Variations in these values should not significantly affect the results and can be applied later if thought to be warranted. The additional waste streams included in Rev. 21 were all considered significant and were incorporated into the simulation model with the "wide triangular
distribution" applied.

\section{D.2 Basis for Model Assumptions}

The following waste volumes were used in the simulation model programming to separate the three key waste streams to promote a better understanding of when capacity limits were being
appoached or exceeded.

All values are in kilogallons.

\section{D.2.1 Complexed Waste}

Initial Inventory: 


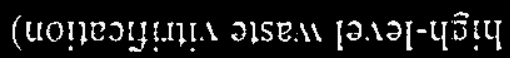

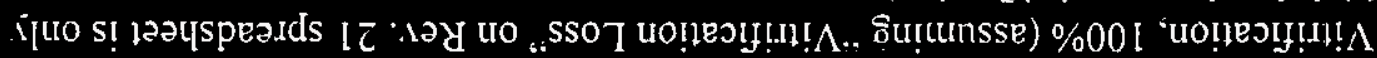

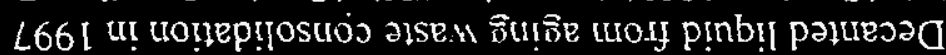

:sureans indino

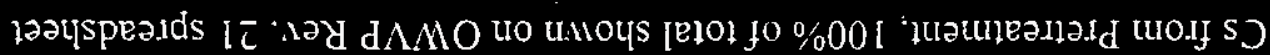

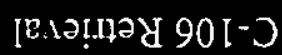

:stuea.luS induI

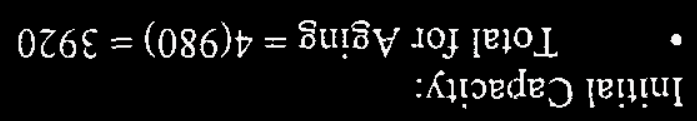

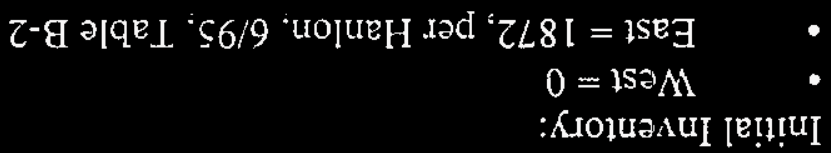

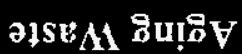

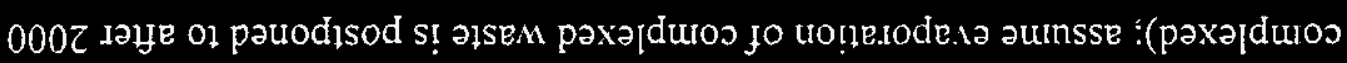

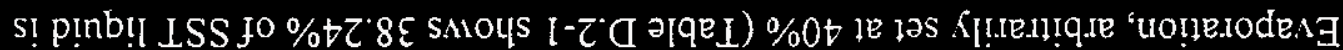

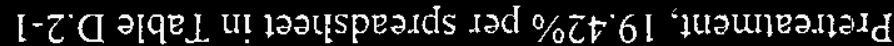

:surearis indino

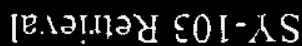

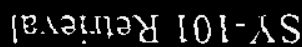

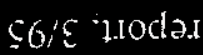

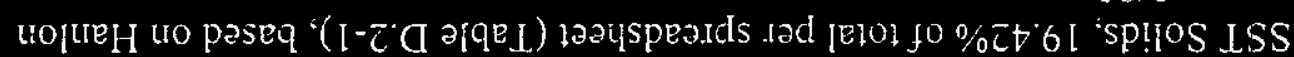

(IZ ^əу ' d $\Lambda$ MO u! pəpnjout)

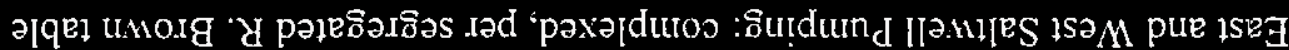

:surea.IS InduI

a.me.nashoj St yumi

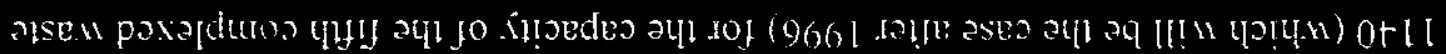

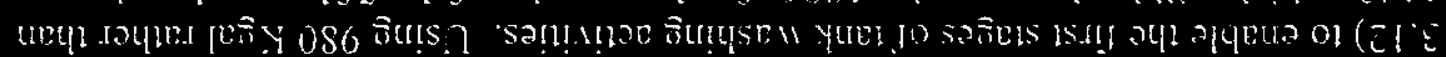

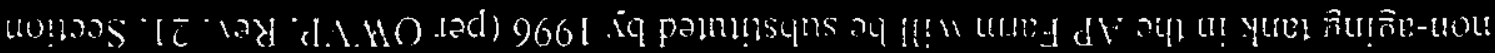

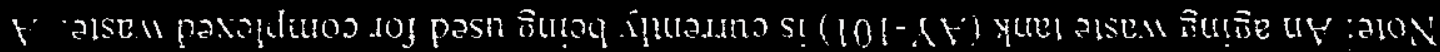

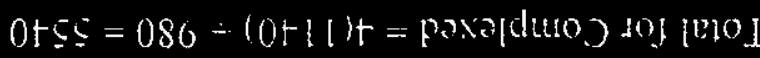

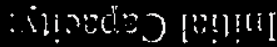

$$
\begin{aligned}
& \mathrm{I} L 0 \Omega=\$ \varsigma 8 \mathrm{I}-9 \mathrm{Z} 6 \mathrm{t}=1 \mathrm{~S} \Omega \mathrm{J} \mathrm{U}
\end{aligned}
$$

Z-g әqqe L ' $\$ 6 / 9$ '( 


\section{Table D.2-1}

\section{Liquid/Solid Fraction in Complexed Waste SSTs}

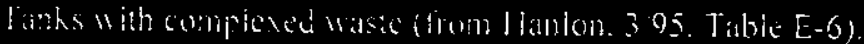

Also Watch L isi hans 1 oreanic salts (Table $A-t$ ).

SSTS

West Watch Type Total Liquid Total-1.ic

$x$ DSSF

S-111 X Ncply

$\mathrm{SX}-101$

$\mathrm{SX}-101$

DC

SX-103 X NcplX

SX-106 X Ncplx

T-111.X

TX-105 $X$

TX-118 $\quad X$

TY-104 X

U- $103 \quad X$

U-105 X

U-106 X

U-107 X

U-1I] $X$

$\mathrm{U}-203$

U-204 X

16
Ncplx

Ncplx

Nicplx

Ncpls

Ncplx

Ncplx

DSSF

DSSF

Ncplx

Ncplx
Ncplx

549

506

456

$456 \quad 146$

$652 \quad 233$

$538 \quad 255$

379

42

$609 \quad 20$

$347 \quad 27$

46

468

418

226

$406 \quad 178$

$329 \quad 122$

\begin{tabular}{rrr}
3 & 1 & 2 \\
3 & 1 & 2 \\
\hline 6025 & 1926 & 4099
\end{tabular}

Fast

Watch Type Total Ligud Tumblic

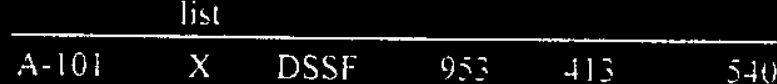

AX-102

AX-103

B-103

C. 102

C. 103

$\mathrm{C} \cdot 107$

$\frac{C-110}{8}$

CC

CC

39

112

Ncplx

59

59

423

195

Ncplx

DC

$\mathrm{DC}$

$\frac{18}{224}$

$275 \quad 11 \quad 264$

589

31

279

239

143

228

207

West Subtotal

$\begin{array}{lll}6025 & 1926 & 4099\end{array}$

East Subtotal

Complexed Total

\begin{tabular}{rrr}
2243 & 658 & 1585 \\
\hline 8268 & 2584 & 5684
\end{tabular}

\begin{tabular}{lrrr} 
& \multicolumn{1}{c}{ Total } & Liquid & Solids \\
\cline { 2 - 4 } Grand Totals, all SSTs & 36028 & 6757 & 29271 \\
C Cmplxd \% of Total & $22.95 \%$ & $38.24 \%$ & $19.42 \%$
\end{tabular}

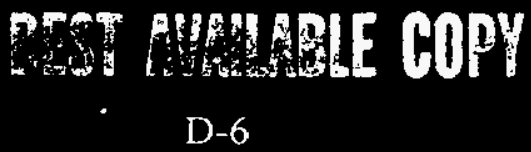




\section{Hog9 Hortatid 1839}

$L-\mathrm{C}$

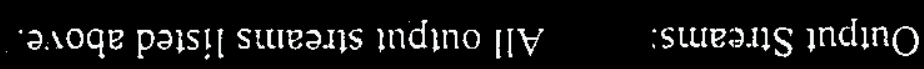

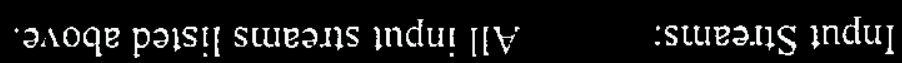

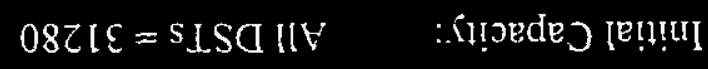

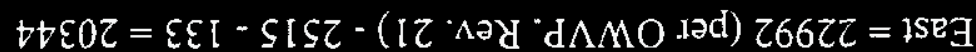

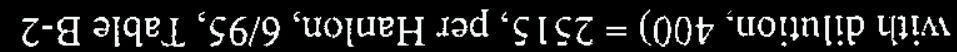

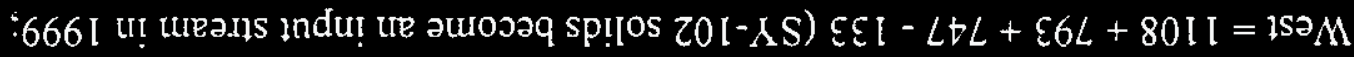

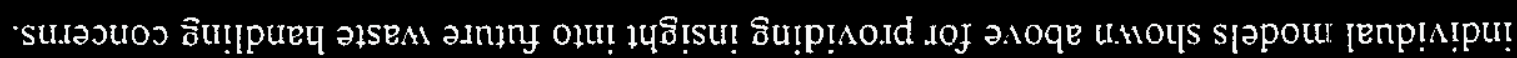

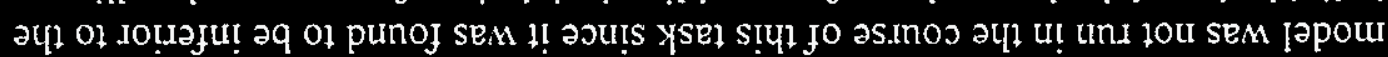

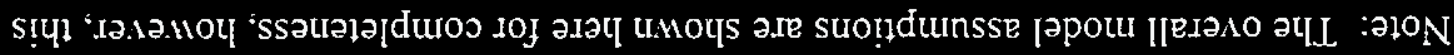

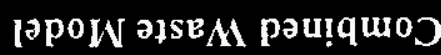

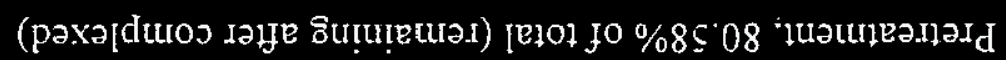

0002

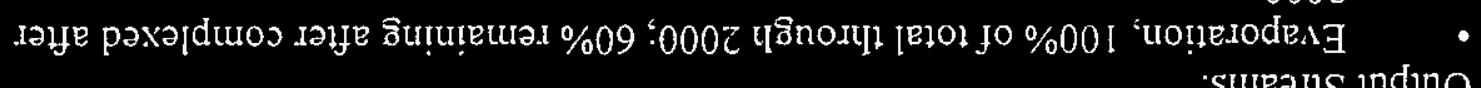

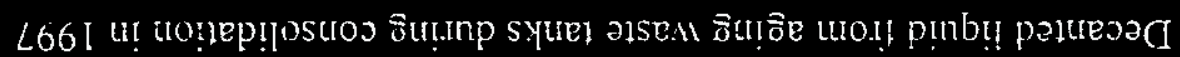

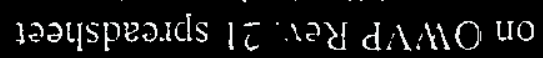

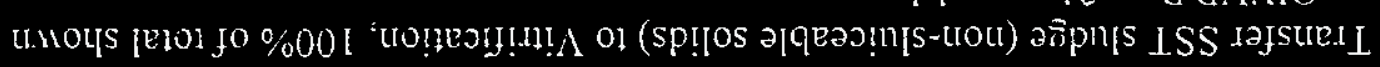

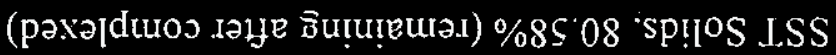
sp!IOS SOI-MV

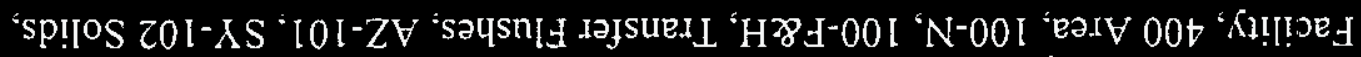

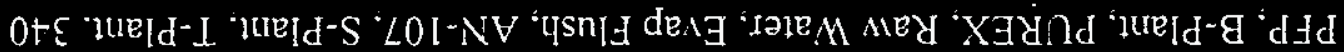

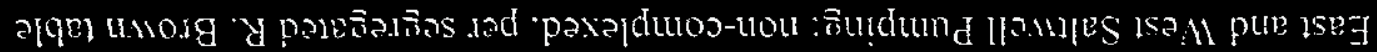
stucans lindul

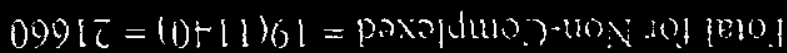

$$
\begin{aligned}
& \text { :irndes jẹtul }
\end{aligned}
$$

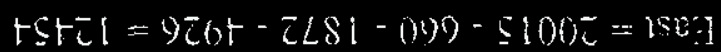

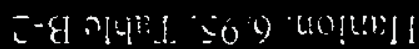

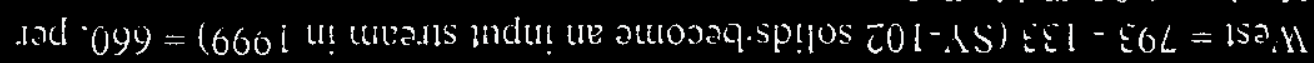




\section{D.3 Assumptions Specifically Relating to OWVP, Rev. 21 Data}

The OWVP. Rev. 21, projections were unclear or inconsistent with interview data in several areas. Therefore. for each inconsistent area. the following assumptions have heen made for use in the simulation madel:

- The assumption made for this task is that "Transfer SST Sludge wo Vitrification" refers to the mostly mobilization water used in the removal of non-sluiccable solids as the last phase of eleanout of the SSTS and is. therefore. dilute non-complexed waste. This is not specifici in the oll'Y'.

- The Evaporator IITR data in OWVP. Rer. 21. Table 10. is assumed to refer wo the 2+2-1 livaporator and has been used as such in the simulation model. The long-term use of the 242-A Evaporator is inconsistent with indications for interviews that there is no more than a ten-year expected life remaining.

- It is assumed that the "Pretreatment Loss" in Table 10 refers to the waste volume reduction (WVR) from the pretreatment evaporator and the Low-Level Vitrification process. The method of reduction is not specified.

- It is assumed that "Vitrification WVR" refers to High-Level Vitrification. where aging "Waste is the initiaily preferred feed stream.

- Dilution/retrieval volumes for SY-101 and SY-103 are equal to the current volumes shown in Hanlon (WHC 1995d), with implies there is no dilution addition. If dilution water is not accounted for in the DST inventory, this is inconsistent with showing other dilution volumes, such as SY-102 and may be based on an incorrect assumption, that the full amount of dilution water can be evaporated, no net increase. This can add a significant volume and needs to be addressed.

- It appears that the PFP terminal cleanout (TCO) has not been included in OWVP, Rev. 21, Table 10. Implication in the text is that, pending the release of the EIR, the TCO is not "official" and, therefore, has not been included. It was not included in this analysis, however, this appears to be inconsistent with other "planning."

- In OWVP, Table 10, the volumes generated by T-Plant equipment decontamination activities are much higher $(180 \mathrm{kgal} / \mathrm{yr})$ than those indicated as the maximum output of the facility $(50 \mathrm{kgal} / \mathrm{yr}$ ) in interviews by the T-Plant personnel. Although this has minimal impact on total waste volumes, it should be clarified.

- It is assumed that the reason for showing a value of $2160 \mathrm{kgal}$ in Table 10 for the amount of waste associated with $\mathrm{N}$-Basin, rather than the $1.4 \mathrm{mgal}$ of as indicated in interviews, is that an additional volume is included for mobilization. However, it is unclear what the difference is caused by.

- K-Basin waste is not included in Rev.21 data, therefore, none was included in the simulation model. Early indications were that $540 \mathrm{kgal}$ would be included in OW VP. Rev. 21.

- The date the Low Level Pretreatment/Vitrification facility comes on line in the OWVP. Rev. 21. appears consistent with the "Demonstration" plant planned for under the Alternative Acquisition strategy. It is not apparent that the "Demonstration" plant can process the volumes shown in the OWVP. This uncertainty should be investigated.

- The OWVP, Rev. 21, does not identify a list of issues requiring resolution. This type of 
information would serve to maintain management focus.

\section{D.4 GPSS Program Code Listings}

The folkwing listings are the actual CPSS simulation modeling computer cold ased io generate the output which was ploted on the chants included in Section t.1 of the report. The three

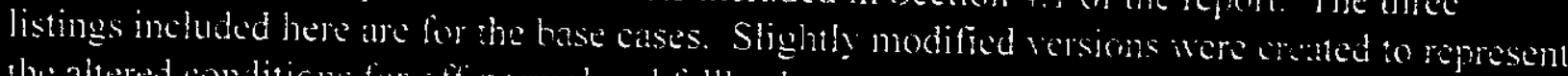
he altered conditions for ofl-nomal and fallback cases.

\section{D.4.1 Aging Waste Model}

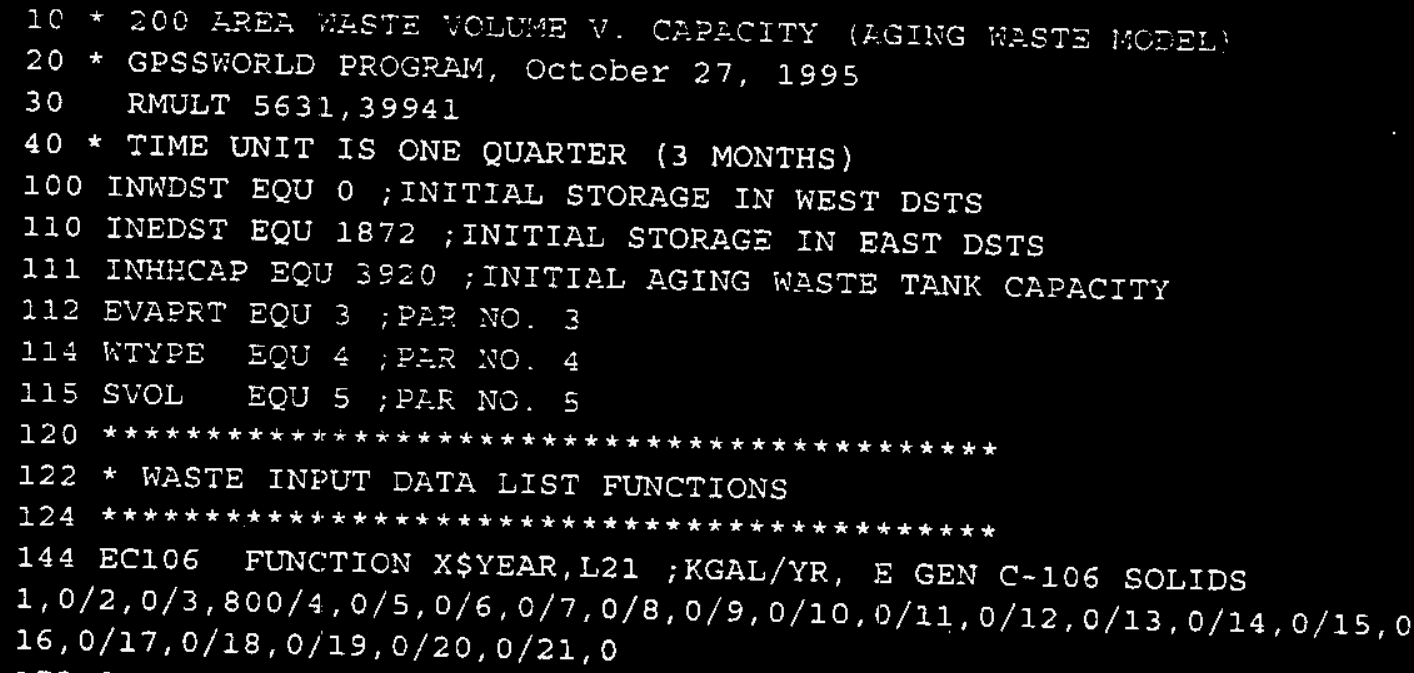

D-9 


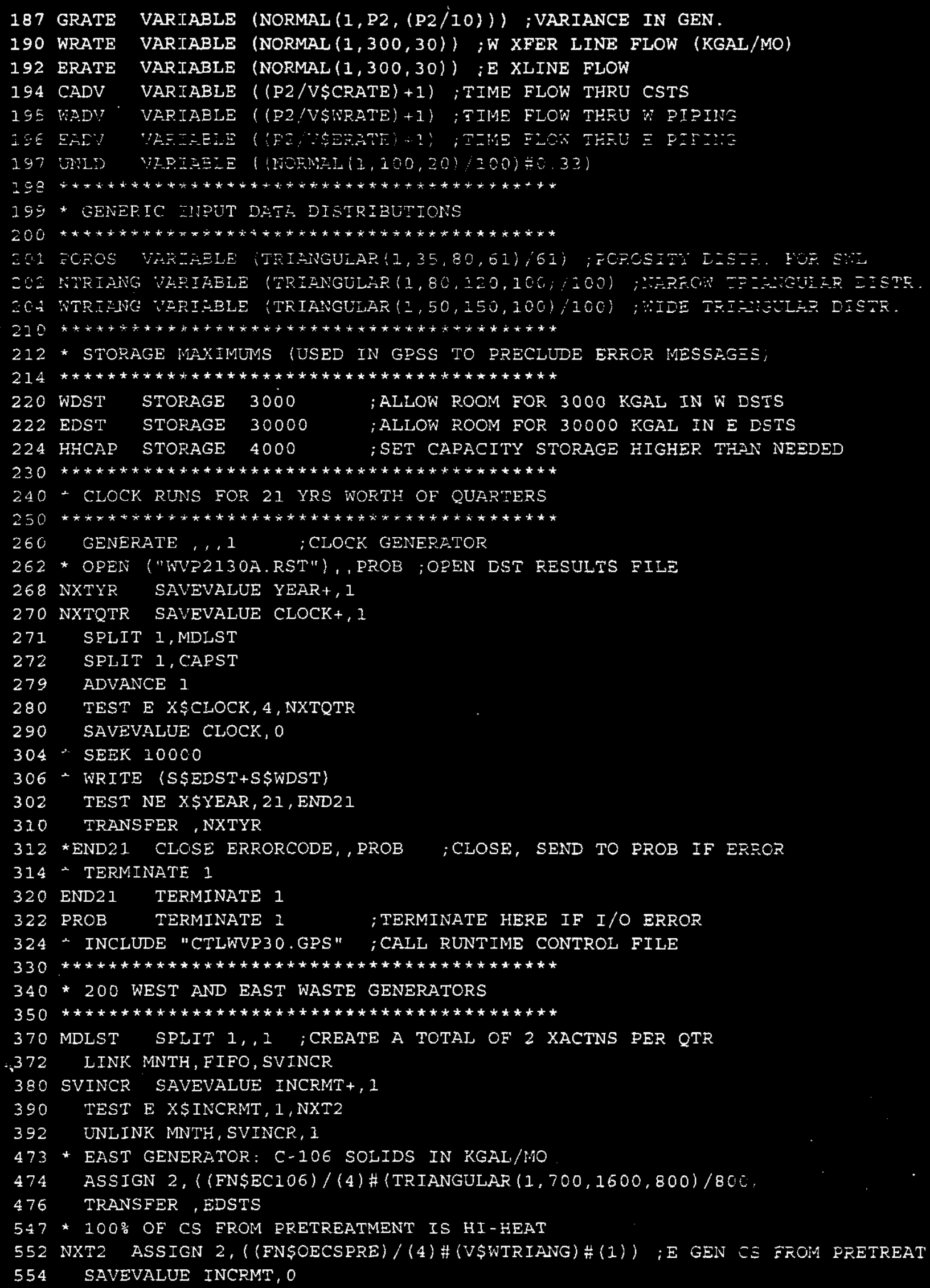




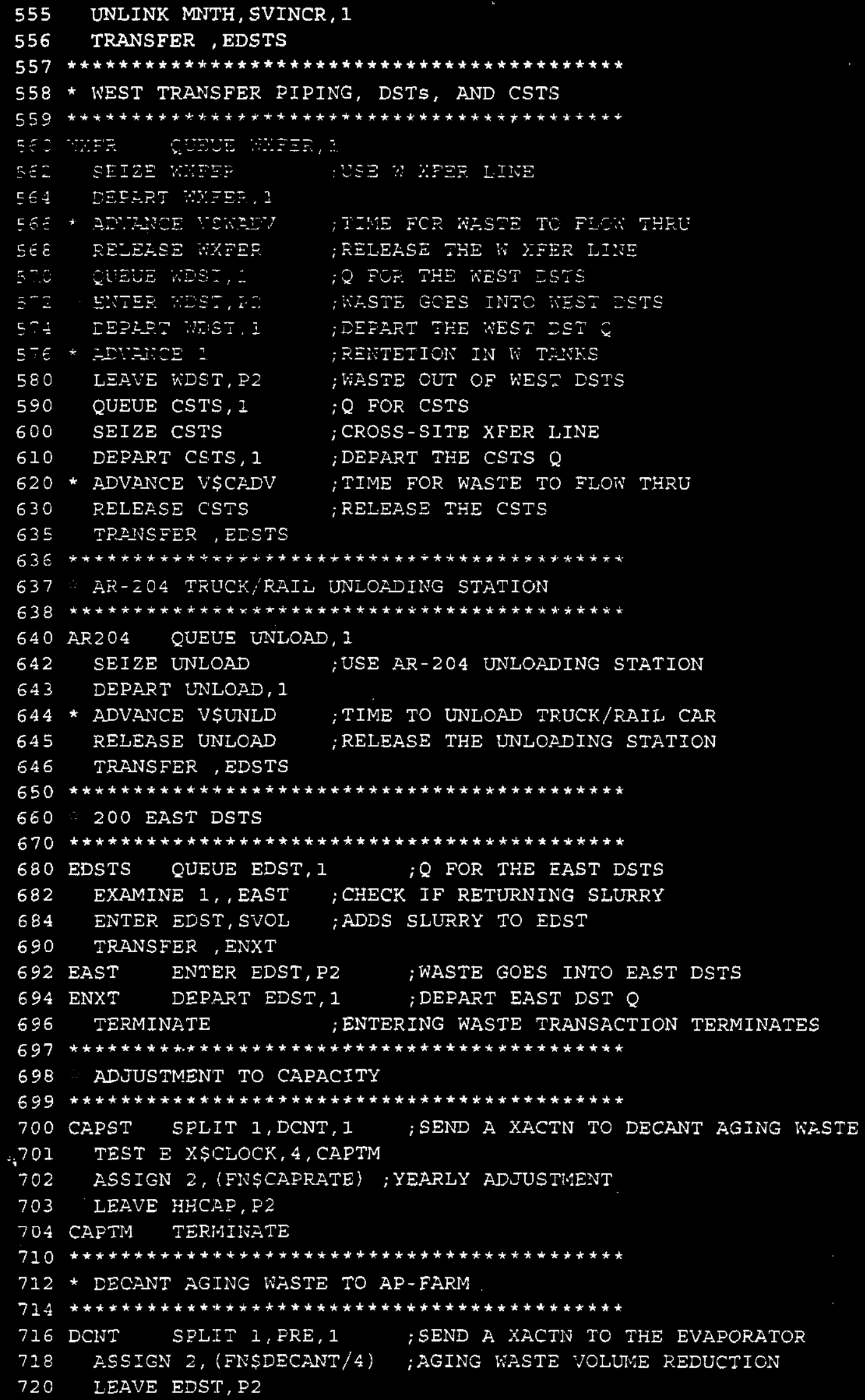

\section{D-11}




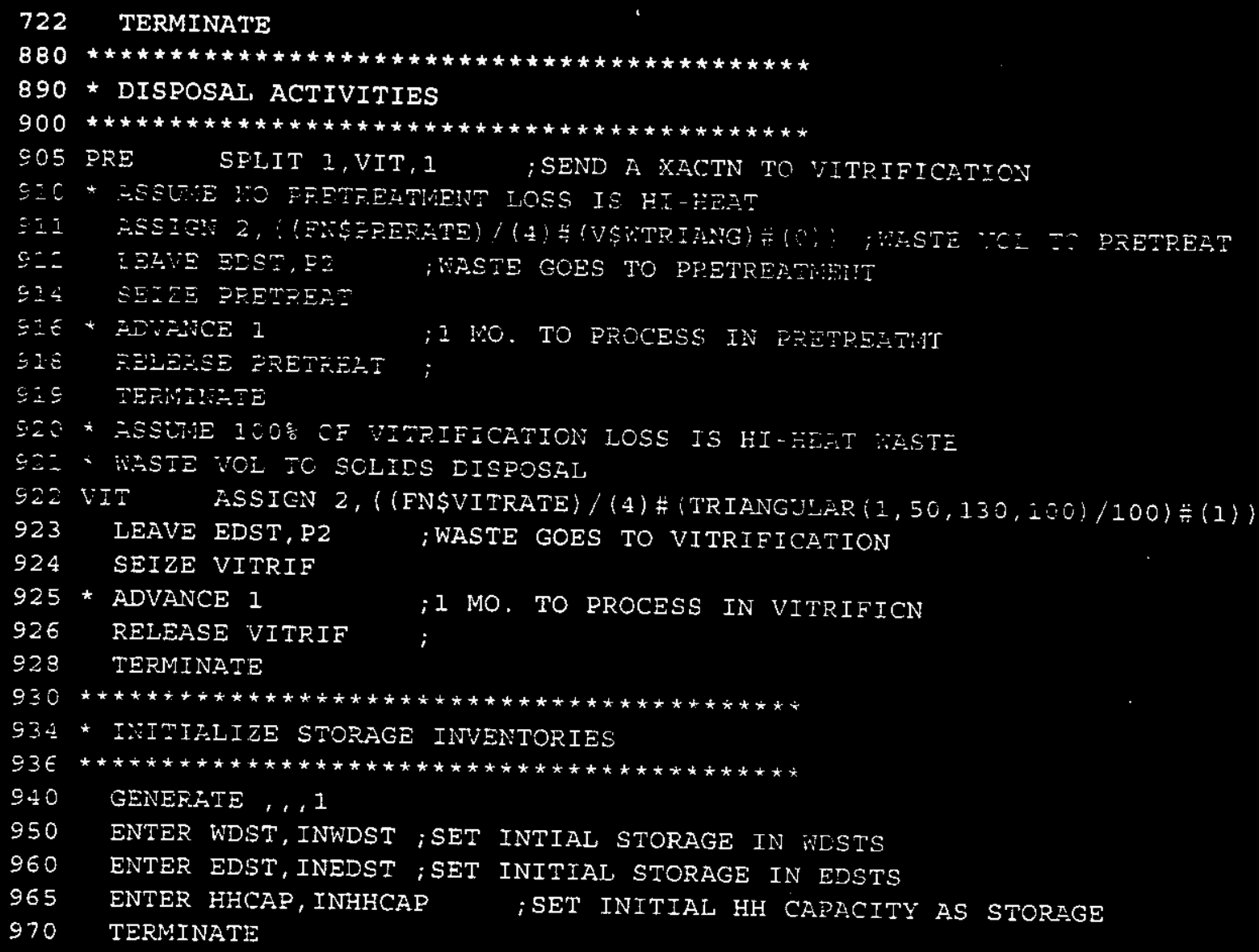

\section{D.4.2 Complexed Waste Model}

10 * 200 AREA WASTE VOLUME V. CAPACITY (COMPLEXED WASTE MODEL)

20 * GPSSWORLD PROGRAM, October 6, 1995

30 RMULT 5631, 39941

40 * TIME UNIT IS ONE QUARTER ( 3 MONTHS)

100 INNDST EQU 1855 ;INIT. STORAGE, WEST DSTS (SY-101\& SY-103)

110 INEDST EQU 3071 iINIT. STORAGE, EAST DSTS (4868-1847)

211 INCMPCAP EOU 5540 ;INITIAL COMPLEXED WASTE TANK CAPACITY

112 EVAPRT EQU 3 ;PAR NO. 3

114 WTYPE EQU 4 ;PAR NO. 4

115 SVOL EQU $5 ;$ PAR NO. 5

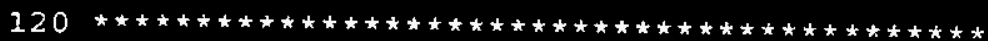

122 * WASTE INEUT DATA IIST FUNCTIONS

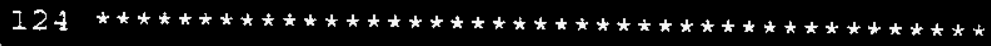

130 WSIL FUNCTION X\$YEAR,L21;KGAL/YR, W SST SALT WELL LIQ $1,0 / 2,39 / 3,483 / 4,641 / 5,237 / 6,18 / 7,0 / 8,0 / 9,0 / 10,0 / 11,0 / 12,0 / 13.0$ $14,0 / 15,0 / 16,0 / 17,0 / 18,0 / 19,0 / 20,0 / 21,0$ 134 ESWL FUNCTION X\$YEAR, L21;KGAL/YR, E SST SALT IVELL LIQ $1,52 / 2,195 / 3,448 / 4,229 / 5,188 / 6,0 / 7,0 / 8,0 / 9,0 / 10,0 / 11,0 / 12,0 / 12: 0$ $14,0 / 15,0 / 16,0 / 17,0 / 18,0 / 19,0 / 20,0 / 21,0$

164 OESOLIDS FUNCTION X\$YEAR, L21; KGAL/YR, OTHER E GEN SST SC:IDS $1,0 / 2,0 / 3,0 / 4,0 / 5,0 / 6,0 / 7,0 / 8,0 / 9,0 / 10,960 / 11,712 / 12,4604 / 13,6744$ $14,11290 / 15,13564 / 16,6044 / 17,8488 / 18,11320 / 19,11444 / 20,12296 / 21,11492$ 166 OWI01SY FUNCTION X\$YEAR, L21;KGAI/YR, OTHER W GEN 101-SY WATCH LIST 
$1,0 / 2,0 / 3,0 / 4,0 / 5,0 / 6,0 / 7,0 / 8,0 / 9,0 / 10,0 / 11,1097 / 22,0 / 13,0$

$14,0 / 15,0 / 16,0 / 17,0 / 18,0 / 19,0 / 20,0 / 21,0$

168 OW103SY FUNCTION X\$YEAR, L21;KGAL/YR, OTHER W GEN $103-$ SY WATCH LIST

$1,0 / 2,0 / 3,0 / 4,0 / 5,0 / 6,0 / 7,0 / 8,0 / 9,0 / 10,748 / 11,0 / 12,0 / 13,0$

$24,0 ! 15,0 / 15,0 / 17,0 / 28,0 / 19,0 / 20,0 / 21,0$

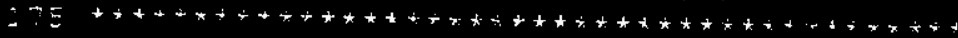

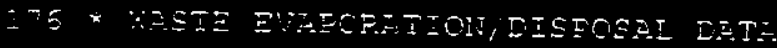

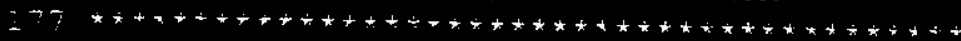

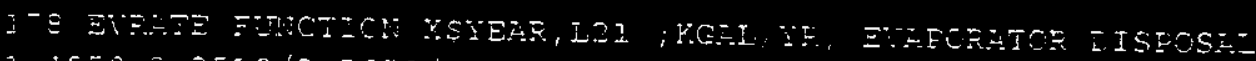

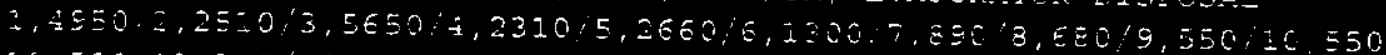

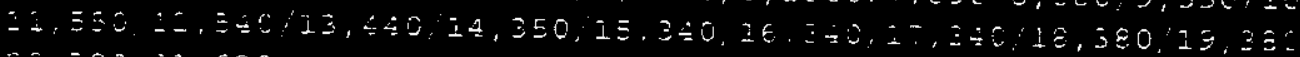

$20, \Sigma \varepsilon: \therefore .620$

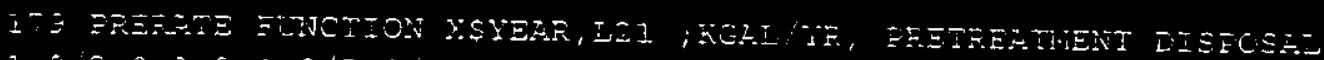

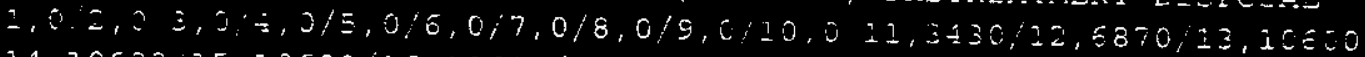

$14,10600, \Sigma E, 10600 / 16,10600 / 17,10620 / 18,10500 / 19,10600 / 20,10600,21,10600$

180 VITRATE FUNCTION X\$YEAR, L21;KGAL/YR, VITRIFICATION DISPOSAL

$1,0 / 2,0 / 3,0 / 4,0 / 5,0 / 6,0 / 7,0 / 8,0 / 9,0 / 10,0 / 11,0 / 12,0 / 13,0 / 14,0 / 15,0$

$16,742 / 17,742 / 18,742 / 19,742 / 20,742 / 21,742$

181 CAPRATE FUNCTION X\$YEAR, L21; USED TO ADUUST CAPACITY

$1,0 / 2,0 / 3,0 / 4,0 / 5,0 / 6,0 / 7,0 / 8,0 / 9,0 / 10,0 / 11,0 / 22,0 / 13,0 / 24,0 / 25,0$

$16,0127,0 / 18,0 / 19,0 / 20,0 / 21,0$

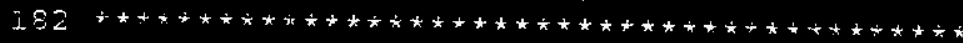

183 * FECW RITE FUNCTIONS FOR FIPING (DEACTIVITED;

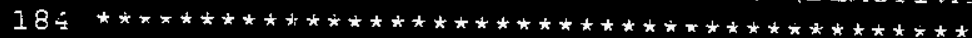

185 CRATE VARIABLE (NORMAL $(1,300,30)$ ) ;CSTS FLON RATE (KGAL/MO)

187 GRATE VARIABLE (NORMAL(1,P2, (P2/10))) ;VARIANCE IN GEN.

188 WRATE VPFIABLE (NORMAL $(1,300,30)$ ) ;W XFER LINE FLON (KGAL/HO)

190 ERATE VAFIABLE (NORMAL $(1,300,30)$ ); $\mathrm{E}$ XLINE FLON

192 CAOV VAFIABLE ((P2/V\$CRATE) +I) ; TIME FLOW THRU CSTS

194 WADV VAFIABLE ((P2/V\$WRATE) +1) ; TIME FLOW THRU W PIPING

195 EADV VAFIABLE ((P2/V\$ERATE)+1); TIME FLOW THRU E PIPING

196 UNLD VARIABLE ((NORMAL $(1,100,20) / 100) \# 0.33)$

197 EPFAIL VARIABLE (NORMAL $(1, .7, .2)$ )

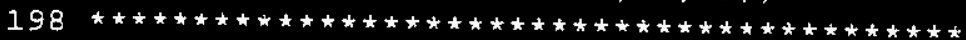

$199 *$ GENERIC INPUT DATA DISTRIBUTIONS

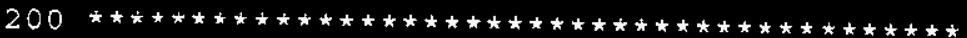

201 POROS VARIABLE (TRIANGULAR $(1,35,80,61$ )/61); POROSITY DISTR. FOR SWL

202 NTRIANG VARIABLE (TRIANGULAR $(1,80,120,100) / 100)$; NARROW TRIANGULAR DISTR.

204 WTRIANG VARIABLE (TRIANGULAR $(1,50,150,100) / 100)$; WIDE TRIANGULAR DISTR.

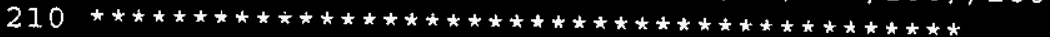

212 * STORAGE MAXIMUMS (USED IN GPSS TO PRECLUDE ERROR MESSAGES)

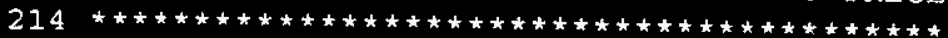

220 WDST STORAGE 3000 ;ALLOW ROOM FOR 3000 KGAL IN W DSTS

222 EDST STORAGE 30000 ;ALLOW ROOM FOR 30000 KGAL IN E DSTS

224 CMPCAP STORAGE 10000 ;SET CARACITY STORAGE HIGHER THEN NEEDED

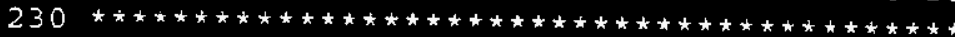

$240 *$ CLOCK RUTNS FOR 21 YRS WORTH OF QUZFTERS

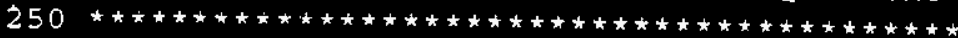

260 GENERATE, , 1. ;CLOCK GENERATOR

262 * OEEN ("WVP2I3OC.RST"), PROB ;OPEN DST RESULTS FILE

268 NXTYR SAVEVALUE YEAR +1

270 NXTQTR SAVEVALUE CLOCK,+ 1

271 SELIT 1, MDLST

272 SPLIT 1 , CAPST

279 ADVANCE ] 


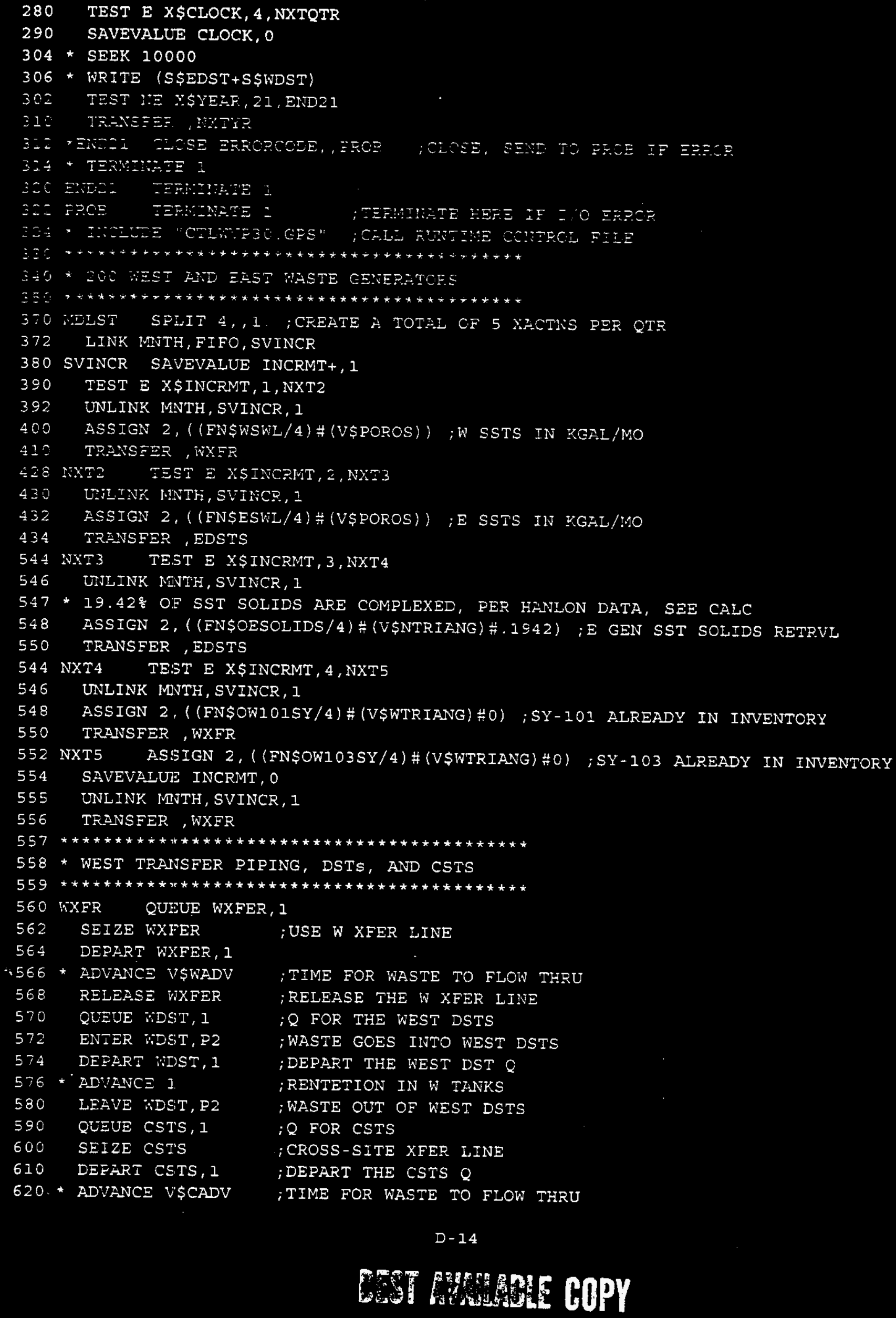




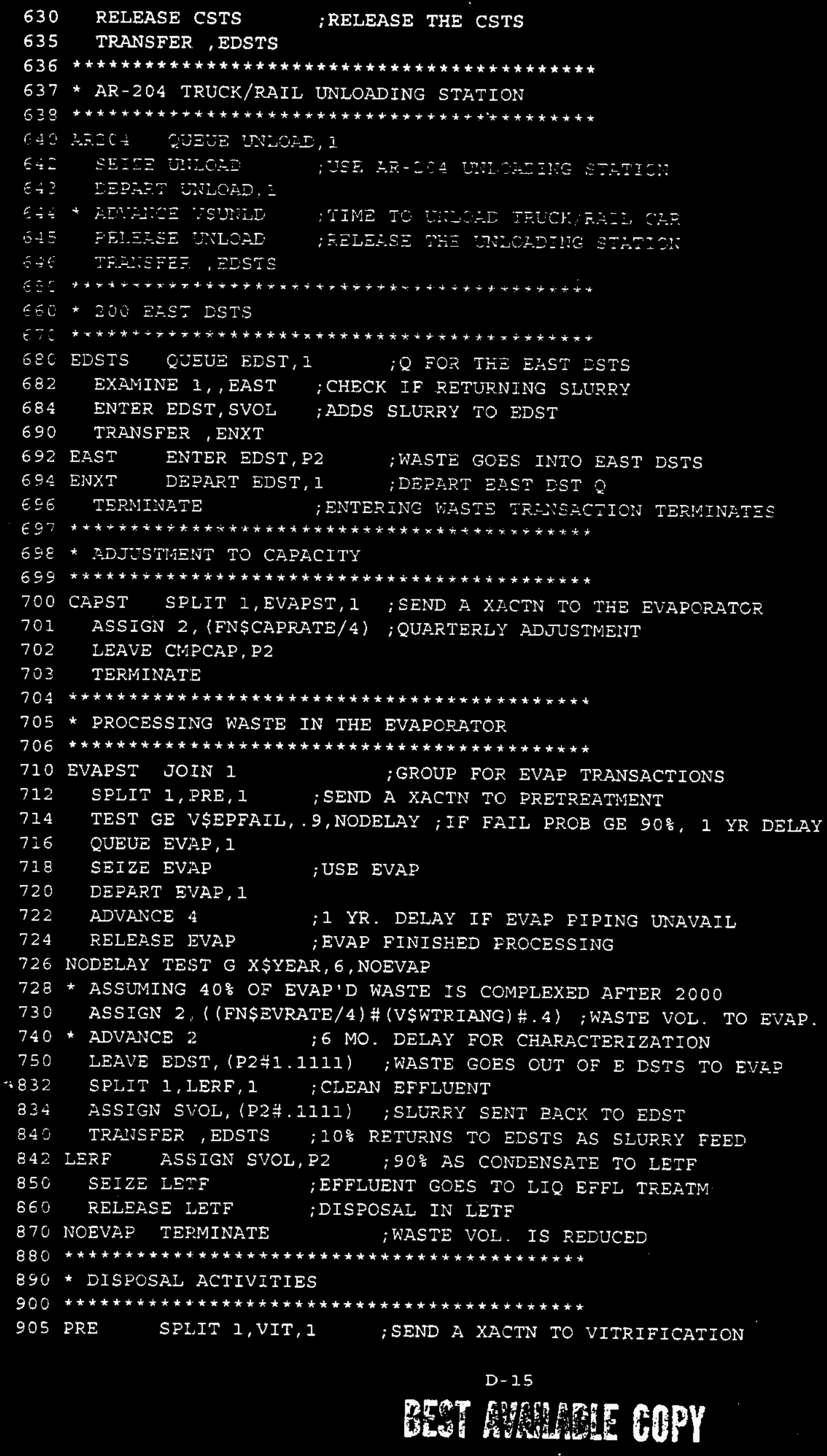




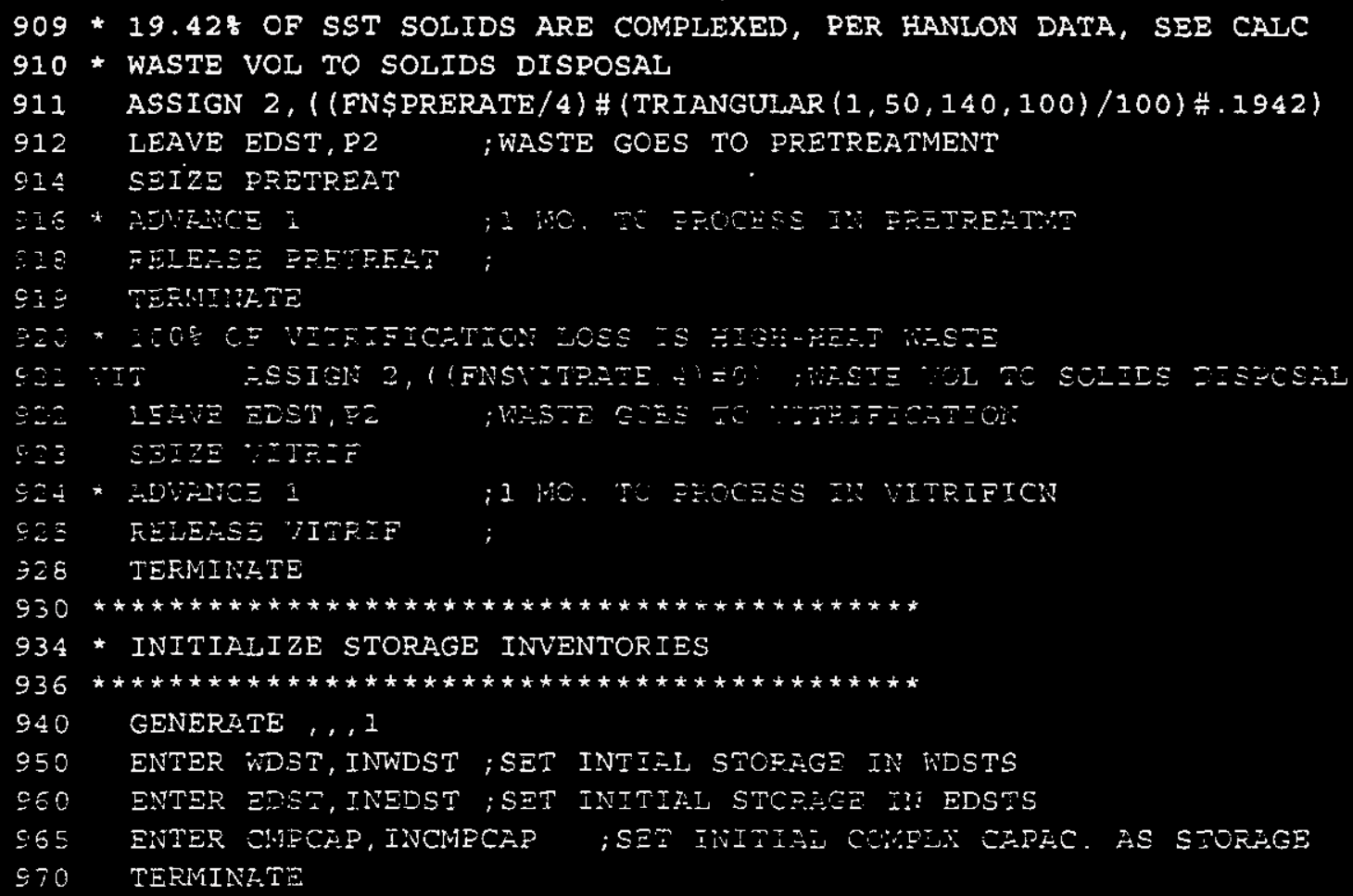

\section{D.4.3 Non-Complexed Waste Model}

(Note: The line numbers were used in a previous version of the program (GPSS-PC), but do not have to be unique in the version used in this analysis (GPSS-World). Therefore, line numbers used more than once ivill not adversely affect the operation of the program.)

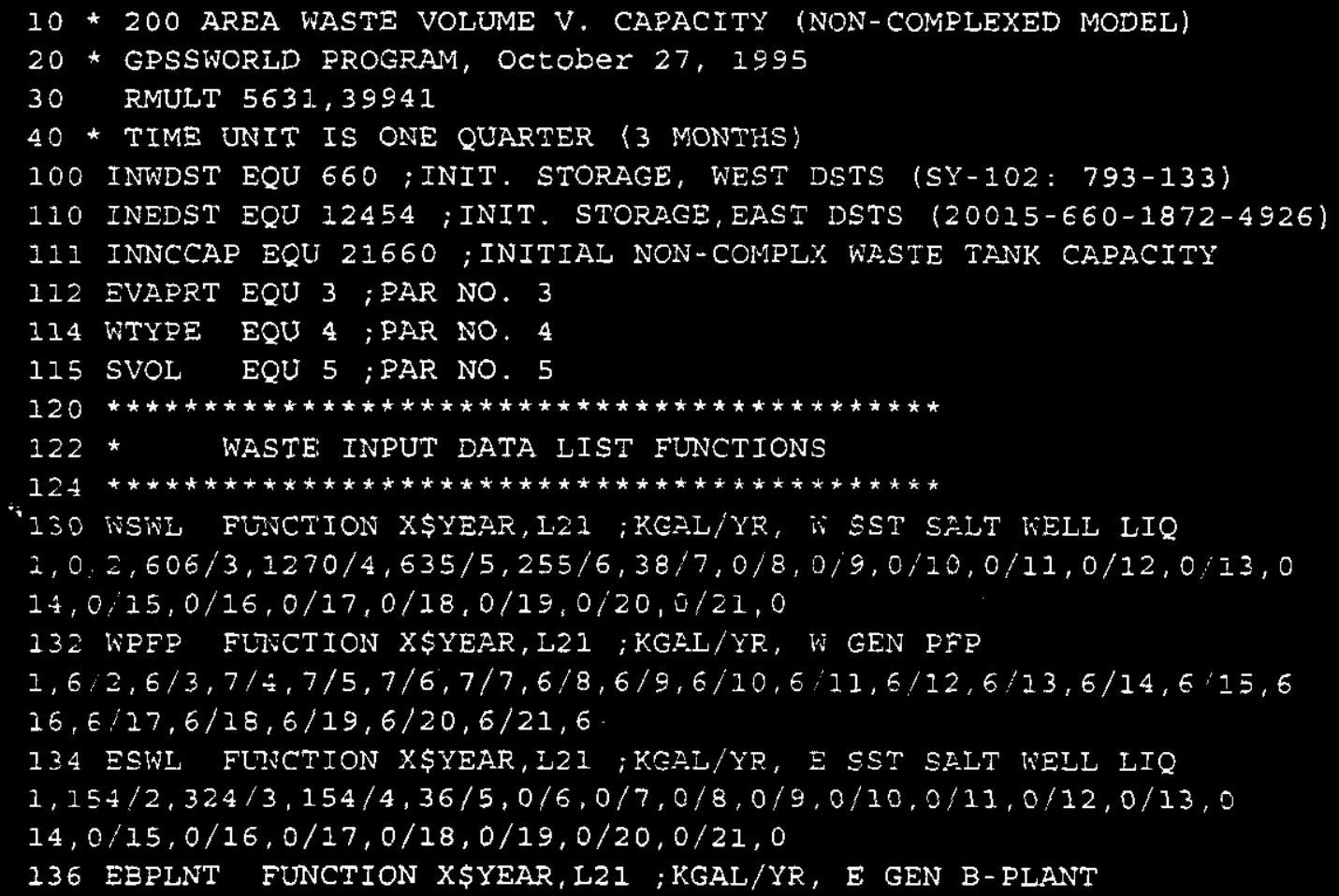

D-16 
$1,60 / 2,60 / 3,159 / 4,159 / 5,159 / 6,159 / 7,159 / 8,5 / 9,5 / 10,5 / 11,5 / 12,5 / 13,5$ $14,5 / 15,5 / 16,5 / 17,5 / 18,5 / 19,5 / 20,5 / 21,5$ 138 EPUREX FUNCTION X\$YEAR,L21;KGAL/YR, E GEN PUREX

$1,460,9 / 2,228.8 / 3,0 / 4,0 / 5,0 / 6,0 / 7,0 / 8,0 / 9,0 / 10,0 / 11,0 / 12,0 / 13,0$

$14,0 / 15,0 / 16,0 / 17,0 / 18,0 / 29,0 / 20,0 / 21,0$

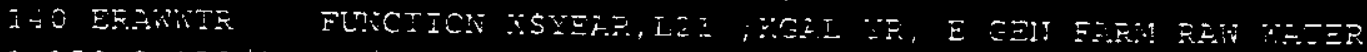

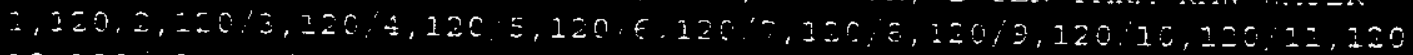

$22,120,13,120 ! 14,120,15,120,10,100,1-120,18,120,19,120,20,12022,120$

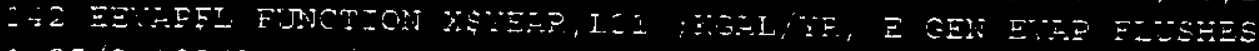

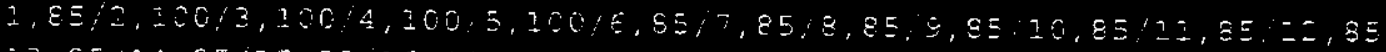

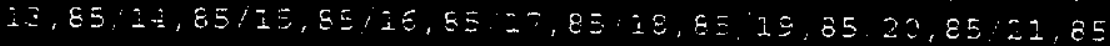

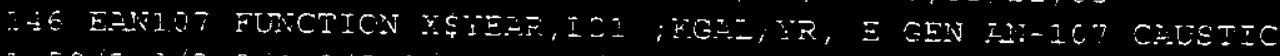

I, 50,2,0,3,0/4,0,5,0/6,0,7,0/8,0,9,0/10,0,11,0/12,0/15,0/14,2, $=5,0$

ZE, 0, I7,0,18,0,15,0/20,0,21,0

İE OESFLNT FUNCTION X\$YEAR, LZI ; KGAL/IR, OTHER E GEN S-PLANI

$1,20 / 2,25 / 3,30 / 4,30 / 5,30 / 6,30 / 7,30 / 8,30 / 9,30 / 10,30 / 11,30 / 22,30 / 13,30$

$14,30 / 15,30 / 16,30 / 17,30 / 18,30 / 19,30 / 20,30 / 21,30$

150 OETPLNT FUNCTION X\$YEAR,L21;KGAL/YR, OTHER E GEN T-PLANT

$1,28 / 2,37 / 3,47 / 4,49 / 5,68 / 6,89 / 7,112 / 8,135 / 9,180 / 10,180 / 11,180 / 12,180$

$13,180 / 14,180,15,180 / 16,180 / 1=, 180 / 18,180 / 19,180 / 20,180 / 21,180$

152 OE340 FUNCTION X\$YEAP, L2I; KGXI/YP, CTFER E GEN 340 ESC

i, $54 / 2,54 / 3,54 / 4,54 / 5,5 \div / 5,54 / 7,54 / 2,54 / 5,54 / 10,54 / 12,54 ! 12,53 / 13,54$

$14,54 / 15,54 / 16,54 / 17,54 / 18,54 ! 19,54 / 20,54 \cdot 21,54$

154 OE400 FUNCTION X\$YEAR, L2I ; KGAL/YR, OTHER E GEN 400 AREA.

$1,6 / 2,6 / 3,6 / 4,6 / 5,6 / 6,6 / 7,6 / 8,6 / 9,6 / 10,6 / 11,6 / 12,6 / 13,6 / 14,6 / 15,6$

$16,6 / 17,6 / 18,6 / 19,6 / 20,6 / 21,6$

156 OE1OON FUNCTION X\$YEAR, L21;KGAL/YR, OTHER E GEN N-EASIN

$1,0 / 2,2160 / 3,0 / 4,0 / 5,0 / 6,0 / 7,0 / 8,0 / 9,0 / 10,0 / 11,0 / 12,0 / 13,0 / 14,0$

$15,0 / 16,0 / 17,0 / 18,0 / 19,0 / 20,0 / 21,0$

158 OEFH FUNCTION X\$YEAR, L21;KGAL/YR, OTHER E GEN 10OFEH

$1,0 / 2,0 / 3,0 / 4,763.2 / 5,360 / 6,0 / 7,0 / 8,0 / 9,0 / 10,0 / 11,0 / 12,0 / 13,0$

$14,0 / 15,0 / 16,0 / 17,0 / 18,0 / 19,0 / 20,0 / 21,0$

160 OEFLUSH FUNCTION X\$YEAR, L21;KGAL/YR, OTHER E GEN FLUSHES

$1,123 / 2,401 / 3,702 / 4,498 / 5,267 / 6,101 / 7,92 / 8,97 / 9,107 / 10,107 / 11,107$

$12,107 / 13,107 / 14,107 / 15,107 / 16,107 / 17,107 / 18,107 / 19,107 / 20,107 / 21,107$

162 OEAZ101 FUNCTION X\$YEAR, L21; KGAL/YR, OTHER E GEN AZ-101 WASH

$1,0 / 2,0 / 3,100 / 4,0 / 5,0 / 6,0 / 7,0 / 8,0 / 9,0 / 10,0 / 11,0 / 12,0 / 13,0$

$14,0 / 15,0 / 16,0 / 17,0 / 18,0 / 19,0 / 20,0 / 21,0$

164 OESOLIDS FUNCTICN X\$YEAR, L21;KGAL/YR, OTHER E GEN SST SOLIDS

$1,0 / 2,0 / 3,0 / 4,0 / 5,0 / 6,0 / 7,0 / 8,0 / 9,0 / 10,960 / 11,712 / 12,4604 / 13,6744$

$14,11290 / 15,13564 / 16,6044 / 17,8488 / 18,11320 / 19,11444 / 20,12296 / 21,11492$

166 AGINGDEC FUNCTION X\$YEAR, L21;KGAL/YR, OTHER W GEN $102-S Y$ SOLIDS

$1,0 / 2,0 / 3,647 / 4,0 / 5,0 / 6,0 / 7,0 / 8,0 / 9,0 / 10,0 / 11,0 / 12,0 / 13,0$

$14,0 / 15,0 / 16,0 / 17,0 / 18,0 / 19,0 / 20,0 / 21,0$

;70 OW102SY FUNCTION X\$YEAR, L21;KGAL/YR, OTHER W GEN 102-SY SOIIDS

$1,0 / 2,0 / 3,0 / 4,0 / 5,400 / 6,0 / 7,0 / 8,0 / 9,0 / 10,0 / 11,0 / 12,0 / 13,0$

$14,0 / 15,0 / 16,0 / 27,0 / 18,0 / 19,0 / 20,0 / 21,0$

271 OEIO5AW FUNCTION X\$YEAR, L21; KGAL/YR, OTHER E GEN $105-$ AW SOLIDS

$1,0 / 2,0 / 3,0 / 4,0 / 5,1148 / 6,0 / 7,0 / 8,0 / 9,0 / 10,0 / 11,0 / 12,0 / 13,0$

$14,0 / 15,0 / 16,0 / 17,0 / 18,0 / 19,0 / 20,0 / 21,0$

172 OECSPRE FUNCTION X\$YEAR,L21;KGAL/YR, OTHER E GEN CESIUM PRETPEAT

$1,0 / 2,0 / 3,0 / 4,0 / 5,0 / 5,0 / 7,0 / 8,0 / 9,0 / 10,0 / 11,200 / 12,200 / 13,200$

$14,200 / 15,200 / 16,200 / 17,200 / 18,200 / 19,200,20,200 / 21,200$

173 OEVITXFR FINNCTION X\$YEAR,L2I;KGAL/YR, OTHER E GEN SLUDGE to VIT

D-17

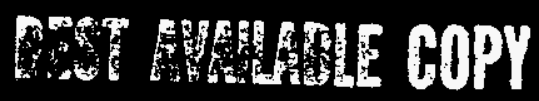


$1,0 / 2,0 / 3,0 / 4,0 / 5,0 / 6,0 / 7,0 / 8,0 / 9,0 / 10,0 / 11,0 / 12,0 / 13,0$

$14,0 / 15,0 / 16,0 / 17,0 / 18,2514 / 19,0 / 20,205 / 21,1190$

174 OEDSTDLN FUNCTION X\$YEAR, L21;KGAL/YR, OTHER E GEN DILUTE DST WASTE

$1,0 / 2,0 / 3,0 / 4,0 / 5,0 / 6,0 / 7,0 / 8,0 / 9,0 / 10,0 / 11,0 / 12,2398 / 13,2537$

$11,171 / 15,0 / 25,0 / 17,0 / 18,0 / 19,0 / 20,0 / 21,0$

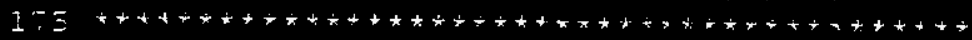

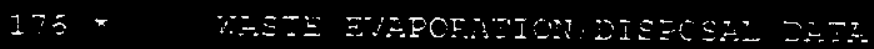

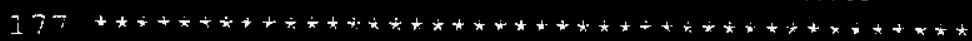

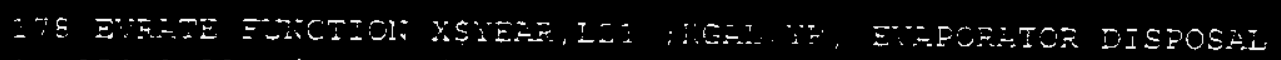

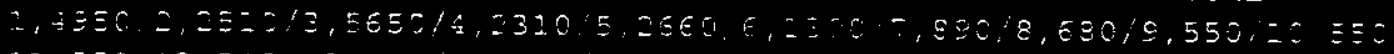

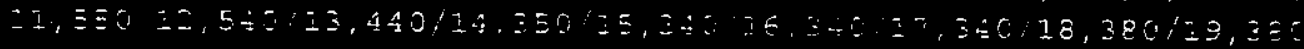

$20,3 \leq 0=2, \varepsilon=0$

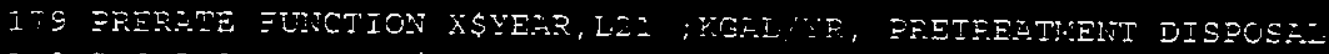

$1,0,2,0,3,0,4,0,5,0 / 6,0,7,0,2,0,5,0,10,0,12,3430 / 12,6870 / 13,2: 550$

$14,10600 / 15, \pm 0600 / 16,10600 / 17,10620 / 15,20600 / 19,10600 / 20,10600,21,14600$

180 VITRATE FUNCTION X\$YEAR, L21;KGAL/YP, VITRIFICATION DISFOSEI.

$1,0 / 2,0 / 3,0 / 4,0 / 5,0 / 6,0 / 7,0 / 8,0 / 9,0 / 10,0 / 11,0 / 12,0 / 13,0 / 14,0 / 15,0$

$16,742 / 17,742 / 18,742 / 19,742 / 20,742 / 21,742$

181 CAPRATE FUNCTION X\$YEAR, L21 ;USED FO ADUUST CAPACITY

$1,0 / 2,0 / 3,0 / 4,0 / 5,0 / 6,0 / 7,0 / 8,0 / 9,0 / 10,0 / 21,0 / 12,0 / 13,0 / 14,0 / 15,0$

$16,0 / 17,0 / 18,0 / 29,0 / 20,0 / 21,0$

$182 * * * * * * * * * * * * * * * * * * * * * * * * * * * * * * *+* * * * * * * * * *$

183 * FLON RATE FUNCTIONS FOR FAPING IDEACTIVATED;

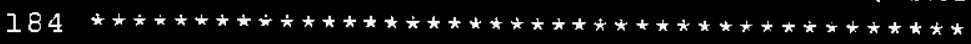

185 CRATE VERIABLE (NORMAL $(1,300,30)$ ) ;CSTS FLOW RATE (KGAL/MO)

387 GRATE VARIABLE (NORMAL $(1, \mathrm{P} 2,(\mathrm{P} 2 / 10))$ ) ;VARIANCE IN GEN.

188 WRATE VZRIABLE (NORMAL $(1,300,30)$ ) ; W XFER LINE FLOW (KGAL/MO)

190 ERATE VLRIABLE (NORMAL $(1,300,30)$ ) ;E XIINE FLOW

192 CADV VARIABLE ((P2/V\$CRATE)+I) ; TINE FLOW THRU CSTS

194 WADV VLRIABLE ( $22 /$ V\$WRATE $)+1)$; TIME FLOW THRU W PIPING

195 EADV VARIABLE ((P2/V\$ERATE) +1) ; TIME FLOW THRU E PIPING

196 UNLD VARIABLE ((NORMAL $(1,100,20) / 100) \# 0.33)$

197 EPFAIL VARIABLE (NORMAL $(1, .7, .2)$ )

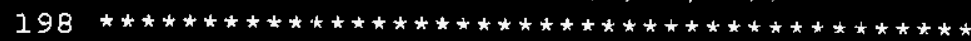

199 * GENERIC INPUT DATA DISTRIBUTICNS

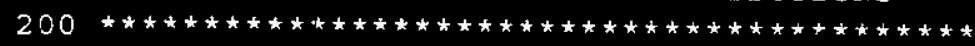

201 POROS VZRIABLE (TRIANGULAR $(1,35,80,61) / 61$ ) ; POROSITY DISTR. FOR SWI

202 NTRIANG VARIABLE (TRIANGULAR $(1,80,120,100) / 100)$;NARROW TRIINGULAR DISTR.

204 WTRIANG VIRIABLE (TRIANGULAR $(1,50,150,100) / 100)$;WIDE TRIENGULAR DISTR,

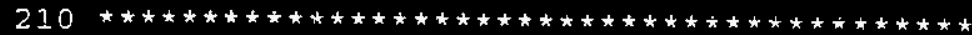

212 STORAGE MAXIMUMS (USED IN GPSS TO PRECLUDE ERROR MESSAGES)

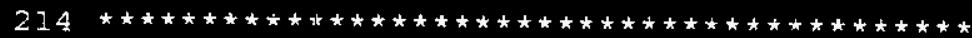

220 WDST STORAGE 3000 ;ALLOW ROOM FOR 3000 KGAL IN W DSTS

222 EDST STORAGE 30000 ;ALLOW ROOM FOR 30000 KGAL IN E DSTS

.224 NCCAP STORAGE 30000 iSET CAPECITY STORAGE HIGHER THE NEEDED

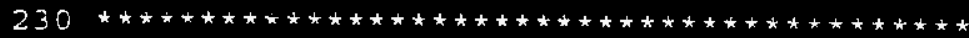

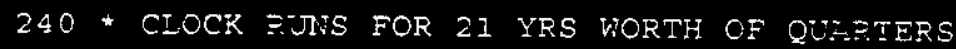

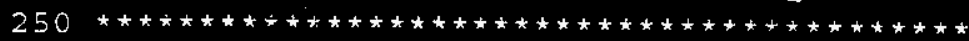

260 GENERAI: , , 1 ; CLOCK GENERATOR

262 * OFEN ("WVP2130N.RST"), RROB ;OPEN DST RESULTS FILE

268 NYTY? SEIVVAUE YEAR,+ 1

270 NXTCTR SAVEVALUE CLOCK+, 1

271 SPIIT 1 , MILLT

272 SFIIT I, CAPST

D-18 


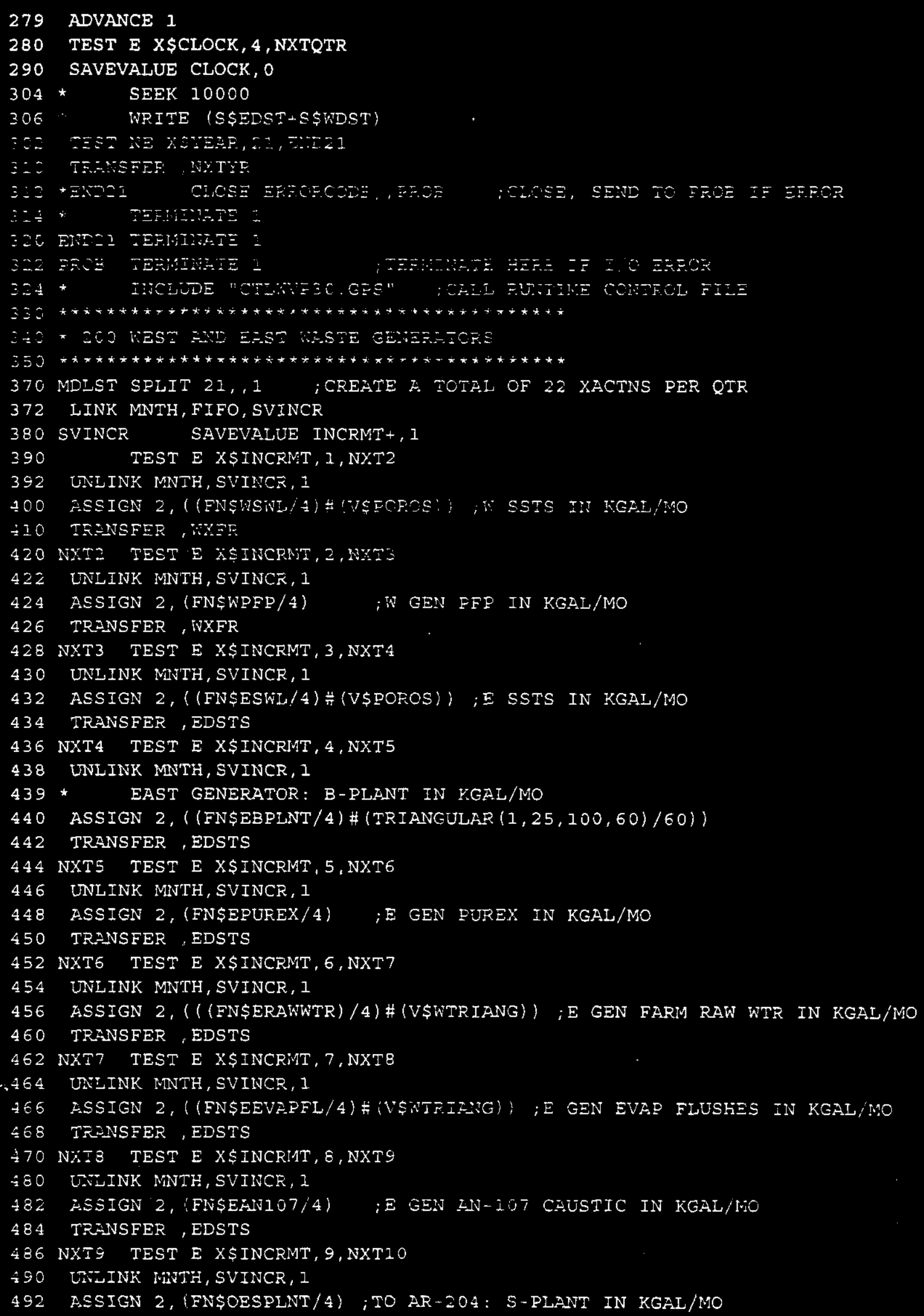




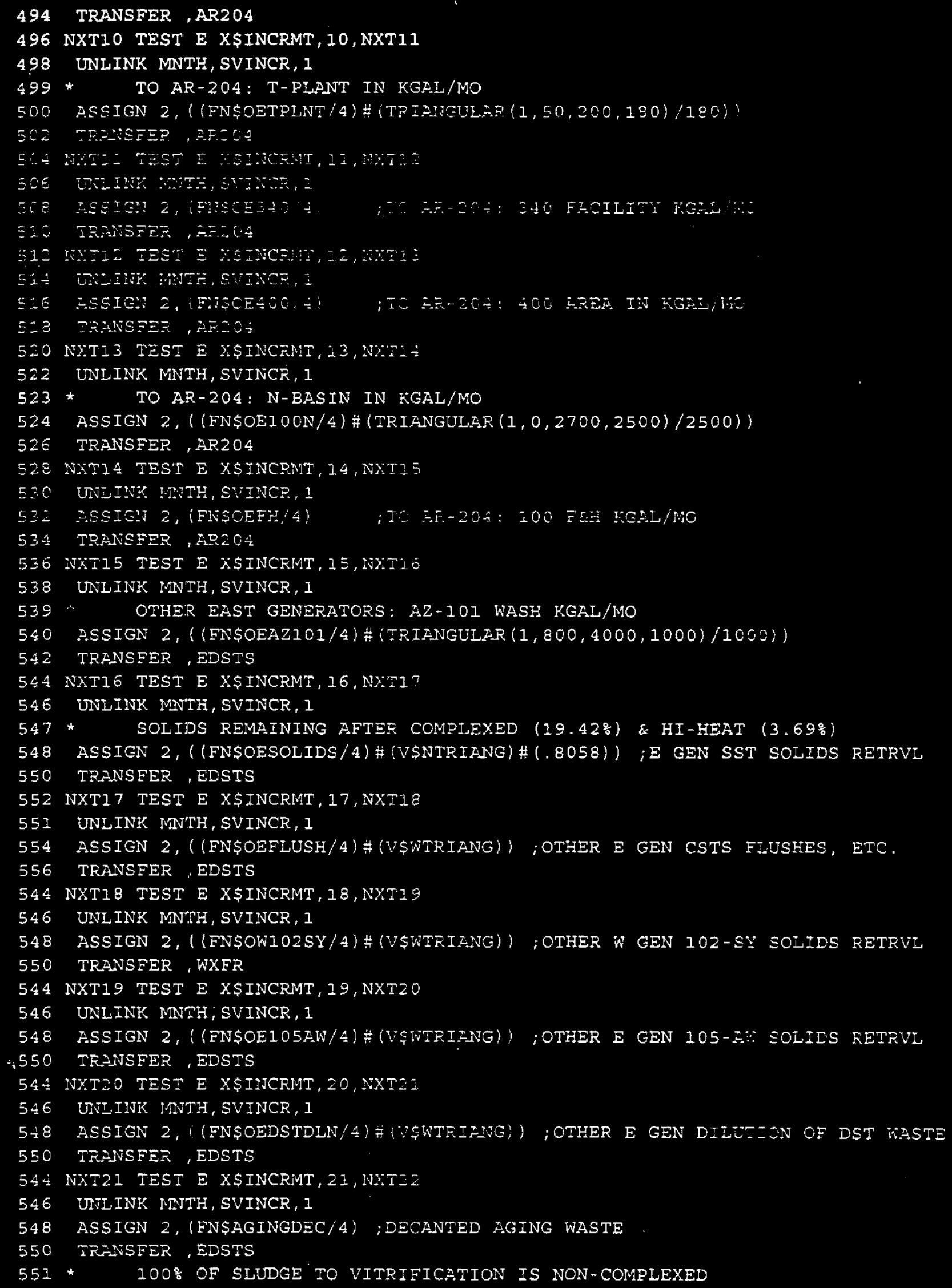


552 * OTHER E GEN SST SLUDGE TO VITRIFICATION

553 NXT22 ASSIGN 2, ((FN\$OEVITXFR)/(4)\# (V\$WTRIANG) \# (1))

554 SAVEVALUE INCRMT, 0

555 UNLINK MNTH, SVINCR, 1

556 TRANSFEP. , EDSTS

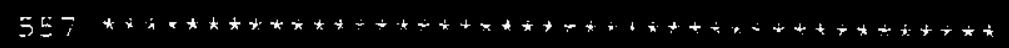

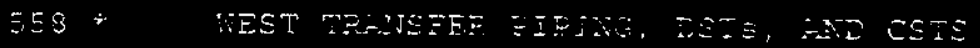

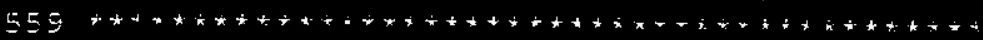

EEO

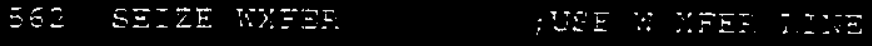

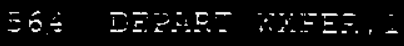

566 * F F.

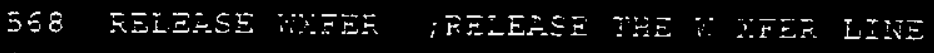

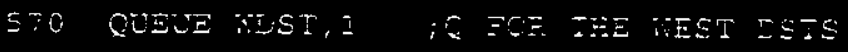

572 ENTLR WEST,E2 ;

574 DEPART WDST, 1 ;DEPART THE VEST DST Q

576 * ADVANCE 1 ;RENTETION IN W TANKS

580 LEAVE WDST,P2 ;WASTE OUT OF WEST DSTS

590 QUEUE CSTS, 1 ;Q FOR CSTS

600 SEIZE CSTS ;CROSS-SITE XFER L.INE

61C DEPLET CSTS, I ;ELPEPT THE CETS Q

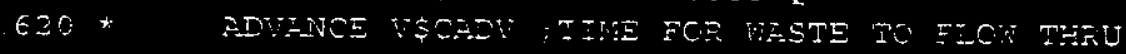

E30 PELEASE CSTS ;EELEESE THE CSTS

635 TRANSFER, EDSTS

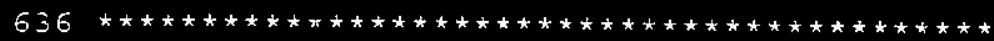

$637 * \quad$ AR -204 TRUCK/RAII UNLOADING STATION

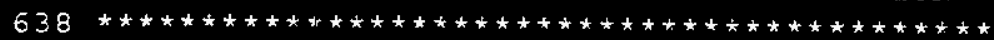

640 AR204 QUEUE UNLOAD, I

642 SEIZE UNIOFD ;USE AR-204 UNLOADING STATION

643 DEPART UNLOAD, 1

644 * ADVANCE V\$UNLD;TIME TO UNLOAD TRUCK/RAIL CAR

645 RELEASE UNLOAD;RELEASE THE UNIOADING STATION

646 TRANSFER, EDSTS

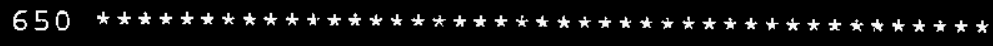

$660 \star 200$ EAST DSTS

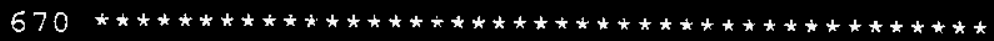

680 EDSTS QUEUE: EDST, 1 ;Q FOR THE EAST DSTS

682 EXAMINE 1, EAST ;CHECK IF RETURNING SLURRY

684 ENTER EDST, SVOL ;ADDS SLURRY TO EDST

690 TRANSFER, ENXT

692 EAST ENTEF EDST, P2 ;WASTE GOES INTO EAST DSTS

694 ENXT DEPAFT EDST, 1 ;DEPART EAST DST Q

696 TERMINATE ;ENTERING WASTE TRINSACTION TERMINATES

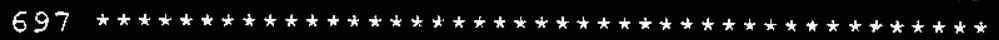

*698* ADJUSTIVENT TO CAPACITY

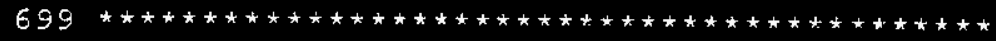

700 CAPST SPIIT 1,EVAEST, 1 ;SEND A XACTN TO THE EVEPORATOR

701 FSSIGN 2, (FN\$CAFRATE/4) ; QUERTERIY IDUUSTMENT

702 LEAVE NCCAP, P2

703 TERMINATE

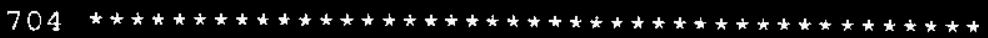

705 PROCESSING WASTE IN THE EVAPORATOR

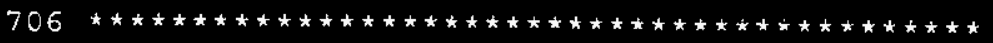

710 EVAPST JOIN 1 ; GROUP FOR EVAP TRANSACTIONS

D-21 
GENERATE, , 1

ENTER WEST, INUDST ; SET INTIAL STORAGE IN WDSTS ENTER EEST, INEDST ;SET INITIAI STOREGE IN EDSTS ENEER NCEAP, INNCCEP ; SET INITIAL NON-CONPLX CAPAC. AS SMCEEGE TERTANZ:E 
Appendix E - 200 Area Tank Farm Hardware Failure Assessment 


\section{APPENDIX E}

\section{AREA TANK FARM HARDWARE FAILURE ASSESSMENT}

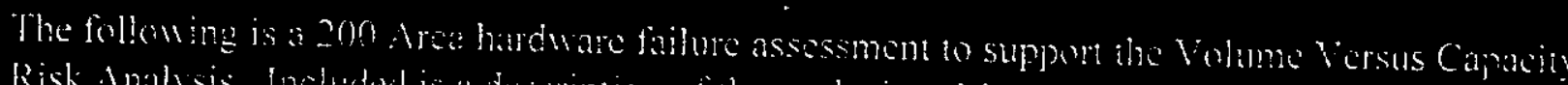

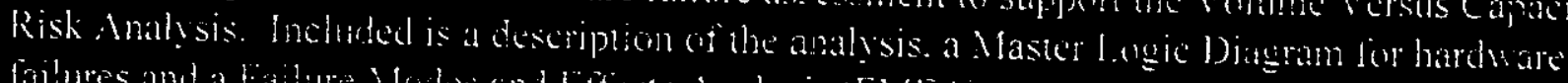

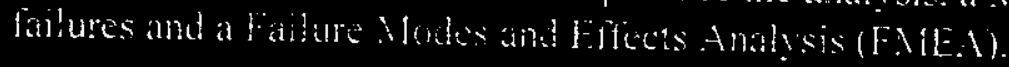

\section{E.1 Description}

This assessment is intended to investigate the failure modes and effects of hardware (e.g. tanks. lines. pumps, etc.) failures on 200 Area tank farm operations. Future plans for facilities and equipment not yet in service are generally not considered here. This assessment consists primarily of two parts: (1) The Master Logic Diagram (MLD) and (2) The Failure Modes and Effects Analy sis (FMEA) table.

The MLD is a logic diagrami that identifies hardware important to tank fam operations. It breaks the cperations into waste transter paths and then identifies hardware associated wh those paths. The FMEA identifies hurdwate failure modes, their effects. mitigating circumstances and other factors related to the consequence or likelihood of certain failures.

In general there are several single point failures in the West Area. cross-site transfer system. and evaporator recirculation loop. However, most failures can be recovered without significant operational delay (e.g. The 102-A W evaporator feed tank pump could be replaced between campaigns). Certain lines including the cross-site lines are exceptions. A number of Double Contained Receiver Tanks (DCRT)s, diversion boxes and pumps are pinch points. but, again the most likely failures are recoverable. The long mission duration allows time to recover most hardware
failures.

\section{E.2 Master Logic Diagram}

The Figures at the end of this Appendix contain the master logic diagram. The top event is "200 Area handling system hardware failure that perturbs Tank Farm operations." In general, hardware failures can be associated with three kind of paths: (1) Paths from a waste generator to the evaporator staging point. (2) Path(s) through the evaporator, and (3) Paths from the evaporator to double shelled storage. Waste generator paths include tanker truck and rail paths as well as piping. Also, considered were "paths needed for consolidating neutralized current acid waste (NCAN") and neutralized cladding 


\section{E.3 Failure Modes and Effects Analysis}

Hardware identified in the MLD were addressed in a simple failure modes and effects analysis. The first column contains an identification label (e.g. 1A) consistent with the labels used in the MLD and

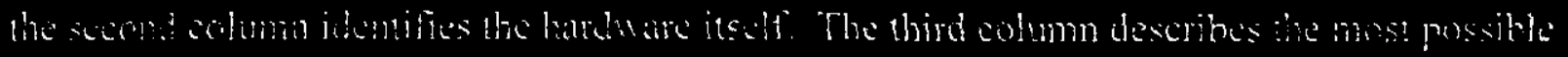

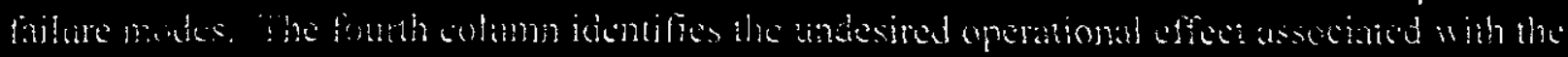

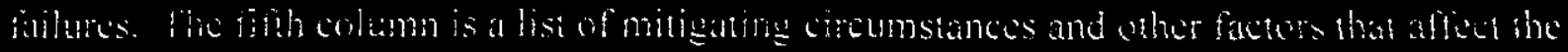

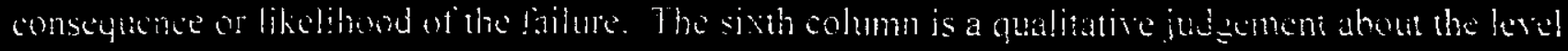

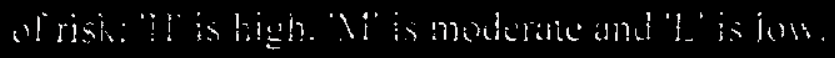

E-3 


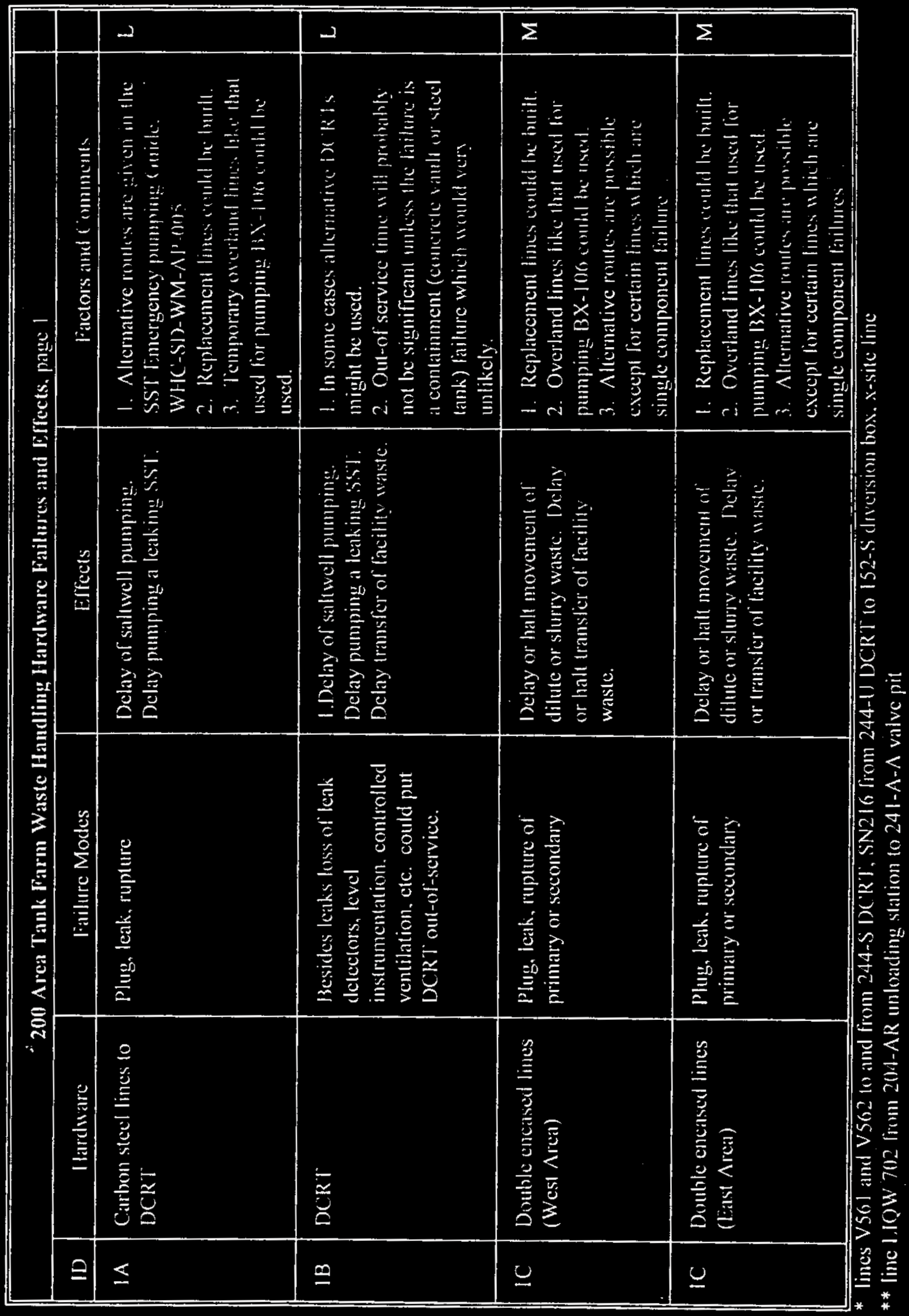




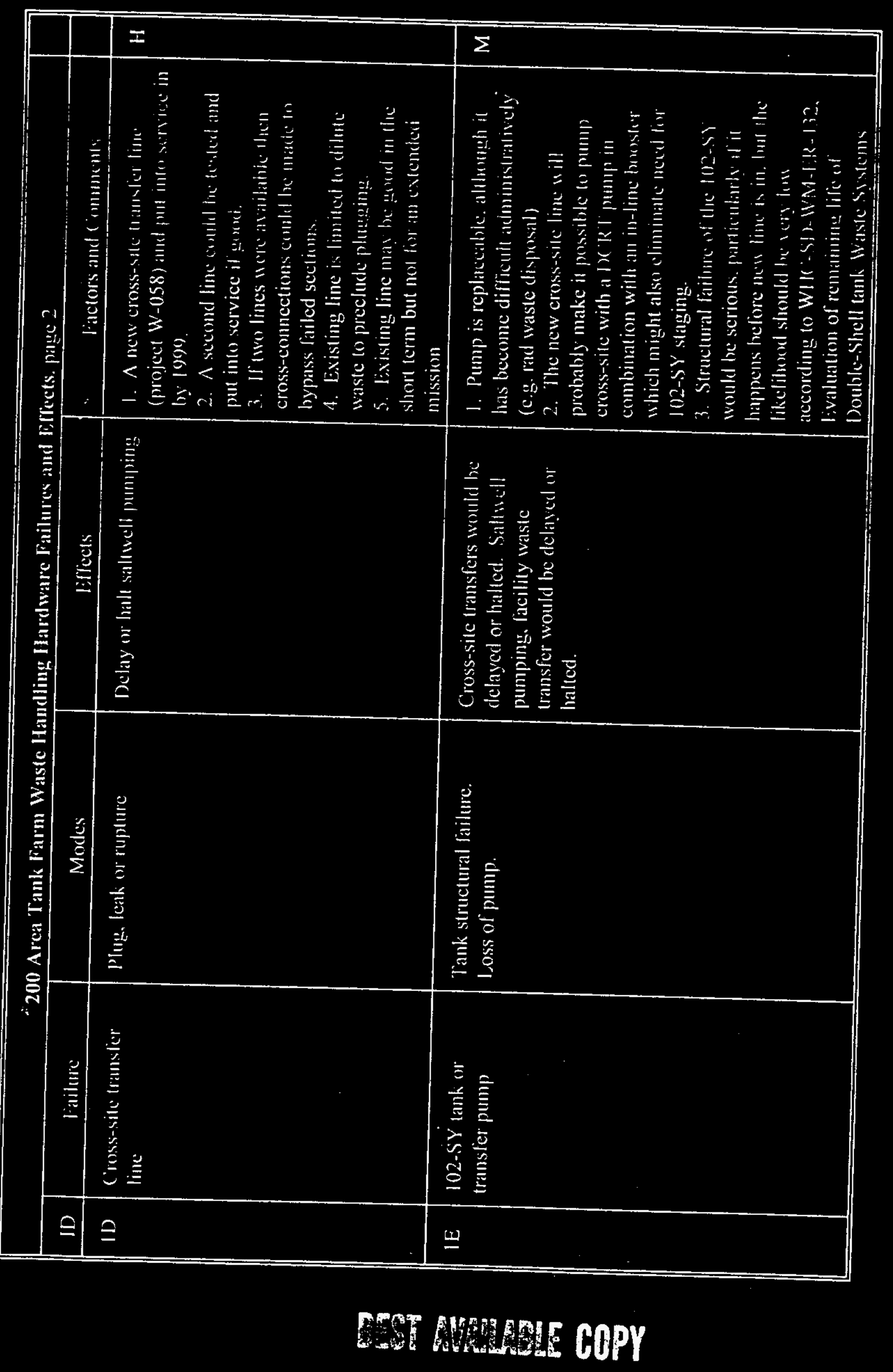

里 


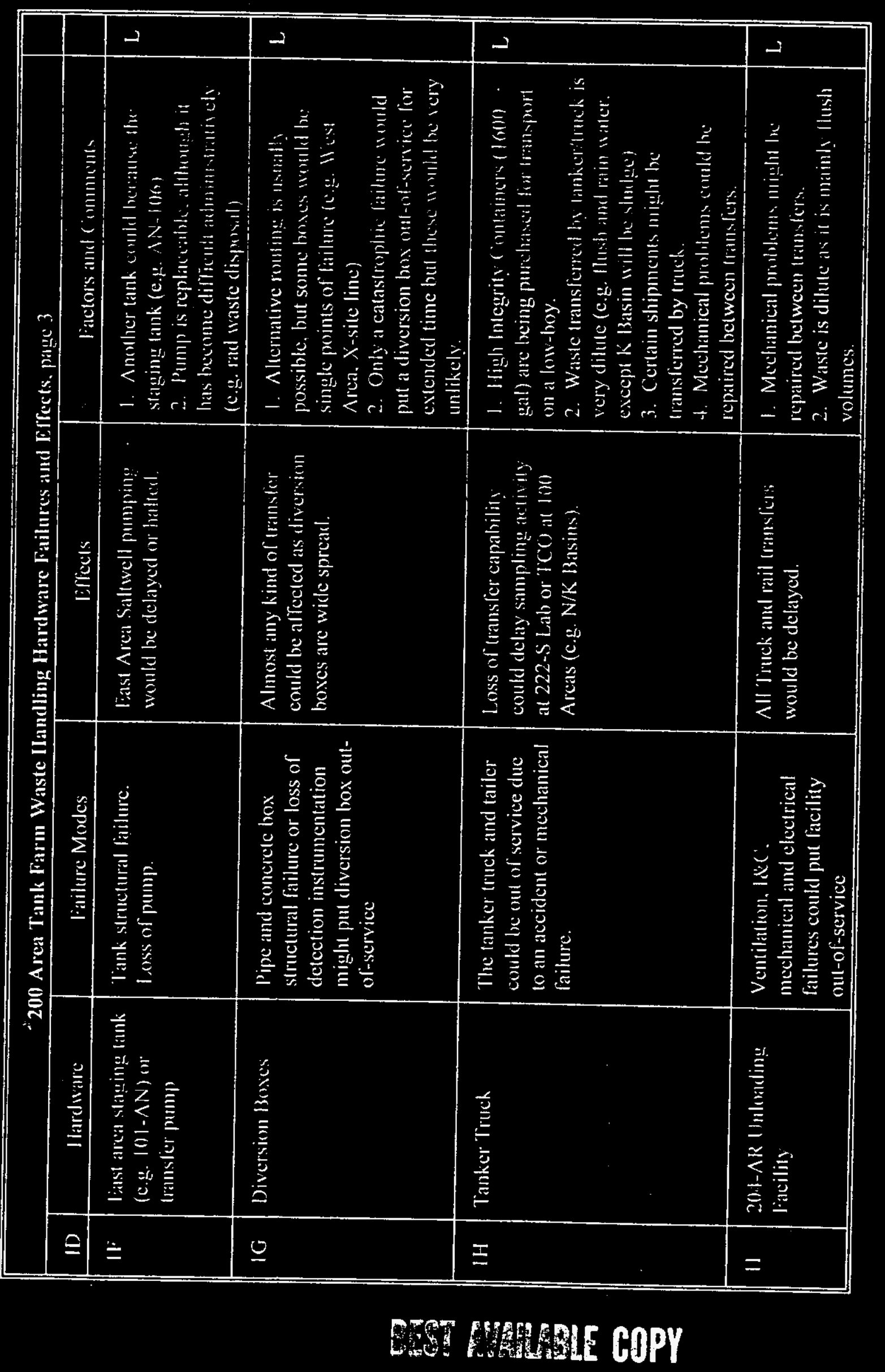

喜 


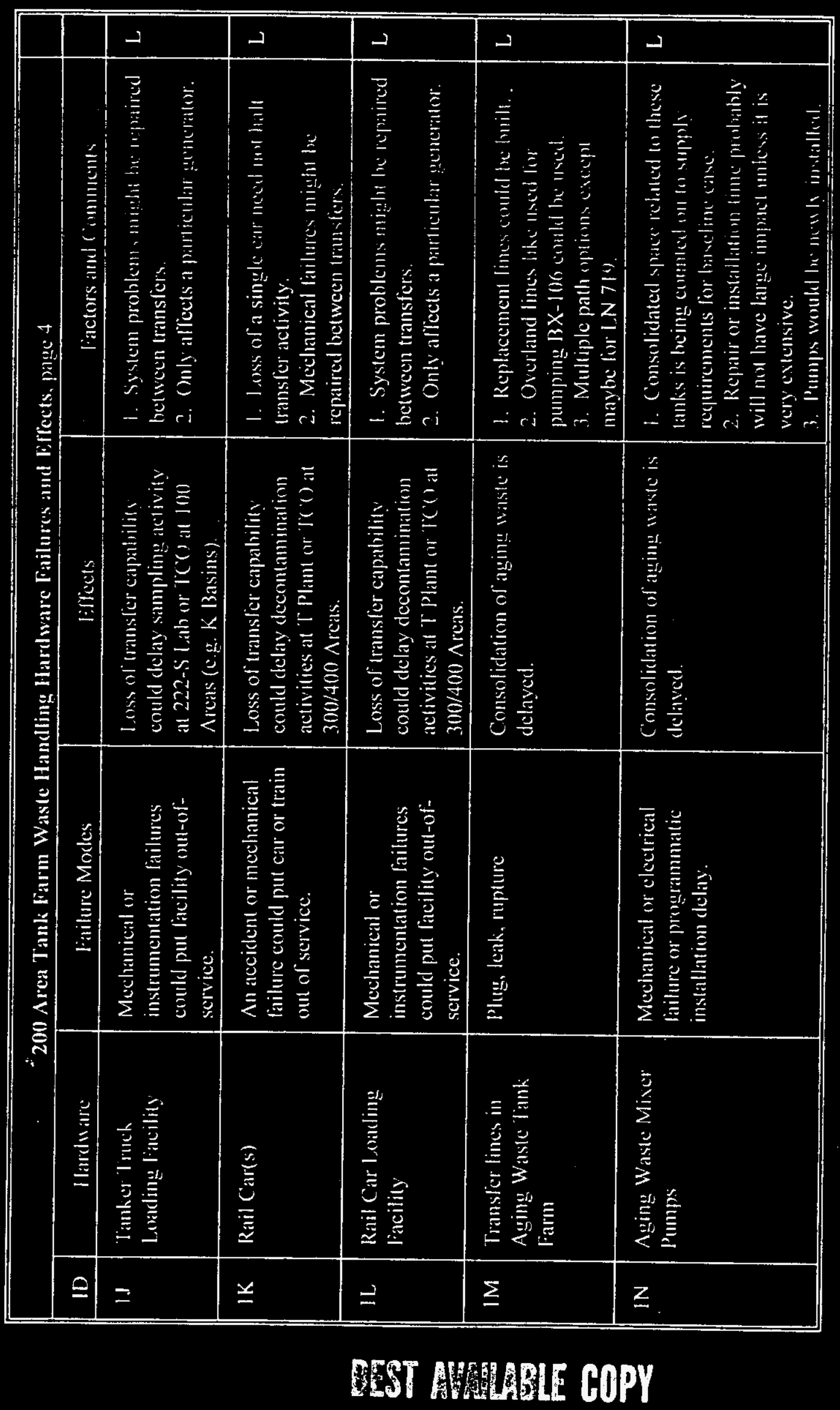

$\therefore$ 


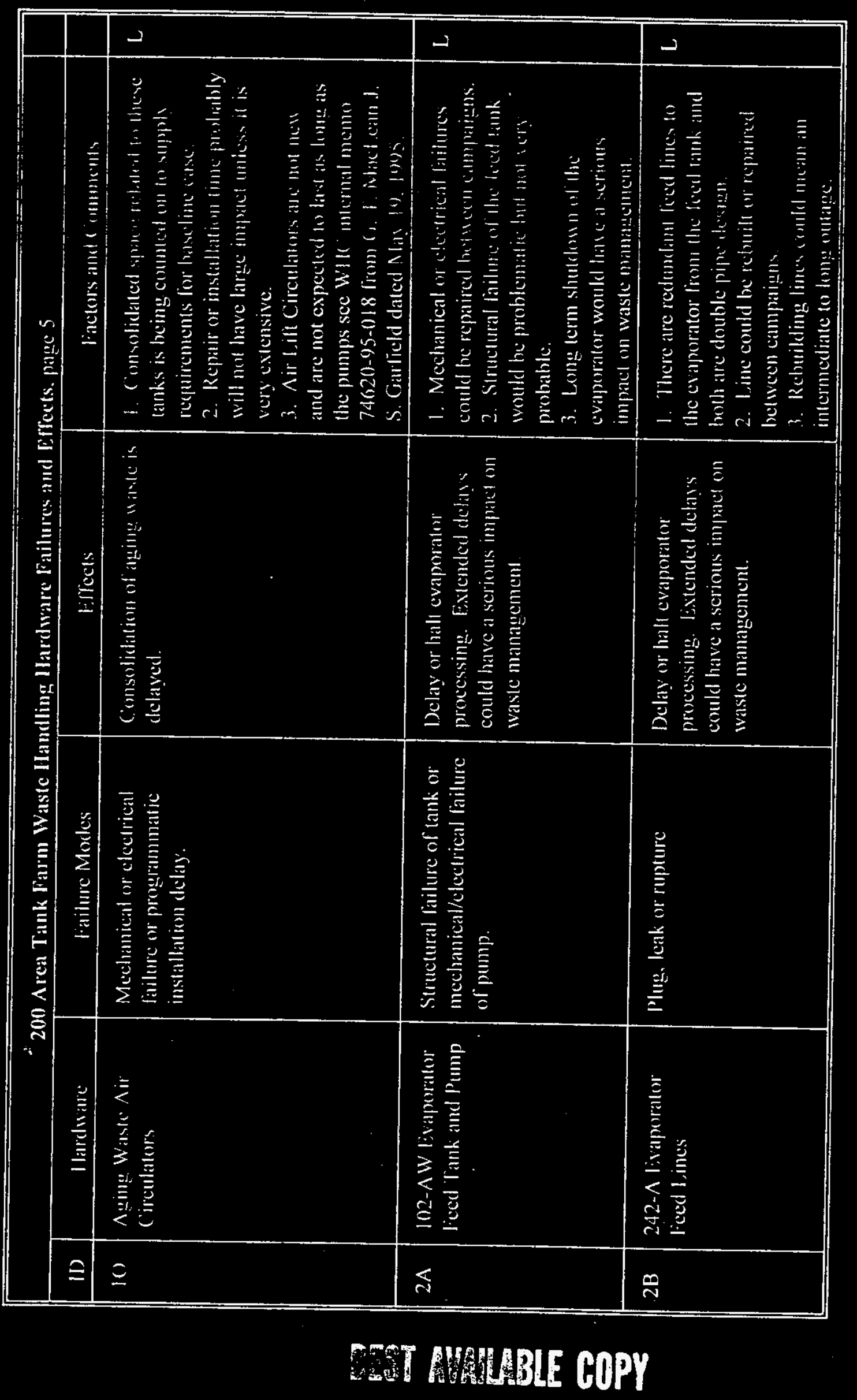




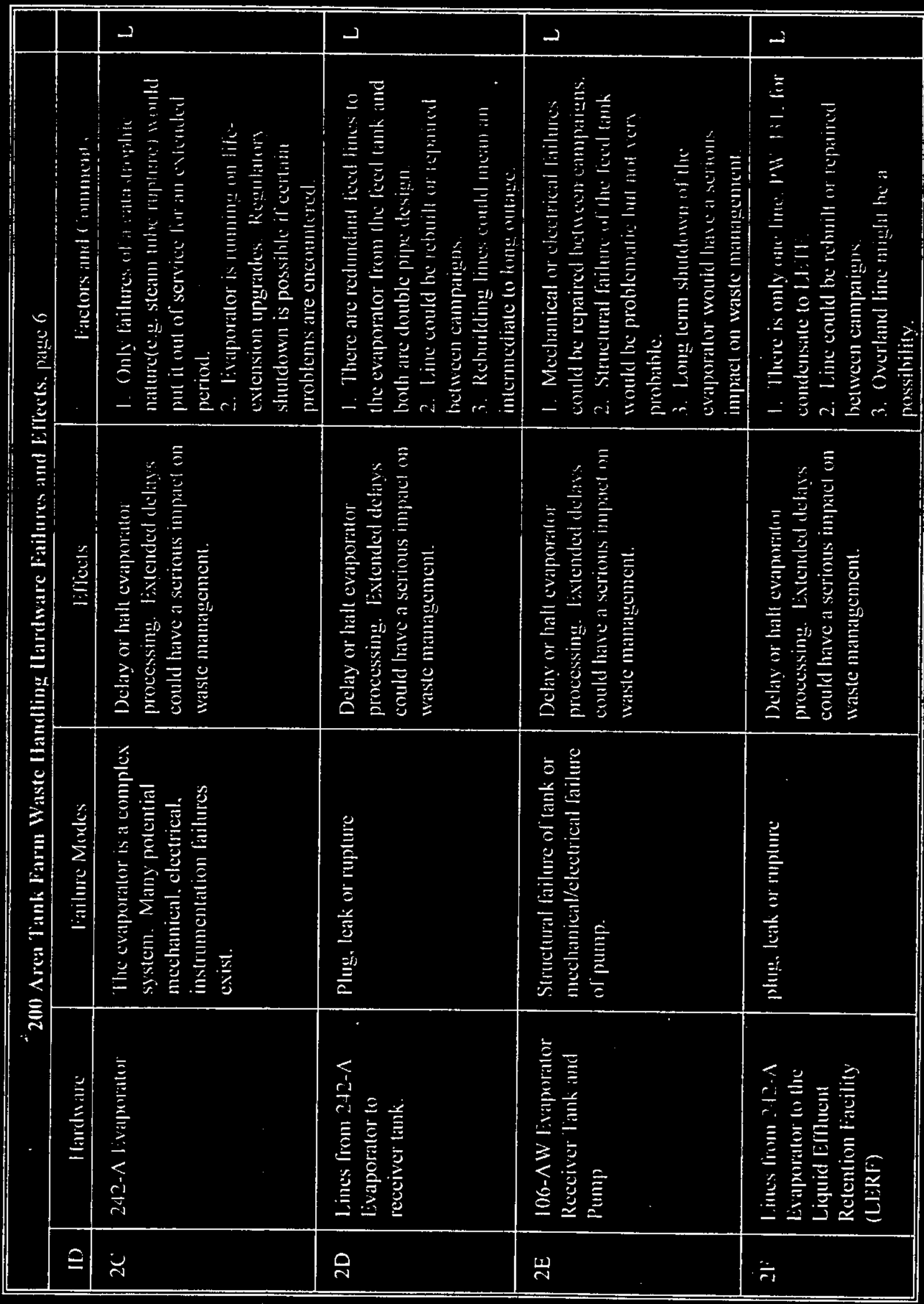




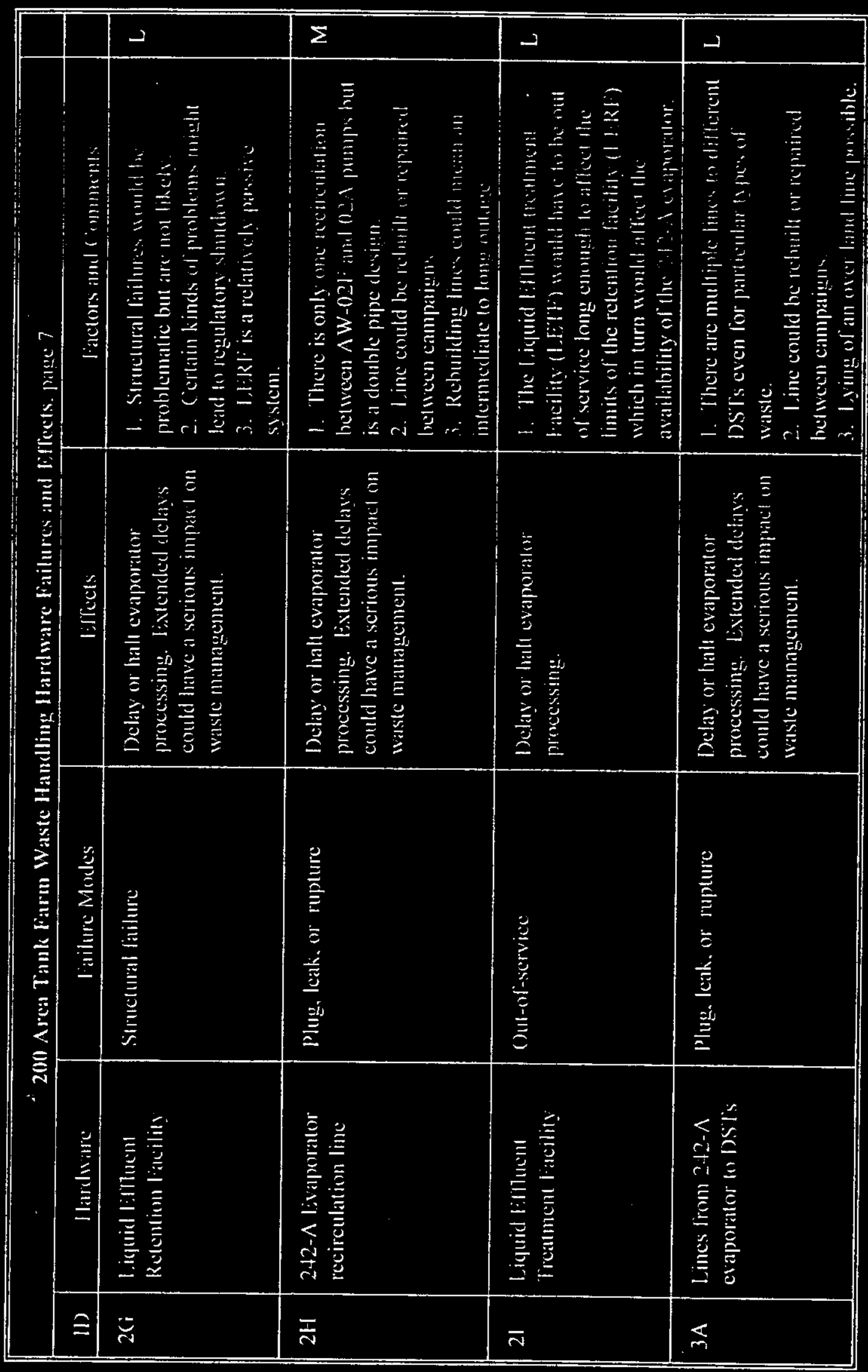

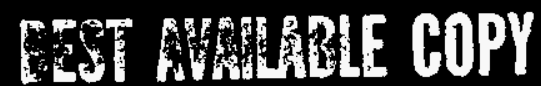




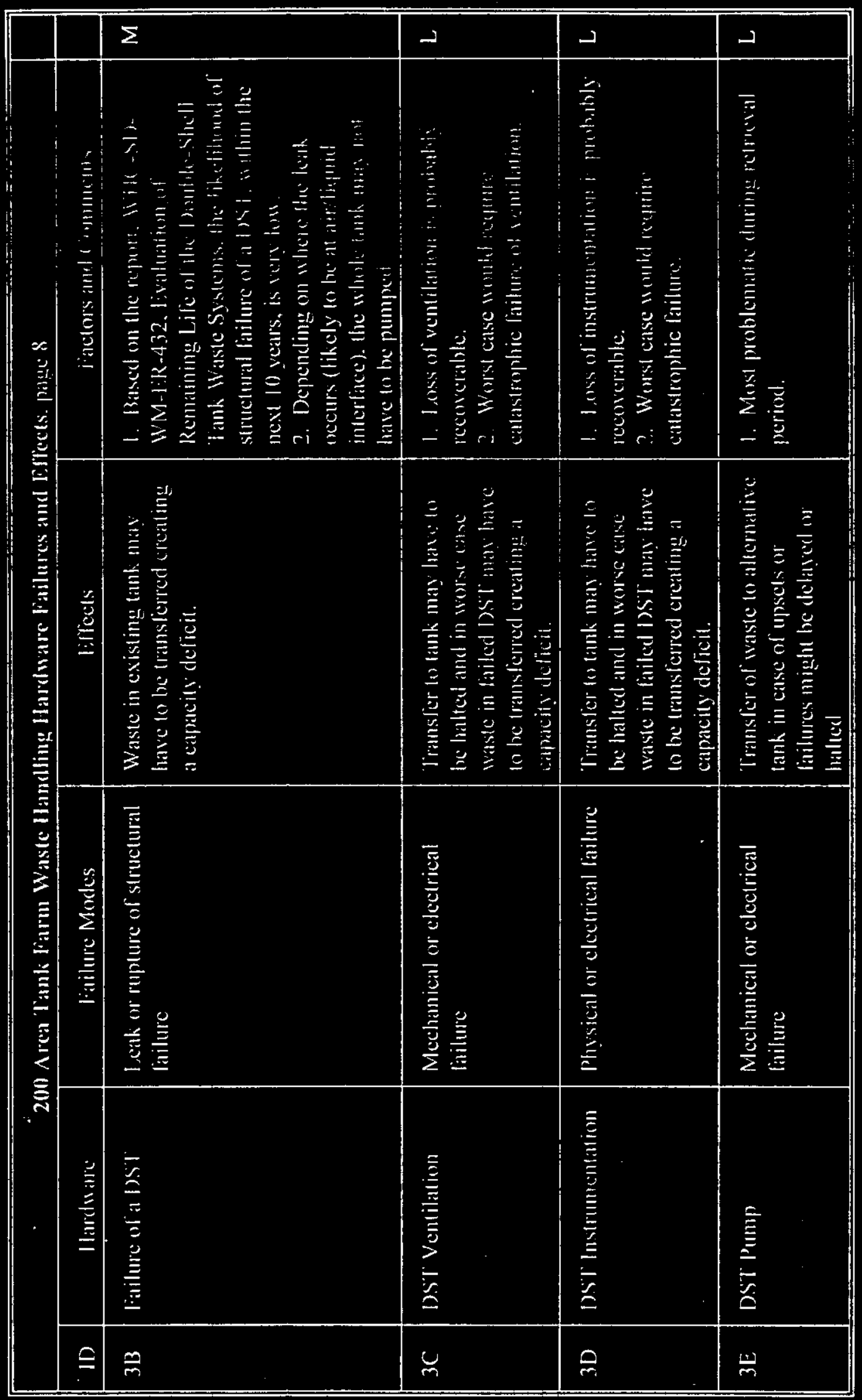




\section{DISTRIBUTION SHEET}

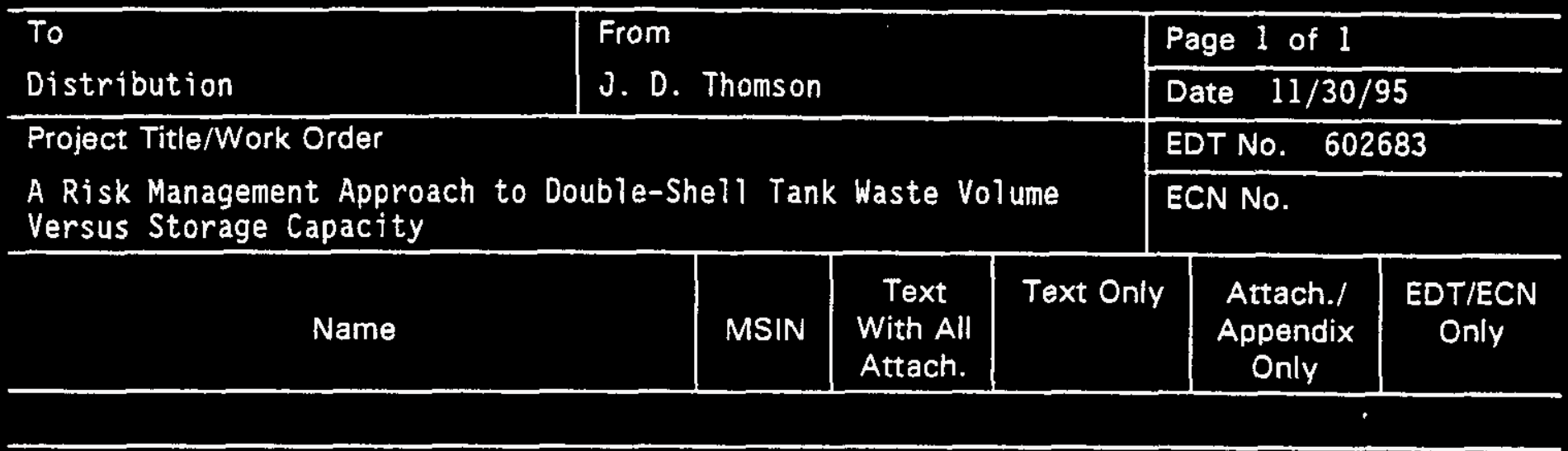

N. G. Awadalla

W. B. Barton

L. E. Borneman

G. A. Coles

C. W. Dunbar

G. L. Dunford

D. B. Enge Iman

L. F. Ermold

R. A. Fordham

L. A. Fort

C. D. Griner

C. E. Jensen

N. W. Kirch

S. C. Klimper

R. E. Lerch

M. A. McLaugh 1 in

C. A. Petersen

R. E. Raymond

A. B. Sidpara

J. P. Sloughter

F. 0 . Strankman

J. A. Swenson

J. D. Thomson

J. E. Truax

A. M. Umek

H. J. Wacek

D. J. Washenfelder

R. W. Winslow

D. D. Wodrich

R. D. Wojtasek

Central Files

\begin{tabular}{|c|}
\hline 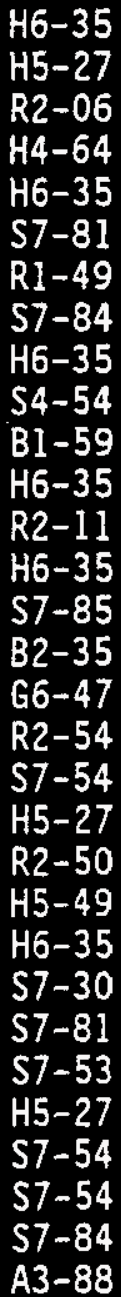 \\
\hline
\end{tabular}

